\title{
INVASION IMPACT AND BIOTIC RESISTANCE BY INVERTEBRATE COMMUNITIES
}

\author{
Habteab Tsegai Habtom
}

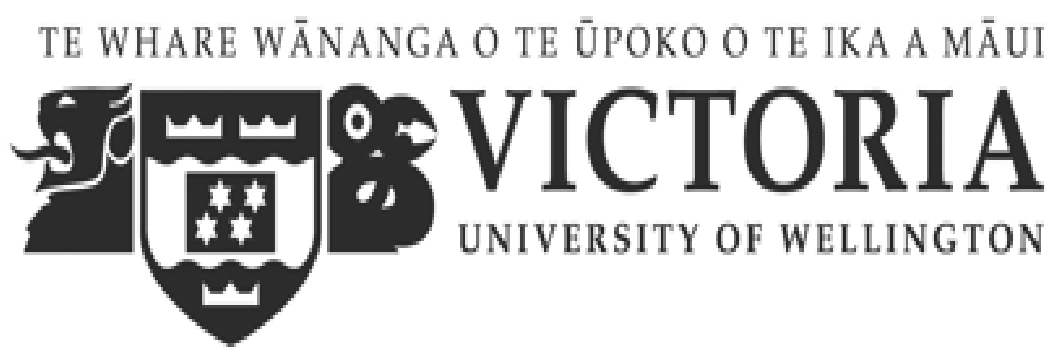

A thesis submitted to the Victoria University of Wellington in fulfilment of the requirements for the degree of Doctor of Philosophy in Ecology \& Biodiversity.

School of Biological Sciences

Faculty of Sciences

Victoria University of Wellington

November 2012 
Habteab Tsegai Habtom: Invasion impact and biotic resistance by invertebrate communities, Victoria University of Wellington, November 2012. 


\begin{abstract}
Invasive species have been recognized as one of the greatest threats to global biodiversity and can have dire economic consequences. Yet rates of invasion are increasing due to the fast and growing network of transportation across the globe. The establishment, spread and impact of invasive species are affected by environmental conditions as well as resident species. Species respond differently to the same abiotic factors and different native species can respond either positively or negatively to invasion.
\end{abstract}

The interaction between invasive and resident species, as well as the effect of temperature on invasive species, has gained much attention. The synergistic effect of suboptimal temperature and biotic resistance could have a much stronger limiting or controlling effect on invasive species than either factor alone. Linepithema humile (Argentine ants) are invasive species originally from a Mediterranean climate, but successfully spreading into extra range habitats. The establishment and spread of these ants in temperate New Zealand represents an ideal model system for studying invasion biology in terms of temperature limits and biotic resistance effects.

I investigated the changing distribution of the invasive species the Argentine ants over multiple years at five sites in New Zealand. To test whether their rate of spread corresponds with microclimate I investigated their fine-scare distribution patterns and evaluated the number of generations they may develop seasonally and annually in different microhabitat types. I also evaluated their impact on other arthropod species. I conducted a laboratory experiment to evaluate the effect of temperature on their aggression towards other species, walking speed, and foraging abundance. Similarly, I tested the effect of biotic resistance from other ant species (Monomorium antarcticum and Prolasius advenus) with varying colony sizes. I investigated whether there was any interactive effect of temperature and biotic resistance on the Argentine ants.

The distribution of Argentine ants had declined across many invasion fronts over the past 7-8 years. They were more likely to be found in concrete, short grass and sandy habitats, which provide warm microsites. Degree-day calculations predicted that they could develop between 2.5 to 3 generations in each of the above microhabitats per year in urban and rural sites while they were predicted to be unable to develop one generation under tree habitats. In tall grass microhabitats they were predicted to develop between 1-1.5 generations per year. 
The Argentine ants were hypothesised to adversely affect many other arthropod species. Richness and abundance of resident beetle species were negatively correlated with the invasion of the Argentine ants. Areas invaded by the Argentine ants were also associated with a greater number of exotic beetle species, which may imply secondary invasion.

Laboratory experiments showed that lowering temperatures below $17^{\circ} \mathrm{C}$ negatively affected the Argentine ants' walking speed, foraging abundance, aggression and their resource control. A high colony size of $M$. antarcticum (the competing ant species) affected the foraging success of Argentine ants, and the effect was stronger when coupled with unsuitable temperature $\left(17^{\circ} \mathrm{C}\right.$ and below). Therefore, Argentine ants are weak competitors at low temperature levels.

The results of my thesis underline the importance of biotic and abiotic resistances, their interactive effect as well as the effect of the Argentine ants on other species. Based on climatic considerations and the habitat preferences of resident species it may be possible to predict future spread of the Argentine ants. More importantly, knowledge of microhabitat preferences and biotic resistance may help future control measures against Argentine ants based on management of vegetation structure and microhabitat availability. 


\section{Acknowledgements}

I would like to thank my supervisors Dr Stephen Hartley and Prof. Phil Lester for their guidance and support throughout my PhD. Particularly, I thank Dr Stephen Hartley for his great support and encouragement within and outside of this project that kept me going. I am grateful to the Bug Club for sharing ideas.

This journey wouldn't have been possible without Neville Higginson, Sandra Taylor, Mary Murray, Delwyn Carter, Patricia Stein and Paul Marsden who created a wonderful working atmosphere at the School of Biological Sciences. Further, I wish to thank Phil Sirvid and Ricardo Palma at Te Papa museum (Wellington), and Philip Howe at Timaru museum for letting me refer to materials for species identification.

I am grateful for the financial support given to me by the Victoria University of Wellington, without which this project would have not been possible.

The long journey of my $\mathrm{PhD}$ would not have been made to the end without the unwavering support and understanding of my family Adiam Weldekidan, Axella and Sham and kind support made by the family of Dr Stephen Hartley, Maxine Hartley and Rebekah Hartley. I am very thankful to my parents, sister and brothers for encouraging me during this journey. I am also equally thankful to my friend Mekonen Weldemichael's encouragement and support. 


\section{Contents}

Abstract. ............................................... i

Acknowledgements. ...................................... ii

List of figures. ......................................... ii

List of tables. .................................................. vii

$1 \quad$ Invasion impact and the effects of biotic or abiotic resistances. .... 1

$1.1 \quad$ Invasive species. ........................................... 1

1.2 Abiotic constraints on species' distribution. ........................ 2

1.3 Biotic constraints on species' distribution. ........................ 3

$1.4 \quad$ Invasive ants. ................................................. 4

1.5 Argentine ants (Linepithema humile) and other ants in New Zealand. 5

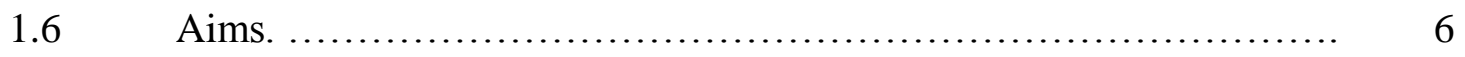

$1.7 \quad$ References. ............................................. 9

2 Local scale spatio-temporal dynamics of Argentine ant populations. ............................................... 15

$2.1 \quad$ Introduction. .................................................... 15

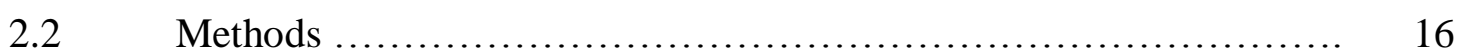

$2.3 \quad$ Results........................................................... 17

$2.4 \quad$ Discussion. ................................................... 23

$2.5 \quad$ References. .................................................. 27

$3 \quad$ Microhabitat Structure and Ant Species Assemblages. ............ 30

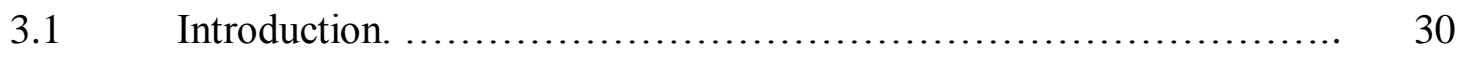

3.2 Method. ................................................ 31

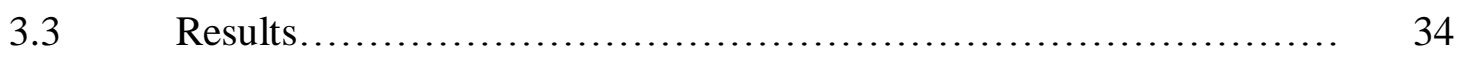

$3.4 \quad$ Discussion. ................................................. 45

References. ................................................. 50

3.6 Appendix. ............................................... 56 
4.2 Method. ........................................................ 60

$\begin{array}{lll}\text { 4.2.1 Study site and vegetation structure } & 60\end{array}$

4.2.2 Sampling. .................................................. 61

4.2.3 Data Analysis. ............................................... 62

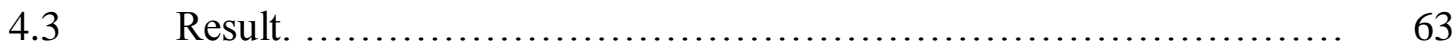

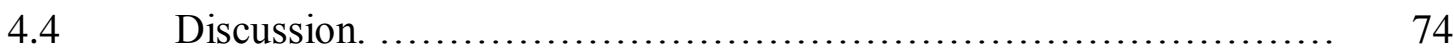

$4.5 \quad$ References. ...................................................... 79

4.6 Appendix. .................................................... 85

$5 \quad$ Role of interspecific competition and temperature in resisting invasion.

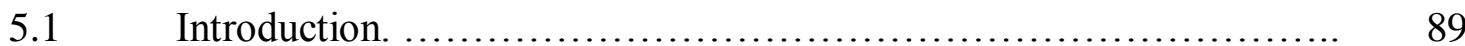

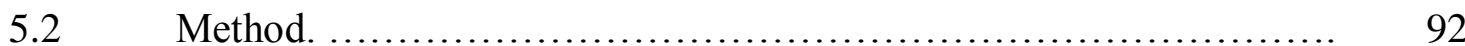

5.2.1 Establishing Laboratory Colonies. ............................... 92

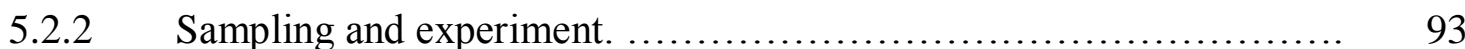

5.2.3 Non-interacting Colonies. ....................................... 95

5.2.4 Species Interactions. .......................................... 95

5.2.5 Data Analysis. ................................................. 96

$5.3 \quad$ Result. ......................................................... 97

5.3.1 Foraging abundance (non-interacting colonies). ................... 97

5.3.2 Speed of walking. ........................................... 98

5.3.3 Species' Interactions 99

5.3.3.1 Interaction between L. humile and M. antarcticum: foraging, fighting, and attack rate and invading. .................................... 99

5.3.3.2 Interaction between L. humile and P. advenus: Foraging, Fighting and Invading. 
$5.4 \quad$ Discussion. .......................................................... 107

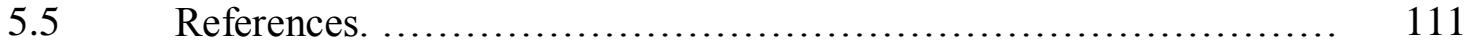

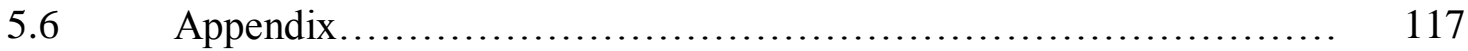

$6 \quad$ Summary and general discussion. ................................ 129

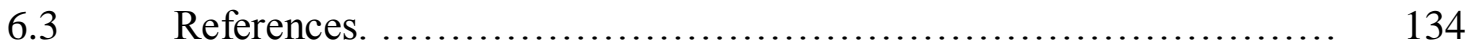

$7 \quad$ Appendix. ....................................................... 138 


\section{List of Figures}

2.1 Location of study sites in the North Island, New Zealand.

2.2 Change in distribution pattern over time of L. humile and other ant species in Dargaville. $\mathrm{n} \approx 200$ baits each year, with no repeat sampling within a year.

2.3 Change in distribution patterns and spreads of $L$. humile and other ant species with Time in Hastings. $n \approx 200$ baits each year. Each year represents one time sample i.e. no repeated sampling within a year.

2.4 Wellington, change in distribution patterns and spreads of L. humile and other ant Species with time. $\mathrm{n} \approx 200$ baits in 2002 and 2005, $\mathrm{n}=100$ baits in 2008 and in 2010. Each year represents one time sample i.e. no repeated sampling within a year.

2.5 Change in distribution patterns and spreads of L. humile and other ant species with time at Baylys Beach. $\mathrm{n}=21$ baits each year. Each year represents one time sample i.e. no repeated sampling within a year.

2.6 Change in distribution patterns and spreads of L. humile and other ant species with time at Piha. $n=21$ baits each year. Each year represents one time sample i.e. no repeated sampling within a year.

2.7 Area deemed occupied by Argentine ants in A) Dargaville, B) Hastings and C) Wellington. Sample size in each year was $\mathrm{n} \approx 200200$ "point" samples but samples with Argentine ant present were 20 or less. There was no repeated sampling in each year, so no standard errors were calculated.

2.8 Change over time in the percentage of baited tubes occupied by Argentine ants in A) Piha and B) Baylys Beach. $n=21$ baits each year.

3.1 The relationships between microhabitat types and ant species community composition in Kelburn, Wellington urban site, assessed using bait traps (n $\approx 200$ baits). The RDA plot was derived from presence/absence data. A significant correlation exists when a species arrow head falls within a circle whose diameter is the microhabitat arrow.

3.2 The relationships between microhabitat types and ant species community composition in Hastings urban site assessed using bait traps $(\mathrm{n} \approx 400$ baits). The RDA plot was derived from presence/absence data. A significant correlation exists when a species arrow head falls within a circle whose diameter is the microhabitat arrow.

3.3 The relationships between microhabitat types and ant species community composition in Dargaville urban site assessed using bait traps $(n \approx 400$ baits). The RDA plot was derived from presence/absence data. A significant correlation exists when a species arrow head falls within a circle whose diameter is the microhabitat arrow. 


\section{vii}

3.4 The relationships between microhabitat types and ant species community composition at Piha duneland site assessed using bait traps $(n=42$ baits). The RDA plot was derived from presence/absence data. A significant correlation exists when a species arrow head falls within a circle whose diameter is the microhabitat arrow. $\mathrm{r}=2 \mathrm{~m}$ is microhabitat sampled in $2 \mathrm{~m}$ radius around a bait sample, and $\mathrm{r}=2-10 \mathrm{~m}$ is microhabitat sampled $2 \mathrm{~m}$ away but not more than $10 \mathrm{~m}$ from a bait sample.

3.5 The relationships between microhabitat types and ant species community composition at Baylys Beach duneland site assessed using bait traps $(n=42$ baits). The RDA plot was derived from presence/absence data. A significant correlation exists when a species arrow head falls within a circle whose diameter is the microhabitat arrow. $\mathrm{r}=2 \mathrm{~m}$ is microhabitat sampled in $2 \mathrm{~m}$ radius around a bait sample, and $\mathrm{r}=2-10 \mathrm{~m}$ is microhabitat sampled $2 \mathrm{~m}$ away but not more than $10 \mathrm{~m}$ from a bait sample.

3.6 Occupancy of Argentine ants (L. humile) and M. antarcticum across different microhabitat types in Kelburn, Wellington. The plot shows the proportion of baits occupied by each species in each microhabitat $($ mean $\pm S E)$. be=bare earth $(n=30)$, co $=$ concrete $(n=44), l l=l i t t e r ~(n=21)$, $\mathrm{sg}=$ short grass $(\mathrm{n}=35), \mathrm{lg}=$ long grass $(\mathrm{n}=16)$ and $\mathrm{tr}=$ tree $(\mathrm{n}=35)$. Proportion $=$ occurrences $/ \mathrm{n}$, where occurrence is presences of a species (not number of individuals of the same species) in total samples in each microhabitat. ......

3.7 Distribution of each ant species in different microhabitat types in Hastings (mean $\pm \mathrm{SE}$ ). The plot shows proportion of the frequency of capture of a species in each microhabitat. Proportion $=$ a species occurrences $/ \mathrm{n}$, where occurrence is presences of a species (not number of individuals of the same species) in total samples in each microhabitat be=bare earth $(\mathrm{n}=97)$, co $=$ concrete $(n=77), 1 l=1$ itter $(n=29), s g=$ short grass $(n=134), \lg =$ long grass $(\mathrm{n}=78)$ and $\operatorname{tr}=\operatorname{tree}(\mathrm{n}=28)$.

3.8 Ant species occupancy of different types of microhabitats in Dargaville (mean \pm SE). The plot shows proportion of the frequency of capture of a species in each microhabitat. Proportion $=$ a species occurrences $/ \mathrm{n}$, where occurrence is presences of a species (not number of individuals of the same species) in total samples in each microhabitat. be=bare earth $(n=71)$, co $=$ concrete $(n=30), 1 l=1$ itter $(n=15), s g=$ short grass $(n=123), l g=$ long grass $(\mathrm{n}=96)$ and $\operatorname{tr}=\operatorname{tree}(\mathrm{n}=27)$.

3.9 Expected annual development rate for Argentine ants within each microhabitat type at Piha. One generation is a development from an egg to an adult, and assumed to occur after 445 degree-days above a threshold of $15.9^{\circ} \mathrm{C}$. Each bar graph shows the number of generations developing over a one year period (mean $\pm \mathrm{SE}$ ). As a result of missing data loggers, the bar graph for short grass at Piha does not show SE. 


\section{viii}

3.10 Expected seasonal developmental progress of Argentine ants in each microhabitat type at Piha. One generation is a development from an egg to an adult, and assumed to occur after 445 degree-days above a threshold of $15.9^{\circ} \mathrm{C}(\mathrm{n}=1$ per habitat type). Data loggers recorded temperature in each microhabitat over one year period. Each data logger was deployed for one year and then the data were separated into seasons.

3.11 Expected annual development rate for Argentine ants within each microhabitat type in Dargaville. One generation is a development from an egg to an adult, and assumed to occur after 445 degree-days above a threshold of $15.9^{\circ} \mathrm{C}(\mathrm{n}=1$ per habitat type). Data loggers recorded temperature in each microhabitat over one year period.

3.12 Expected seasonal developmental progress of Argentine ants in each microhabitat type in Dargaville. One generation is a development from an egg to an adult, and assumed to occur after 445 degree-days above a threshold of $15.9^{\circ} \mathrm{C}(\mathrm{n}=1$ per habitat type $)$. Data loggers recorded temperature in each microhabitat over one year period. Each data logger was deployed for one year and then the data were separated into seasons. ...

4.1 Change in the distribution of Argentine ants (L. humile) and other ant species between 2002 and 2010 at Baylys Beach $(n=21$ in each year (bait samples)). One baited tube sample was taken at each point in each year and included multiple species of ants (i.e., there was no repeat sampling each year).

4.2 Change in the distribution of Argentine ants ( $L$. humile) and other ant species between 2002 and 2010 at Piha ( $\mathrm{n}=21$ in each year (bait samples)). One baited tube sample was taken at each point in each year and included multiple species of ants (i.e., there was no repeated sampling each year). ...

4.3 Distribution patterns of arthropod orders according to variation in vegetation structure and Argentine ant (L. humile) invasion at Piha analysed using RDA ( $\mathrm{n}=126$ pitfall traps). $\mathrm{r}=2 \mathrm{~m}$ is the microhabitat type within $2 \mathrm{~m}$ around a sample and $\mathrm{r}=2-10 \mathrm{~m}$ is the microhabitat $2 \mathrm{~m}$ away but not more than $10 \mathrm{~m}$ from a sample.

4.4 Distribution patterns of arthropod orders according to variation in vegetation structure and Argentine ant (L. humile) invasion at Baylys Beach analysed using RDA ( $\mathrm{n}=126$ pitfall traps). $\mathrm{r}=2 \mathrm{~m}$ is the microhabitat type within $2 \mathrm{~m}$ around a sample and $\mathrm{r}=2-10 \mathrm{~m}$ is the microhabitat $2 \mathrm{~m}$ away but not more than $10 \mathrm{~m}$ from a sample.

4.5 Beetle species association with variation in vegetation structure and $L$. humile invasion at Piha. Distribution patterns were analysed using RDA $(\mathrm{n}=126) . \mathrm{r}=2 \mathrm{~m}$ is the vegetation type within $2 \mathrm{~m}$ around a sample. $\mathrm{r}=2-10 \mathrm{~m}$ is the vegetation type $2 \mathrm{~m}$ away but not more than $10 \mathrm{~m}$ from a sample. Underlined names are exotic species and beetles designated "?" are beetles unspecified as either exotic or endemic. 
ix

4.6 Beetle species distribution pattern in relation to Argentine ant invasion at Baylys Beach derived from RDA analysis ( $n=126$ pitfall traps). $r=2 m$ is microhabitat type within $2 \mathrm{~m}$ around a sample and $\mathrm{r}=2-10 \mathrm{~m}$ is microhabitat type $2 \mathrm{~m}$ away but not more than $10 \mathrm{~m}$ from a sample. The underlined beetle name is an exotic species.

4.7 Principle components analysis of the variation in beetle species composition in relation to the history of Argentine ant invasion at Piha $(n=28)$. The legend refers to beetle species composition in areas where Argentine ants were always present, recently spread, retreated and never present respectively.

4.8 Local change in species richness of beetles (mean \pm SE) in relation to the history of Argentine ant invasion at Piha. Data for species collected in 2002 and 2004 were pooled together as was data for species collected in 2009 and 2010. Change in species richness between the two groups was calculated as $(2009+2010)-(2002+2004)$. Species richness change is per station $(\mathrm{n}=10)$.

4.9 Beetle species richness variation at A) Piha and B) Baylys Beach in areas invaded and uninvaded by Argentine ants (mean $\pm \mathrm{SE}, \mathrm{n}=10$ stations with three pitfall traps per station) in 2002/03 and 200/10.

4.10 Temporal changes in species richness of beetles in Argentine ant invaded sites at A) Piha and B) Baylys Beach (mean $\pm \mathrm{SE}, \mathrm{n}=21$ stations with three pitfall traps $1 \mathrm{~m}$ apart in each station).

4.11 Changes in relative abundances of endemic and exotic beetle species between 2002/2003 and 2009/2010 at A) Piha and B) Baylys Beach. The change in relative abundance of each beetle species was calculated as $\left(\mathrm{x}_{2}+0.5\right) /\left(\mathrm{x}_{1}+0.5\right)$, where $\mathrm{x}_{1}$ is the number of individuals of a species collected in 2002/03 and $\mathrm{x}_{2}$ is the number of individuals of "the same species collected in 2009/10. ( $n=42$ stations with three pitfall traps in each, $1 \mathrm{~m}$ apart). ?=species unspecified either as endemic or exotic.

5.1 Experimental set-up with middle chamber labelled "empty" for species interaction tests. Access to the central chamber was controlled by temporary removal of cotton wool bungs.

5.2 Nest connected to a foraging arena for testing foraging abundance and walking speed change with temperature in the absence of other ant species competitors.

5.3 Graphs show mean number of foragers in the foraging chamber \pm SE. Bars sharing the same letter do not have significant difference. Comparison is within a colony. Graphs with smooth curves represent the higher colony sizes' foraging abundances and the broken for lower colony sizes of A) $L$. humile, B) $M$. antarcticum and C) $P$. advenus. $\mathrm{n}=15$ counts of numbers of foragers every hour between $10 \mathrm{am}$ and $1 \mathrm{pm}$. 


\section{$\mathbf{X}$}

5.4 Walking speed changes of ants with temperature (mean \pm SE). $n=20$ (speed of 20 individuals measured). Solid curve $=L$. humile, dashed curve is $M$. antarcticum and dotted curve is $P$. advenus. Comparison is within a species. Bars sharing the same letter are not significantly different $(\mathrm{P}>0.05)$.

5.5 Sample of interaction progress. Abundance and number of fights were measured in the central chamber. Invading refers to the number of L. humile crossing into the foraging arena of $M$. antarcticum. Interaction observed at $18^{\circ} \mathrm{C}$ when the colony size of L. humile was 800 and that of $M$.

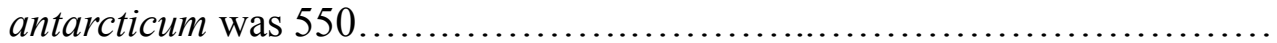

5.6 Interaction between $L$. humile and M. antracticum at different colony sizes and temperature levels. Black points refer to crossing into foraging arena of the other species termed as 'invading'. Abundance of each species was recorded (no replication and thus no SE) just before the subordinate species starts to be disrupted in its nest. At this stage interaction test stops as both species were needed for subsequent test at another temperature level. ........

5.7 Intensity of fighting change with temperature: Fighting was recorded for an hour From the start of interaction although interaction continued for extra half an hour in some tests. Interaction after an hour is mostly biting and not fighting. As one species loses the fight the other starts to bite and chase.

5.8 Biting (attack) rate of $L$. humile at different temperature levels (mean \pm $\mathrm{SE}$ ). The interaction was between high L. humile and low M. antarcticum. Each observation was for 1 minute, $n=20$ per temperature.

5.9 Interactive effect of temperature and colony size of $M$. antarcticum on the mean foraging abundance of L. humile $(\mathrm{n}=10)$. $\mathrm{Y}$-axis is foraging abundance of $L$. humile. When lines are parallel there is no interactive effect. Significance of interactive effect is detailed under the subtitle "5.3.3 Species' Interactions.".

5.10 Regression tree analysis of the foraging performance of L. humile in the face of multiple factors: temperature, its own colony size, and colony size of $M$. antarcticum. The most important factor is placed on the top of the diagram and the next after that. The model divides each explanatory factor at the threshold that best separates the responses variable into homogeneous sub-groups: relatively higher numbers of L. humile to the right and relatively fewer to the left. Unbranched limb means no significant explanatory variable and the value at the tips is the mean expected number of foraging $L$. humile. 


\section{xi}

5.11 Interaction between $L$. humile and $P$. advenus at different colony sizes and temperature levels. Black points refer to crossing into foraging arena of the other species termed as 'invading'. Abundance of each species was recorded (no replication and thus no SE) just before the subordinate species starts to be disrupted in its nest. At this stage interaction test stops as both species were needed for subsequent tests at another temperature level. ......

5.12 Intensity of fighting change with temperature. Fighting recorded for an hour from the start of interaction although interaction continued for extra half an hour in some tests. Interaction after an hour is mostly biting and not fighting. As one species loses the fight the other starts to bite and chase. ....

5.13 Foraging performance of $L$. humile in the face of multiple factors: its own size, temperature, and colony size of $P$. advenus. The most important factor is placed on the top of the diagram and the next after that. The model divides each explanatory factor at the threshold between the upper and lower levels, right side upper and the left side lower level. Unbranched limb means no significant explanatory variable and the value given is the mean foraging density of $L$. humile. 


\section{List of Tables}

\section{xii}

2.1 Long-term change in trend of L. humile. Data are percent of bait occupied by

L. humile in total sample. The dashes indicate no data collected.

2.2 Regression (generalized linear model, GLM) results of change in spread among different years in each study site.

3.1 Table 3.1. Total ant species collected in the austral summers of 2008/09 and 2009/10. The numbers are occurrences (frequency of capture) of each species in total samples. For abundance of each species refer to appendix.

3.2 Seasonal and annual degree-days above $15.9^{\circ} \mathrm{C}$ recorded in different microhabitats at Piha and Dargaville. Values in bold are greater than 445, the number of degree days required by $L$. humile to complete one generation. .......

3.6.1 Ant species collected by bait trapping in Kelburn, Wellington in 2009 and 2010. Presence $=$ frequency of capture, abundance $=$ total number of individuals. be=bare earth, $\mathrm{co}=$ concrete, $\mathrm{sg}=$ short grass, $\mathrm{lg}=$ tall grass, $1 \mathrm{l}=$ litter and tr=trees.

3.6.2 Data collected in 2009 and 2010 in Hastings. Presence =frequency of capture, abundance $=$ total number of individuals. be=bare earth, $\mathrm{co}=$ concrete, $\mathrm{sg}=$ short grass, $\mathrm{lg}=$ tall grass, $11=$ litter and $\mathrm{tr}=$ trees.

3.6.3 Ant species at Piha collected in 2009 and 2010. Total sample size (n) is 42. Microhabitat structures are presented here as each sample was in close proximity to multiple microhabitats.

3.6.4 Data collected in 2009 and 2010 in Dargaville. Presence =frequency of capture, abundance $=$ total number of individuals. be $=$ bare earth, $c o=$ concrete, $\lg =$ tall grass, $11=$ litter, $\mathrm{sg}=$ short grass and $\mathrm{tr}=$ trees.

3.6.5 Ant species at Baylys Beach sampled in 2009 and 2010. Sample size $(n)=42$. Microhabitat structures are presented here as each sample was in close proximity to multiple microhabitats.

4.1 Dissimilarity in the beetle community composition sampled over time at Baylys Beach and Piha. Bray-Curtis distance measures of dissimilarity are reported. The scale ranges from 0 to $1.0=100 \%$ species compostion similarity and $1=100 \%$ species compostion dissimilarity.

4.6.1 Beetle species at Piha in invaded and uninvaded habitats $(2009+2010, n=49$ pitfall traps in invade areas and 77 pitfall taps in uninvaded areas). ?=not yet determined as either exotic or endemic. 
4.6.2 Total number of beetle species at Piha. The number of pitfall traps was 63 in each year.

\section{xiii}

4.6.3 Total number of beetle species at Baylys Beach. The number of pitfall traps in each year was 63 .

4.6.4 Most abundant exotic and endemic beetle species exhibiting large changes in relative abundance at Piha.

5.1 Description of the ant colonies used in species-interaction pairings. Numbers are rounded to the nearest ten. No interaction between high colony sizes of $L$. humile ant low $P$. advenus was tested. The first row, interaction between $L$. humile and $P$. advenus was estimated to be high $L$. humile against low $P$. advenus; however the actual count proved it high against high. In the last row although higher than the matching colony size of L. humile, P. advenus is defined as 'low' as it was difficult to sustain an interacting colony below this size.

5.2 Colony sizes of non-interacting groups.

5.3 Methods of data transformation. Data not meeting the statistical assumptions (normality and homogeneity) were transformed using appropriate methods. ...

5.4 Dominant species in the interaction chamber at different temperatures and with pairings of different size colonies. $*=L$. humile numerically dominant by $5: 1, \#=M$. antarcticum numerically dominant by $5: 1$

5.5 Dominant species in the interaction chamber at different temperatures and with pairings of different size colonies. $*=$ L. humile numerically dominant by $5: 1, \#=$ P.advenus numerically dominant by $5: 1.0: 0=$ both absent in foraging chamber. Colony sizes in row two L.huminle low (620) vs $P$. advenus high (2820) and row three L. humile low (1300) vs P. advenus high (1830).

5.6.1 Interaction between L. humile and M. antarcticum at different temperature $\left({ }^{\circ} \mathrm{C}\right)$ levels. $\mathrm{Lh}=L$. humile and $\mathrm{Ma}=M$. antarcticum.

5.6.2 Interaction between L. humile and P. advenus at different temperature $\left({ }^{\circ} \mathrm{C}\right)$ levels.

5.6.3 Rate of biting of Argentine ants at different temperature levels. Rate of biting was measured in terms of number of bites per minute.

5.6.4 Walking speed of ants at different temperature $\left({ }^{\circ} \mathrm{C}\right)$ levels.

5.6.5 Foraging abundance change of non-interacting ant species with temperature. ...

7.1 Coordinate points (New Zealand Map Grid) in each study site from which samples were collected. Prefixes: PI=Piha, BB=Baylys Beach.

7.2 Coordinate points (New Zealand Map Grid) in each study site from which samples were collected. Prefixes: $\mathrm{K}=$ Wellington (Kelburn), $\mathrm{H}=\mathrm{Hastings,}$ 
DG=Dargaville.

xiv 


\section{Chapter 1}

\section{Invasion impact and the effects of biotic or abiotic resistances}

\subsection{Invasive species}

Understanding biodiversity is critical for informed environmental management and conservation. The current high rate of species extinction mainly caused by human activities has drawn attention of scientific and social endeavours to rectify the situation (Huston, 1994; Cartron et al., 2005). Ecologists are striving to understand the processes and factors involved in biodiversity deterioration. They are identifying ways and means for restoring and maintaining biodiversity (Miguel and Huerta, 2007). Three of the main issues are climatic change caused by human activities (Hagerman et al., 2010; Liu, 2008), habitat modification and the impact of invasive species (Tokeshi, 1999). Both climate change and biological invasions provide huge challenges to policies set to respond to future risks (Bardsley and Edwards-Jones, 2007). Invasive species are environmentally and economically damaging: for instance, in the United States alone, invasive species cause about 137 billion USD worth of damage per year due to loss of productivity and control measures (Pimentel et al. 2000). About $42 \%$ of endangered species are at risk mainly due to the effects of invasive species (Pimentel et al., 2006). It is commonly observed that landscape alteration and habitat homogenization by human activities (Tokeshi, 1999; Karen et al., 2008) facilitate the establishment and proliferation of invasive species. In particular, human settlements are susceptible to invasion and have been common invasion fronts (Carpintero et al., 2003). An indirect threat of climate change is through facilitation of invasions as habitats previously unavailable to exotic species become within their climate tolerance range (Simberloff, 2000). Biodiversity is also threatened directly by climate change (Nenzén and Araújo, 2011), thus suffering from the effects of climate change twice over through the facilitation of invasion and the loss or alteration of habitat.

Although not all exotic species are harmful, a number of them are invasive. From an ecological perspective, invasive species can be defined as those that interact strongly with native species causing a major threat to biodiversity and ecosystem function (Bremner and Park, 2007; Jager et al., 2009). According to the definition of Williamson and Fitter (1996) exotic species brought into a country are called "imported" species, and those found in the wild are called "introduced" species. The self-sustaining species are recognized as established ones. According to the tens rule, Williamson and Fitter (1996) stated that the probability of transition from imported to introduced is approximately $10 \%$ and from introduced to established is $10 \%$, and 
finally only $10 \%$ of the established species become pests. The probability of establishment of non-native species is therefore often very low. However, those that do establish can disrupt endemic communities and consequently change the balance of species' relative abundance (Elton, 1958). Typically, this occurs when an invasive species interacts strongly with resident keystone species such as important predators and pollinator species (Cole et al., 1992). Removal or disturbance of keystone species causes community disintegration (Paine, 1971).

\subsection{Abiotic constraints on species' distribution}

Environmental conditions are recognized as some of the most prominent predictors in the establishment and distribution patterns of species (Huston 1994; May and Maclean, 2007; Krebs, 1994). Environmental conditions may vary from place to place. Most striking is the variation in temperature that occurs with changes in latitude (Huston, 1994), which correlates strongly with the well-known gradient in species richness (Rosenzweig, 1995). Another important cause of variation in temperature is altitude (Sparrow, 1925). Some other factors also contribute to temperature differences. Soil and air temperature close to the surface are affected by incoming solar radiation, which is also dependent on slope and aspect. In turn, differences in soil temperature interact with rates of precipitation to result in different soil moisture contents (Bennie et al., 2008). Temperature differences across habitats also arise as a result of variation in radiation across different vegetation structures and cover (Martens, 2000). It also varies within microhabitats, for example average degree-days measured in soil are $25 \%$ greater than air degree-days (Hartley and Lester, 2003). Apart from those species uniquely adapted to particular extreme conditions (Worland and Block, 2003), most species are stressed upon exposure to extra-range temperature limits (Laluette et al., 2011). Accordingly, climate variation between different habitats plays an important role in influencing the establishment potential of invasive species (Lester 2005; Hartley et al., 2006). However, individual organisms experience broad-scale climate variation at the microhabitat level. Hence difference in microhabitat structures can be important in species fine-scale distribution (James and M'Closkey, 2003), especially for small-bodied species such as insects. Most often, species distribution patterns are uneven due to variation in microhabitat structure, for example, variations induced by grazing (Lindsay and Cunningham, 2009). A number of exotic species distributions are regulated by microhabitat structure. In warmer habitats, for example, Argentine ants prefer moist riparian corridors rather than adjacent dry scrubs (Holway, 2005), whereas in cool-wet climates they prefer to nest in open, bare soil situations (Hartley et al., 2010). In either case, unfavourable microhabitat types may restrict the local spread of exotic species. 


\subsection{Biotic constraints on species' distribution}

In addition to the abiotic environment, biotic constraints may negatively affect establishment and spread of invasive species. Population dynamics take place in a community context. Local community structure of species is affected by a series of factors such as competition, predation and abiotic factors (Simberloff, 2004). Density and behaviour of predators are of great importance in population regulation (Perez-Matus and Shima, 2010). In communities driven by top-down effects the patterns of abundance of organisms and their dynamics are regulated by the trophic level above. Predators control the trophic level below them and herbivores control primary producers; however, organisms whose resources scarce are regulated in a bottom-up trophic level (Hairston et al., 1960).

Competition for food and space is perhaps the most significant biotic constraint. During competition organisms may employ interference or exploitative strategies of competition (Huang, 2010; Jensen, 1987); either way, abundances of less competitive species decline (Wieters et al., 2009; Kath and Dunn, 2009). Interaction between species favours competitively successful species to assemble in an area. High species diversity is thought to shrink niches over evolutionary time, and this allows coexistence of more species locally (Rosenzweig and Ziv, 1999). As a result, areas of high species richness are considered to be less vulnerable to invasions as there is presumably less empty "niche space" available (Stachowicz et al., 1999); an idea first introduced by Elton (1958) by the name "biotic resistance". The effect of biotic resistance and its application has been an important part of ecological studies in addressing exotic species establishment and control measures (e.g. Levine et al., 2004; Walters and Mackay, 2005). One of the developments is the enemies-release hypothesis (Keane and Crawley, 2002). This hypothesis proposes that invading species are successful partly because they are released from the top-down pressure of their natural enemies as the enemies (herbivores or predators) are rarely introduced with the invasive species into new invasion fronts. However, resident predators are still important components of the application of biotic resistance (Derivera et al., 2005). The establishment and rate of spread of a novel species may depend on density of predators (Amarasekare, 2004). High predator density decreases prey density and can cause collapse of the prey species population if they are driven to such low levels that Allee effects takes hold (Boukal et al., 2007). Allee effect is a condition where organisms find it difficult to encounter mates due to low species density (Myers et al., 1995). Exotic or invasive species are likely to be susceptible to Allee effects immediately after their arrival and during the early stages of establishment; at this stage predators may have a prominent effect on their establishment success. However, contrary to 
our common sense invasive species are less likely to be regulated by Allee effect as at the time of establishment their initial population size is usually above the critical size (Mistro et al., 2012). To overcome the effect of competition and predation, high propagule pressure is often necessary for an invasive species to establish which usually depends on the mode of dispersal generating entry into the new region (Wilson et al. 2008).

Long-distance dispersal is critical for rapid range expansions and establishment of pioneer populations (Hampe 2011). In addition to human-assisted dispersal (Vitt et al, 2010), wind and rivers are important natural vectors for long-distance plant dispersals (Saumel and Kowarik, 2010). Moreover, rivers play an important role in long-distance fish dispersal (Rempel and Smith, 1998). Introduction of species into new sites by humans is typically by "jump dispersal" compared to slow natural movement more often akin to "diffusion" (Suarez et al., 2001). Wilson et al. (2008) have reviewed in detail different pathways and their contribution to establishment success. Human-mediated mass dispersal or multiple entries were implicated in high success of invasive species establishment in extra range habitats. This is due to the need for high propagule pressure to overcome endemic species resistance and predator pressure as discussed above. For example, in Southern Australia the invasive species, Linepithema humile requires population sizes 5 to 10 times greater than that of Iridomyrmex 'rufoniger' to overcome the competitive interaction (Walters and Mackay, 2005). However, multiple constraints at a time pose strong controls on exotic species establishments. Assisted dispersal pathways and the availability of suitable diet enhance establishment of exotic species (Dighton, 1997). Models assessing species distribution patterns indicate that distribution is predictable when there is strong immigration and weak stochasticity (Haegeman and Loreau, 2011). However, random movement of species may positively or negatively confound the effect of other deterministic factors (Lv and Pitchford, 2007; Kac, 1983).

\subsection{Invasive ants}

Insects are abundant members of virtually all terrestrial ecosystems, due in part to their small size, their high rate of reproduction and rapid adaptation to environmental changes (Schiwlter, 2006; Speight et al., 2008). Ants are among the world's worst invasive species (Holway and Case, 2000; Moller, 1996). Many species of invasive ants have established colonies in extra range habitats because of human-mediated dispersal (McGlynn, 1999). Among the mechanisms enabling them to succeed in spread is their colony partitioning (Masse et al., 2011; Holway \& Case, 2000) and competitive strategy, such as employing chemical secretions to overcome competitors (Dejean et al., 2008). Other characteristics of invasive ant species include general 
nesting habit, diverse diets, and reduced intraspecific aggression, in addition to aggression, high propagule pressure, and high territoriality (Holway et al., 2002). A striking characteristic observed in ants is their quick genetic change with introduction into a new environment that promotes their invasion success through rapid adaptation (Tsutsui and Suarez, 2003). Some of the highly successful invasive ants are Wasmannia auropunctata (see Masse et al., 2011), red imported fire ants (Solenopsis invicta Burn) (see Showler et al., 1990) and Pheidole megacephala (see Dejean et al., 2008). Another invasive ant species that shares similar characteristics with the aforementioned ants is Linepithema humile (the Argentine ant) (Holway et al., 2002). The distribution patterns of this species are regulated by both biotic and abiotic factors. For example, biotic resistance by endemic species affects the establishment and spread of Argentine ants in Australia (Walters and Mackay, 2005) and their successful competition depends on their own colony size relative to competitors (Holway and Case, 2001). Moreover, their developmental processes are highly regulated by temperature (Hartley and Lester, 2003; Abril et al., 2008), which further governs their distribution patterns (Speight et al., 2008).

\subsection{Argentine ants (Linepithema humile) and other ants in New Zealand}

Introduced by human-assisted transportation, invasive species have caused serious damage especially, in island biota (Lodge, 1993; Cole et al., 1992). To prevent this effect New Zealand has long implemented strong border control against invasive species. Examining records of ant species intercepted at New Zealand border from 1955 to 2005, Ward et al. (2006) reported that 115 species were identified. However, only 20 species account for $90 \%$ of the records. Although small ant body size is important for establishment, rate of interception and climate were also secondarily important (Lester, 2005). The New Zealand's border intercept of invasive species covers only $48-78 \%$ of the trade routes and thus there may be more ant species entering undetected (Ward et al., 2006). To date, studies confirm that within New Zealand there are 11 endemic species ( 7 genera) of ants, 24 exotic which are established species (17 genera), 6 species (5 genera) recently arrived, and 7 to 8 species (5 genera) in doubt of establishment (Don, 2007). While most of the exotic ant species seem to be localized in the northern part of the North Island, Technomyrmex jocosus (formerly identified as Technomyrmex albipes) are widely distributed in both Islands of New Zealand (Don, 2007). A globally important invasive ant species, the Argentine ants, have also established colonies in New Zealand. 
The Argentine ant is native to South America (Suarez et al., 2001), though it is now a globally distributed invasive species (Holway et al., 2002). First detected in New Zealand in 1990 in Auckland (Green, 1990), the Argentine ant has invaded a wide range of areas in the North Island of New Zealand, and some parts of the South Island (Hartley and Lester, 2003; Don, 2007, Ward et al., 2010). Argentine ants are predicted to farther spread even to the southern part of the South island on the basis of temperature requirements (Hartley and Lester, 2003). Their dispersal mainly depends on human mediated transport (Ward et al., 2010), as naturally their diffusion into adjacent habitat is less than hundred meters a year (Ingram and Gordon, 2003; Krushelnycky et al., 2004). In the Mediterranean, Argentine ants were found to displace virtually all other ant species (Holway and Suarez, 2006) and also negatively impact other species of arthropods (Cole et al., 1992). However, there was a contrasting result showing that the Argentine ants did not affect other non-ant arthropods in northern California riparian woodlands (Holway, 1998). In New Zealand, though thought to be at an earlier stage of expansion, Argentine ants have generated extreme concern in agriculture, conservation and social lives, and have inflicted economic damage due to cost of treatment and loss of productivity (Ward et al., 2010). Argentine ants can reach extremely high density. A study shows that they can reach over 1.3 million queens in a 19 -acre (7.7-ha) in a one year period (quoted in Tsutsui and Suarez, 2003) in Louisiana. In some cases in New Zealand, people have sold their houses, children were unable to play in their backyards, and caged pets have died because of the Argentine ants' infestation (Ward et al., 2010).

\subsection{Aims}

The aim of my study is to investigate how biotic and abiotic factors contribute to the invasion and establishment processes of invasive species, particularly the Argentine ant. To understand the likely cause and effect of relationships leading to establishment, I will evaluate patterns of distribution and the mechanisms shaping the patterns. Because most of New Zealand is thought to be close to the cool-wet limit of the Argentine ant's climate envelope (Hartley and Lester 2003; Hartley et al., 2006), I expect the abundance of the Argentine ants to be less in forested and shady habitat types. I predict that their distribution will be partly affected by their reproduction and developmental processes. At lower temperatures the Argentine ants should be less active and thereby become less competitive. On the other hand, I predict that native ant species will be less sensitive to bushy and similar habitat types and thus they may successfully defend these habitats. 
Brief descriptions of aims of each data chapter follow below. Each chapter is written in the style of a scientific article with its own list of references and appendix section.

\section{Chapter 2}

\section{Rate of Argentine ants' spread}

In this chapter, I surveyed several field sites to evaluate whether the Argentine ants were spreading into new areas or retracting from already colonized habitats. I also evaluated the average rate of change in occupation.

\section{Chapter 3}

\section{Microhabitat Structures and Ant Species Assemblages}

The aim of this chapter was to study the distribution patterns of the Argentine ant as well as other common ant species in different microhabitats. I hypothesized that all ants species should be positively associated with warmer short grass/herbs and concrete microhabitat types. However, I expected native ant species to be less affected by relatively cooler microhabitats. To determine whether temperature (specifically different rates of development) could explain the observed distribution patterns I recorded soil temperatures and calculated the number of generations the Argentine ants could develop in different microhabitat types in a year.

\section{Chapter 4}

\section{Effect of Argentine ant invasion on beetle species richness and composition in the face of different microhabitats}

The community-level effect of the Argentine ant on other arthropods was assessed in two coastal dune sites in northern New Zealand. The assessment was conducted at the order and species level. Invasion impact at the species level was specifically evaluated based on beetle species responses. Beetle species were chosen due to their high abundance and species richness. In this study I expected that beetles, which were unable to resist the invasion of the Argentine ants, would have a refuge in microhabitats unavailable to the Argentine ants. However, there may be some species that strictly prefer the same habitat types as the Argentine ants so that they may be at greater risk of extirpation if they cannot coexist with Argentine ants.

\section{Chapter 5}

\section{Role of interspecific competition and temperature in resisting invasion}

The effect of multiple factors on the invasion of the Argentine ants was investigated in this chapter. In a controlled laboratory setting I tested the foraging activity and walking speed of 
Argentine ants at different temperature levels in the absence of other interacting species. Their competitive and aggressive behaviours interacting against varying colony sizes of other competing species (Monomorium antarcticum and Prolasius advenus) were also tested at different temperature levels. I hypothesized that at low temperature $\left(17^{\circ} \mathrm{C}\right.$ and below $)$ the Argentine ants would be weak competitors as their developmental threshold is $15.9^{\circ} \mathrm{C}$ (Hartley and Lester 2003). My prediction was that the mechanisms underlying their weakness would be decrease in abundance of foragers, slowed walking speed and decreased aggression towards the other species. I expected that native ants would be less affected by low temperatures than Argentine ants and thus would be more successful during competition at these lower temperatures. 


\subsection{References}

Abril S., J. Oliveras, and C. Gomez, 2008. Effect of temperature on the oviposition rate of Argentine ant queens (Linepithema humile Mayr) under monogynous and polygynous experimental conditions. Journal of Insect Physiology 54: 265-272.

Amarasekare, P., 2004. The role of density-dependent dispersal in source-sink dynamics. Journal of Theoretical Biology 226:159-168.

Bardsley, D. K. and G. Edwards-Jones, 2007. Invasive species policy and climate change: social perceptions of environmental change in the Mediterranean. Environmental Science and policy 10: 230-242.

Bennie, J., B. Huntley, A. Wltshire, M. O. Hill, and R. Baxter, 2008. Slope, aspect and climate: Spatially explicit and implicit models of topographic microclimate in chalk grassland. Ecological Modelling 216: 47-59.

Boukal, D. S., M. W. Sabelis, and L. Berec, 2007. How predator functional responses and Allee effects in prey affect the paradox of enrichment and population collapses. Theoretical Population Biology 72: 136-147.

Bremner, A. and K. Park, 2007. Public attitudes to the management of invasive non-native species in Scotland. Biological Conservation 139: 306-314.

Carpintero, S., J. Reyes-Lopez, and L. A. Reyna, 2003. Impact of human dwellings on the distribution of the exotic Argentine ant: a case study in the Donana National Park, Spain. Biological Conservation 115: 279-289.

Cole, F. R., A. C. Medeiros, L. L. Loope, and W. W. Zuehlke, 1992. Effect of the Argentine ant on arthropod fauna of Hawaiian high-elevation shrubland. Ecology 73: 1313-1322.

Dejean, A., C. S. Moreau, M. Kenne, and M. Leponce, 2008. The raiding success of Pheidole megacephala on other ants in both its native and introduced ranges. Comtes Rendus Biologies 331: 631-635.

Derivera, C. E., G. M. Ruiz, A. H. Hines, and P. Jivoff, 2005. Biotic resistance to invasion: native predator limits abundance of an introduced crab. Ecology 86: 3364-3376.

Dighton, J., H. E. Jones, C. H. Robinson, and J. Beckett, 1997. The role of abiotic actors, cultivation practices and soil fauna in the dispersal of genetically modified microorganisms in soils. Applied Soil Ecology 5: 109-131.

Don, W., 2007. Ants of New Zealand. University of Otago Press in association with the Otago Museum, Dunedin.

Elton, C. S., 1958. The ecology of invasions by animals and plants. Methuen and Co. Ltd. London.

Green, O. R., 1990. Entomologist sets new record at Mt Smart for Iridomyrmex humilis established in New Zealand. Weta 13:14-16. 
Grover, C. D., K. C. Dayton, S. B. Menke, and D. A. Holway, 2008. Effects of aphids on foliar foraging by Argentine ants and the resulting effects on other arthropods. Ecological Entomology 33: 101-106.

Haegeman, B. and M. Loreau, 2011. A mathematical synthesis of niche and neutral theories in community ecology. Journal of Theoretical Biology 269: 150-165.

Hagerman, S., H. Dowlatabadi, T. Satterfield, and T. McDaniels, 2010. Expert views on biodiversity conservation in an era of climate change. Global Environmental Change 20: 192-207.

Hampe, A., 2011. Plants on the move: The role of seed dispersal and initial population establishment for climate-driven range expansions. Acta Oecologica 37: 666-673.

Hairston, N. G., F. E. Smith, and S. L. Slobodkin, 1960. Community structure, population control, and competition. American Naturalist 94: 421-425.

Harris, R. J. and G. Barker, 2007. Relative risk of invasive ants (Hymenoptera: Formicidae) establishing in New Zealand. New Zealand Journal of Zoology 34: 161-178.

Hartley, S. and P. Lester, 2003. Temperature-dependent development of the Argentine ant, Linepithema humile (Mayr) (Hymenoptera: Formicidae): a degree-day model with implication of range limits in New Zealand. New Zealand Entomologist 26: 91-100.

Hartley, S., R. Harris, and P. J. Lester, 2006. Quantifying uncertainty in the potential distribution of an invasive species: climate and the Argentine ant. Ecology Letters 9: 1068079.

Holway, D. A., 2005. Edge effects of an invasive species across a natural ecological boundary. Biological Conservation 121: 561-567.

Holway, D. A., 1998. Effect of Argentine ant invasions on ground-dwelling arthropods in Northern California riparian woodlands. Oecologia 116:252-258.

Holway, D. A. and A. V. Suarez, 2006. Homogenization of ant communities in Mediterranean California: The effects of urbanization and invasion. Biological Conservation 127: 319-326.

Holway, D. A., L. Lach, A. V. Suarez, N. D. Tsutsui, and T. J. Case, 2002. The ecological causes and consequences of ant invasions. Annual Review of Ecology and Systematics $33: 181-233$.

Holway, D. A. and T. J. Case, 2001. Effects of colony-level variation on competitive ability in the invasive Argentine ant. Animal Behaviour 61: 1181-1192.

Holway, D. A. and T. J. Case, 2000. Mechanisms of dispersed central-place foraging in polydomous colonies of the Argentine ant. Animal Behaviour 59: 433-441.

Huston, M. A., 1994. Biological Diversity: The coexistence of species on changing landscapes. Cambridge University Press, New York.

Huang, W., 2010. Foraging behaviours of two sympatric ant species in response to lizard eggs. Zoology 113: 85-90. 
Ingram, K. K. and D. M. Gordon, 2003. Genetic analysis of dispersal dynamics in an invading population of Argentine Ants. Ecology 84: 2832-2842.

Jager, H., I. Kowarik, and A. Tye, 2009. Destruction without extinction: long-term impacts of an invasive tree species on Galapagos highland vegetation. Journal of Ecology 97: 12521263.

James, S. E. and R. T. M'Closkey, 2003. Lizard microhabitat and fire fuel management. Biological Conservation 114: 293-297.

Jensen A. L., 1987. Simple Model for exploitative and interference competition. Ecological Modelling 35: 113-121.

Kac M., 1983. When is random random? Mathematical Social Science 4: 181-188.

Karen, M., O. John, B. John, G. Paul, P. Josephine, and K. Thomas, 2008. Distribution and composition of carabid beetle (Coleoptera, Carabidae) communities across the plantation forest cycle-implications for management. Forest Ecology and Management 256: 624-632.

Kath, J., M. Maron, and P. K. Dunn, 2009. Interspecific competition and small bird diversity in an urbanizing landscape. Landscape and Urban Planning 92: 72-79.

Keane, R. M. and M. J. Crawley, 2002. Exotic plant invasions and the enemy release hypothesis. Trends in Ecology and Evolution 17: 164-170.

Krebs, C. J., 1994. Ecology: The experimental analysis of distribution and abundance. Harper Collins College Publishers, New York.

Krushelnycky, P. D., L. L. Loope, and S. M. Joe, 2004. Limiting spread of a unicolonial invasive insect and characterization of seasonal patterns of range expansion. Biological Invasions 6: 47-57.

Lalouette, L., C. M. Williams, F. Hervant, B. J. Sinclair, and D. Renault, 2011. Metabolic rate and oxidative stress in insects exposed to low temperature thermal fluctuations. Comparative Biochemistry and Physiology 158: 229-234.

Lester, P. J., 2005. Determinants for the successful establishment of exotic ants in New Zealand. Diversity and Distribution 11: 279-288.

Levine, J. M, P. B. Adler, and S. G. Yelenik, 2004. A meta-analysis of biotic resistance to exotic plant invasions. Ecology Letters 7: 975-989.

Lindsay, E. A. and S. A. Cunningham, 2009. Livestock grazing exclusion and microhabitat variation affect invertebrates and litter decomposition rates in woodland remnants. Forest Ecology and Management 258: 178-187.

Liu, X., A. Vedlitz, and L. Alston, 2008. Regional news portrayals of global warming and climate change. Environmental Science and Policy 11: 379-393.

Lodge, D. M., 1993. Biological invasions: lesson for ecology. Trends in Ecology and Evolution 8: 133-137. 
Lv, Q. and J. W. Pitchford, 2007. Stochastic von Bertalanffy models, with applications to fish recruitment. Journal of Theoretical Biology 244: 640-655.

MacArthur, R. H. and F. O. Wilson, 1963. An equilibrium theory of insular zoogeography. Evolution 17: 373-387.

Martens, S. N., D. D. Breshears, and C. W. Meyer, 2000. Spatial distributions of understorey light along the grassland/forest continuum: effects of cover, height, and spatial pattern of tree canopies. Ecological Modelling 126: 79-93.

Masse, P. S. M., M. Kenne, R. Mony, A. Dejean, and M. Tindo, 2011. Initial behaviour in colony fragments of an introduced population of the invasive ant Wasmannia auropunctata. Comptes Rendus Biologies 334: 572-576.

May, R. and A. Mclean, 2007. Theoretical ecology: principles and applications. Oxford University press, New York.

McGlynn, T. P., 1999. The worldwide transfer of ants: geographical distribution and ecological invasions. Journal of Biogeography 26: 535-548.

Miguel, A. and O. Huerta, 2007. Fragmentation patterns and implications for biodiversity conservation in three biosphere reserves and surrounding regional environments, Northeastern Mexico. Biological Conservation 134: 83-95.

Mistro, D. C., L. A. D. Rodrigues, and S. Petrovskii, 2012. Spatiotemporal complexity of biological invasion in a space- and time-discrete predator-prey system with the strong Allee effects. Ecological Complexity 9: 16-32.

Moller, H., 1996. Lessons for invasion theory from social insects. Biological Conservation 78: 125-142.

Myers, R. A., N. J. Barrowman, J. A. Hutchings, A. A. Rosenberg, 1995. Population dynamics of exploited fish stocks at low population levels. Science 269: 1106-1108.

Nenzén, H. K. and M. B. Araújo, 2011. Choice of threshold alters projections of species range shifts under climate change. Ecological Modelling 222: 3346-3354.

Ohnishi, S., T. Miyoshi, and S. Shirai, 2010. Low temperature stress at different flower developmental stages affects pollen development, pollination, and pod set in soybean. Environmental and Experimental Botany 69: 56-62.

Perez-Matus, A. and J. S. Shima, 2010. Density and trait-mediated effects of fish predators on amphipod grazers: indirect benefits for the giant kelp, Macrocystis pyrifera. Marine Ecology Progress Series 417:151-158.

Pimentel, D., R. Zuniga, and D. Morrison, 2006. Update on the environmental and economic costs associated with alien-invasive species in the United States. Ecological Economics 52: 273-288.

Pimentel, D., L. Lach, R. Zuniga, and D. Morrison, 2000. Environmental and economic costs of nonindigenous species in the United States. Bioscience 50: 53-65. 
Rempel, L.L. and D. G. Smith, 1998. Postglacial fish dispersal from the Mississippi refuge to the Mackenzie River basin. Canadian Journal of Fisheries and Aquatic Sciences 55(4): 893899.

Ricketts, T. and M. Imhoff, 2003. Biodiversity, urban areas, and Agriculture: Locating priority ecoregions for conservation. Conservation Ecology 8:1-15.

Rosenzweig, M. L., 1995. Patterns in space: species diversity in Space and time.

Cambridge University Press, Cambridge.

Rosenzweig, M. L. and Y. Ziv, 1999. The echo pattern of species diversity: Pattern and processes. Ecography 22:614-628.

Saumel, I. and I. Kowarik, 2010. Urban rivers as dispersal corridors for primarily winddispersed invasive tree species. Landscape and Urban Planning 94: 244-249.

Showler, A. T., R. M. Knaus, and T. E. Reagan, 1990. Studies of the Territorial Dynamics of the Red Imported Fire Ant (Solenopsis invicta Burn, Hymenoptera: Formicidae). Agriculture, Ecosystems and Environment 30: 97-105.

Simberloff, D., 2004. Community ecology: is it time to move on? American Naturalist 163: 787-799.

Simberloff, D., 2000. Global climate change and introduced species in United States forests. The Science of the Total Environment 262: 253-261.

Sparrow, S. W., 1925. Aviation Engine Performance. Journal of The Franklin Institute 200: 711-730.

Speight, M. R., M. D. Hunter, and A. D. Watt, 2008. Ecology of Insects: Concepts and Applications. Wiley-Blackwell, Chichester.

Stachowicz, J. J., R. B. Whitlatch, and R. W. Osman, 1999. Species Diversity and Invasion Resistance in a Marine Ecosystem. Science 286: 1577-1579.

Suarez, A. V., D. A. Holway, and T. J. Case, 2001. Patterns of spread in biological invasions dominated by long-distance jump dispersal: Insights from Argentine ants. Proceedings of Natural Academy of Sciences 98: 1095-1100.

Tokeshi, M., 1999. Species coexistence, ecological and evolutionary perspective. Blackwell Science Ltd., London.

Tsutsui, N. D. and A. V. Suarez 2003. The colony structure and population biology of invasive ants. Conservation Biology 17: 2003: 48-58.

Verberk, W. C. E. P., G. A. van Duinen, A. M. T. Brock, R. S. E. W. Leuven, H. Siepel, P. F. M. Verdonschot, G. van der Velde, and H. Esselink, 2006. Importance of landscape heterogeneity for the conservation of aquatic microinvertebrate diversity in bog landscapes. Journal for Nature Conservation 14: 78-90.

Vitt, P., K. Havens, A. T. Kramer, D. Sollenberger, and E. Yates, 2010. Assisted migration of plants: changes in latitudes, changes in attitudes. Biological Conservation 143: 18-27. 
Walters, A. C. and D. A. Mackay, 2005. Importance of large colony size for successful invasion by Argentine ants (Hymenoptera: Formicidae): evidence for biotic resistance by native ants. Austral Ecology 30: 395-406.

Ward, D. F., J. R. Beggs, M. N. Clout, R. J. Harris, and S. O’Connor, 2006. The diversity and origin of exotic ants arriving in New Zealand via human-mediated dispersal. Diversity and Distributions 12: 601-609.

Ward, D. F, C. Green, R. J. Harris, S. Hartley P. J. Lester, M. Stanley, D. M. Suckling, and R. J. Toft, 2010. Twenty years of Argentine ants in New Zealand: past research and future priorities for applied management. New Zealand Entomologist 33: 68-78.

Wieters, E. A., E. Salles, S. M. Januario, and S. A. Navarrete, 2009. Refuge utilization and preferences between competing intertidal crab species. Journal of Experimental Marine Biology and Ecology 374: 37-44.

Williamson, M. and A. Fitter, 1996. The varying success of invaders. Ecology 77: 1661-1666.

Wilson, J. R .U., E. E. Dormontt, P. J. Prentis, A. J. Lowe, and D. M. Richardson, 2008. Something in the way you move: dispersal pathways affect invasion success. Trends in Ecology and Evolution 24: 136-144.

Worland, M. Roger and W. Block, 2003. Desiccation stress at sub-zero temperatures in polar terrestrial Arthropods. Journal of Insect Physiology 49: 193-203. 


\section{Chapter 2}

\section{Local scale spatio-temporal dynamics of Argentine ant populations}

\subsection{Introduction}

Invasive species are increasingly recognized as one of the greatest threats to global biodiversity and can have dire economic consequences (Mack et al., 2000). There are multiple pathways for exotic species to gain extra range habitat, but they are more likely to establish in a novel area when the founder species has high propagule pressure and greater genetic diversity. This typically happens during human-mediated introduction in a mass dispersal or multiple entries (Wilson et al, 2008). One of the most important environmental factors to predict establishment of exotic ant species is temperature (Lester, 2005). Global species richness distribution is high towards the lower latitudes and is mainly associated with increases in temperature and precipitation (Huston, 1994). Countries like New Zealand have large temperature differences along their latitudinal gradient and this has a huge effect on species distribution patterns along the South and North Islands. Specifically, insects are sensitive to temperature changes as their physiology and behavioural responses are strongly regulated by temperature (Speight et al., 2008). Accordingly, ant species abundance in New Zealand is greater in the North Island and this response is also observed in established exotic species (Don, 2007).

One of the exotic ant species established in New Zealand is Linepithema humile (Argentine ants). Argentine ants are native to South America, mainly the drainage basin of Parana' (Wild 2004). They are believed to prefer a Mediterranean climate (Suarez et al., 2001). In the last century, assisted by human transport, they have successfully invaded ranges outside this climatic region except Antarctica (Suarez et al., 2001). Invasion by the Argentine ants has been associated with reduction of other arthropod communities in their invasion fronts (Cole et al., 1992; Blancafort and Gómez 2005). In New Zealand, Argentine ants were first detected in 1990 in Auckland (Green, 1990) and have since invaded numerous areas across the country (Don, 2007; Ward et al 2010). There are on-going endeavours to build predictive models to foretell potential impacts and future distributions of invasive species (Austin, 2007). Hartley et al. (2006) developed a species-specific model to reflect the Argentine ant global future invasion frontiers. In another study, based on temperature requirements for developmental process, Hartley and Lester (2003) developed a degree-day model to predict distribution of the Argentine ants throughout New Zealand. This model predicts the persistence of the Argentine ants in the invaded localities and it also forecasts that this species would spread to the South Island as far as Otago. According to their findings, Argentine ants require 445 degree-days above $15.9^{\circ} \mathrm{C}$ to complete development from egg to adult stage. However, in spite of all these 
endeavours, the actual trend of local spread of the Argentine ants in New Zealand remains untested. Therefore, the objective of the study is to use current and archived data to evaluate the rate of spread of this species across different habitat types in rural (coastal) as well as urban settings.

\subsection{Methods}

Study sites: the study was conducted in two types of habitats, rural (Piha and Baylys Beach) and urban (Dargaville, Hastings and Wellington) (Fig. 2.1). I conducted surveys in 2009 and 2010. I also used pre-existing unpublished data obtained from Dr Stephen Hartley collected in 2002, 2003, 2004 and 2005.

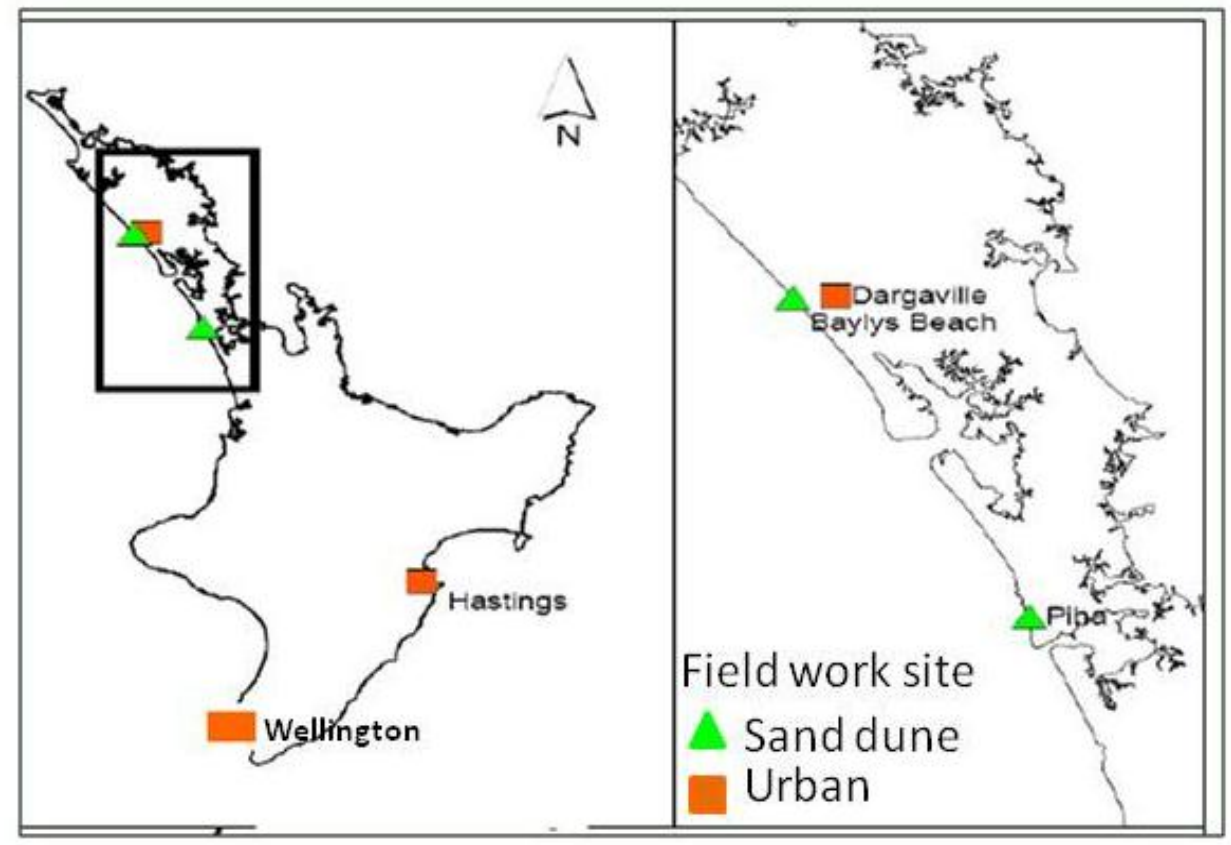

Fig. 2.1. Location of study sites in the North Island, New Zealand.

Sampling: Data were collected by Dr Stephen Hartley, Victoria University of Wellington from 2002 to 2005 using the same sampling method as used in this study. These data allowed us to evaluate the invasion trend over an extended period of time. The location of baits in the earlier surveys were available as New Zealand Map Grid coordinates, and using a GPS for guidance, these were matched as closely as possible in the current survey (generally with an accuracy of +/- 10m). I sampled ants using non-toxic Xstinguish ant attractant bait and peanut butter in $2008 / 09$ and 2010. Vials of $65 \mathrm{~mm}$ depth and $25 \mathrm{~mm}$ diameter were used to collect ants. About $5 \mathrm{~g}$ of each bait type was put on opposite sides of the inner surface of the vials. The vials with baits were laid in the field and collected after 24hrs. In the urban habitats, about 200 baits were laid in each site over a $2 \times 2 \mathrm{~km}$ area, and in the rural coastal habitats 21 baits were laid along a 
$1 \mathrm{~km}$ transect at each site each year. In Kelburn, Wellington the area of survey was intensified into a $0.5 \times 0.5 \mathrm{~km}$ area as the population was confined to this zone.

Ant samples were frozen and then transferred to vials containing $70 \%$ alcohol for subsequent identification to their species level. Baited traps may not be an efficient method of collecting all ant species present in an area as different species respond differently to bait (Glotelli et al., 2011; Vele et al., 2009). However, combining both bait and visual search may enhance probability of ant capture. Accordingly, I conducted a visual survey for one minute at the time of collection of the bait tubes. The probability of detection ants by visual search is estimated to be 0.895 for ant sampling (Ward and Stanley, 2012).

Data analysis: The local range size (area of occupancy) in each year was estimated using GIS (geographic information system) by generating "Thiessen polygons" around each sample point. Area was calculated around each sample where Argentine ants were found and summed to estimate total area occupied in that year. Areas without Argentine ants were excluded. In calculating the Thiessen polygons a maximum diameter of $100 \mathrm{~m}$ was used in the urban sites (Wellington, Hastings and Dargaville). The linear rate-of-spread of the Argentine ant population were calculated as the "radius" ( $r$ ) of the change in invaded area, where $r=(A / \pi)^{0.5}$.

Surveys at Piha and Baylys Beach were conducted along linear transects. Calculating Thiessen polygons is not practical in such a situation. Because some of the baits were placed about $10 \mathrm{~m}$ from edge of bare sand, the circular area calculation would include areas where ants would not inhabit. Therefore, I calculated the proportion of baits occupied rather than an area. Regression analysis (generalized linear model, GLM, assuming Poisson distribution) was used to test change in the number of bait stations occupied with time, separately in each study site.

\subsection{Results}

Rate and trend of spread: the area occupied by Argentine ants increased in Dargaville from 2002 to 2005 (Fig. 2.7A) with an average rate of spread of $19567 \mathrm{~m}^{2} / \mathrm{yr}$ (a linear change of $79 \mathrm{~m} / \mathrm{yr}$ ). However, their distribution declined from 2005 to 2009 and the rate was found to be $19713 \mathrm{~m}^{2} / \mathrm{yr}$ (a linear change of $-79 \mathrm{~m} / \mathrm{yr}$ ). There was an increase of $1766 \mathrm{~m}^{2} / \mathrm{yr}$ from 2009 to 2010 (a linear increase of 24m/yr). Their increase in spread in Hastings continued until 2004 (Fig. 2.7B). The rate of increase from 2002 to 2003 was $42166 \mathrm{~m}^{2} / \mathrm{yr}$ (a linear increase of $116 \mathrm{~m} / \mathrm{yr}$ ). They also increased their spread from 2003 to 2004 in a rate of $28218 \mathrm{~m}^{2} / \mathrm{yr}$ (a linear increase of $95 \mathrm{~m} / \mathrm{yr}$ ). However, they declined from 2004 to 2009 at a rate of $-9812 \mathrm{~m}^{2} / \mathrm{yr}$ (a linear decline of $56 \mathrm{~m} / \mathrm{yr}$ ) and from 2009 to 2010 the decline was found to be $-118544 \mathrm{~m}^{2} / \mathrm{yr}$ (a 
linear decrease of $196 \mathrm{~m} / \mathrm{yr}$ ). In Wellington, there was a sharp decline in spread from 2002 to 2003 and in the next period, from 2003 to 2004 they increased. However, their spread continued to decline from 2004 to 2010 and seems to be on the brink of extirpation from that locality (Fig. 2.7C). The average rate of change in spread in Wellington was $-13474 \mathrm{~m}^{2} / \mathrm{yr}$ over an 8-year period.

At Piha, the comparison between 2002 and 2008 shows that their distribution declined, however, they spread slightly from 2008 to 2010 (Fig. 2.8A). At Baylys Beach the size of the invaded area was the greatest in 2002, however, starting from 2008 until last sltudy, 2010 their distribution appeared to increase slightly (Fig. 2.8B) (see Table 2.1). Except at Piha and Baylys Beach declines have been found to be significant (GLM, p < 0.001) (see Table 2.2). The changes in spread of the Argentine ants for all sites are detailed in Fig. 2.2-2.6. Other ant species have been displayed in Fig. 2.2-2.6. This is to show the distribution patterns of the Argentine ants in the presence of other native and exotic ant species.

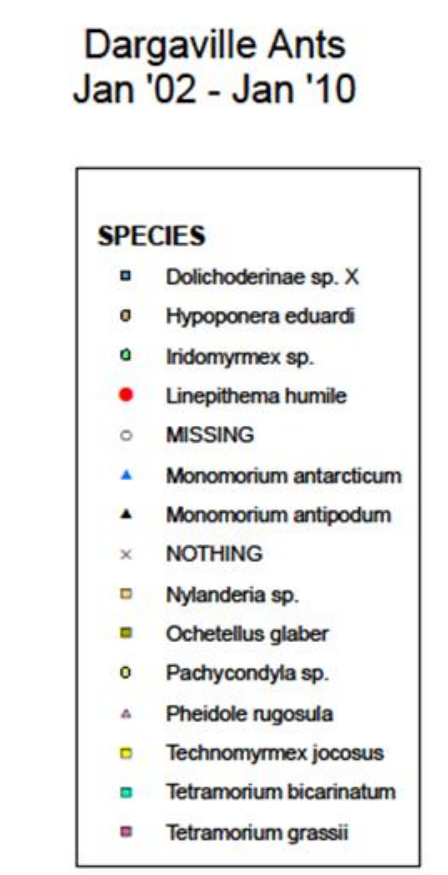
Habteab Habtom $\&$ Stephen Hartley.
Biological Sciences, Victoria University of Wellington

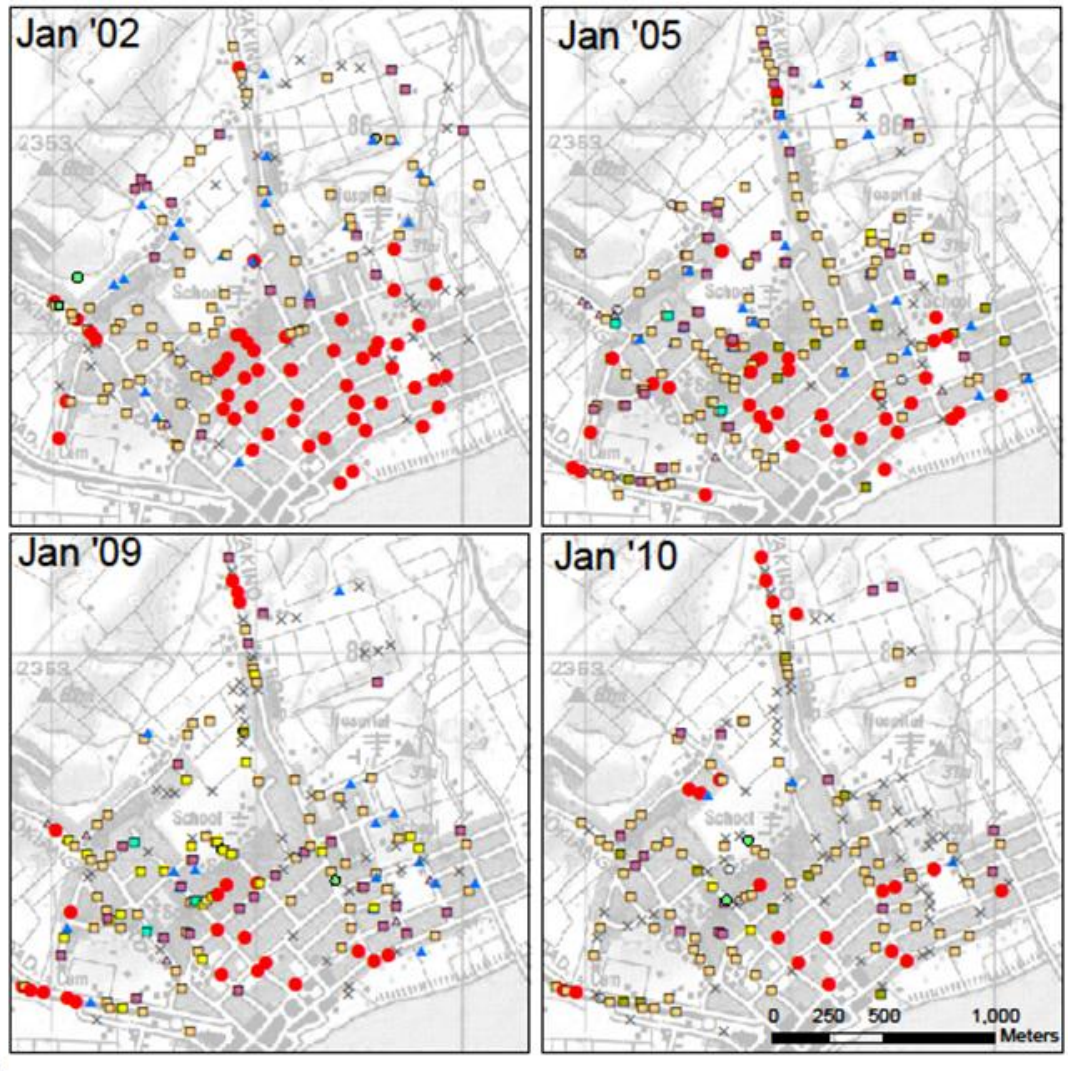

Fig. 2.2. Change in distribution pattern over time of $L$. humile and other ant species in Dargaville. $\mathrm{n} \approx 200$ baits each year, with no repeat sampling within a year. 


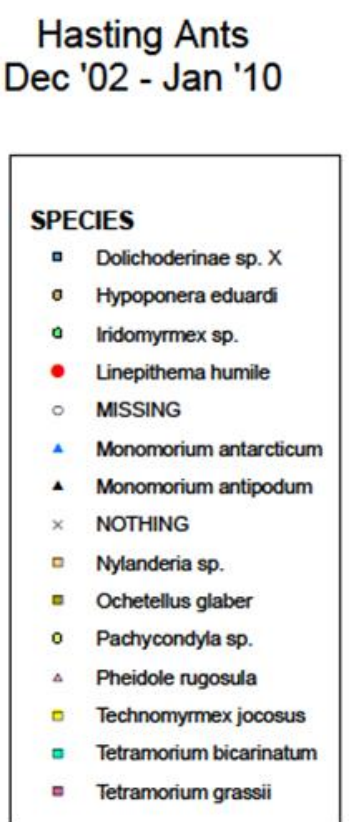

Habteab Habtom \& Stephen Hartley.

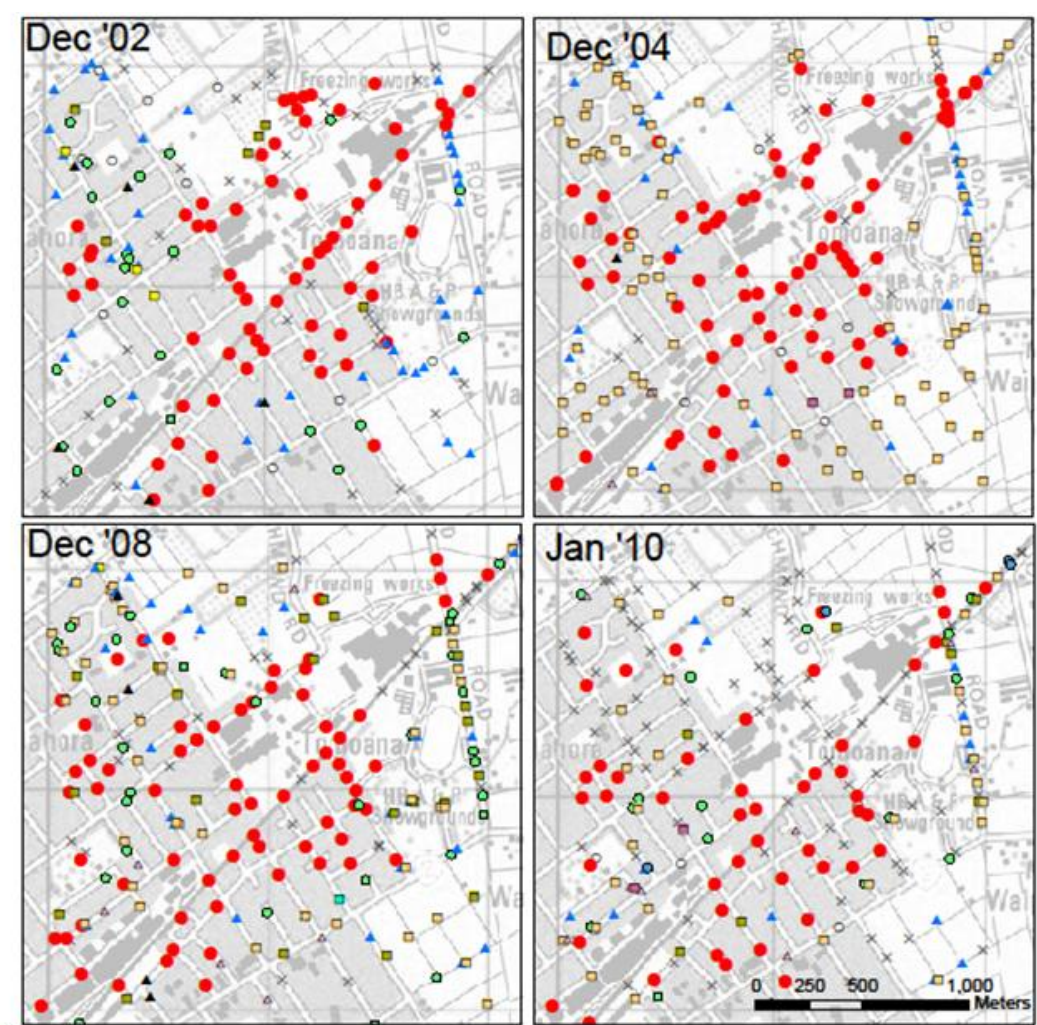

Fig. 2.3. Change in distribution patterns and spreads of $L$. humile and other ant species with time in Hastings. $n \approx 200$ baits each year. Each year represents one time sample i.e. no repeated sampling within a year.

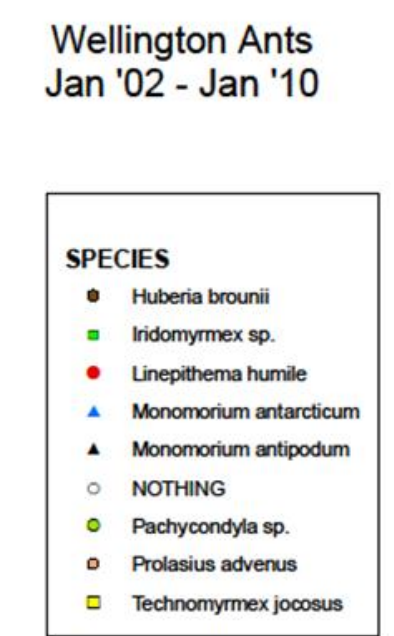

Habteab Habtom 8 Stephen Hartley.

Biological Sciences, Victoria University of Wellington

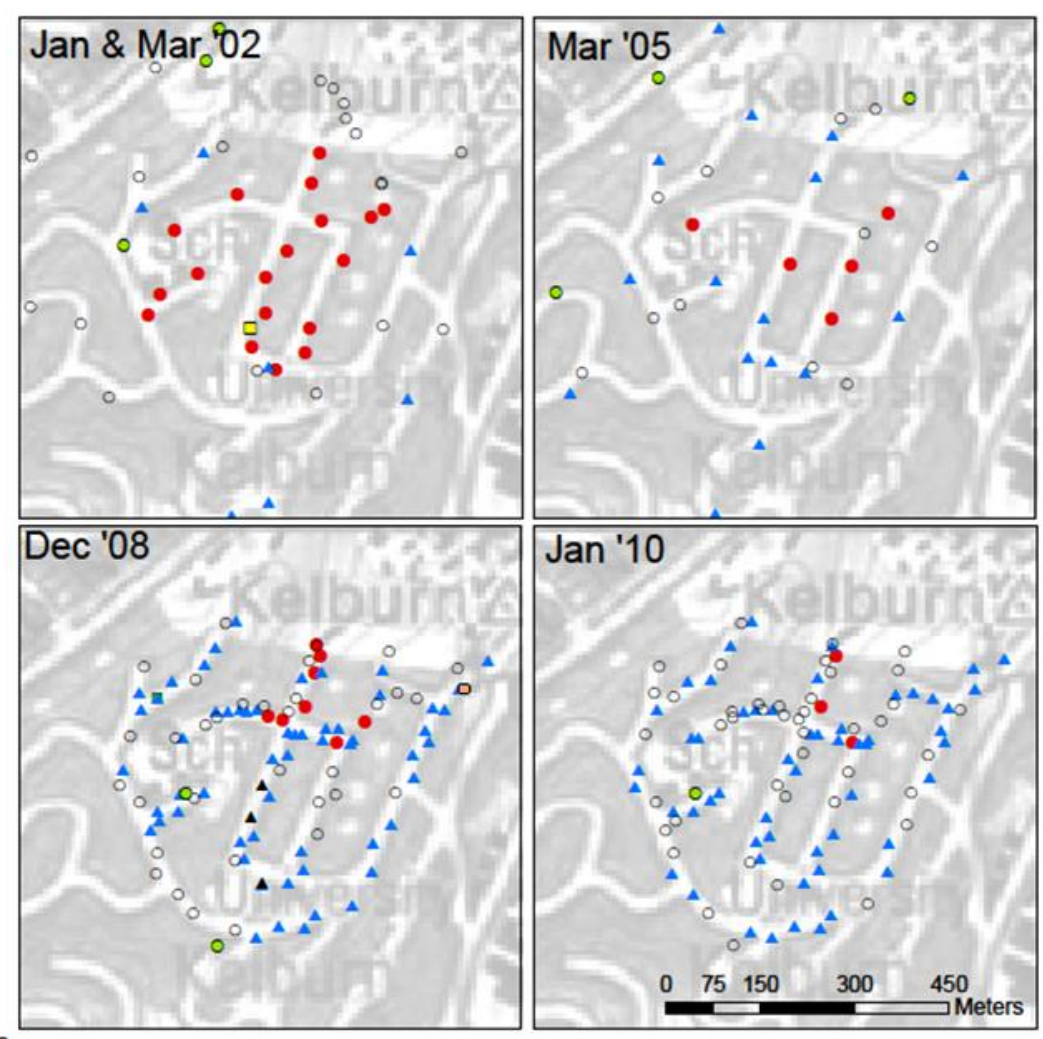

Fig. 2.4. Change in distribution patterns and spreads of $L$. humile and other ant species with time in Wellington. $\mathrm{n} \approx 200$ baits in 2002 and 2005, $\mathrm{n}=100$ baits in 2008 and in 2010. Each year represents one time sample i.e. no repeated sampling within a year. 


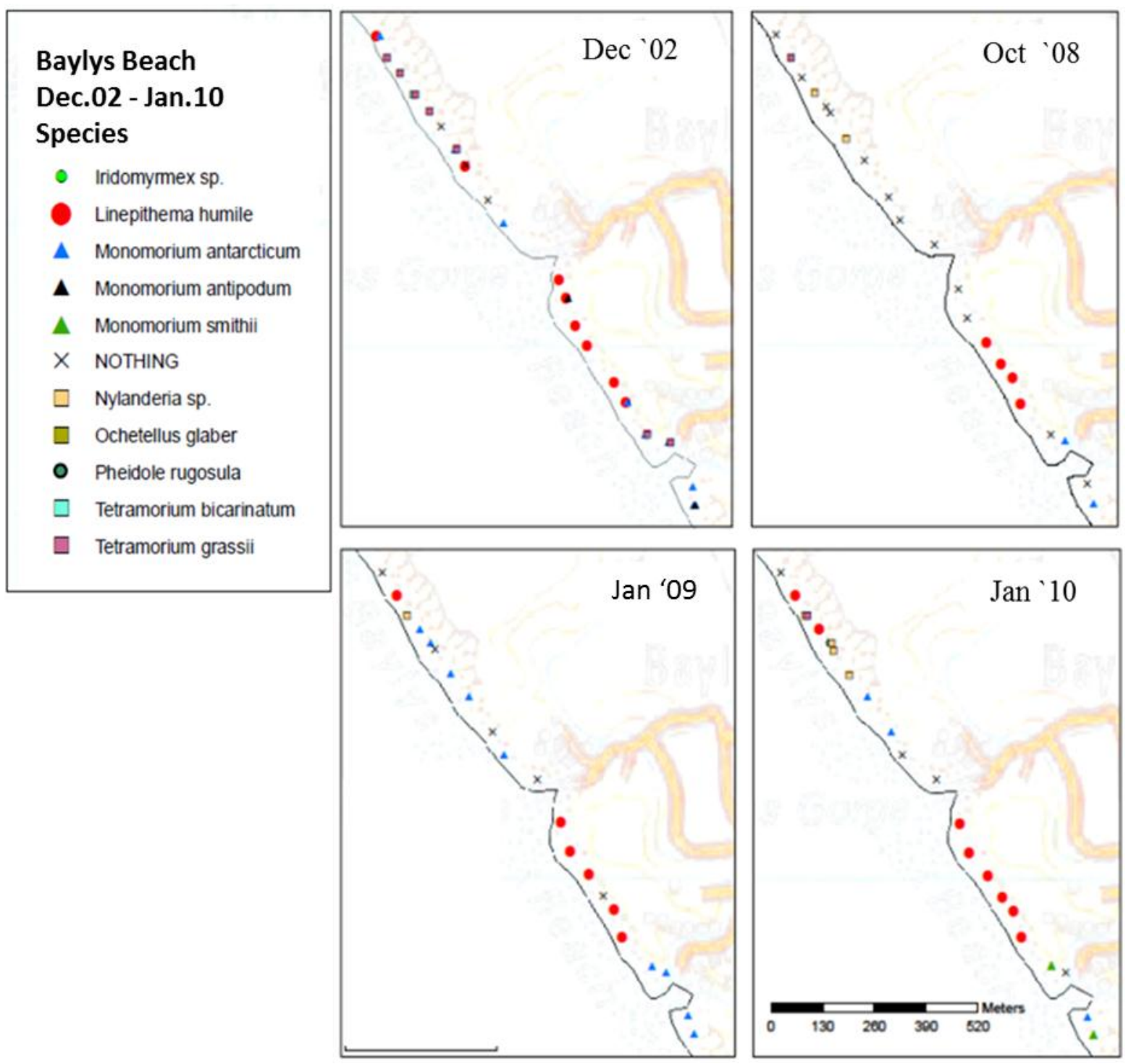

Fig. 2.5. Change in distribution patterns and spreads of $L$. humile and other ant species with time at Baylys Beach. $n=21$ baits each year. Each year represents one time sample i.e. no repeated sampling within a year. 

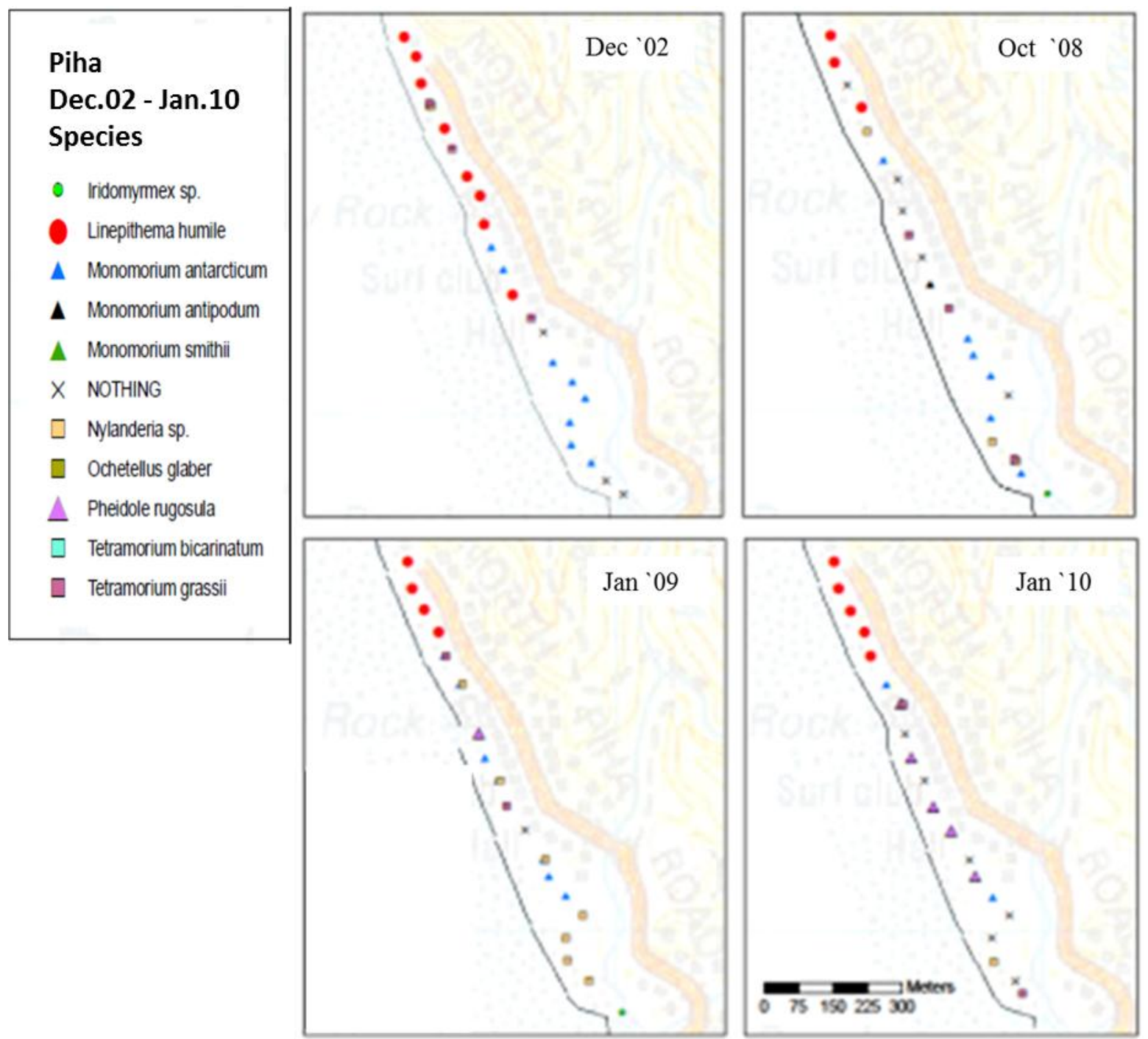

Fig. 2.6. Change in distribution patterns and spreads of $L$. humile and other ant species with time at Piha. $n=21$ baits each year. Each year represents one time sample i.e. no repeated sampling within a year. 

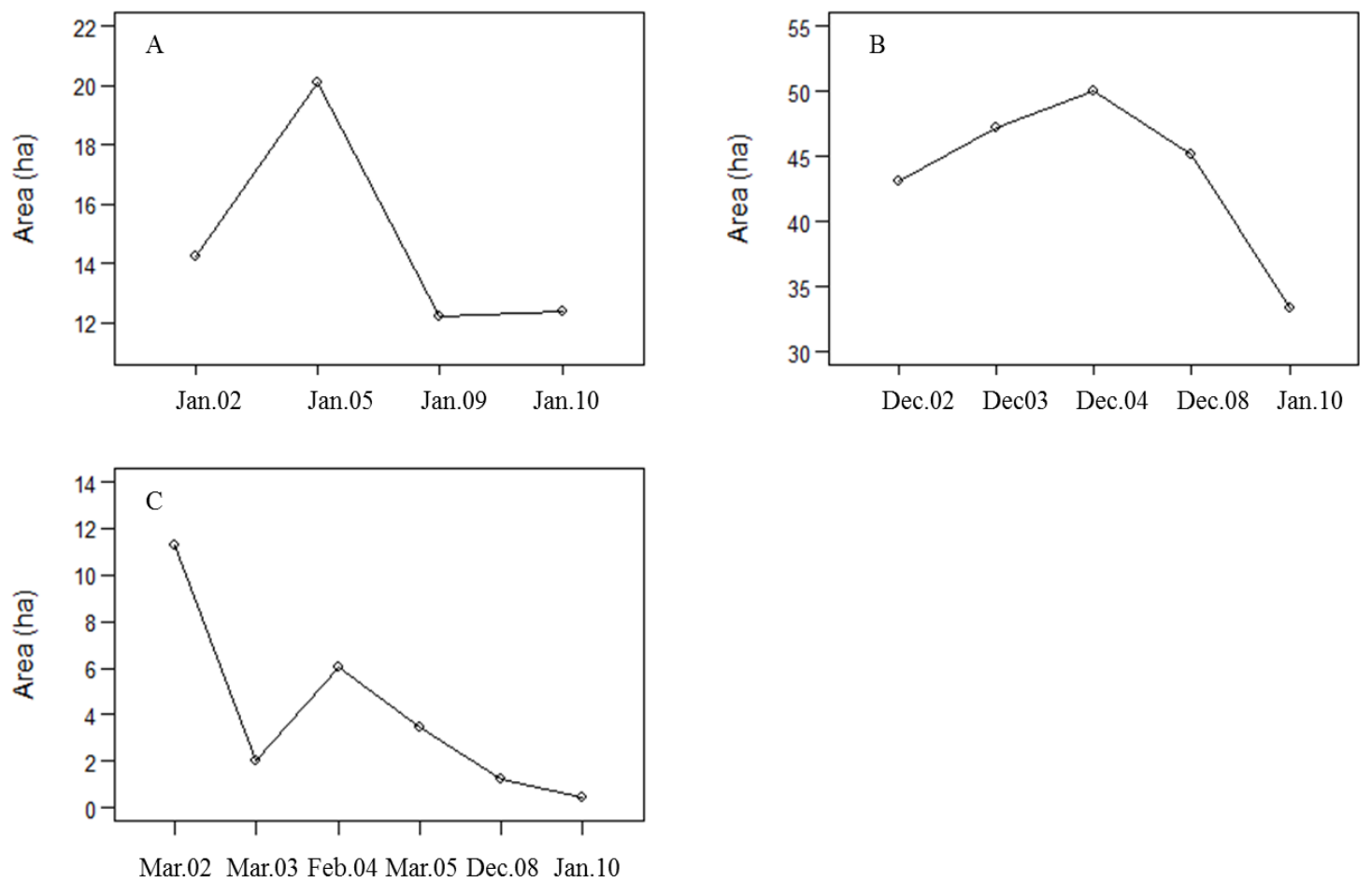

Fig. 2.7. Area deemed occupied by Argentine ants in A) Dargaville, B) Hastings and C) Wellington. Sample size in each year was $n \approx 200$ "point" samples but samples with Argentine ant present were 20 or less. There was no repeated sampling in each year, so no standard errors were calculated.
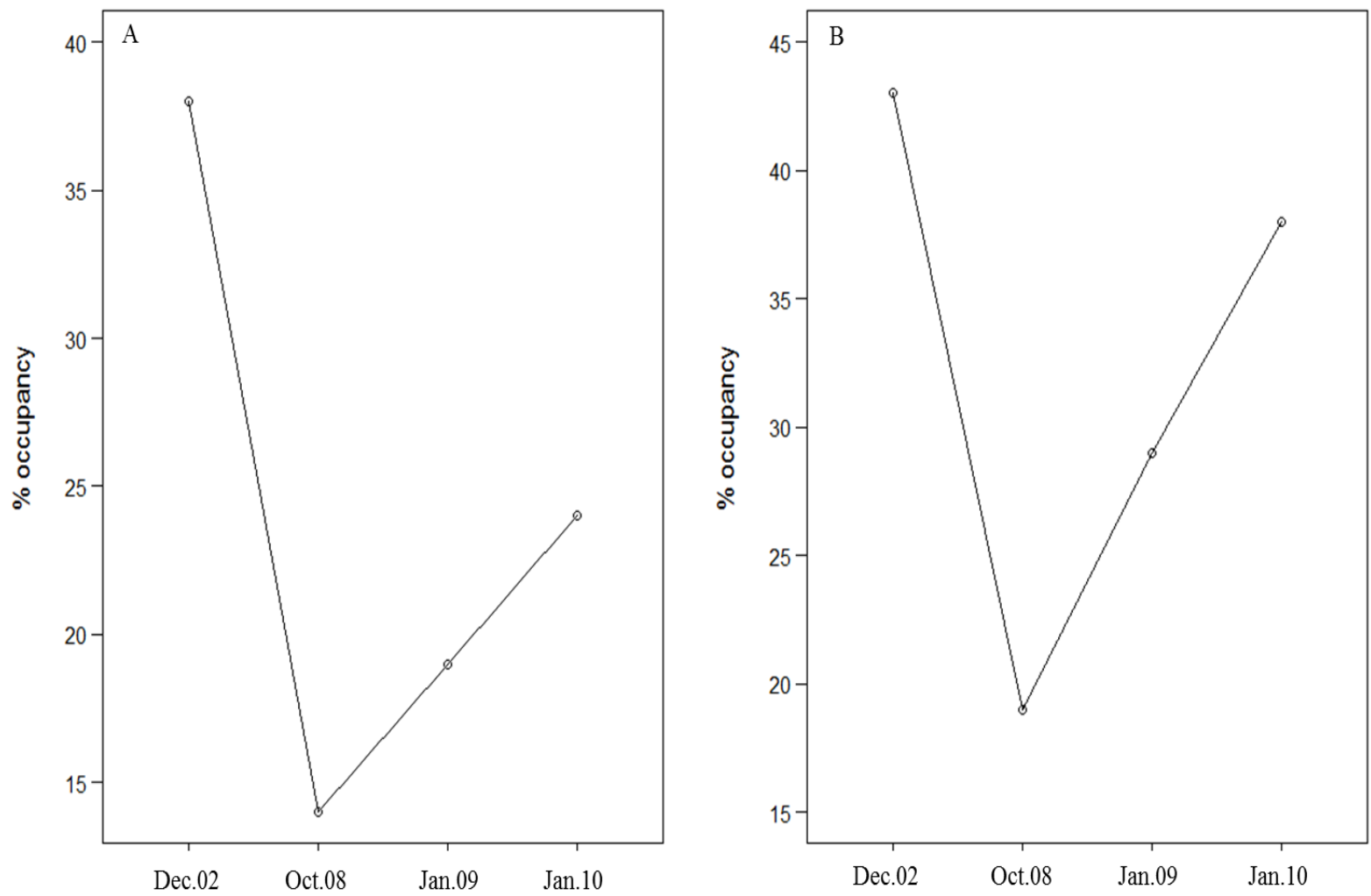

Fig. 2.8. Change over time in the percentage of baited tubes occupied by Argentine ants in A) Piha and B) Baylys Beach (B). $n=21$ baits each year. 
Table 2.1. Long-term change in trend of $L$. humile. Data are percent of bait occupied by $L$. humile in total sample. The dashes indicate no data collected.

\begin{tabular}{lrrrrrrr} 
& \multicolumn{8}{c}{ \% presence of $\boldsymbol{L}$. humile } \\
study site & $\mathbf{0 2 / 0 3}$ & $\mathbf{0 3 / 0 4}$ & $\mathbf{0 4 / 0 5}$ & $\mathbf{0 5 / 0 6}$ & $\mathbf{0 8 / 0 9}$ & $\mathbf{0 9 / 1 0}$ & $\mathbf{1 0 / 1 1}$ \\
\hline Baylys Beach & 43.0 & - & - & - & 19.0 & 29.0 & 38.0 \\
Dargaville & 9.9 & - & - & 15.0 & - & 9.5 & 9.6 \\
Piha & 38.0 & - & - & - & 14.0 & 19.0 & 23.8 \\
Hastings & 28.0 & 30.0 & 32.8 & - & - & 27.6 & 21.8 \\
Wellington & 11.3 & 5.8 & 6.4 & 3.0 & 7.5 & - & 3.0 \\
\hline
\end{tabular}

Table 2.2. Regression (generalized linear model, GLM) results of change in spread among different years in each study site.

\begin{tabular}{lcccccc} 
Study Site & & Estimate & $\begin{array}{c}\text { Std. } \\
\text { Error }\end{array}$ & $\mathbf{z}$ value & $\begin{array}{c}\text { residual } \\
\text { df }\end{array}$ & $\operatorname{Pr}(>|\mathbf{z}|)$ \\
\hline Baylys Beach & Year & -0.0155 & 0.0788 & -0.197 & 2 & 0.844 \\
Dargaville & Year & -0.03 & 0.0004 & -82.41 & 2 & $<0.00001$ \\
Piha & Year & -0.157 & 0.09 & -1.69 & 1 & 0.0907 \\
Hastings & Year & -0.03 & 0.0002 & -119.6 & 3 & $<0.00001$ \\
Wellington & Year & -0.35 & 0.0011 & -302.1 & 4 & $<0.00001$ \\
\hline
\end{tabular}

\subsection{Discussion}

The precise history of arrival of the Argentine ants at each study site is not known (Ward et al., 2010) apart from being detected first in Auckland in 1990 (Green, 1990). Despite this uncertainty, there was an increase in spread in the earlier years of study (2002 to 2005), but in the later years (2005 to 2010) the trends of spread of the Argentine ants were found to be declining in all three of the urban study sites. They also declined in one of the rural sites (Piha) from 2002 to 2008, and remained more or less stable towards recent years (2010). They slightly increased their spread in the other rural site (Baylys Beach). Previous study by Nonacs and Soriano (1998) found that the Argentine ants retreated from certain invasion fronts and this was associated with food depletion. Another study documented that the Argentine ants spread and retraction both seasonally and annually (Heller et al., 2006). Unassisted spread of the Argentine ants is very slow. A number of studies indicate that Argentine ants spread locally an average of 100m per year (Ingram and Gordon, 2003; Krushelnycky et al., 2004), but it is possible that they can spread through natural budding up to about $150 \mathrm{~m} / \mathrm{yr}$ (Suarez et al., 2001). In my study I found that they fluctuated between $79 \mathrm{~m} / \mathrm{yr}$ and $116 \mathrm{~m} / \mathrm{yr}$ although at one point in Dargaville the spread was $24 \mathrm{~m} / \mathrm{yr}$. A model developed to predict the potential future distribution of the Argentine ant at a national scale suggests that they could spread farther even 
to the southern part of the South Island, New Zealand (Hartley and Lester, 2003). However, my relatively fine-scale measurements of actual field distribution showed signs of contraction from their established fronts in four out of the five study sites.

Although invasive species are commonly perceived to show a one-way increase in their introduced range, at a local scale the situation can be more dynamic. Hastings, Dargaville, Baylys Beach and Piha are all considered climatically suitable for Argentine ants (Hartley et $a l ., 2006)$. In spite of this suitability, the Argentine ants seem to be declining in four of the sites (Dargaville, Piha, Hastings and Wellington), in particular, Argentine ants seem to be on the verge of collapse in Wellington. Of the five sites studied Wellington has the lowest annual temperatures (mean annual temperature of $12^{\circ} \mathrm{C}$ ) and is considered the most marginal in terms of climatic suitability (Hartley \& Lester 2003, Hartley et al. 2008).

A number of factors can lead to observed fluctuations in the distribution of a population. Firstly, Argentine ants spread and retract seasonally (Heller et al., 2006). For this reason distributions in this study were consistently sampled in summer as far as possible. Densities of other invasive hymenopterans are also known to change annually (Barlow et al., 2002). Thus, some changes in spread may be due to demographic stochasticity (Haegeman and Loreau, 2011). Effects of random sampling (mostly false negatives) could also lead to apparent shifts in distribution, however such random fluctuations should not generate long-term trends over time as was recorded at four of the five sites studied.

The population declines recorded here may not be an isolated event. In a separate study, Argentine ants have been reported to be locally collapsed in over one-third of the sites they previously occupied across New Zealand (Cooling et al., 2012). In contrast, a decade-long study conducted in Corsica revealed an expansion of the Argentine ants' range as a result of "human-mediated jump dispersal" (Blight et al., 2009). The establishment of new invasion fronts by jump dispersal is not necessarily in contradiction with decline from already invaded sites. Argentine ants can abandon areas where they have been for long time while invading new areas (Heller et al., 2008). An implication of this is that in New Zealand there is a dynamic situation of invasions, declines and new invasions, operating as a fluid metapopulation.

No control measures organized by city council or the government have been conducted at any of the study sites. However, some household treatments, for example poisoning in a kitchen or other parts of a building may have occurred very rarely. Nevertheless, this measure is unlikely to affect the overall spread of the Argentine ants. The theory of population growth states that 
populations start to decline when they grow beyond the carrying capacity, which is typically associated with food depletion (Nonacs and Soriano, 1998). Biotic resistance by competitors is an important factor in resisting invasion especially at the early stage of establishments (Stachowicz, 1999), Walters and Mackay (2005) demonstrated that resident Iridiomyrmex sp. in Australia presented a significant competitive barrier to the establishment of Argentine ants, that could only be overcome if Argentine ants outnumbered Iridiomyrmex by 5-10 times. In contrast, the work of Sagata and Lester (2008) showed that increased propagule pressure did not help Argentine ants to outcompete another ant species (Monomorium antarcticum) in a manipulative field study in New Zealand. This implies that the Argentine ant's response to biotic resistance may vary with the type of competitor species and/or environmental conditions. In either case, biotic resistance does not provide a satisfactory explanation of declines that occur after a species has already established itself. The role of infectious diseases (Hayes and Richardson, 2001) and the build-up of specialist predators (Derivera et al., 2005) in causing the decline of invasive species is a strong theoretical possibility. A number of insect species are controlled by pathogens (Hajek et al., 2007). However, so far there is no empirical evidence to implicate infection or predation as the cause of the local declines of Argentine ants.

Although all the factors discussed above may contribute in the decline of the Argentine ants, some studies suffer from false negative or false positive findings (Ebrahimi, 2008). Indeed food locating ability of the Argentine ants depends on their colony size (Gordon, 1995). Failure to detect Argentine ants in baits does not necessarily confirm absence of the Argentine ants in that area - although it is indicative of low abundance and/or unsuitable temperatures at the time of survey. The low occupancy recorded in Wellington in March 2003 may have been due to sampling occurring on a particularly hot day which dried inhibited ant activity on concrete and tarmac surfaces (Hartley pers. comm.) Interaction with other species may also result in false negatives. It is possible that other ants from the bait tube could displace them, however, Argentine ants are generally considered to be a behaviourally dominant species (Holway and Suarez, 2006) so this is unlikely to be an important factor in this study. At the same time they could still remain undetected from visual search although other studies have concluded that visual searching is a fairly reliable method of detection (Sanders and Barton, 2001; Ward and Stanley, 2012).

While the individual distribution pattern recorded on a particular day may be subject to many of the sampling effects described above, the fact that three out of five of the sites showed significant declines in distribution over time suggests that this is likely a general pattern of the 
Argentine ant's fine-scale spatio-temporal dynamics in New Zealand. The results of Cooling et al. (2012) add weight to this interpretation. What remains unknown, however, is the mechanistic cause behind these dynamics and how the rates of local decline compared against the rate of establishment of new populations via large-scale jump-dispersal events. It is the balance of these two processes (and how they interact with other factors such as climate, competitors and disease) that will determine the long-term change in the density and distribution of this important invasive species across New Zealand. Chapters 3 and 5 investigate in more detail some of these abiotic and biotic influences on the fine-scale distribution and competitive ability of Argentine ants. 


\subsection{References}

Austin, M., 2007. Species distribution models and ecological theory: A critical assessment and some possible new approaches. Ecological Modelling 200: 1-19.

Barlow, N. D., J. R. Beggs, and M.C. Barron, 2002. Dynamics of common wasps in New Zealand beech forests: A model with density dependence and weather. Journal of Animal Ecology 71: 663-671.

Blancafort, X. and C. Gómez, 2005. Consequences of the Argentine ant, Linepithema humile (Mayr), invasion on pollination of Euphorbia characias (L.) (Euphorbiaceae). Acta Oecologica 28: 49-55.

Blight, O., J. Orgeas, M. Renucci, A. Tirard, and E. Provost, 2009. Where and how Argentine ant (Linepithema humile) spreads in Corsica? Comptes Rendus Biologies 332: 747-751.

Cooling, M., S. Hartley, D. A. Sim, and P. J. Lester, 2012. The widespread collapse of an invasive species: Argentine ants (Linepithema humile). Biology Letters 8: 430-433.

Derivera, C. E., G. M. Ruiz, A. H. Hines, and P. Jivoff, 2005. Biotic Resistance to Invasion: Native Predator limits Abundance and Distribution of an Introduced Crab. Ecology 86: 3364-3376.

Ebrahimi, N., 2008. Simultaneous control of false positives and false negatives in multiple hypotheses testing. Journal of Multivariate Analysis 99: 437-450.

Gordon, D. M., 1995. The expandable network of ant exploration. Animal Behaviour 50: 9951007.

Gotelli, N. J., A. M. Ellison, R. R. Dunn, and N. J. Sanders, 2011. Counting ants (Hymenoptera: Formicidae): biodiversity sampling and statistical analysis for myrmecologists. Myrmecological News 15: 13-19.

Green, O. R., 1990. Entomologist sets new record at Mt Smart for Iridomyrmex humilis established in New Zealand. Weta 13:14-16.

Haegeman, B. and M. Loreau, 2011. A mathematical synthesis of niche and neutral theories in community ecology. Journal of Theoretical Biology 269: 150-165.

Hajek, A. E., M. L. McManus, and I. D. Junior, 2007. A review of introductions of pathogens and nematodes for classical biological control of insects and mites. Biological Control 41: $1-13$.

Hartley, S. and P. J. Lester, 2003. Temperature-dependent development of the Argentine ant, Linepithema humile (Mayr) (Hymenoptera: Formicidae): a degree-day model with implications for range limits in New Zealand. New Zealand Entomologist 26: 91-100.

Hartley, S., R. Harris, and P. J. Lester, 2006. Quantifying uncertainty in the potential distribution of an invasive species: climate and the Argentine ant. Ecology Letters 9: 10681079. 
Hayes, R. A. and B. J. Richardson, 2001. Biological control of the rabbit in Australia: lessons not learned? Trends in Microbiology 9: 459-460.

Heller, N. E., N. J. Sanders, and D. M. Gordon, 2006. Linking temporal and spatial scales in the study of an Argentine ant invasion. Biological Invasions 8: 501-507.

Heller, N. E., N. J. Sanders, J. W. Shors, and D. M. Gordon, 2008. Rainfall facilitates the spread, and time alters the impact, of the invasive Argentine ant. Oecologia 55, 385-395.

Holway, D. A. and A. V. Suarez, 2006. Homogenization of ant communities in Mediterranean California: The effects of urbanization and invasion. Biological Conservation 127: 319-326.

Huston, M. A., 1994. The coexistence of species on changing landscapes. Cambridge University Press, Cambridge.

Ingram, K. K. and D. M. Gordon, 2003. Genetic analysis of dispersal dynamics in an invading population of Argentine Ants. Ecology 84: 2832-2842.

Kac M., 1983. When is random random? Mathematical Social Science 4: 181-188.

Kibbler, H., M. E. Johnston, and R. R. Williams, 2004. Adventitious root formation in cuttings of Backhousia citriodora F. Muell. Seasonal influences of temperature, rainfall, flowering and auxins on the stock plant. Scientia Horticulturae 102: 343-358.

Krebs, C. J., 1994. Ecology: The Experimental Analysis of Distribution and Abundance. Harper Collins, College Publishers, New York.

Krushelnycky, P. D., L. L. Loope, and S. M. Joe, 2004. Limiting spread of a unicolonial invasive insect and characterization of seasonal patterns of range expansion. Biological Invasions 6: 47-57.

Lester, P. J., 2005. Determinants for the successful establishment of exotic ants in New Zealand. Diversity and Distributions 11: 279-288.

Lv, Q. and J. W. Pitchford, 2007. Stochastic von Bertalanffy models, with applications to fish recruitment. Journal of Theoretical Biology 244: 640-655.

Mack, R. N., D. Simberloff, W. M. Lonsdale, H. Evans, M. Clout, and F. A. Bazzaz, 2000. Biotic invasions: causes, epidemiology, global consequences, and control. Ecological Application 10: 89-0.

Nonacs, P. and J. L. Soriano, 1998. Patch sampling behaviour and future foraging expectations in Argentine ants, Linepithema humile. Animal Behaviour 55: 519-527.

Sagata, K. and P. J. Lester, 2008. Behavioural plasticity associated with propagule size, resources, and the invasion success of the Argentine ant Linepithema humile. Journal of Applied Ecology 46: 19-27.

Sanders, N. J. and K. E. Barton, 2001. Long-term dynamics of the distribution of the invasive Argentine ant, Linepithema humile, and native ant taxa in northern California. Oecologia 127: $123-130$. 
Speight, M. R., M. D. Hunter, and A. D. Watt, 2008. Concepts and Applications. Ecology of Insects. SPi Publisher services, Pondicherry.

Stachowicz, J. J., R. B. Whitlatch, and R. W. Osman, 1999. Species diversity and invasion resistance in a marine ecosystem. Science 286: 1577-1579.

Suarez, A. V., D. A. Holway, and T. J. Case, 2001. Patterns of spread in biological invasions dominated by long distance jump dispersal: insights from Argentine ants. Proceedings of the National Academy of Sciences 98: 1095-1100.

Vele, A., J. Holusa, and J. Frouz, 2009. Sampling for ants in different-aged spruce forests: a comparison of methods. European Journal of Soil Biology 45: 301-305.

Walters, A. C. and D. A. Mackay, 2005. Importance of large colony size for successful invasion by Argentine ants (Hymenoptera: Formicidae): evidence for biotic resistance by native ants. Austral Ecology 30: 395-406.

Ward, D. F. and M. C. Stanley, 2012. Site occupancy and detection probability of Argentine ant populations. Journal of Applied Entomology [Online Early] Doi: 10.1111/j.14390418.2012.01722.x.

Ward, D. F., C. Green, R. J. Harris, S. Hartley, P. J. Lester, M. C. Stanley, D. M. Sucking, and R. J. Toft, 2010. Twenty years of Argentine ants in New Zealand: past research and future priorities for applied management. New Zealand Entomologist 33: 68-78.

Wilson, J. R. U., E. E. Dormontt, P. J. Prentis, A. J. Lowe, and D. M. Richardson, 2008. Something in the way you move: dispersal pathways affect invasion success. Trends in Ecology and Evolution 24: 136-144.

Wild, A. L., 2004. Taxonomy and distribution of the Argentine ant, Linepithema humile (Hymenoptera: Formicidae). Annals of the Entomological Society of America 97: 1204-1215. 


\section{Chapter 3}

\section{Microhabitat Structure and Ant Species Assemblages}

\subsection{Introduction}

Species richness is affected by many different factors such as latitudinal and altitudinal gradients, size, age and connectivity of habitat, dispersal and migration barriers (Gaston, 2007; Freeman and Bell, 2011; Huston, 1994), disturbances (e.g. Gibb and Hochuli, 2001; Ricketts and Imhoff, 2003), productivity (e.g. Kruess and Tscharntke, 2002) and spatial heterogeneity of habitat (Mitchell et al., 2006; Flick et al., 2012). In the natural environment the main factors shaping species diversity distributions along latitudinal gradients are variability in temperature (Huston, 1994; Sun et al., 2009) and photoperiod (Vinagre et al., 2009) that decreases species diversity with increasing latitude. However, similar environmental gradients can occur across much shorter scales, e.g. differences in microclimate can be induced by a patchy distribution of plants due to radiation differences between plant covered and open areas (Dai, 1996; Martens et al., 2000).

Adverse environments pose stress to organisms that are not adapted to these environments. Insect activity, reproduction and development are affected by temperature and photoperiod (Schiesari et al., 2011; Xue et al., 2002). Low temperature affects the activity of most insects negatively (Dolezal et al., 2007; Abril et al., 2008). On the other hand, high temperature accompanied by dry weather can have a negative impact through its desiccating effect (Worthen and Haney, 1999). Many species require a specific range of environmental conditions for survival and reproduction (Worthen and Haney, 1999). However, different species have different habitat preferences (Malavasi et al., 2007; Marianov et al., 2008). In patchy landscapes, organisms may respond differently to different patch types as different patch types have different microclimates (Heithecker and Halpern, 2006; Martens, 2000). Thus, species assemblages in a system may be a function of microhabitat patterns which induce microclimate differences among patch types. Small bodied animals such as insects easily perceive variations in these microhabitat structures (Ober and Hayes, 2008; Guido and Gianelle, 2001). Ectothermic organisms more considerably perceive and respond to temperature variation than endotherms do (Moreno-Rueda and Pizarro, 2007). As regulation of body temperature of ectotherms depends on environmental temperature their microhabitat preference and movement are controlled by ambient temperature (Dillon et al., 2012). Ant distribution patterns are strongly associated with vegetation structures (Ríos-Casanova et al., 2006) because of low temperature under dense tree covers. 
There are 11 endemic ant species in New Zealand. While seven of these endemic species are widespread, the remaining four are restricted to one island (Don, 2007). In addition to the endemic species, there are 24 exotic, established species, six recently arrived and seven to eight species present that may be unable to establish (Don, 2007). One of the most globally wellknown introduced species; the South American native Argentine ants (Linepithema humile) have invaded a wide range of areas in New Zealand (Don 2007). The first detection of the Argentine ants in New Zealand was in Auckland in 1990 (Green, 1990; Harris, 2002).

\section{Objective}

The aim of this chapter was to study the distribution patterns of Argentine ants and other common ant species across different microhabitat types. I hypothesized that most ants would be more strongly associated with warmer microhabitats (short grass/herbs and concrete). To investigate whether differences in temperature might explain the observed distribution patterns I recorded soil temperatures and calculated the number of generations that Argentine ants could theoretically achieve in different microhabitat types based on a degree-day model of development.

\subsection{Methods}

\section{Bait-sampling}

In order to determine distribution patterns of ant species, I sampled three urban locations (Kelburn (a Wellington suburb), Hastings and Dargaville) and two coastal duneland sites (Baylys Beach and Piha) using plastic tubes baited with non-toxic Xstinguish (Xstinguish ${ }^{\mathrm{TM}}$ Argentine Ant Bait, Bait Technology Ltd., Auckland) and peanut butter in 2009 and 2010. . About 200 baits tubes were laid in each of the urban sites Hastings and Dargaville whereas in Wellington 100 baits were laid each year. At Piha and Baylys Beach, 21 baits were placed in each site each year, sampling habitats parallel to the coast for $1 \mathrm{~km}$, with bait stations every $50 \mathrm{~m}$. Chapter 2 outlines full details of the bait sampling methods. Ant species were identified following Don (2007).

\section{Microhabitat characterisation}

Microhabitats at the point of bait placement in the urban sites were categorized as concrete, bare earth, litter, short grass $(<5 \mathrm{~cm}$ high), long grass $(>5 \mathrm{~cm}$ high) and trees (including woody shrubs). The microhabitats in the duneland sites were recorded in circles of $2 \mathrm{~m}$ radius around each bait station as percentage cover of short herbs $(0-50 \mathrm{~cm})$, tall herbs $(50-100 \mathrm{~cm})$, short trees $(2-5 \mathrm{~m})$ and tall trees (5m and above). I have used the word "herbs" here as there were many plants including a mixture of dicots and monocots. Percent cover of each of the same 
microhabitat types was also recorded in a wider annulus $2 \mathrm{~m}$ to $10 \mathrm{~m}$ away, as larger trees often influenced ground condition.

\section{Soil temperatures}

To evaluate whether the distribution of the Argentine ants was association with temperature or degree-day levels temperature data loggers (UTBI-001TidbiT v2, MicroDAQ) were used to measure soil temperature over the course of one year or more. The data loggers were deployed in the field from January 2009 to May 2010 at Piha (duneland) and from January 2010 to July 2011 in Dargaville (urban). Data loggers were buried $10 \mathrm{~cm}$ below the ground surface. In each study site temperatures under four different microhabitat types were recorded. Microhabitats sampled were about $50 \mathrm{~m}$ or more apart from each other in both study sites. In Dargaville the microhabitats sampled were concrete, short grass, long grass and under tall trees. At Piha, the microhabitats were bare sandy habitat, short herbs, tall herbs and under tall trees. Temperature sampling from bare sand at Piha was taken to evaluate whether the absence of ant species in this habitat was associated with extreme temperatures. Data loggers recorded temperature once every hour a day. At Piha, five data loggers were put in each microhabitat type at different localities. In Dargaville, one data logger was placed in each microhabitat.

\section{Data analysis}

Ant species community ordination: Community composition in relation to microhabitat variables was visualised using RDA (Redundancy Analysis) implemented in the Canoco 453 ordination software (Canoco for Windows 4.53). I preferred RDA over PCA (Principal Components Analysis) as it emphasises the relationship between species and selected environmental factors (direct gradient analysis) while PCA does not show species relationships with environmental factors (Leps and Smilauer, 1999). It is appropriate to use RDA instead of CCA (Canonical Correspondence Analysis) because the species distribution curves were found to be linear when tested using eigenvalues (Leps and Smilauer, 1999). To evaluate whether species' association with any microhabitat type was statistically significant I analyzed the data using a Monte Carlo permutation test (run under the Canoco for Windows 4.53 package). I used frequency of capture of a species (presence/absence data) rather than abundance of each species at baits because a dominant species may reduce the abundance of the other at the bait.

Single species and microhabitats: the ordination RDA analyses described above show ant species projected towards the microhabitat they were typically associated with. However, this analysis does not show precisely how the proportion of each species in each microhabitat type 
varied among sites. Therefore, at the urban sites (where habitat types were classified as discrete categories) I analysed each species separately to show proportion of each species captured in each microhabitat. To test the statistical significance of microhabitat association I employed logistic regression. The dependent variable was the proportion of baits that were occupied by the species in question, and the independent factor was microhabitat (six nominal categories). The microhabitat categories were: bare earth, concrete, litter, short grass (mown, $<5 \mathrm{~cm}$ high), tall grass (un-mown $>5 \mathrm{~cm}$ high), and under and tall trees. The reference category was varied from species to species depending on what microhabitat the species is more positively or negatively associated. I specified the reference factor for the test as the analysis takes one level of a factor and compares the other levels against it. Reference specifications were made based on graph observations. Analyses were performed using the statistical and computing program $\mathrm{R}$ version 2.11.1. In calculating the standard error (SE) of proportions, I employed the formula for a binomial distribution, $\mathrm{SE}=\left(\operatorname{prop}^{*}(1-\mathrm{prop}) / n\right)^{0.5}$, where prop $=$ the proportion of baits within a microhabitat category where a species was present, and $n=$ number of baits placed within that microhabitat category. At the duneland sites (Piha and Baylys Beach) I did not analyse proportion of a single species in each microhabitat. In these sites each microhabitat was estimated as a percent cover per site and there were strong cross-correlations between microhabitat variables. Therefore, I chose to use only the RDA analysis method as this method effectively shows the effect of the microhabitat gradients (see Fig. 3.4 and 3.5).

\section{Argentine ant degree-day development}

Seasonal and annual degree-days experienced in each microhabitat type were calculated to evaluate whether the microhabitat provided a suitable thermal environment for nesting and development of brood according to the degree-day model of development for Argentine ants (Hartley \& Lester, 2003). Degree-days were calculated from the dataloggers as average daily temperature minus the developmental threshold $\left(15.9^{\circ} \mathrm{C}\right)$ (see Hartley and Lester, 2003). Degree-days zero and below were excluded from the data as they don't contribute to the development of the Argentine ants. The optimum reproduction temperature for the ants is $28^{\circ} \mathrm{C}$ (Abril et al., 2008). The average daily temperature in summer was $22-26.5^{\circ} \mathrm{C}$ in concrete and short grass/herbs. Therefore there was no high temperature record that may have limited development as the average daily temperature was below the optimal temperature for reproduction. Although laboratory records show that the Argentine ants die at about $46^{\circ} \mathrm{C}$, they can actively forage in a soil temperature of $70^{\circ} \mathrm{C}$ in the field (Human et al., 1998). Argentine ants require 445 degree-days to complete development from the egg to adult stage (Hartley and Lester, 2003) and this environmental threshold also appears to match their limits at Haleakala 
National Park, Hawaii (Hartley et al. 2010). Based on this I calculated number of generations of Argentine ants that could develop in each microhabitat type annually and seasonally. I was unable to calculate degree-days relevant for the rest of the ant species collected due to lack of information on their developmental threshold.

\subsection{Results}

\section{Spatial patterns of ant community composition}

In 2009 and 2010 I found fourteen ant species across the five sites. In Dargaville eleven ant species were collected and three species were found only in this site. I recorded six species each from Wellington and Baylys Beach. I also recorded seven ant species from each of Hastings and Piha (Table 3.1). Species assemblages differed among sites, as did the associations of ant community composition with microhabitat type. In Kelburn, Wellington, concrete was found to have significantly higher presence of L. humile and M. antarcticum (Monte Carlo permutation, permutations=500, pseudo-F=3.88, $\mathrm{p}<0.05$ (Fig. 3.1). In Hastings, L. humile were again positively associated with concrete microhabitat, while all other species were negatively associated with the concrete microhabitat (Monte Carlo permutation, permutations $=500$, pseudo-F $=15.9, \mathrm{p}<0.01$, Fig. 3.2). In the urban Dargaville site, almost all ants species were negatively associated with the bare earth microhabitat (Monte Carlo permutation, permutations $=500$, pseudo-F=2.42, $\mathrm{p}<0.05$, Fig. 3.3), whereas at Piha, tall trees had a significant negative correlation with ant species richness and abundance (Monte Carlo permutation, permutations $=500$, pseudo-F=6.08, $\mathrm{p}<0.01$, Fig. 3.4). At Baylys Beach, the percent cover of the herbs was consistent at around 30\%. There was no significant correlation between L. humile presence and microhabitat there (Fig. 3.5) which could be due to the lack of variation in vegetation structure. 
Table 3.1. Total ant species collected in the austral summers of 2008/09 and 2009/10. The numbers are occurrences (frequency of capture) of each species in total samples. For abundance of each species refer to appendix.

\begin{tabular}{lccccc}
\hline \multirow{2}{*}{ species } & \multicolumn{5}{c}{ Frequency of capture in } \\
\cline { 2 - 6 } & Wellington & Hastings & Dargaville & Piha & $\begin{array}{c}\text { Baylys } \\
\text { Beach }\end{array}$ \\
\hline Hypoponera eduardi & 0 & 0 & 11 & 0 & 0 \\
Iridomyrmex sp. & 1 & 47 & 5 & 2 & 0 \\
Linepithema humile & 11 & 117 & 38 & 9 & 14 \\
Monomorium antarcticum & 112 & 46 & 6 & 10 & 12 \\
Monomorium antipodium & 3 & 4 & 18 & 0 & 0 \\
Monomorium smithii & 0 & 0 & 0 & 0 & 2 \\
Nylanderia sp. & 0 & 76 & 132 & 8 & 3 \\
Ochetellus glaber & 0 & 34 & 8 & 2 & 0 \\
Pachycondyla sp. & 4 & 0 & 0 & 0 & 0 \\
Pheidole rugosula & 0 & 17 & 8 & 6 & 0 \\
Prolasius advenus & 1 & 0 & 0 & 0 & 1 \\
Technomyrmex jocosus & 0 & 0 & 27 & 0 & 0 \\
Tetramorium bicarinatum & 0 & 0 & 3 & 0 & 0 \\
Tetramorium grassii & 0 & 0 & 40 & 4 & 1 \\
\hline Number of species & 6 & 7 & 11 & 7 & 6 \\
\hline
\end{tabular}




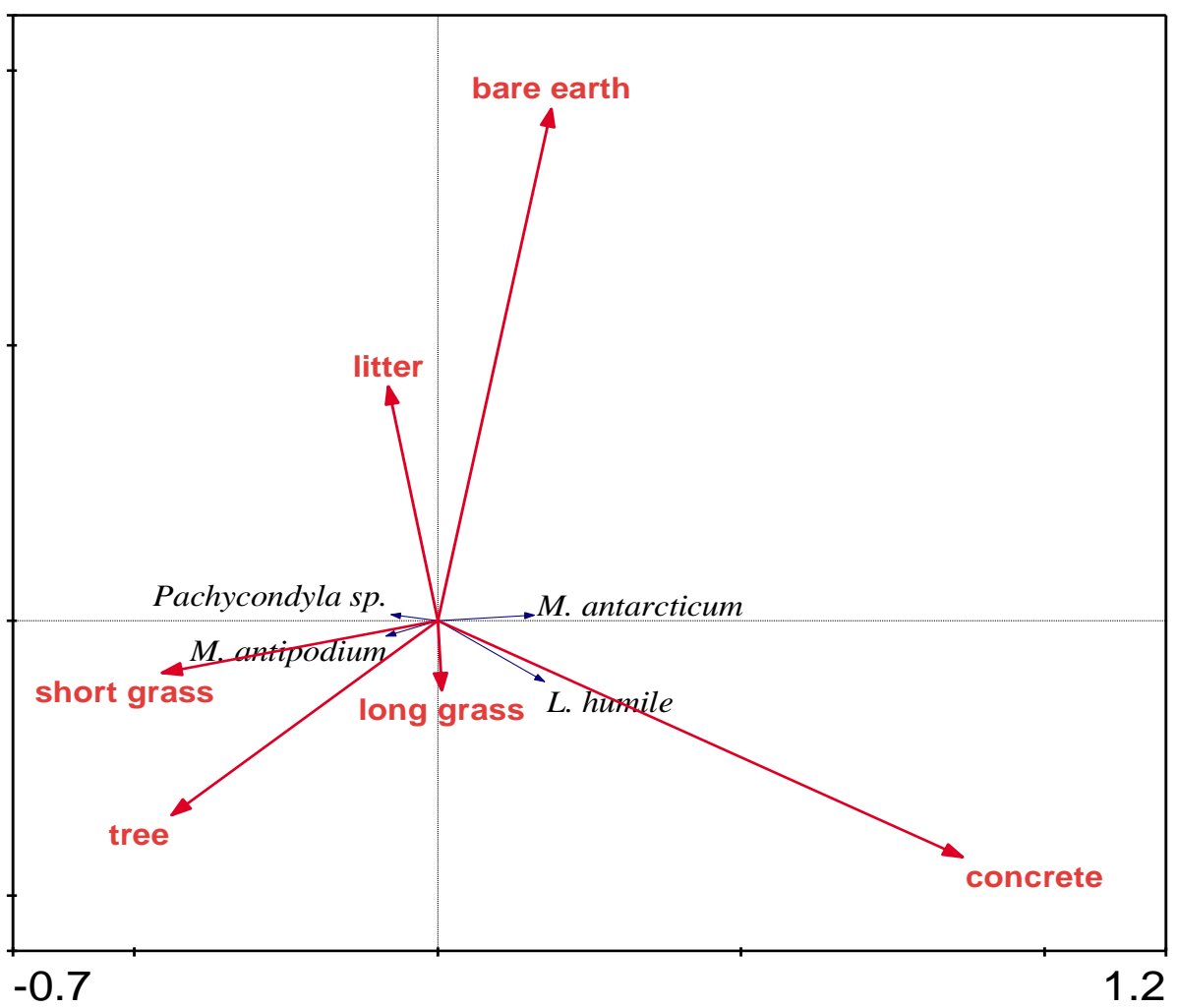

Fig. 3.1. The relationships between microhabitat types and ant species community composition in Kelburn, Wellington urban site, assessed using bait traps $(\mathrm{n} \approx 200$ baits). The RDA plot was derived from presence/absence data. A significant correlation exists when a species arrow head falls within a circle whose diameter is the microhabitat arrow. For example, L. humile and $M$. antarcticum are significantly positively associated with concrete and negatively correlated with shrot grass.

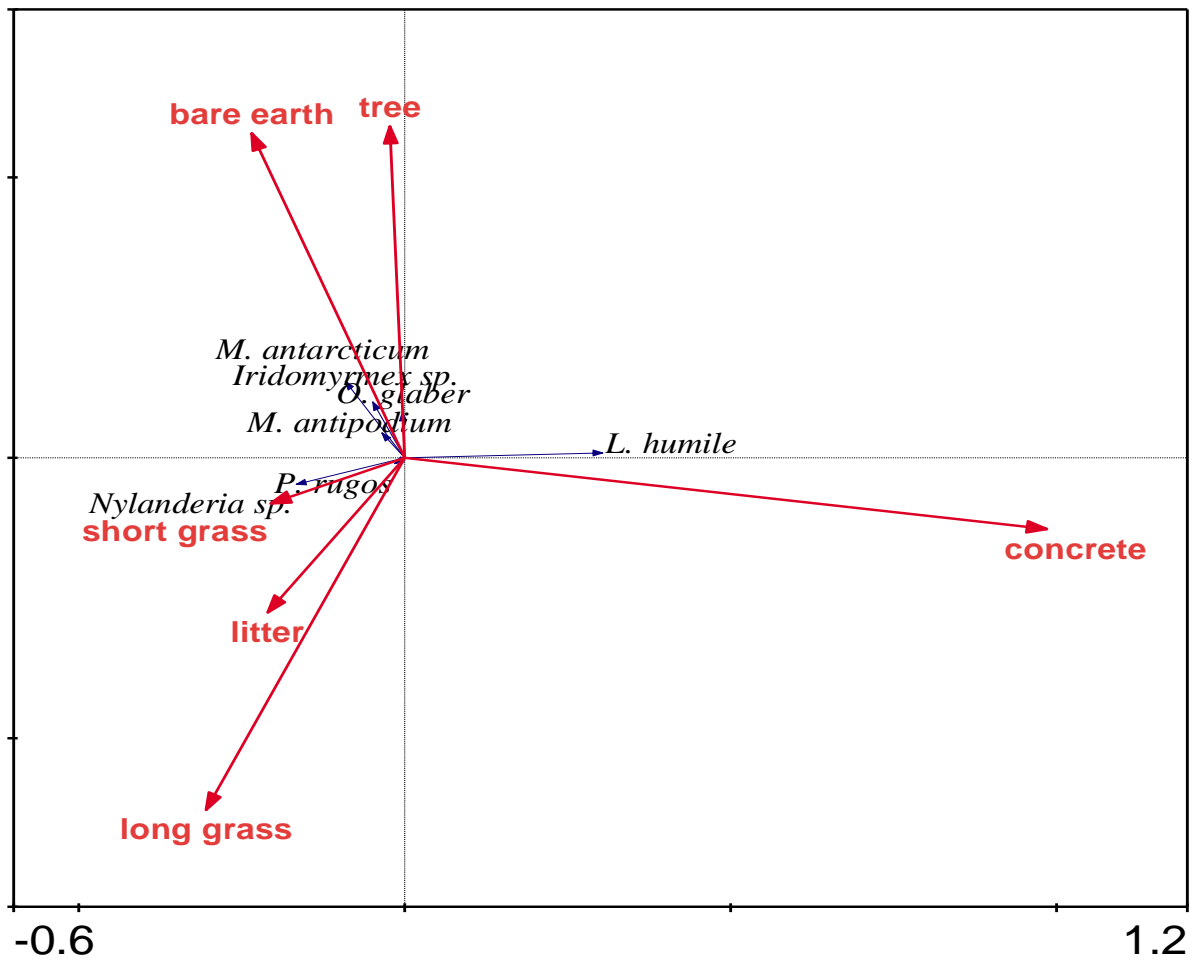

Fig. 3.2. The relationships between microhabitat types and ant species community composition in Hastings urban site assessed using bait traps ( $\mathrm{n} \approx 400$ baits). The RDA plot was derived from presence/absence data. A significant correlation exists when a species arrow head falls within a circle whose diameter is the microhabitat arrow. 


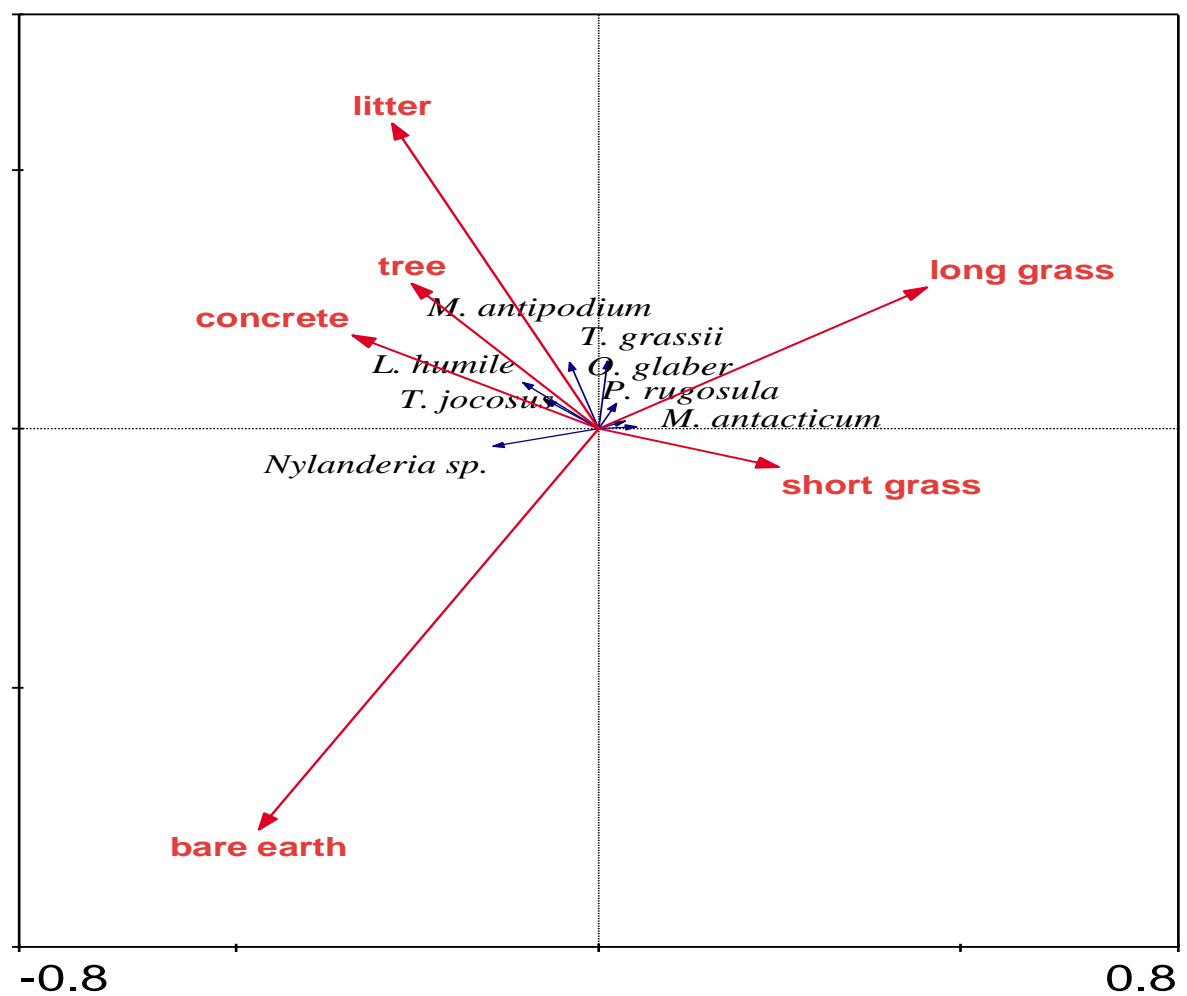

Fig. 3.3. The relationships between microhabitat types and ant species community composition in Dargaville urban site assessed using bait traps $(\mathrm{n} \approx 400$ baits). The RDA plot was derived from presence/absence data. A significant correlation exists when a species arrow head falls within a circle whose diameter is the microhabitat arrow. 


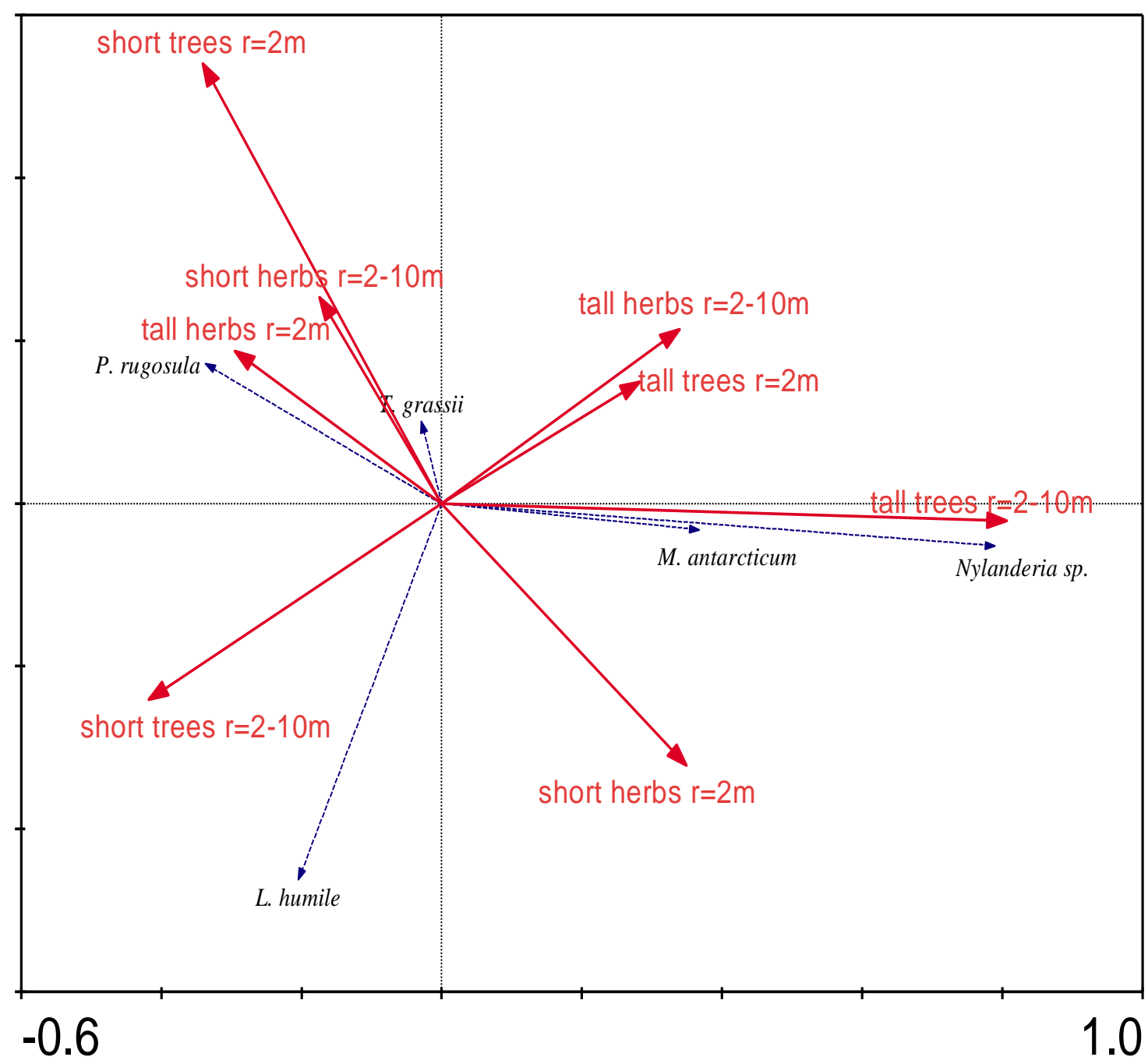

Fig. 3.4. The relationships between microhabitat types and ant species community composition at Piha duneland site assessed using bait traps ( $\mathrm{n}=42$ baits). The RDA plot was derived from presence/absence data. A significant correlation exists when a species arrow head falls within a circle whose diameter is the microhabitat arrow. $\mathrm{r}=2 \mathrm{~m}$ is microhabitat sampled in $2 \mathrm{~m}$ radius around a bait sample, and $\mathrm{r}=2-10 \mathrm{~m}$ is microhabitat sampled $2 \mathrm{~m}$ away but not more than $10 \mathrm{~m}$ from a bait sample. 


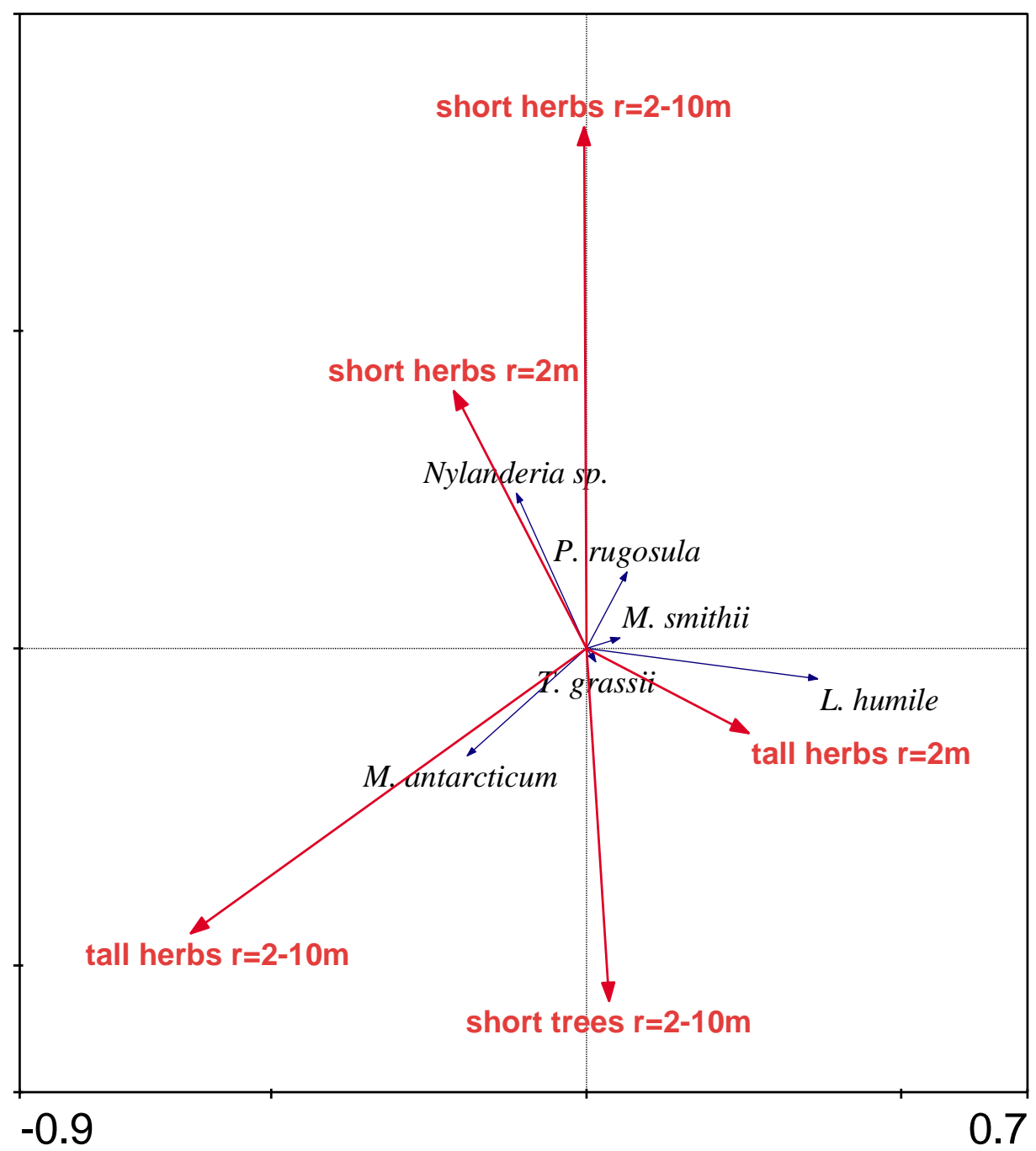

Fig. 3.5. The relationships between microhabitat types and ant species community composition at Baylys Beach duneland site assessed using bait traps $(n=42$ baits). The RDA plot was derived from presence/absence data. A significant correlation exists when a species arrow head falls within a circle whose diameter is the microhabitat arrow. $r=2 \mathrm{~m}$ is microhabitat sampled in $2 \mathrm{~m}$ radius around a bait sample, and $\mathrm{r}=2-10 \mathrm{~m}$ is microhabitat sampled $2 \mathrm{~m}$ away but not more than $10 \mathrm{~m}$ from a bait sample.

\section{Single species and microhabitats}

The proportion of each species in each microhabitat type varied among the urban sites. Number of ants species collected has been described in the above paragraph (see Table 1 and Appendix). In Wellington (Kelburn) I found two numerically dominant species, L. humile and M. antarcticum. The proportion of $L$. humile was higher in concrete habitats relative to trees, though not statistically significant $(\beta=0.82, \mathrm{z}=1.08, \mathrm{P}=0.28$, Fig. 3.6). M. antarcticum were found in significantly higher proportion in litter relative to trees $(\beta=-1.81, \mathrm{z}=-2.92, \mathrm{P}<0.01$, Fig. 3.6). In Hastings compared with the rest of the microhabitats, L. humile were found to be significantly positively associated with concrete (e.g. $\beta=-1.47, z=-4.37 p<0.01$ relative to bare earth, Fig. 3.7). Monomorium antarcticum were found to be in significantly higher 
proportion under tree microhabitats relative to concrete $(\beta=-2.53, z=-3.01, p<0.01$, Fig. 3.7). Nylanderia $s p$. species were significantly lower in concrete than in litter $(\beta=-1.94, \mathrm{z}=-2.94$ $\mathrm{p}<0.01$, Fig. 3.7) while Iridomyrmex sp. were found to be in significantly higher proportion in bare earth microhabitat type than in long grass $(\beta=-1.37, \mathrm{z}=-2.37, \mathrm{p}<0.05$, Fig. 3.7) while $P$. rugosula and $O$. glaber did not show greater occupancy in one microhabitat than the other (Fig. 3.7). In Dargaville, L. humile were found in significantly higher proportions in concrete relative to long grass $(\beta=-1.26, \mathrm{z}=-2.32 \mathrm{p}<0.05$, Fig. 3.8). Momomorium antarcticum were not found in concrete, litter or under trees and the proportion of occupancies in the bare earth, short grass and long grass were low $(<0.05$, Fig. 3.8). Nylanderia sp. were at higher proportions in bare earth than in tall grass $(\beta=-0.64, \mathrm{z}=-1.96 \mathrm{p}<0.05$, Fig. 3.8). Three other species at Dargaville, $P$. rugosula, $O$. glaber and Iridomyrmex sp. did not show any significant difference among microhabitats. Although there were no captures of P. rugosula in bare earth, concrete and litter, they were collected at negligible proportions $(<0.05$, Fig. 3.8) in short grass, long grass and tree habitats.
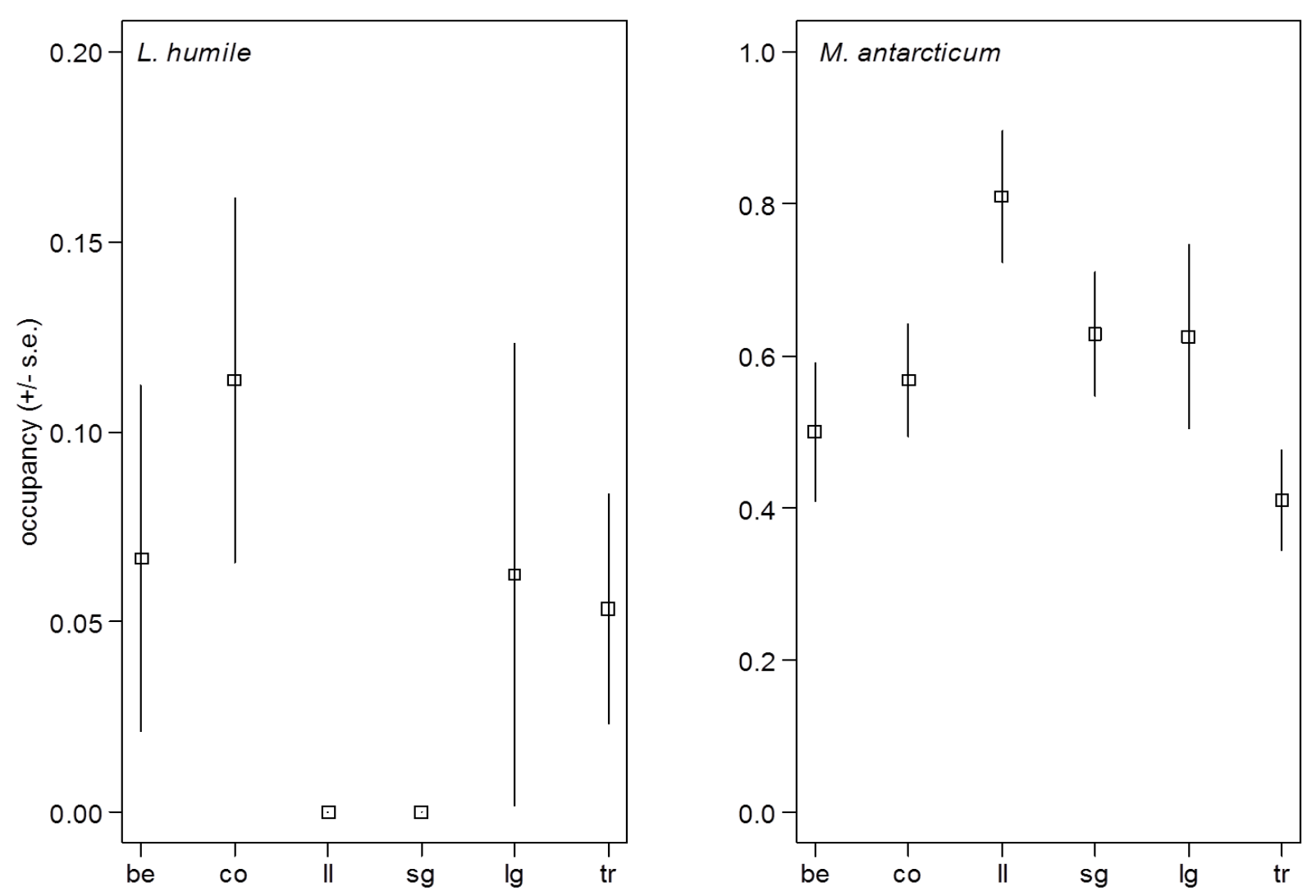

Fig. 3.6. Occupancy of Argentine ants (L. humile) and M. antarcticum across different microhabitat types in Kelburn, Wellington. The plot shows the proportion of baits occupied by each species in each microhabitat $($ mean $\pm S E)$. be=bare earth $(n=30)$, co=concrete $(n=44)$, $1 \mathrm{l}=$ litter $(n=21), \mathrm{sg}=$ short grass $(n=35), \mathrm{lg}=$ long grass $(\mathrm{n}=16)$ and $\mathrm{tr}=\operatorname{tree}(\mathrm{n}=35)$. Proportion $=$ occurrences/n, where occurrence is presences of a species (not number of individuals of the same species) in total samples in each microhabitat. 

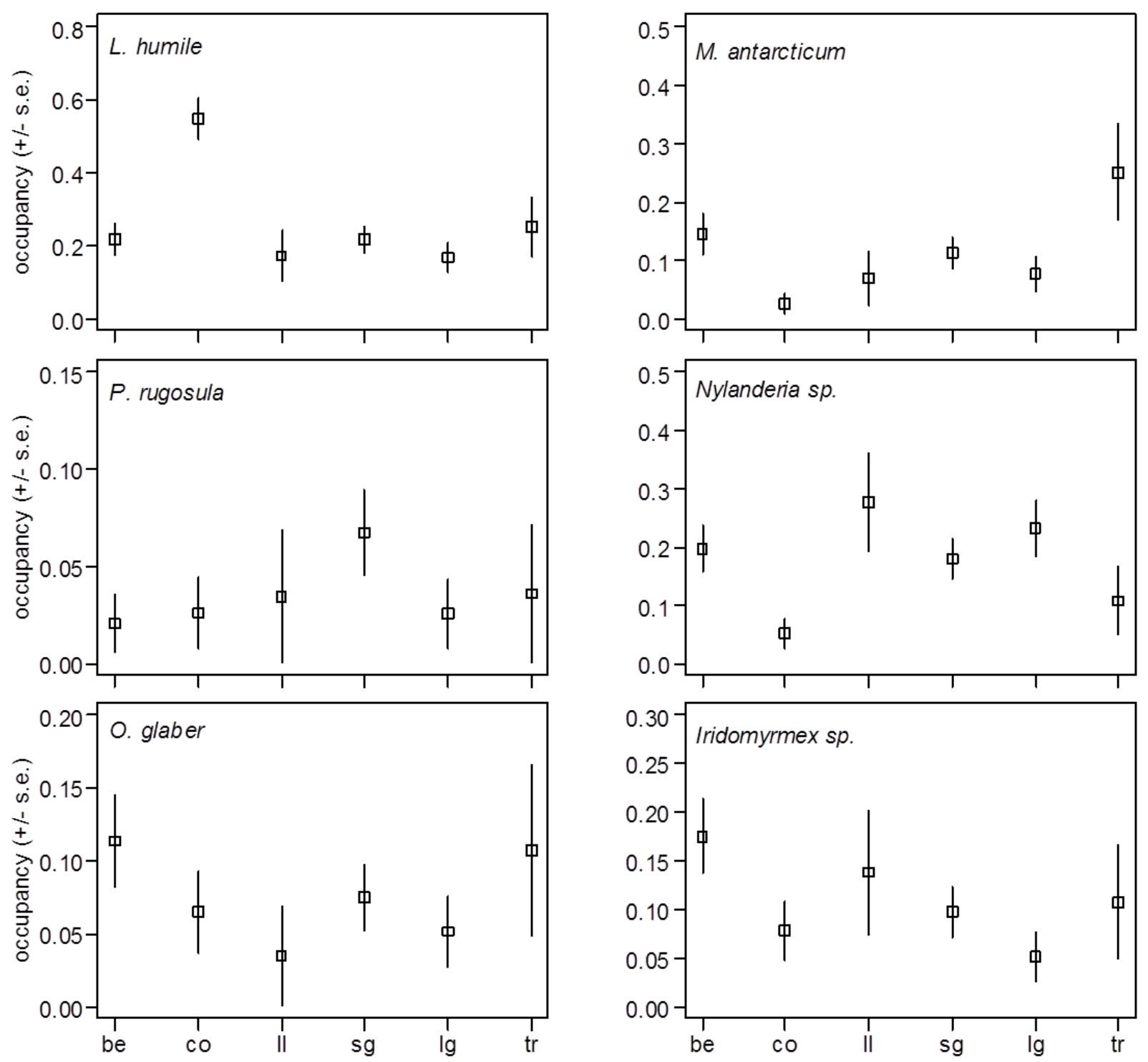

Fig. 3.7. Distribution of each ant species in different microhabitat types in Hastings (mean \pm SE). The plot shows proportion of the frequency of capture of a species in each microhabitat. Proportion $=$ a species occurrences $/ \mathrm{n}$, where occurrence is presences of a species (not number of individuals of the same species) in total samples in each microhabitat be=bare earth $(n=97)$, co=concrete $(n=77), 1 l=l i t t e r(n=29), s g=$ short grass $(n=134), l g=l o n g$ grass $(n=78)$ and tr=tree $(n=28)$. 

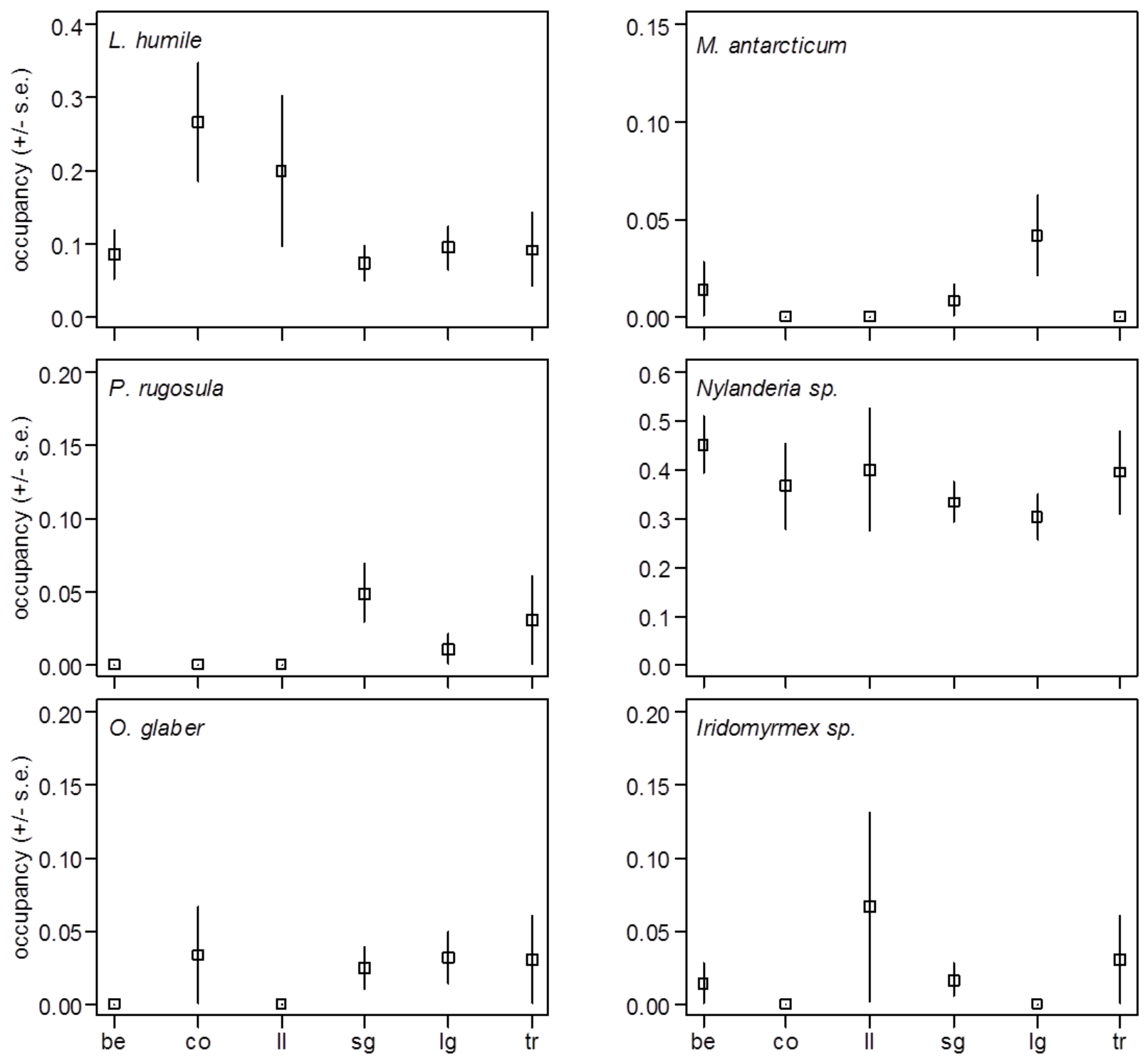

Fig. 3.8. Ant species occupancy of different types of microhabitats in Dargaville (mean $\pm \mathrm{SE}$ ). The plot shows proportion of the frequency of capture of a species in each microhabitat. Proportion $=$ a species occurrences $/ \mathrm{n}$, where occurrence is presences of a species (not number of individuals of the same species) in total samples in each microhabitat. be=bare earth $(n=71)$, co=concrete $(n=30), 1 l=$ litter $(n=15), s g=$ short grass $(n=123), \lg =$ long grass $(n=96)$ and $t r=t r e e$ $(n=27)$.

\section{Argentine ant development}

Soil temperatures, and hence expected developmental rates of Argentine ants were found to be affected by microhabitat type. A degree-day model was used to predict the expected number of generations that could develop per year for nests in different microhabitats. The degree-day predictions varied with microhabitat type and differed in urban and rural sites (Table 3.2). At Piha Argentine ant nests are expected to develop more than three generations within a year in short herbs and in open sandy microhabitats. However, as there were no ants in this open sand area I did not include this microhabitat in the ant distribution patterns. Soil temperatures 
recorded under tall herbs or under tree microhabitats seem insufficient to allow L. humile nests there to raise even a single generation per year (Fig. 3.9). Breaking down the year into seasons, of the degree-day model predicts no development in winter, while the ants are expected to show some potential for development in spring. In summer the ants are expected to develop more than two generations in short herbs and more than one in open sandy microhabitat. In autumn, even though some development could occur, no complete generation is expected in any of the microhabitat types (Fig. 3.10).

In the urban site, Dargaville, Argentine ants are predicted to produce more than three generations if they nest in short grass microhabitats, more than two and half generations in concrete microhabitats and more than one in the tall grass microhabitat type. However, the ants might not complete even one generation under tree microhabitats (Fig. 3.11). When analysed by season, in short grass and concrete, the ants are predicted not to show any development in winter, while in spring they may develop a half generation. In summer, in short grass and in concrete they could develop to more than one and a half generations, while in tall grass they could develop one generation. In autumn, even though some development could occur, no complete generation is expected in any of the microhabitat types (Fig. 3.12).

I had deployed five data loggers in each microhabitat type. However, I was unable to recover them all. For short herbs only one data logger was found, for sand and tall herbs two data loggers each, and for tree microhabitat type all five were recovered. As I used GIS data points for positioning, I had accurate location for recollection, so it appeared that the lost data loggers were removed by other people.

Table 3.2. Seasonal and annual degree-days above $15.9^{\circ} \mathrm{C}$ recorded in different microhabitats at Piha and Dargaville. Values in bold are greater than 445 , the number of degree days required by $L$. humile to complete one generation.

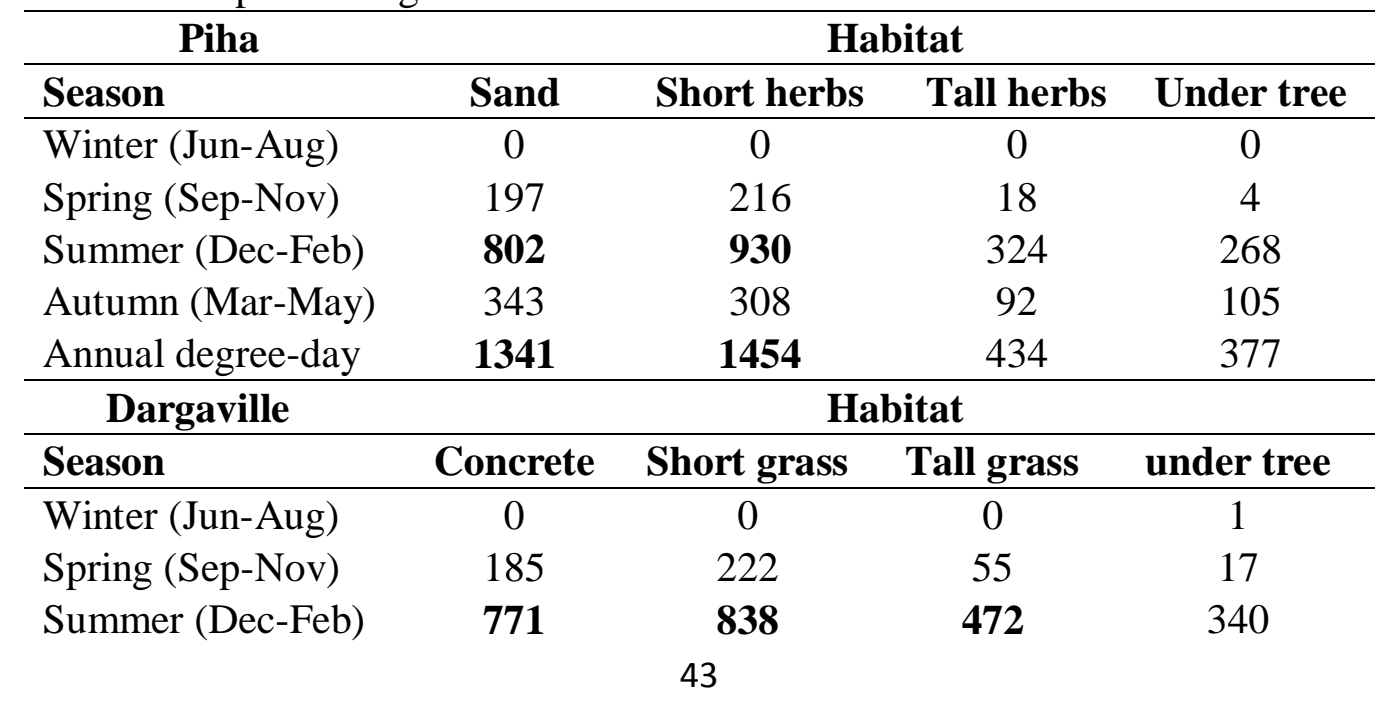




\begin{tabular}{lcccc} 
Autumn (Mar-May) & 247 & 298 & 138 & 127 \\
Annual degree-day & $\mathbf{1 2 0 2}$ & $\mathbf{1 3 5 7}$ & $\mathbf{6 6 5}$ & $\mathbf{4 8 3}$ \\
\hline
\end{tabular}

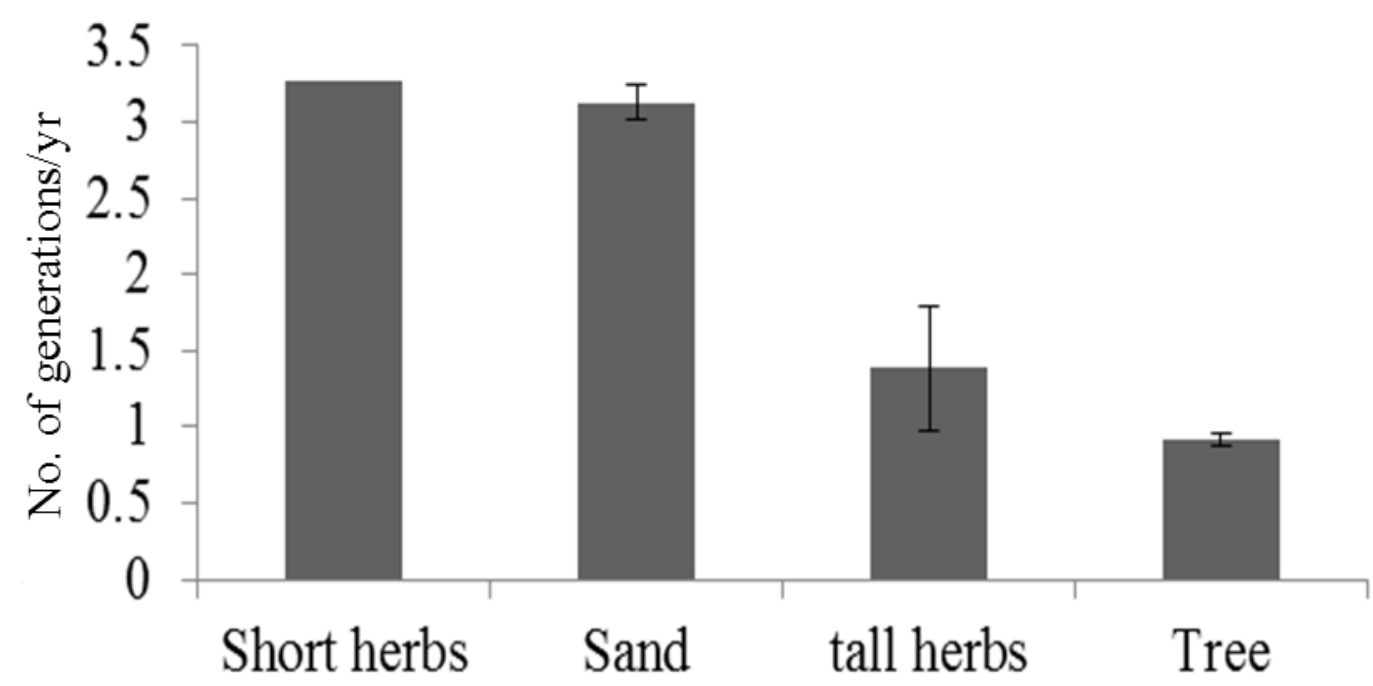

Fig. 3.9. . Expected annual development rate for Argentine ants within each microhabitat type at Piha. One generation is a development from an egg to an adult, and assumed to occur after 445 degree-days above a threshold of $15.9^{\circ} \mathrm{C}$. Each bar graph shows the number of generations developing over a one year period (mean $\pm \mathrm{SE}$ ). As a result of missing data loggers, the bar graph for short grass at Piha does not show SE.

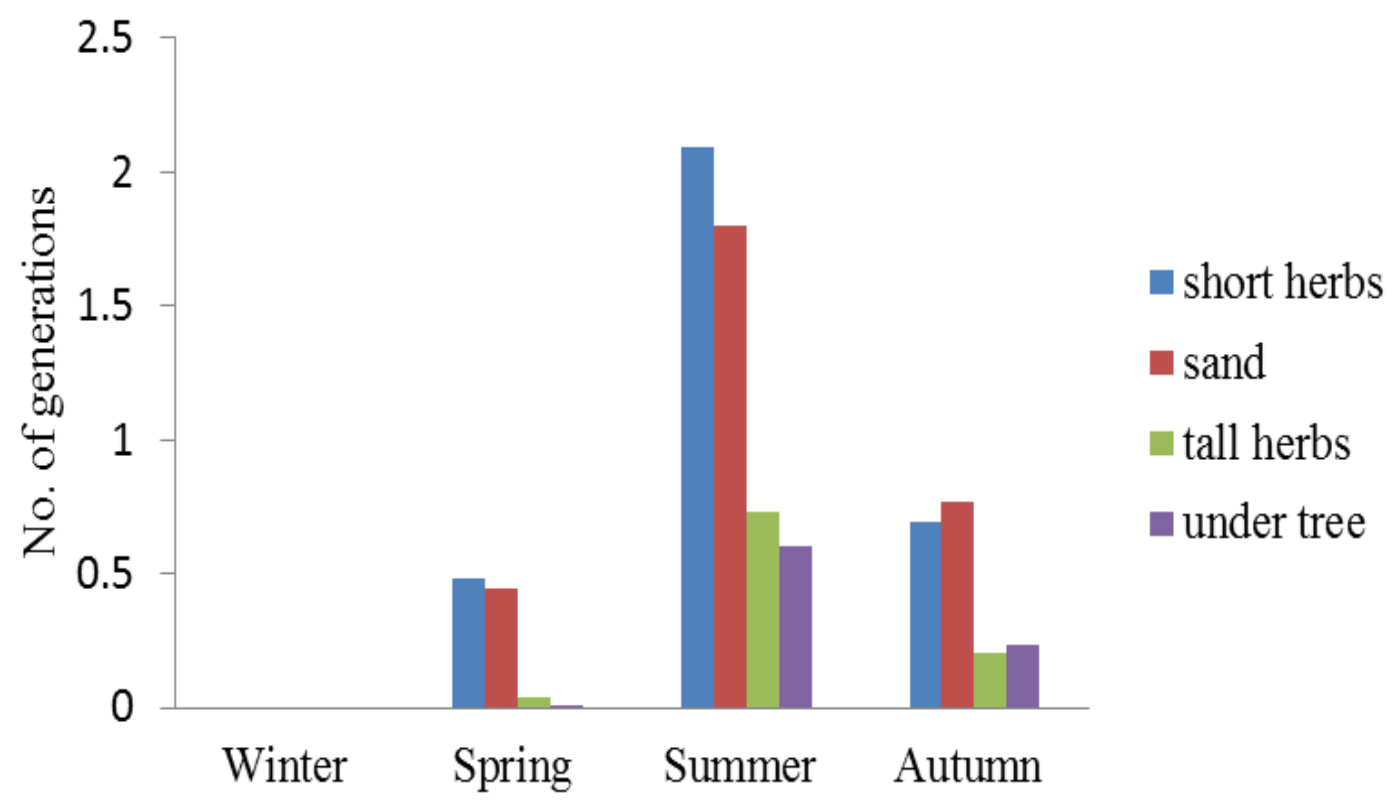

Fig. 3.10. Expected seasonal developmental progress of Argentine ants in each microhabitat type at Piha. One generation is a development from an egg to an adult, and assumed to occur after 445 degree-days above a threshold of $15.9^{\circ} \mathrm{C}(\mathrm{n}=1$ per habitat type). Data loggers recorded temperature in each microhabitat over one year period. Each data logger was deployed for one year and then the data were separated into seasons. 


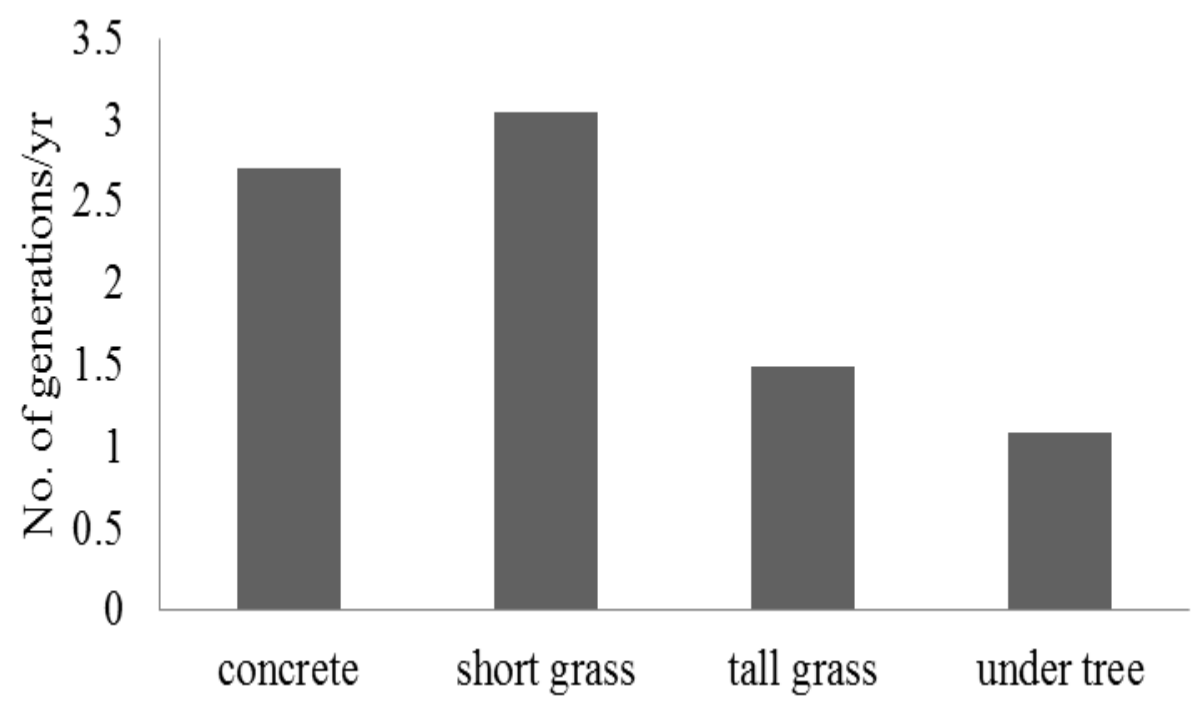

Fig. 3.11. Expected annual development rate for Argentine ants within each microhabitat type in Dargaville. One generation is a development from an egg to an adult, and assumed to occur after 445 degree-days above a threshold of $15.9^{\circ} \mathrm{C}(\mathrm{n}=1)$. Data loggers recorded temperature in each microhabitat over one year period.

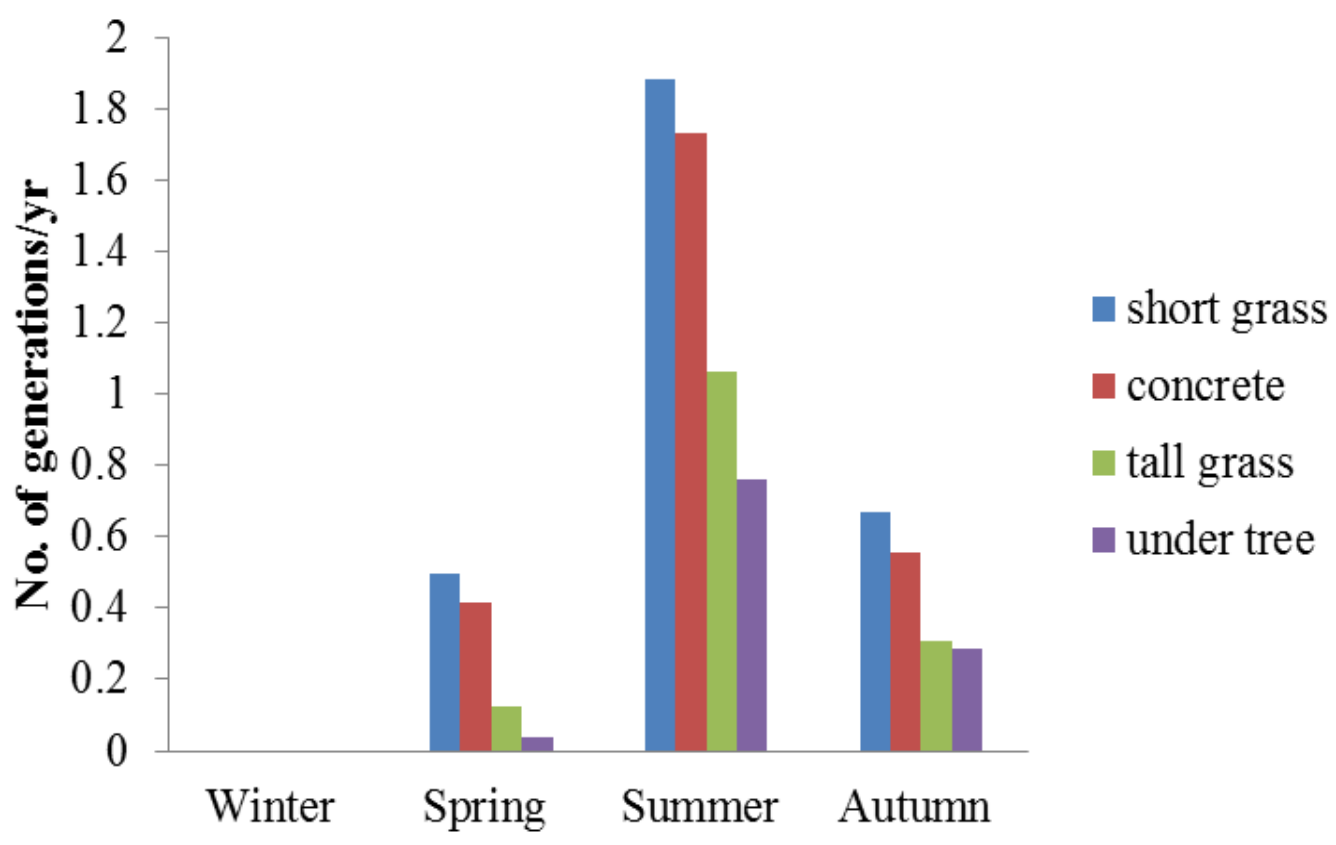

Fig. 3.12. Expected seasonal developmental progress of Argentine ants in each microhabitat type in Dargaville. One generation is a development from an egg to an adult, and assumed to occur after 445 degree-days above a threshold of $15.9^{\circ} \mathrm{C}(\mathrm{n}=1)$. Data loggers recorded temperature in each microhabitat over one year period. Each data logger was deployed for one year and then the data were separated into seasons.

\subsection{Discussion}

In this study I found that differences in microhabitat type were associated with differences in ant species' community composition in urban and rural sites in the North Island of New Zealand. 


\section{Ant association with microhabitat in urban sites}

In the southern part of the North Island, Wellington (Kelburn), the two most abundant ant species (L. humile and $M$. antarcticum) were positively associated with each other in the RDA ordination. This may be due to their need for warmer microhabitat as they were both associated with concrete habitats. In the warmer areas further north, at Hastings and Dargaville, L. humile were also found to be associated with concrete microhabitats. On the other hand, at these sites $M$. antarcticum were found to be less frequent in concrete microhabitats and more often present under trees (Hastings) or in long grass (Dargaville). Field studies conducted near Wellignton have revealed that Argentine ants are little affected by M. antarcticum (Sagata and Lester, 2008). However, in my laboratory experiment (chapter 5), although M. antarcticum showed increased aggression with higher temperatures, $L$. humile were found to be more active at high temperatures (around $20^{\circ} \mathrm{C}$ ) and better able to displace $M$. antarcticum at high temperatures. Typically, Argentine ants aggressively displace all other resident ant species when they invade (Holway and Suarez, 2006). Even so, to displace other ant species Argentine ants heavily depend on their larger colony size (Walters and Mackay, 2005; Sagata and Lester, 2008) which is initially regulated by the mode of dispersal at their early stage of establishment (Wilson et al., 2008).

As $M$. antarcticum are native to New Zealand, I expected them to be less affected by cooler temperatures and thereby to be found in abundance in cooler, shadier habitats in warmer areas such as Hastings. As predicted, M. antarcticum were more frequently found in tall grass and/or under trees in Dargaville and Hastings respectively. At Dargaville M. antarcticum may have been displaced by other species, for example Nylanderia sp. were found at highly frequency of occurrence $(>0.4)$ under trees, and/or the tall grass habitat may have provided optimal temperature conditions. Although competition between native and non-native species may have a negative effect on species diversity (Burns and Lester 2007), it has an important implications for biotic resistance to invasive species. My data show that the invasive species, L. humile are more often associated with concrete and short grass microhabitats (summer daily average temperature $20-26.5^{\circ} \mathrm{C}$ ) in urban areas. This result is consistent with the temperature suitability for the Argentine ants as they are originally endemic to a Mediterranean climate (Wild, 2004; Holway et al., 2002). On the other hand, the New Zealand endemic ant species M. antarcticum seem to have flexible microhabitat associations in different microhabitat types in Wellington. This flexibility may help them overcome or tolerate the effect of invasion by L. humile as they may find a refuge in microhabitats less suitable to L. humile. 
Despite temperature being recognized as one of the most important factors influencing ant species' distribution and establishment (Lester, 2005), resource availability such as food can also strongly regulate population growth (Letcher and Bengtson, 1993) and resource availability may also vary with habitat type. Resource availability is also an important factor in predicting competition outcome (Radford and Ridley, 2008; Rochette et al., 2010; Wang eat al., 2011; Amezaga and Rodriguez, 1998). In resource limited habitats it is difficult to recruit more species without displacing the existing species ( $\mathrm{Li}$ and Smith, 2003). Although there is no report to show effect of predators on ant species in New Zealand, studies show that there are predator species that prey upon ant species in other part of the world (Ito et al., 2009) that could have effect on the abundance of ant species. Distribution of predator species also varies with microhabitat structure (Harvey et al., 2008).

\section{Ant association with microhabitat in rural duneland sites}

As in the urban sites, ant species distribution patterns were found to vary with microhabitat type in the rural areas. In urban areas $L$. humile more frequently occurred in concrete microhabitat. However, in the absence of this microhabitat type L. humile may have alternative habitat. In the rural site of Piha, with sandy soil, L. humile were found in short herbs $(0-50 \mathrm{~cm}$ tall) at high frequency and less often in other microhabitat types, whereas the other ant species, for example $M$. antarcticum, were found across a wide range microhabitat types from short herbs to tall trees. Temperature is considered as an important predictor of the distribution of exotic ants (Lester, 2005) and in the case of L. humile activity, temperature can be a limiting factor (Abril et al, 2008; Hartley and Lester, 2003). Although L. humile are able to invade short herb microhabitat types, their temperature tolerance range may still be limiting as the lower threshold for appreciable development is $15.9^{\circ} \mathrm{C}$ (Hartley and Lester, 2003). Species with wider ranges of temperature tolerance have an advantage in overcoming adverse conditions and contribute to the community structure in a system (Worthen and Haney, 1999). At Daragville it appears that Nylanderia sp. occupy a wide range of habitats at relative high frequency.

Some of the important factors attributed to different responses of organisms to microhabitat variation are radiation (Martens, 2000), temperature and moisture differences (Bennie et al, 2008), differences in resource availability, competitors, predators and prey. Food availability is second only to the effect microclimate (temperature and moisture) on ants' activities such as foraging and fecundity (Heller and Gordon, 2006). Climate has greater impact on species richness of ectotherms than on edontherms (Dillon et al., 2012). Due to this effect the 
developmental process of the Argentine ants is well regulated by temperature that they stop growth at temperature level $15.9{ }^{\circ} \mathrm{C}$ and below (Hartley and Lester, 2003). In warmer areas such as southern California Argentine ants prefer moist rather than relatively dry habitats (Holway, 2005), whereas in relatively cool areas they prefer drier microhabitats (Hartley et al., 2010). Argentine ants are thought to be less affected by food availability as they are capable of shifting diet between carnivory and herbivory according to food availability (Tillberg et al 2007). I did not test whether there was resource variation among patch types that could be a reason behind the different responses of ants to different microhabitats. However, other studies point out that some carnivorous insects prefer open habitat types and herbivorous insects often prefer high plant species richness (Harvey et al., 2008). Herbaceous plant species richness is generally higher in open patches (Perez-Ramos et al, 2008). All these relationships suggest that insect abundance and richness will generally be higher in more open patches. My speculation is that ants will move into habitats with more resources if the temperature is within their tolerance range.

\section{Sampling effects}

Where two or more habitats occur in close spatial proximity to one another there is an increased opportunity for ants to forage flexibly across multiple habitats depending on seasonal fluctuations in resource availability and access to suitable thermal environments (Scharf et al., 2008; O'Neill and Kemp, 1992). It is possible for ants to be captured outside of their primary foraging or nesting microhabitat. A microhabitat where the bait is placed may be within foraging distance of alternative microhabitats. My observations during this study were that foraging trails of $L$. humile extended about $5-7 \mathrm{~m}$ from the nest. There were occasionally longer trails, but with nests along the trails, and as found by Ingram (2002) the Argentine ants occupy multiple nests. Nests can be linked within a trail of $15 \mathrm{~m}$ (Heller and Gordon, 2006). Nevertheless, I believe the occasional long trails are unlikely to affect the overall result. As the baits I used were about $5 \mathrm{~g}$ each, only the dominant ant species may have been captured as a result of competitive exclusion, although the other ant species may be at high abundance at that microhabitat type (Grover et al., 2008; Li and Smith, 2003). To minimize this effect I used absence or presence data in the analysis instead of abundance of each species at baits. Arboreal ants also may not readily be captured using the bait collection method (Schonberg et al., 2004; Gotelli et al., 2011). But this effect can be greatly minimized by visual searches as I did during sample collection (Ward and Stanley, 2012; Sanders and Barton, 2001).

\section{Degree-days}


Measured degree-days corresponded well with the Argentine ants' presence in high incidence in concrete and short herbs/grass microhabitats. My degree-day calculation indicates that Argentine ants have the greatest opportunity to complete rapid development when their nests are located in concrete and in short herbs/grass microhabitat types, while nests located under the shade of trees will rarely allow the completion of a complete life cycle in one year. The calculated high development rate in summer is supported by existing knowledge of the effect of high temperatures on summer insect outbreaks (Berg et al., 2006) and summer outbreaks are also evident in the case of the Argentine ants (Markin, 1970). Wherever the fecundity of Argentine ants is limited by temperature, so too will be their distribution (Hartley et al., 2010; Hartley and Lester, 2003). Most climate envelope models used to predict the potential distribution of invasive species operate with data averaged across relatively coarse scales (e.g. grid cells of $10 \mathrm{~km}$ or greater). Measurements taken here indicate that within a broad area the actual distribution of an invasive insect may be restricted to particular microhabitats, and the identity of these microhabitats may also be predictable based on micro-climatic and ecophysiological considerations (Hartley et al. 2010; Chown et al., 2002).

\section{Conclusion}

Differences in ant community composition were associated with differences in microhabitat. Specifically, Argentine ants, the main focus of this study were strongly positively associated with concrete in urban sites and short herbs at the rural sites. This association is consistent with Argentine ants favouring warmer microsites where they are more likely to be behaviourally dominant and wherein their nests can support multiple generations per year. However, because this study was entirely observational it is not possible to discount other factors such as differences in food availability that can also occur between different microhabitats. Further studies, for example using temperature-controlled lab experiments of interacting ant colonies, are the obvious next step to try and separate the influence of these two contributing factors. At a global level, the importance of such studies is relevant to understanding the interactive effects of climate change, habitat modification and invasive species that so frequently threaten endemic biodiversity. 


\subsection{References}

Abril S., O. Jordi, and G. Crisanto, 2008. Effect of temperature on the oviposition of Argentine ant queens (Linepithema humile Mayr) under monogynous and polygynous experimental conditions. Journal of Insect Physiology 54: 265-272.

Amezaga, I. and M. A. Rodriguez, 1998. Resource partitioning of four sympatric bark beetles depending on swarming dates and tree species. Forest Ecology and Management 109: 127135.

Angel, M. V, K. Blachowiak-Samolyk, I. Drapun, and R. Castillo, 2007. Changes in the composition of planktonic ostracod populations across a range of latitudes in the North-east Atlantic. Progress in Oceanography 73: 60-78.

Bennie, J., B. Huntley, A. Wiltshire, M. O. Hill, and R. Baxter, 2008. Slope, aspect and climate: Spatially explicit and implicit models of topographic microclimate in chalk grassland. Ecological Modelling 216: 47-59.

Berg, E. E., J. D. Henry, C. L. Fastie, A. D. De Volder, and S. M. Matsuoka, 2006. Spruce beetle outbreaks on the Kenai Peninsula, Alaska, and Kluane national park and reserve, Yukon territory: relationship to summer temperatures and regional differences in disturbance regimes. Forest Ecology and Management 227: 219-232.

Burns, K. C. and P. J. Lester, 2007. Competition and coexistence in model populations. In Jørgensen, S. E. and B. D. Fath (Ed.), Population Dynamics: Encyclopedia of Ecology (vol.5, pp.701-707). Elsevier, Oxford.

Chown, S. L., A. Addo-Bediako, and K. J. Gaston, 2002. Physiological variation in insects: large-scale patterns and their implications. Comparative Biochemistry and Physiology Part B 131: 587-602.

Cole, F. R., A. C. Medeiros, L. L. Loope, and W. W. Zuehlke, 1992. Effect of the Argentine ant on arthropod fauna of Hawaiian high-elevation shrubland. Ecology 73: 1313-1322.

Dai X., 1996. Influence of light conditions in canopy gaps on forest regeneration: a new gap light index and its application in a boreal forest in east-central Sweden. Forest Ecology and Management 84: 187-197.

Dillon, M. E., R. Liu, G. Wang, and R. B. Huey, 2012. Disentangling thermal preference and the thermal dependence of movement in ectotherms. Journal of Thermal Biology 37: 631639.

Dolezal, P., O. Habustova, and F. Sehnal, 2007. Effects of photoperiod and temperature on the rate of larval development, food conversion efficiency, and imaginal diapause in Leptinotarsa decemlineata. Journal of Insect Physiology 53P: 849-857.

Don, W., 2007. Ants of New Zealand. University of Otago Press in association with the Otago Museum, Dunedin.

Flick, T., S. Feagan, and L. Fahrig, 2012. Effects of landscape structure on butterfly species richness and abundance in agricultural landscapes in eastern Ontario, Canada. Agriculture, Ecosystems and Environment 156: 123-133. 
Freeman, R. C. and K. P. Bell, 2011. Conservation versus cluster subdivisions and implications for habitat connectivity. Landscape and Urban Planning 101: 30-42.

Gaston, K. J., 2007. Latitudinal gradient in species richness. Current Biology 17: R574.

Gibb, H. and D. F. Hochuli, 2002. Habitat fragmentation in an urban environment: large and small fragments support different arthropod assemblages. Biological Conservation 106: 91100.

Gotelli, N. J., A. M. Ellison, R. R. Dunn, and N. J. Sanders, 2011. Counting ants (Hymenoptera: Formicidae): biodiversity sampling and statistical analysis for myrmecologists. Myrmecological News 15: 13-19.

Green, O. R., 1990. Entomologist sets new record at Mt Smart for Iridomyrmex humilis established in New Zealand. Weta 13:14-16.

Grover, C. D., K. C. Dayton, S. B. Menke, and D. A. Holway, 2008. Effects of aphids on foliar foraging by Argentine ants and the resulting effects on other arthropods. Ecological Entomology 33: 101-106.

Guido, M. and D. Gianelle, 2001. Distribution patterns of four orthoptera species in relation to microhabitat heterogeneity in an ecotonal area. Acta Oecologica 22: 175-185.

Harris, R. J., 2002. Potential impact of the Argentine ant (Linepithema humile) in New Zealand and options for its control. Science for Conservation 196: 1-36.

Harris, R. J. G. and Barker, 2007. Relative risk of invasive ants (Hymenoptera: Fomicidae) establishing in New Zealand. New Zealand Journal of Zoology 34: 161-178.

Hartley, S., P. D. Krushelnycky, and P. J. Lester, 2010. Integrating physiology, population dynamics and climate to make multi-scale predictions for the spread of an invasive insect: the Argentine ant at Haleakala National Park, Hawaii. Ecography 33: 83-94.

Hartley, S. and P. Lester, 2003. Temperature-dependent development of the Argentine ant, Linepithema humile (Mayr) (Hymenoptera: Fomicidae): a degree-day model with implications for range limits in New Zealand. New Zealand Entomologist 26: 91-100.

Harvey, J. A., W. H. van der Putten, H. Turin, R. Wagenaar, and T. M. Bezemer, 2008. Effects of changes in plant species richness and community traits on carabid assemblages and feeding guilds. Agriculture, Ecosystems and Environment 127: 100-106.

Heithecker, T. D. and C. B. Halpern, 2006. Variation in microclimate associated with dispersed-retention harvests in coniferous forests of western Washington. Forest Ecology and Management 226: 60-71.

Heller, N. E. and D. M. Gordon, 2006. Seasonal spatial dynamics and causes of nest movement in colonies of the invasive Argentine ant (Linepithema humile). Ecological Entomology 31: 499-510.

Hölldobler, B. and E. O. Wilson, 1990. The Ants. Harvard University Press, Cambridge. 
Holway, D. A. 2005. Edge effects of an invasive species across a natural ecological boundary. Biological Conservation 121: 561-567.

Holway, D. A. and A. V. Suarez 2006. Homogenization of ant communities in Mediterranean California: the effects of urbanization and invasion. Biological Conservation 127: 319-326.

Holway, D. A., A. V. Suarez, and T. J. Case, 2002. Role of Abiotic Factors in Governing Susceptibility to invasion: a test with argentine ants. Ecology 83: 1610-1619.

Human, K. G, S. Weiss, A. Weiss, B. Sandler, and D. M. Gordon, 1998. The effect of abiotic factors on the local distribution of the invasive Argentine ant (Linepithema humile) and native ant species. Environmental Entomology 27:822-833.

Huston, M. A., 1994. Biological diversity: The coexistence of species on changing landscapes. Cambridge University Press, Cambridge.

Ingram, K. K., 2002. Flexibility in nest density and social structure in invasive populations of the Argentine ant, Linepithema humile. Oecologia 133: 492-500.

Ingram, K. K. and D. M. Gordon, 2003. Genetic analysis of dispersal dynamics in an invading population of Argentine Ants. Ecology 84: 2832-2842.

Ito, F., M. Okaue, and T. Ichikawa, 2009. A note on prey composition of the Japanese treefrog, Hyla japonica, in an area invaded by Argentine ants, Linepithema humile, in Hiroshima Perefecture, western Japan (Hymenoptera: Fromicidae). Myrmecological News 12: 35-39.

Kruess, A. and T. Tscharntke, 2002. Contrasting responses of plant and insect diversity to variation in grazing intensity. Biological Conservation 106: 293-302.

Kolasa, J. and C.D. Rollo, 1991. The Heterogeneity of Heterogeneity. Pages 1-23 in Kolsa, J. and S. T. A. Pickett, editors. A glossary: ecological heterogeneity. Springer-Verlag New York Inc., New York.

Krushelnycky, P. D., L. L. Loope, and S. M. Joe, 2004. Limiting spread of a unicolonial invasive insect and characterization of seasonal patterns of range expansion. Biological Invasions 6: 47-57.

Lepš, J. and P. Šmilauer, 1999. Multivariate analysis of ecological data. Faculty of Biological Sciences, University of South Bohemia. Ceské Budejovice.

Lester, P. J., 2005. Determinants for the successful establishment of exotic ants in New Zealand. Diversity Distributions 11: 279-288.

Letcher, B. H. and D. A. Bengtson, 1993. Effects of food density on growth and on patterns of prey depletion by larval silverside fish, Menidia berrllina (Cope); a laboratory investigation with image analysis. Journal of Experimental Marine Biology and Ecology 167: 197-213.

Li, B. and H. L. Smith, 2003. Periodic coexistence of four species competing for three essential resources. Mathematical Biosciences 184: 115-135. 
Ling-Ling, C. and L. Zhen-Shan, 2008. The effect of habitat destruction on metapopulations with the Allee-like effect: A study case of Yancheng in Jiangsu province, China. Ecological Modelling 213: 356-364.

Lodge, D. M., 1993. Biological invasions: lesson for ecology. Trends in Ecology and Evolution 8: 133-137.

Malavasi, S., A. Franco, F. Riccato, C. Valerio, P. Torricelli, and P. Franzoi, 2007. Habitat selection and spatial segregation in three pipefish species. Estuarine, Coastal and Shelf Science 75: 143-150.

Marianov, V., C. ReVelle, and S. Snyder, 2008. Selecting compact habitat reserves for species with differential habitat size needs. Computers and Operations Research 35: 475-487.

Markin, G. P., 1970. The seasonal life cycle of the Argentine ant, Iridomyrmex humilis (Hymenoptera: Formicidae), in southern California. Annals of the Entomological Society of America 63: 1238-1242.

Martens, S. N., D. D. Breshears, and C. W. Meyer, 2000. Spatial distributions of understorey light along the grassland/forest continuum: effects of cover, height, and spatial pattern of tree canopies. Ecological Modelling 126: 79-93.

Miller, S. L., J. S. Shima, and N. E. Phillips, 2012. Effects of microhabitat availability on estimates of density of a reef fish: implications for assessments of marine protected areas. Hydrobiologia 685: 173-190.

Mitchell, M. S., S. H. Rutzmoser, T. B. Wigley, C. Loehle, J. A. Gerwin, P. D. Keyser, R. A. Lancia, R. W. Perry, C. J. Reynolds, R. E. Thill, R. Weih, D. White, and P. B. Wood, 2006. Relationships between avian richness and landscape structure at multiple scales using multiple landscapes. Forest Ecology and Management 221 155-169.

Moreno-Rueda, G. and M. Pizarro, 2007. The relative influence of climate, environmental heterogeneity, and human population on the distribution of vertebrate species richness in south-eastern Spain. Acta Oecologica 32: 50-58.

Ober, H. K. and J. P. Hayes, 2008. Influence of forest riparian vegetation on abundance and biomass of nocturnal flying insects. Forest Ecology and Management 256: 1124-1132.

O’Neill, K. M. and W. P. Kemp, 1992. Behavioural thermoregulation in two species of robber flies occupying different grassland microhabitats. Journal of Thermal Biology 17: 323-331.

Perez-Ramos, I. M., M. A. Zavala, T. Maranon, M. D. Diaz-Villa, and F. Valladares, 2008. dynamics of understorey herbaceous plant diversity following shrub clearing of cork oak forests: a five-year study. Forest Ecology and Management 255: 3242-3253.

Radford, A. N. and A. R. Ridley, 2008. Close calling regulates spacing between foraging competitors in the group-living pied babbler. Animal Behaviour 75: 519-527.

Ricketts, T. and M. Imhoff, 2003. Biodiversity, urban areas, and agriculture: locating priority ecoregions for conservation. Conservation Ecology 8:1-15. 
Ríos-Casanova, L., A. Valiente-Banuea, and V. Rico-Gray, 2006. Ant diversity and its relationship with vegetation and soil factors in an alluvial fan of the Tehuacán Valley, Mexico. Acta Oecologica 29: 316-323.

Rochette, S., E. Rivot, J. Morin, S. Mackinson, P. Riou, and O. L. Pape, 2010. Effect of nursery habitat degradation on flatfish population: application to Solea solea in the Eastern Channel (Western Europe). Journal of Sea Research 64: 34-44.

Roder, J., C. Bassler, R. Brandl, L. Dvorak, A. Floren, M. M. Gosner, A. Gruppe, A. JarzabekMuller, O. Vojtech, C. Wagner, and J. Muller, 2010. Arthropod species richness in the Norway Spruce (Picea abies (L.) Karst.) canopy along an elevation gradient. Forest Ecology and Management 259: 1513-1521.

Sagata, K. and P. J. Lester, 2008. Behavioural plasticity associated with propagule size, resources, and the invasion success of the Argentine ant Linepithema humile. Journal of Applied Ecology 46: 19-27.

Sanders, N. J. and K. E. Barton, 2001. Long-term dynamics of the distribution of the invasive Argentine ant, Linepithema humile, and native ant taxa in northern California. Oecologia 127: $123-130$.

Scharf, I., A. Subach, and O. Ovadia, 2008. Foraging behaviour and habitat selection in pitbuilding antlion larvae in constant light or dark conditions. Animal Behaviour 76: 20492057.

Schiesari, L., C. P. Kyriacou, and R. Costa, 2011. The hormonal and circadian basis for insect photoperiodic timing. Federation of European Biochemical Societies Letters 585: 14501460 .

Schonberg, L. A., J. T. Longino, N. M. Nadkarni, and S. P. Yanoviak, 2004. Arboreal ant species richness in primary forest, secondary forest, and pasture habitats of a tropical montane landscape. Biotropica 36: 402-409.

Suarez, A. V., D. A. Holway, and T. J. Case, 2001. Patterns of spread in biological invasions dominated by longdistance jump dispersal: insights from Argentine ants. Proceedings of the National Academy of Sciences of the United States of America 98: 1095-1100.

Sun, J., X. Li, X. Wang, J. Lv, Z. Li, and Y. Hu, 2009. Latitudinal changes in species diversity of permafrost wetland plant communities in Great Xing'an Mountain valleys of Northeast China. Acta Ecologica Sinica 29: 272-277.

Tillberg, C. V., D. A. Holway, E. G. LeBrun, and A. V. Suarez, 2007. Trophic ecology of invasive Argentine ants in their native and introduced ranges. Proceedings of the National Academy of Science of the United States of America 104: 20856-20861.

Vinagre, C., T. Ferreira, L. Matos, M. J. Costa, and H. N. Cabral, 2009. Latitudinal gradients in growth and spawning of sea bass, Dicentrarchus labrax, and their relationship with temperature and photoperiod. Estuarine, Coastal and Shelf Science 81: 375-380.

Walters, A. C. and D. A. Mackay, 2005. Importance of large colony size for successful invasion by Argentine ants (Hymenoptera: Formicidae): evidence for biotic resistance by native ants. Austral Ecology 30: 395-406. 
Ward, D. F., J. R. Geggs, M. N. Clout, R. J. Harris, and S. O'Connor, 2006. The diversity and origin of exotic ant arriving in New Zealand via human-mediated dispersal. Diversity and Distributions 12: 601-609.

Wild, A.L., 2004. Taxonomy and distribution of the Argentine ant, Linepithema humile (Hymenoptera: Formicidae). Annals of the Entomological Society of America 97: 1204-1215.

Wilson, J. R .U., E. E. Dormontt, P. J. Prentis, A. J. Lowe, and D. M. Richardson, 2008. Something in the way you move: dispersal pathways affect invasion success. Trends in Ecology and Evolution 24: 136-144.

Worland, M. R. and W. Block, 2003. Desiccation stress at sub-zero temperatures in polar terrestrial arthropods. Journal of Insect Physiology 49: 193-203.

Worthen, W. B. and D. C. Haney, 1999. Temperature tolerance in three mycophagous drosophila species: relationships with community structure. Oikos 86: 113-118.

Xue, F., H. R. Spieth, L. Aiqing, and H. Ai, 2002. The role of photoperiod and temperature in determination of summer and winter diapause in the cabbage beetle, Colaphellus bowringi (Coleoptera: Chrysomelidae). Journal of Insect Physiology 48: 279-286. 


\subsection{Appendix}

3.6.1. Ant species collected by bait trapping in Kelburn, Wellington in 2009 and 2010. Presence $=$ frequency of capture, abundance $=$ total number of individuals. be $=$ bare earth, $\mathrm{co}=$ concrete, $\mathrm{sg}=$ short grass, $\mathrm{lg}=$ tall grass, $\mathrm{ll}=$ litter and $\mathrm{tr}=$ trees.

\begin{tabular}{|c|c|c|c|c|c|c|c|c|c|}
\hline 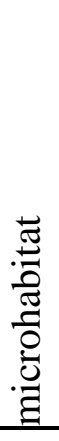 & 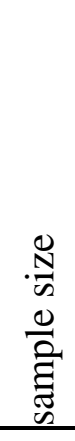 & 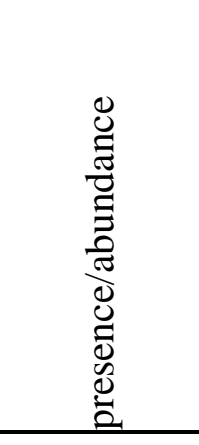 & 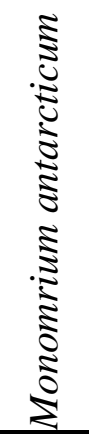 & 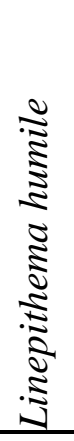 & 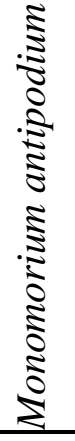 & 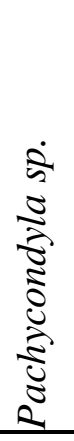 & 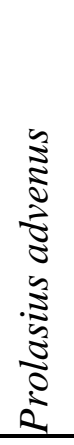 & 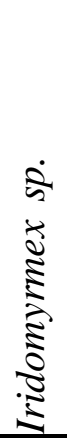 & $\begin{array}{l}\dot{2} \\
\hat{n} \\
\dot{n} \\
\dot{0} \\
\dot{0} \\
\dot{z}\end{array}$ \\
\hline \multirow{2}{*}{ be } & \multirow{2}{*}{30} & presence & 15 & 2 & 0 & 0 & 0 & 0 & 2 \\
\hline & & abundance & 346 & 8 & 0 & 0 & 0 & 0 & 2 \\
\hline \multirow{2}{*}{ co } & \multirow{2}{*}{44} & presence & 25 & 5 & 0 & 0 & 0 & 0 & 2 \\
\hline & & abundance & 341 & 5 & 0 & 0 & 0 & 0 & 2 \\
\hline \multirow{2}{*}{$\lg$} & \multirow{2}{*}{16} & presence & 1 & 1 & 0 & 0 & 0 & 0 & 2 \\
\hline & & abundance & 157 & 26 & 0 & 0 & 0 & 0 & 2 \\
\hline \multirow{2}{*}{ ll } & \multirow{2}{*}{21} & presence & 17 & 0 & 0 & 1 & 0 & 0 & 2 \\
\hline & & abundance & 159 & 0 & 0 & 3 & 0 & 0 & 2 \\
\hline \multirow[b]{2}{*}{ sg } & \multirow{2}{*}{35} & presence & 22 & 0 & 2 & 0 & 0 & 0 & 3 \\
\hline & & abundance & 225 & 0 & 8 & 0 & 0 & 0 & 3 \\
\hline \multirow{2}{*}{$\operatorname{tr}$} & \multirow{2}{*}{35} & presence & 23 & 2 & 1 & 3 & 1 & 0 & 5 \\
\hline & & abundance & 379 & 6 & 19 & 7 & 1 & 0 & 5 \\
\hline
\end{tabular}


3.6.2. Data collected in 2009 and 2010 in Hastings. Presence =frequency of capture, abundance $=$ total number of individuals. $b e=$ bare earth, $c o=$ concrete, $\mathrm{sg}=$ short grass, $\mathrm{lg}=$ tall grass, $11=$ litter and $\operatorname{tr}=$ trees.

\begin{tabular}{|c|c|c|c|c|c|c|c|c|c|c|c|c|c|c|}
\hline 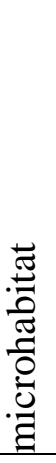 & 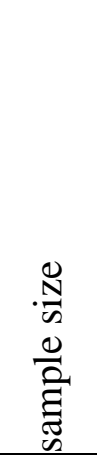 & 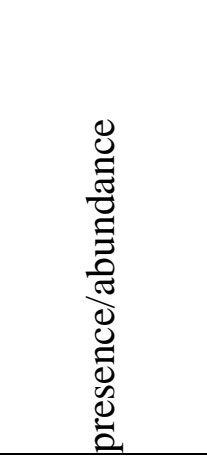 & 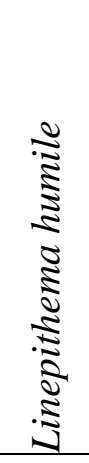 & 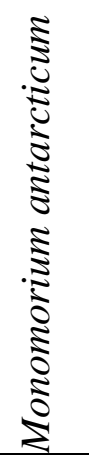 & 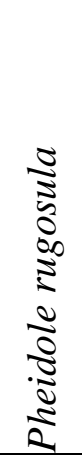 & 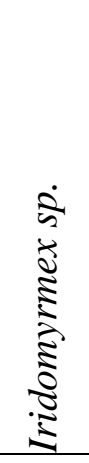 & 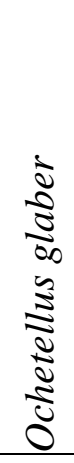 & 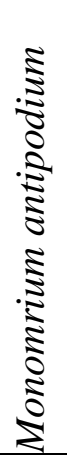 & 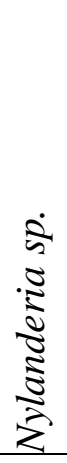 & $\frac{x}{\infty}$ & 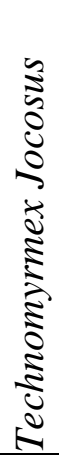 & 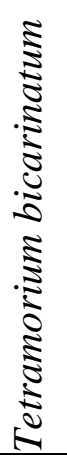 & 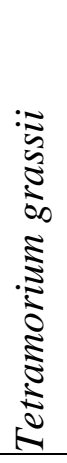 & $\begin{array}{l}\dot{a} \\
\dot{n} \\
\dot{0} \\
\dot{0} \\
\dot{2}\end{array}$ \\
\hline \multirow{2}{*}{ be } & \multirow{2}{*}{97} & presence & 21 & 14 & 2 & 17 & 11 & 1 & 19 & 0 & 0 & 1 & 0 & 8 \\
\hline & & abundance & 196 & 120 & 57 & 148 & 138 & 6 & 64 & 0 & 0 & 2 & 0 & 8 \\
\hline \multirow{2}{*}{ co } & \multirow{2}{*}{77} & presence & 42 & 2 & 2 & 6 & 5 & 0 & 4 & 1 & 0 & 0 & 0 & 7 \\
\hline & & abundance & 384 & 26 & 57 & 18 & 10 & 0 & 5 & 1 & 0 & 0 & 0 & 7 \\
\hline \multirow{2}{*}{$\lg$} & \multirow{2}{*}{78} & presence & 13 & 6 & 2 & 4 & 4 & 1 & 18 & 1 & 0 & 0 & 0 & 8 \\
\hline & & abundance & 192 & 23 & 3 & 26 & 12 & 2 & 52 & 6 & 0 & 0 & 0 & 8 \\
\hline \multirow{2}{*}{11} & \multirow{2}{*}{29} & presence & 5 & 2 & 1 & 4 & 1 & 0 & 8 & 0 & 1 & 0 & 0 & 7 \\
\hline & & abundance & 51 & 59 & 2 & 10 & 2 & 0 & 22 & 0 & 5 & 0 & 0 & 7 \\
\hline \multirow{2}{*}{ sg } & \multirow{2}{*}{134} & presence & 26 & 12 & 6 & 13 & 7 & 1 & 21 & 2 & 0 & 0 & 0 & 8 \\
\hline & & abundance & 261 & 79 & 114 & 34 & 28 & 4 & 43 & 20 & 0 & 0 & 0 & 8 \\
\hline \multirow{2}{*}{$\operatorname{tr}$} & \multirow{2}{*}{28} & presence & 7 & 7 & 1 & 3 & 3 & 1 & 3 & 0 & 0 & 0 & 2 & 8 \\
\hline & & abundance & 26 & 121 & 6 & 16 & 57 & 23 & 3 & 0 & 0 & 0 & 2 & 8 \\
\hline
\end{tabular}

3.6.3. Ant species at Piha collected in 2009 and 2010. Total sample size (n) is 42. Microhabitat structures are presented here as each sample was in close proximity to multiple microhabitats.

\begin{tabular}{|c|c|c|c|c|c|c|c|}
\hline Piha & 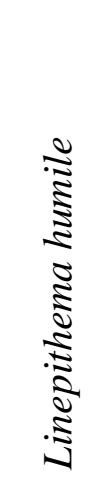 & 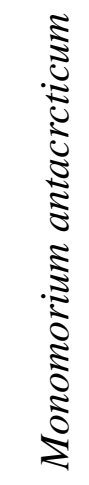 & 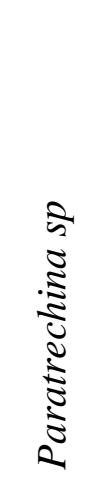 & 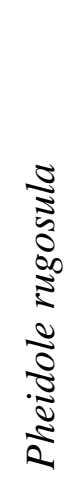 & 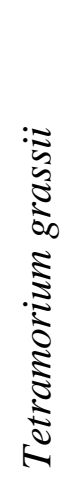 & 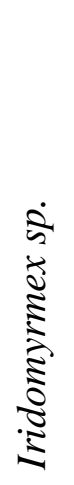 & 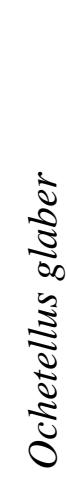 \\
\hline \# presences in 42 baits & 9 & 10 & 8 & 6 & 4 & 2 & 2 \\
\hline \# individuals in 42 baits & 215 & 113 & 144 & 52 & 11 & 4 & 3 \\
\hline
\end{tabular}


3.6.4. Data collected in 2009 and 2010 in Dargaville. Presence =frequency of capture, abundance $=$ total number of individuals. be $=$ bare earth, $c o=$ concrete, $l g=$ tall grass, $11=$ litter, $\mathrm{sg}=$ short grass and $\mathrm{tr}=$ trees.

\begin{tabular}{|c|c|c|c|c|c|c|c|c|c|c|c|c|c|c|}
\hline 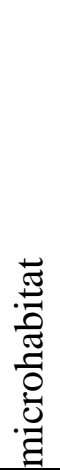 & 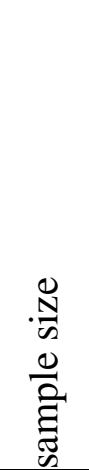 & 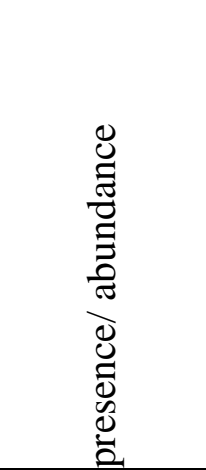 & 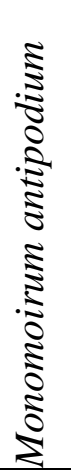 & 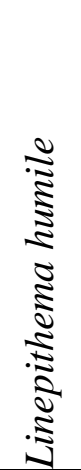 & 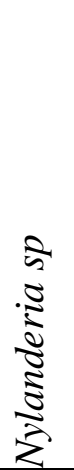 & 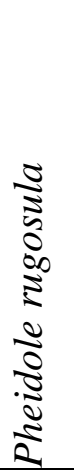 & 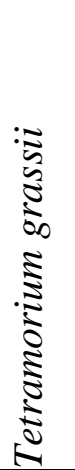 & 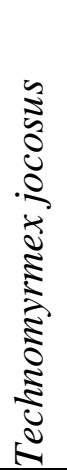 & 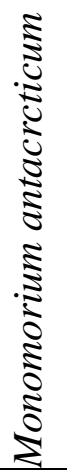 & 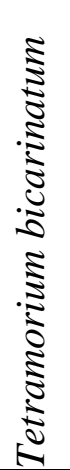 & 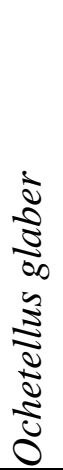 & 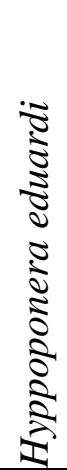 & 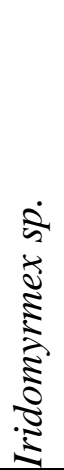 & $\begin{array}{l}\dot{2} \\
\text { के } \\
+0 \\
\dot{0} \\
\dot{0}\end{array}$ \\
\hline \multirow{2}{*}{ be } & \multirow{2}{*}{71} & presence & 2 & 6 & 32 & 0 & 3 & 3 & 1 & 0 & 0 & 1 & 0 & 7 \\
\hline & & abundance & 31 & 22 & 56 & 0 & 8 & 7 & 3 & 0 & 0 & 1 & 0 & 7 \\
\hline \multirow{2}{*}{ co } & \multirow{2}{*}{30} & presence & 0 & 8 & 11 & 0 & 2 & 4 & 0 & 0 & 1 & 1 & 0 & 6 \\
\hline & & abundance & 0 & 111 & 20 & 0 & 14 & 12 & 0 & 0 & 3 & 8 & 0 & 6 \\
\hline \multirow{2}{*}{$\lg$} & \multirow{2}{*}{96} & presence & 5 & 9 & 29 & 1 & 14 & 2 & 4 & 0 & 3 & 1 & 0 & 9 \\
\hline & & abundance & 15 & 89 & 76 & 5 & 62 & 4 & 9 & 0 & 6 & 1 & 0 & 9 \\
\hline \multirow{2}{*}{11} & \multirow{2}{*}{15} & presence & 3 & 3 & 6 & 0 & 3 & 2 & 0 & 0 & 0 & 0 & 1 & 6 \\
\hline & & abundance & 25 & 4 & 14 & 0 & 16 & 3 & 0 & 0 & 0 & 0 & 1 & 6 \\
\hline \multirow{2}{*}{ sg } & \multirow{2}{*}{123} & presence & 5 & 9 & 41 & 6 & 13 & 11 & 1 & 2 & 3 & 1 & 2 & 11 \\
\hline & & abundance & 60 & 105 & 87 & 45 & 38 & 32 & 7 & 2 & 3 & 1 & 7 & 11 \\
\hline \multirow{2}{*}{$\operatorname{tr}$} & \multirow{2}{*}{27} & presence & 3 & 3 & 12 & 1 & 5 & 2 & 0 & 1 & 1 & 0 & 0 & 8 \\
\hline & & abundance & 46 & 15 & 67 & 2 & 35 & 3 & 0 & 17 & 2 & 0 & 0 & 8 \\
\hline
\end{tabular}

3.6.5. Ant species at Baylys Beach sampled in 2009 and 2010. Sample size $(n)=42$. Microhabitat structures are presented here as each sample was in close proximity to multiple microhabitats.

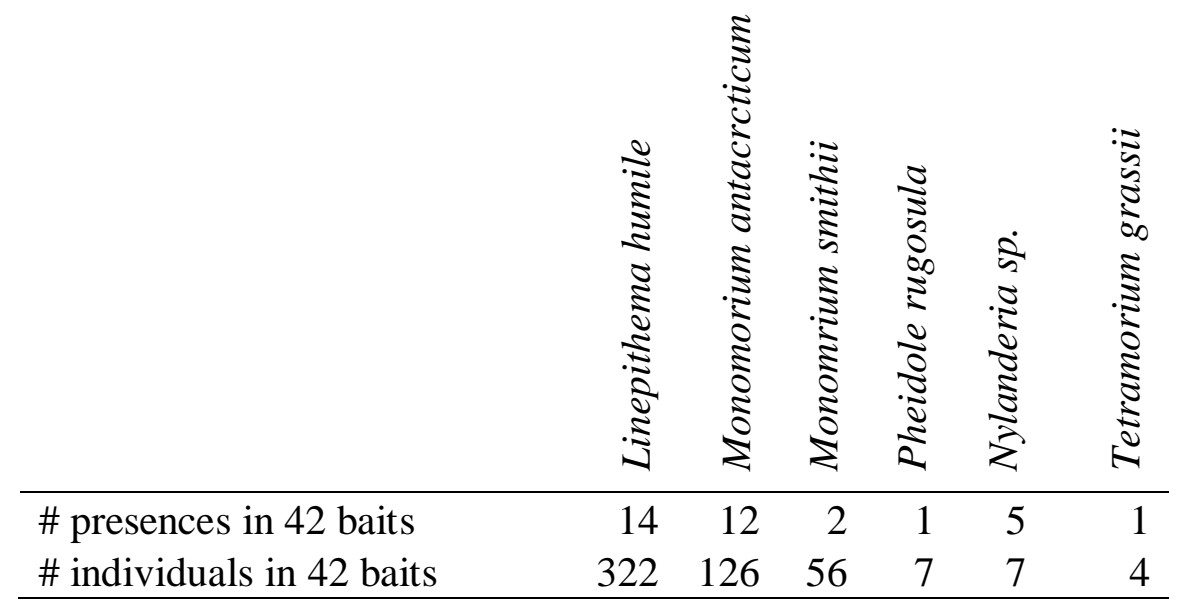




\section{Chapter 4}

Effect of Argentine ant invasion on beetle species richness and community composition in different vegetation types

\subsection{Introduction}

Loss of biodiversity has been recognized as one of the major issues of species conservation and environmental sustainability (Dietz, and Adger, 2003; Vitousek et al., 1997). Among the main factors contributing to loss of biodiversity are habitat destruction (Olff and Ritchie, 2002), anthropogenic disturbance (Biggs et al., 2008), invasive species (Vitousek et al., 1997) and climate change (Brooker et al., 2007). The negative effect of invasive exotic species on the loss of biodiversity is second only to the effect of habitat destruction (Wotton et al., 2004; Wilcove et al., 1998) and invasive species are regarded as one of the leading causes of species extinctions (Wilcove et al., 1998; Pimentel et al., 2006). Invasive species also inflict serious economic damage due to loss of productivity and the cost of control measures (Kaiser and Burnett, 2010; Yemshanov et al., 2011; Cook and Fraser, 2008; Pimentel et al., 2000). The spread of invasive species is facilitated by climate change (Simberloff, 2000) and humanmediated long distance dispersal (Floerl and Coutts, 2009; Carrasco et al., 2010).

Invasive species colonize habitats previously inaccessible and establish their population via various dispersal pathways. Dispersal is a process that contributes to community assembly and the maintenance of local species richness, but not all types of dispersal events are "natural" (Wilson et al., 2008). Human-assisted dispersal can occur accidentally (Lodge, 1993; Cole et $a l ., 1992)$ or by the deliberate introduction of species as part of biological control measures (Jonsen et al., 2007) or cultivation (Pellikka, 2009). Factors such as food availability (Nonacs and Soriano, 1998) and environmental suitability contribute to the success (or failure) of exotic species and their transition to invasive status (Holway, 2005). Exotic species are more likely to establish in a novel area when the founder species has high propagule pressure and high genetic diversity, which may be more likely to occur through human-mediated mass dispersal or multiple introductions (Wilson et al., 2008).

One of the most notoriously invasive species is Linepithema humile (Argentine ants) (Holway et al., 2002). This worldwide invasive ant species (Hartley et al., 2006) is the focus of this study. The presence of these ants in New Zealand was first detected in 1990 in Auckland (Green, 1990). Though thought to be at their earlier stage of expansion, they have been of extreme concern in agriculture and have inflicted economic damage due to the costs of control and loss of productivity in New Zealand (Ward et al., 2010). Argentine ants are highly efficient 
and flexible competitors partly because of their rapid recruitment of workers to food, highly aggressive behaviour toward other ant species, occupation of multiple nests and nest budding ability (Ingram, 2002), redistribution of workers among nests, and relocation of brood (Holway and Case, 2000). They have also a unique ability to maximize food search by forming convoluted trails (Gordon, 1995).

Argentine ants are found to negatively affect plants' reproductive success via at least two mechanisms: they can hinder seed dispersal by other ant species and expose the seeds to seed predators (Carney et al., 2003), and they can deter pollination of flowers by other insects (Lach, 2007). Holway and Suarez (2006) found that Argentine ants displace all native ants in coastal California. Another study by Cole et al. (1992), in Hawaii, also showed a reduction in the number of other arthropods in areas where Argentine ants were present. A contrasting result shows that Argentine ants do not always affect other arthropod species (Holway, 1998). The effects of the Argentine ants may not be the same in different regions or habitat types. Therefore, there is a need for thorough study on the effect of Argentine ants on other arthropod species. The objective of this study was to evaluate the association between Argentine ant invasion on beetle species richness and abundance. A preliminary analysis was also conducted on all captured arthropod species orders to assess a general distribution pattern in response to vegetation structure and Argentine ant invasion.

\subsection{Method}

\subsubsection{Study site and vegetation structure}

Two study sites were selected in the North Island, New Zealand at Piha and Baylys Beach. Previous invertebrate studies conducted at these sites, in December 2002 and January 2004 (Hartley unpub. data) provided important background information on the invasion history and earlier community composition. Both sites are rural, coastal dune and scrub habitats. The relatively open vegetation and northerly location allows soil temperatures to warm-up during summer. Baylys Beach is located about $138 \mathrm{~km}$ north of Auckland and the study site had homogeneously similar habitat type between the invaded and uninvaded areas. These areas (invaded and uninvaded) were mostly dominated by grass (Spinifex sericeus) and the soil type was mostly loose sand. The second study site at Piha is located about $29 \mathrm{~km}$ west of Auckland city. In this study site the habitat invaded by Argentine ants was structurally different from the uninvaded area in terms of vegetation type and cover. The uninvaded area had shrub and tree cover of $45-100 \%$ whereas the invaded area was mostly open with short herbs and about $30 \%$ canopy cover according to visual estimation. To evaluate whether there was any association 
between species and habitat type, I estimated plant height and percent cover in all study areas. This helps to infer whether variation in distribution was due to invasion by the Argentine ants or microhabitat structure.

\subsubsection{Sampling}

Invertebrates: To sample surface-active invertebrates I used standard pitfall trapping methods. Plastic cups with depth of $9 \mathrm{~cm}$ and diameter $7 \mathrm{~cm}$ were buried flush with the soil surface. Each plastic cup was filled with about $50 \mathrm{ml}$ salt solution $(\mathrm{NaCl} 100 \mathrm{~g} / \mathrm{l})$ and a few drops of detergent were added to break the surface tension. At each sampling station three replicate pitfall traps were placed $1 \mathrm{~m}$ apart from each other at each vertex of an equilateral triangle. Twenty-one stations (63 pitfall traps) were established at intervals of $50 \mathrm{~m}$ forming a $1 \mathrm{~km}$ transect running through the dune vegetation parallel to the beach. At the centre of the triangle was placed $5 \mathrm{~g}$ Argentine ant attractant bait, non-toxic Xstinguish (Xstinguish ${ }^{\mathrm{TM}}$ Argentine Ant Bait) and peanut butter in a plastic vial to provide further confirmation of the distribution of Argentine ants. The distribution of Argentine ants in these studies was studied in chapter 2 and provides background for this chapter. Traps were left in the field for 24 hours in January 2009 at Piha and Baylys Beach. Invertebrate sampling was repeated in January 2010 in both sites. After collection, the salt solution was drained and samples were transferred into $70 \%$ ethanol and subsequently identified and separated by taxonomic order. In addition to samples in 2009 and 2010 I also used unpublished data for samples collected in a similar manner from the same area in December 2002 and January 2004 (Hartley unpub. data). As coleopterans were my target response taxon, I identified them to species or genus level using a beetle identification key (Klimaszewski and Watt, 1997) and referring to samples from Te Papa museum (Wellington), Timaru museum as well as material from the 2002-04 survey that had been identified by Dr Stephen Thorpe.

Vegetation: To test whether the arthropod assemblage was associated with habitat structure, I categorized vegetation structure as percent cover in each of four tiers: $0-50 \mathrm{~cm},>50 \mathrm{~cm}-1 \mathrm{~m}$, $>1 \mathrm{~m}-2 \mathrm{~m}$, and $>2 \mathrm{~m}-5 \mathrm{~m}$, for convenience named as "short herbs", "tall herbs", "short trees" and "tall trees" respectively. Percent cover of each plant category was recorded in two concentric rings: the first within two metres around a station and the second from two up to ten metres away from a sample. At Baylys Beach the vegetation was mostly tall and short herbs while at Piha there was high vegetation structure diversity (short herbs, tall herbs, short trees and tall trees). Historically, tree cover (tall and short) at Piha was about $12 \%$ according to early study 
(Hartley unpub. data, 2002). During the years 2009 and 2010 tree cover (tall and short) was about $45-100 \%$ while at Baylys Beach vegetation remained almost unchanged.

\subsubsection{Data Analysis}

Argentine ant distribution: To provide an overview of the distribution of the Argentine ants as well as other ant species at both the study sites, Piha and Baylys Beach in 2002 and 2010, I drew maps for the first and final survey using GPS (Garmin 60) and GIS (ArcGIS version 9.3). Detailed studies of the Argentine ants' spread and association with microhabitat types were conducted in chapters 2 and 3 respectively.

Arthropod community structure: I performed a preliminary analysis at the level of arthropod orders using a constrained ordination, redundancy analysis (RDA) (Leps and Smilauer, 1999). This analysis shows in two-dimensions the variation in arthropod community composition that is most directly associated with the presence-absence of Argentine ants and vegetation structure.

Beetle species: I selected coleoptera to investigate a species-level response to Argentine ants' invasion. Coleoptera were chosen due to their high abundance and diversity of species, representing a wide range of ecological guilds (Chinery, 1986). I used RDA to evaluate the spatial distribution of beetles in response to microhabitat structure and presence of the Argentine ants. I also used an unconstrained ordination method, Principal Components Analysis (PCA) to see whether invaded versus uninvaded areas, with recent versus long-term invasion history, were evident in the major axes of variation in community composition.

To test whether species richness (number of species) showed any statistically significant difference between the invaded and uninvaded areas, and within the same habitat but different years, I analyzed the data using either parametric or nonparametric methods. I checked statistical assumptions for parametric tests, and data that failed to meet these assumptions after either square root or logarithmic transformation were analyzed using nonparametric methods (Wilcoxon rank-sum test). The Bray-Curtis distance measure was used to quantify differences (dissimilarity) in species composition across time and space. Differences in species composition were compared between the invaded and uninvaded habitats and among different years. The Bray-Curtis distance method was preferred as it takes into account not only the presence/absence data but also abundance of each species (Faith et al, 1987). At Piha, as there were two environmental variables, habitat type and invasion status (invaded or uninvaded), I ran either generalized (GLM) assuming Poisson distribution or nonparametric (Wilcoxon rank- 
sum test and Bray-Curtis distance measure) analyses. In the application of ordination methods I employed RDA as it shows the relationship between species and environmental factors (microhabitat and presence/absence for Argentine ant) whereas PCA was used to uncover the maximum variation in species composition regardless of the effect of these two factors (Leps and Smilauer, 1999).

Change in the abundance $(x)$ of each beetle species was calculated as the difference between the total number of individuals in the early surveys $\left(2002+2004=x_{1}\right)$ and subsequent surveys $\left(2009+2010=x_{2}\right)$. The relative changes over time $\left(x_{2}+0.5\right) /\left(x_{1}+0.5\right)$ were then compared between the groups of endemic species and exotic species using the non-parametric Wilcoxon rank sum test. A value of half an individual (0.5) was added to the counts to avoid problems in calculating relative change when zero individuals were recorded in $2002+2004\left(\mathrm{x}_{1}=0\right)$.

Software: R version 2.11.1 was used to run GLM and Wilcoxon rank-sum test. Statistica version 7.1 was used for graph building. The Canoco453 ordination package (Canoco for Windows 4.53) was used to analyze spatial patterns on order as well as species level. ArcGIS version 9.3 was used to depict the change in distribution of the Argentine ants in both the study sites.

\subsection{Results}

Distribution of Argentine ants: The distribution patterns of Argentine ants at Piha and Baylys Beach have been outlined fully in chapter 2 . Here I give a brief background together with other ant species' distribution. At Baylys Beach the distribution patterns of Argentine ants did not change with time. I found that the distributions recorded in 2002 to be similar to that of 2010 (Fig. 4.1). The distributions in January 2004 and 2009 were also similar (see chapter 2). Historically, they had a wide distribution at Piha in 2002. However, in 2010, the ants were found to be localized into a habitat type of short herbs which is in the north part of Piha (Fig. 4.2). 

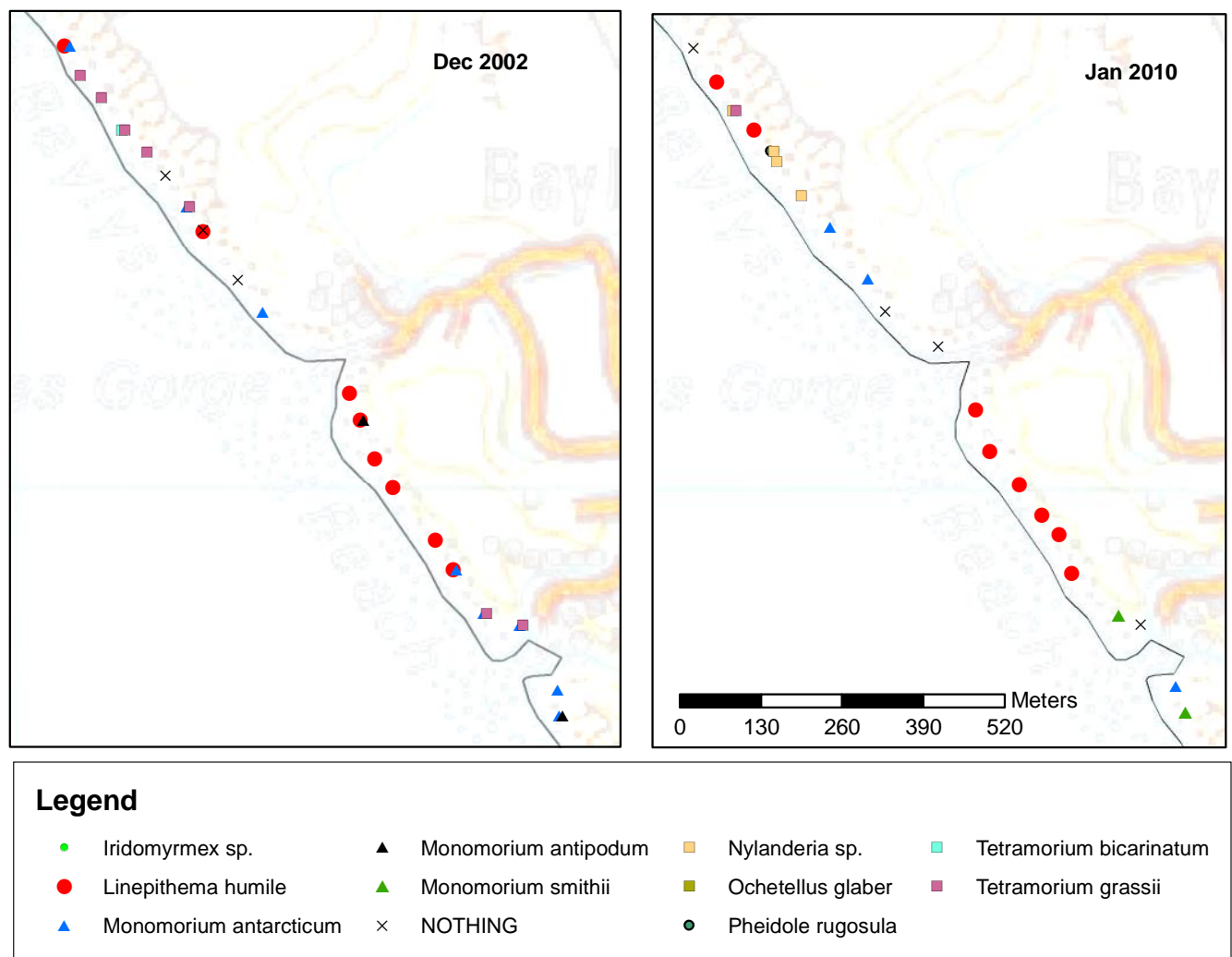

Fig. 4.1. Change in the distribution of Argentine ants (L. humile) and other ant species between 2002 and 2010 at Baylys Beach $(n=21$ in each year (bait samples)). One baited tube sample was taken at each point in each year and included multiple species of ants (i.e., there was no repeat sampling each year).
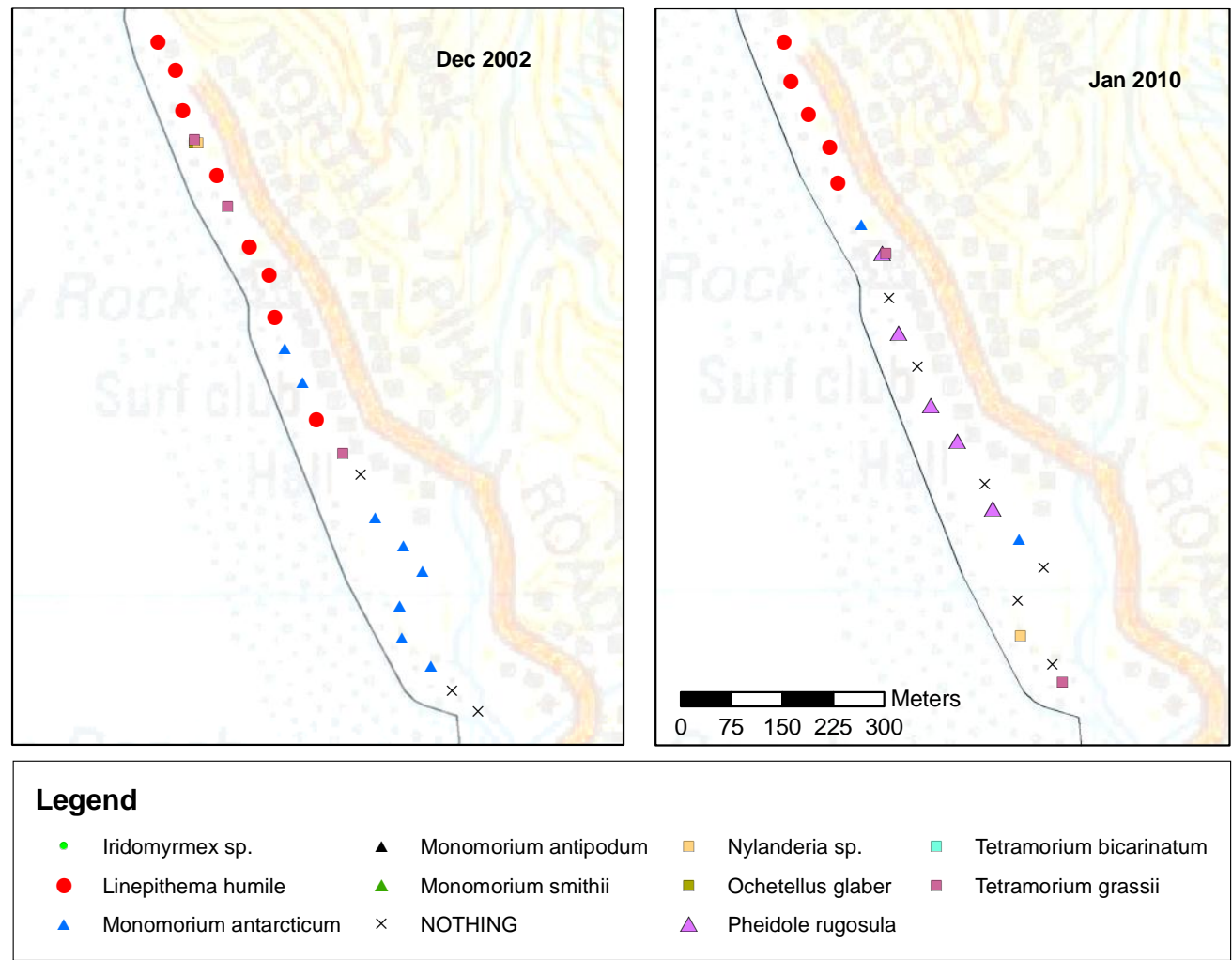

Fig. 4.2. . Change in the distribution of Argentine ants (L. humile) and other ant species between 2002 and 2010 at Piha ( $\mathrm{n}=21$ in each year (bait samples)). One baited tube sample was taken at each point in each year and included multiple species of ants (i.e., there was no repeated sampling each year). 


\section{Arthropod community structure}

According to RDA analysis for Piha, six arthropod orders (lepidoptera, hymenoptera, orthoptera, homoptera, isopoda and coleoptera) were found in high abundance in areas where the Argentine ants were present (Fig. 4.3). These arthropods were found to be associated with short herb habitat in the immediate vicinity of the traps (within $2 \mathrm{~m}$ ) and tall herbs in the general area (within $10 \mathrm{~m}$ ). Argentine ants were also found in these habitat types. At Piha three taxonomic groups, isopoda, araneae and opiliones were unaffected i.e. they were found evenly in all habitat types and areas where the Argentine ants were present and absent. The other four orders (amphipoda, diptera, sarcoptiformes and hemiptera) were associated with areas uninvaded by the Argentine ants (Fig. 4.3).

At the other study site, Baylys Beach, there was not much variation in microhabitat structure. Most of the area was characterised by tall herbs, mostly Spinifex. Four taxonomic groups tended to be more abundant in areas of sparse vegetation (regardless of vegetation height). These were L. humile, amphipods, isopods and homopterans (Fig. 4.4).

\section{Beetle species richness}

At Piha the total number of beetle species found in 2002, 2004, 2009 and 2010 was 36. The numbers of species collected in 2002 and 2004 were 12 and 17 respectively. Species collected in 2009 and 2010 were 17 and 11 respectively (appendix 4.6.2). At the level of species in 2009/10, the RDA analysis showed higher abundances of 17 beetle species in the Argentine ant invaded habitat, while only six species were found in high abundance in the uninvaded area (Fig. 4.5). Eleven species were found only in the invaded habitat, and five species were only found in the uninvaded area, while seven species were found in both invaded and uninvaded areas (see appendix. 4.6.1, Fig. 4.7). Species richness was significantly higher in the invaded area compared to the uninvaded area in 2009/10 (GLM: $\mathrm{z}=-2.94, \mathrm{df}=19, \mathrm{p}<0.01$; Fig. 4.9A). The uninvaded area had a lower species richness than the invaded area in 2002, although the difference was not statistically significant (GLM: $\mathrm{z}=-0.64$, $\mathrm{df}=19, \mathrm{p}=0.52$; Fig. 4.9A). Species richness decreased between 2002/2004 and 2009/2010 (GLM: $z=-2.63, d f=81, p<0.01$; Fig. 4.10A). Based on the history of invasion, the change in species richness between earlier years $(2002+2004)$ and recent years $(2009+2010)$ was significant $(G L M: z=-2.8, d f=19, p<0.05$; Fig. 4.8). Exotic species increased in abundance between 2002/2004 and 2009/2010 significantly more than endemic species (Wilcoxon rank-sum test: $W=8, n=28,4, p<0.01$, Fig. 4.11A).

At Baylys Beach 44 species were recorded in the years 2002, 2004, 2009 and 2010. In 2002 there were 17 species, and in 2004 there were 32 species. I collected 11 species in 2009 and 
nine species in 2010 (appendix 4.6.3). In contrast to Piha, the RDA analysis of combined data from 2009 and 2010 found nine species of beetles were more abundant in the uninvaded area and five other species were more abundant in the invaded habitat (Fig. 4.6). This difference was also reflected in higher species richness in uninvaded areas, although not significant in 2010 (GLM: $\mathrm{z}=0.89, \mathrm{df}=19, \mathrm{p}=0.37$; Fig. 4.9B). Nevertheless, in 2002, there was a significantly higher species richness of beetles in the invaded area (GLM: $z=-2.27, \mathrm{df}=19$, p<0.05; Fig. 4.9B). Similarly, differences in species richness among the years 2002, 2004 and 2010 which showed a significant decrease towards the recent years (GLM: $\mathrm{z}=-4.76, \mathrm{df}=82$, $\mathrm{p}<0.001$, Fig. 4.10B). Although not significant, there was change in the relative abundance of exotic and endemic species ( $\mathrm{W}=135, \mathrm{n}=35,11, \mathrm{p}=0.054$; Fig. 4.11B).

At both study sites, Piha and Baylys Beach, exotic beetles, Anthicus kreusleri were more abundant in the uninvaded areas while other exotic beetles, Diomus notescens were found only in the invaded areas (see Appendix 4.6.1). Two endemic species (Phycosecis limbata and Sapintus aucklandensis) appear to have disappeared from the Piha site while another species (Zeadolopus sp.) may be on the verge of extirpation (Appendix 4.6.4). 


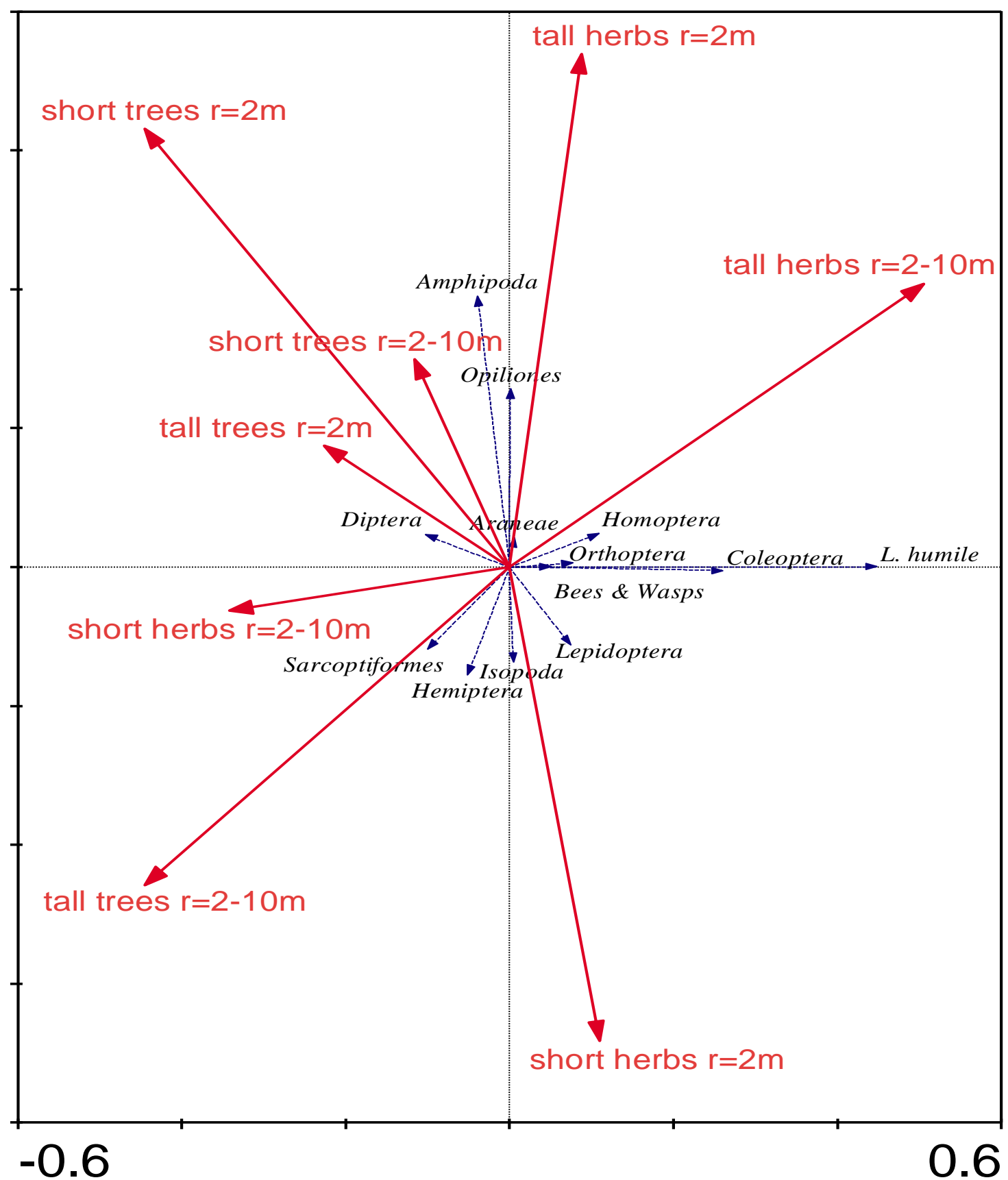

Fig. 4.3. Distribution patterns of arthropod orders according to variation in vegetation structure and Argentine ant (L. humile) invasion at Piha analysed using RDA ( $\mathrm{n}=126$ pitfall traps). $\mathrm{r}=2 \mathrm{~m}$ is the microhabitat type within $2 \mathrm{~m}$ around a sample and $\mathrm{r}=2-10 \mathrm{~m}$ is the microhabitat $2 \mathrm{~m}$ away but not more than $10 \mathrm{~m}$ from a sample. 


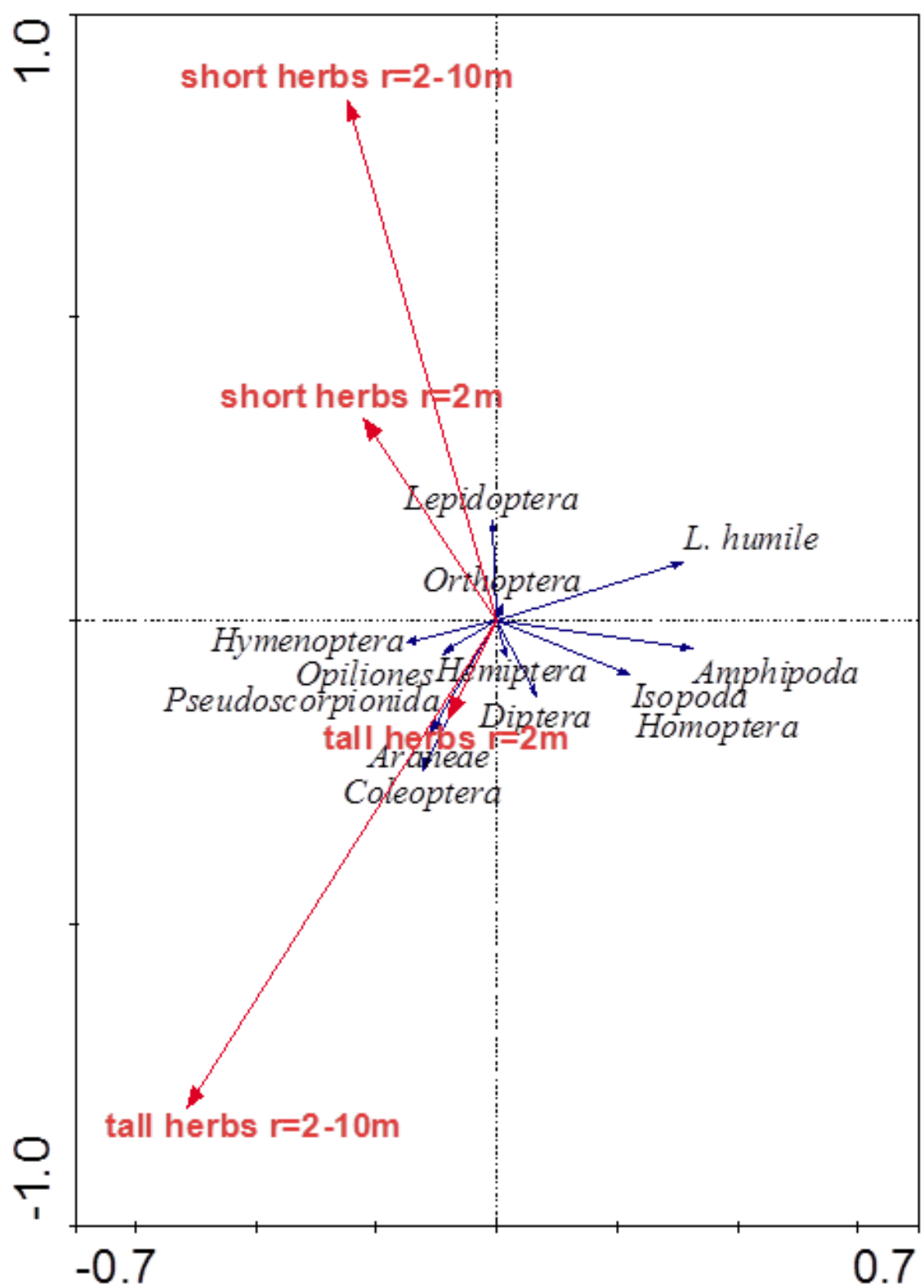

Fig. 4.4. Distribution patterns of arthropod orders according to variation in vegetation structure and Argentine ant (L. humile) invasion at Baylys Beach analysed using RDA ( $\mathrm{n}=126$ pitfall traps). $\quad \mathrm{r}=2 \mathrm{~m}$ is the microhabitat type within $2 \mathrm{~m}$ around a sample and $\mathrm{r}=2-10 \mathrm{~m}$ is the microhabitat $2 \mathrm{~m}$ away but not more than $10 \mathrm{~m}$ from a sample 


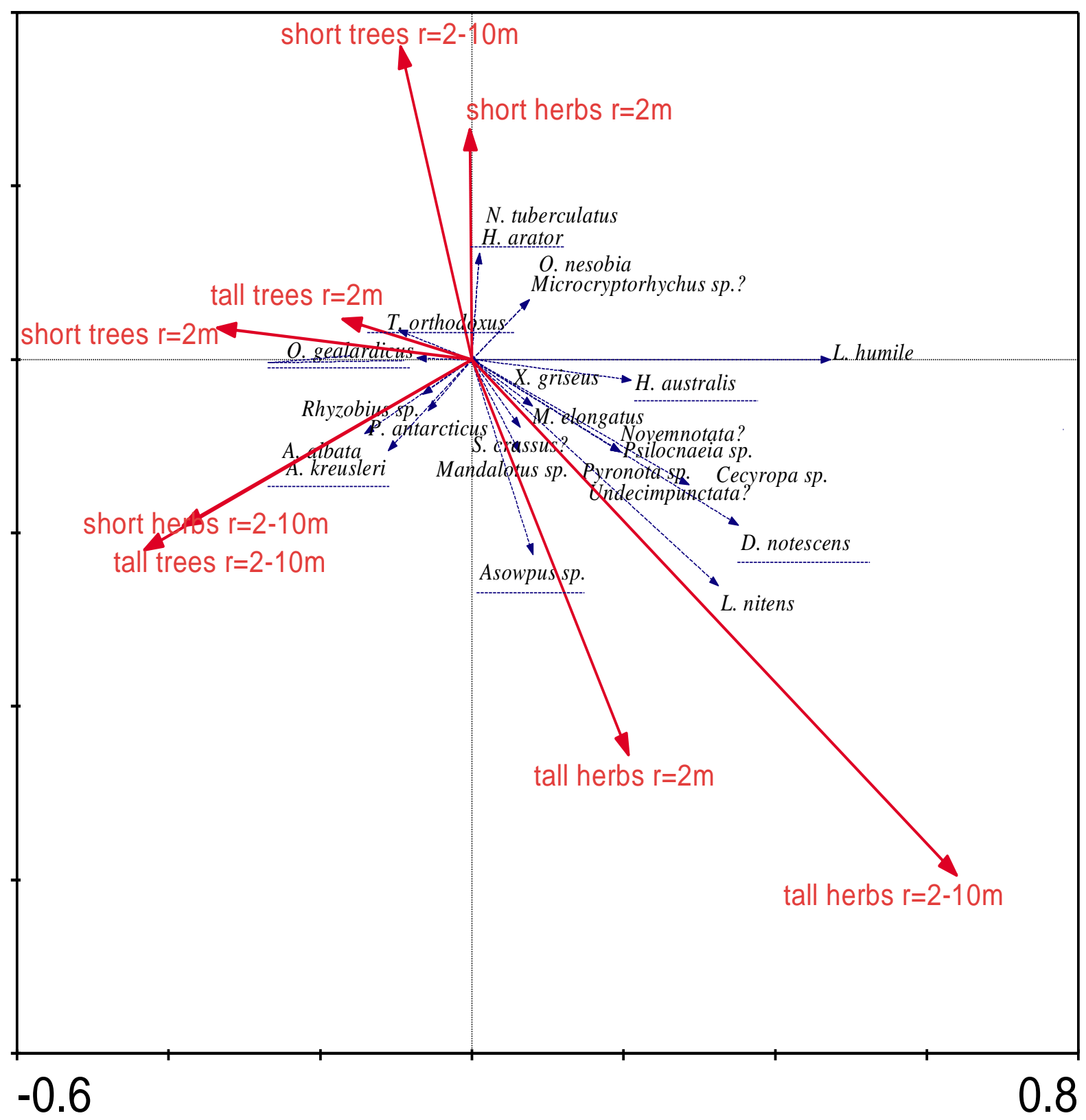

Fig. 4.5. Beetle species association with variation in vegetation structure and L. humile invasion at Piha. Distribution patterns were analysed using RDA $(n=126) . r=2 m$ is the vegetation type within $2 \mathrm{~m}$ around a sample. $\mathrm{r}=2-10 \mathrm{~m}$ is the vegetation type $2 \mathrm{~m}$ away but not more than $10 \mathrm{~m}$ from a sample. Underlined names are exotic species and beetles designated "?" are beetles unspecified as either exotic or endemic. 


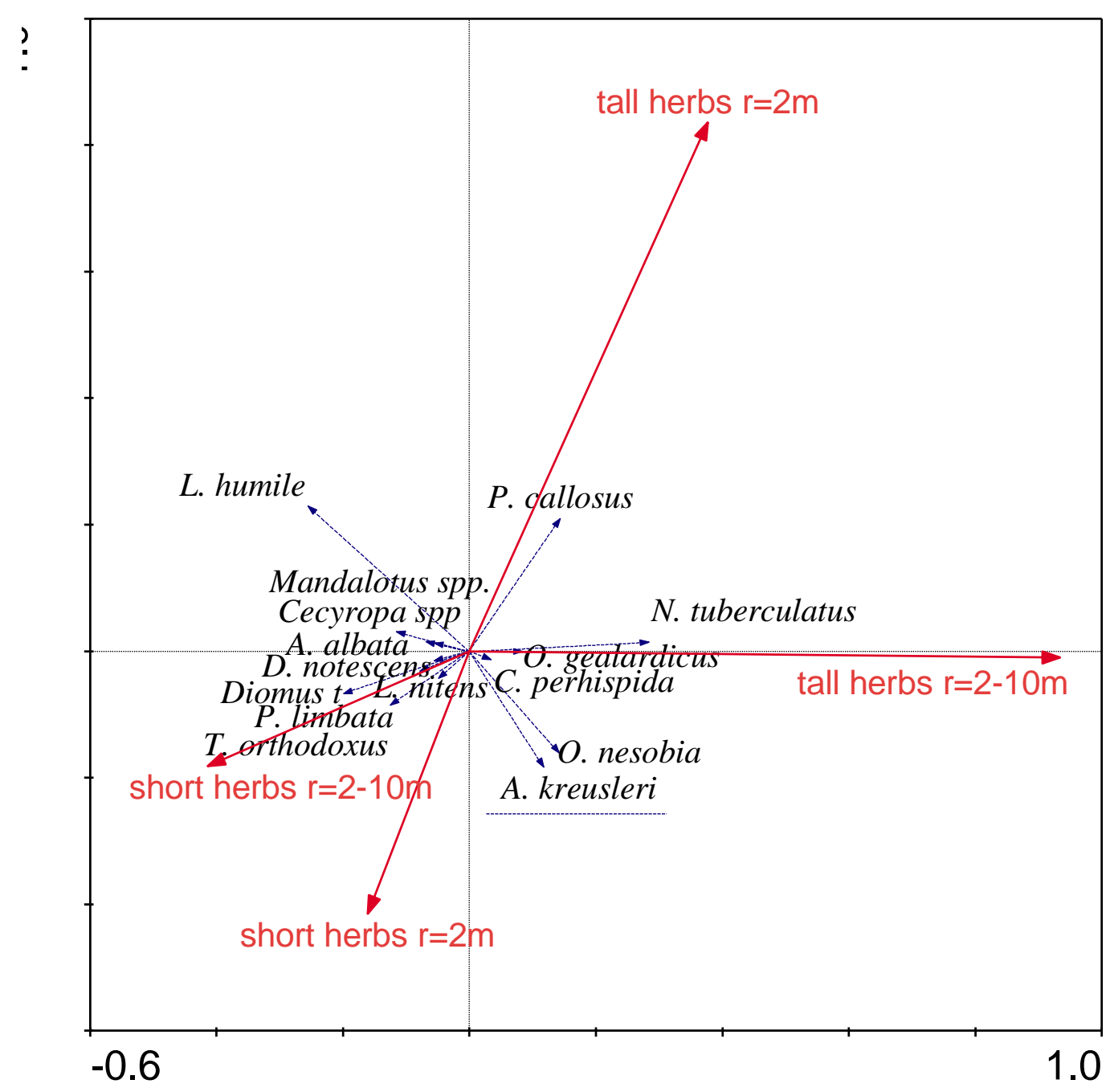

Fig. 4.6. Beetle species distribution pattern in relation to Argentine ant invasion at Baylys Beach derived from RDA analysis ( $n=126$ pitfall traps). $r=2 \mathrm{~m}$ is microhabitat type within $2 \mathrm{~m}$ around a sample and $\mathrm{r}=2-10 \mathrm{~m}$ is microhabitat type $2 \mathrm{~m}$ away but not more than $10 \mathrm{~m}$ from a sample. The underlined beetle name is an exotic species. 


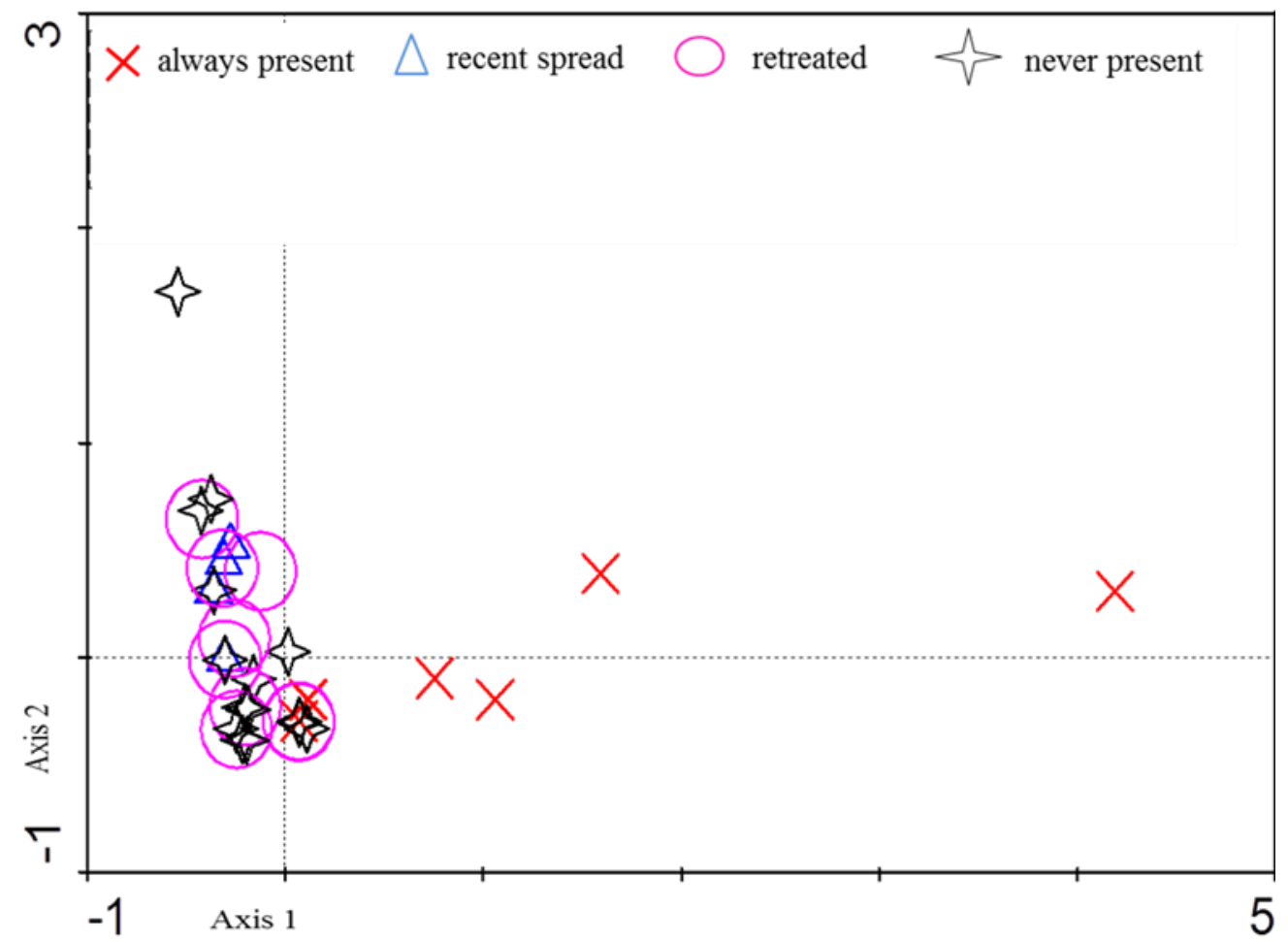

Fig. 4.7. Principle components analysis of the variation in beetle species composition in relation to the history of Argentine ant invasion at Piha $(n=28)$. The legend refers to beetle species composition in areas where Argentine ants were always present, recently spread, retreated and never present respectively.

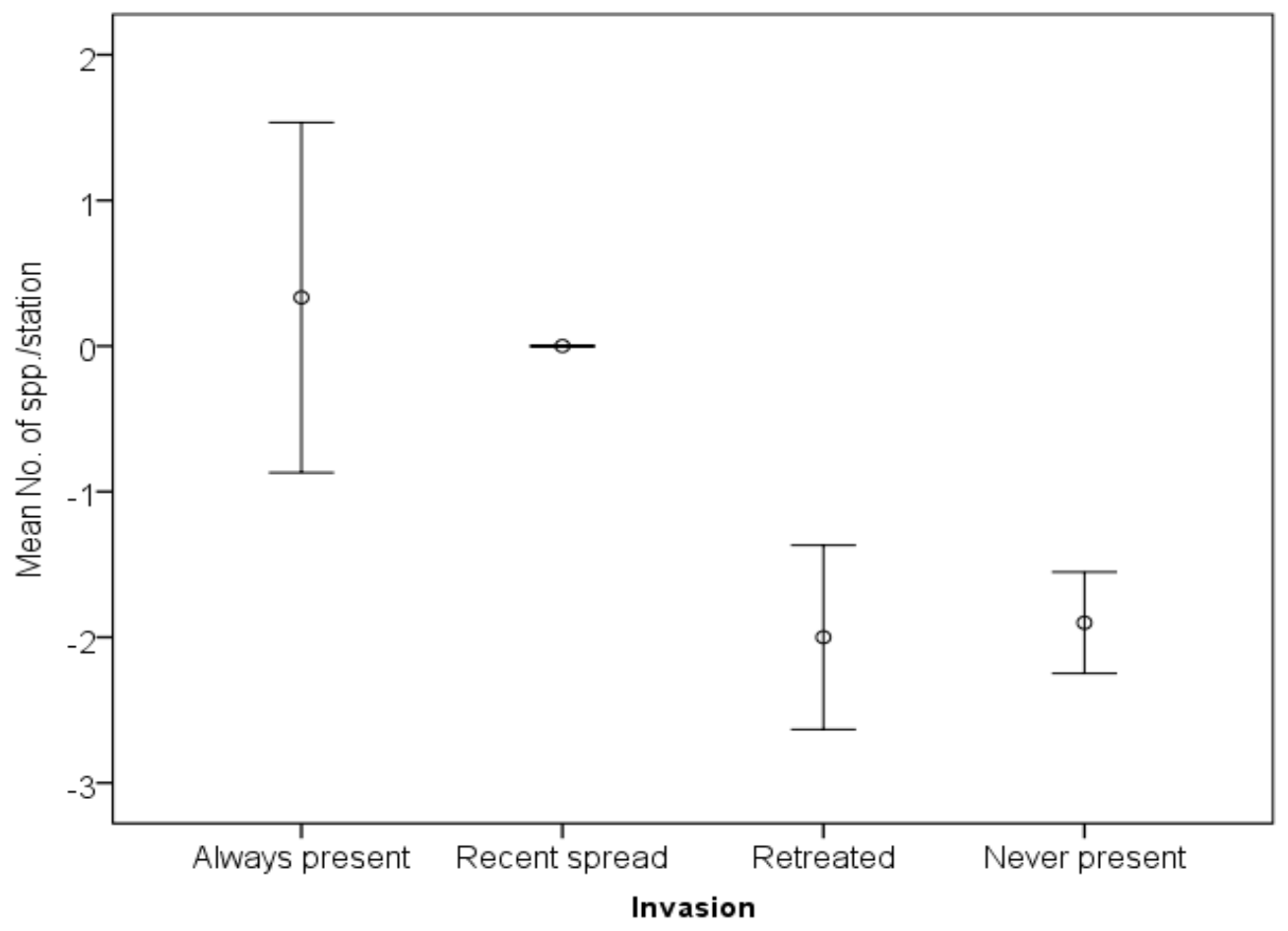

Fig. 4.8. Local change in species richness of beetles (mean $\pm S E$ ) in relation to the history of Argentine ant invasion at Piha. Data for species collected in 2002 and 2004 were pooled together as was data for species collected in 2009 and 2010. Change in species richness between the two groups was calculated as $(2009+2010)-(2002+2004)$. Species richness change is per station $(\mathrm{n}=10)$. 

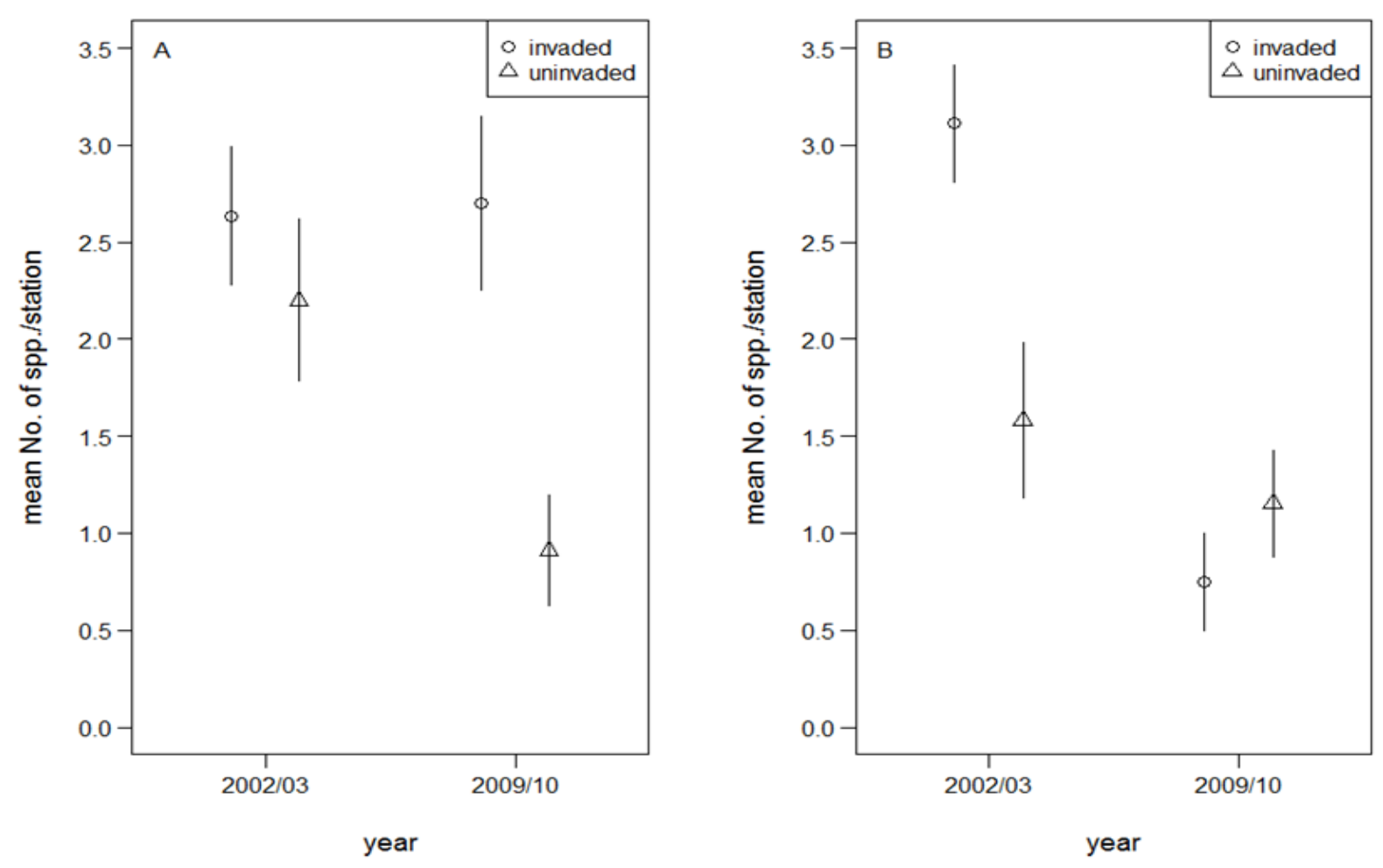

Fig. 4.9. Beetle species richness variation at A) Piha and B) Baylys Beach in areas invaded and uninvaded by Argentine ants (mean $\pm \mathrm{SE}, \mathrm{n}=10$ stations with three pitfall traps per station) in 2002/03 and 200/10.
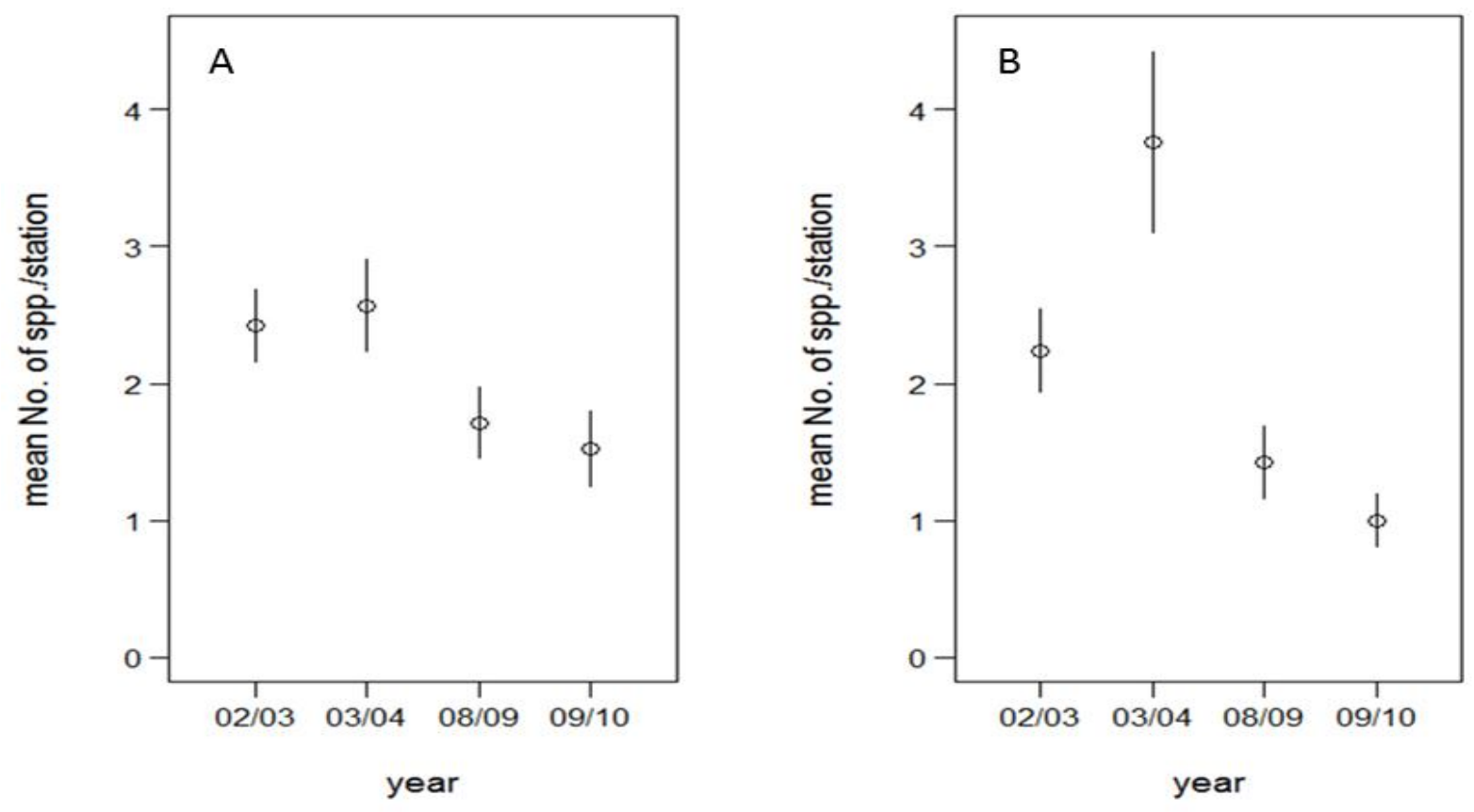

Fig. 4.10. Temporal changes in species richness of beetles in Argentine ant invaded sites at A) Piha and B) Baylys Beach (mean $\pm \mathrm{SE}, \mathrm{n}=21$ stations with three pitfall traps $1 \mathrm{~m}$ apart in each station). 

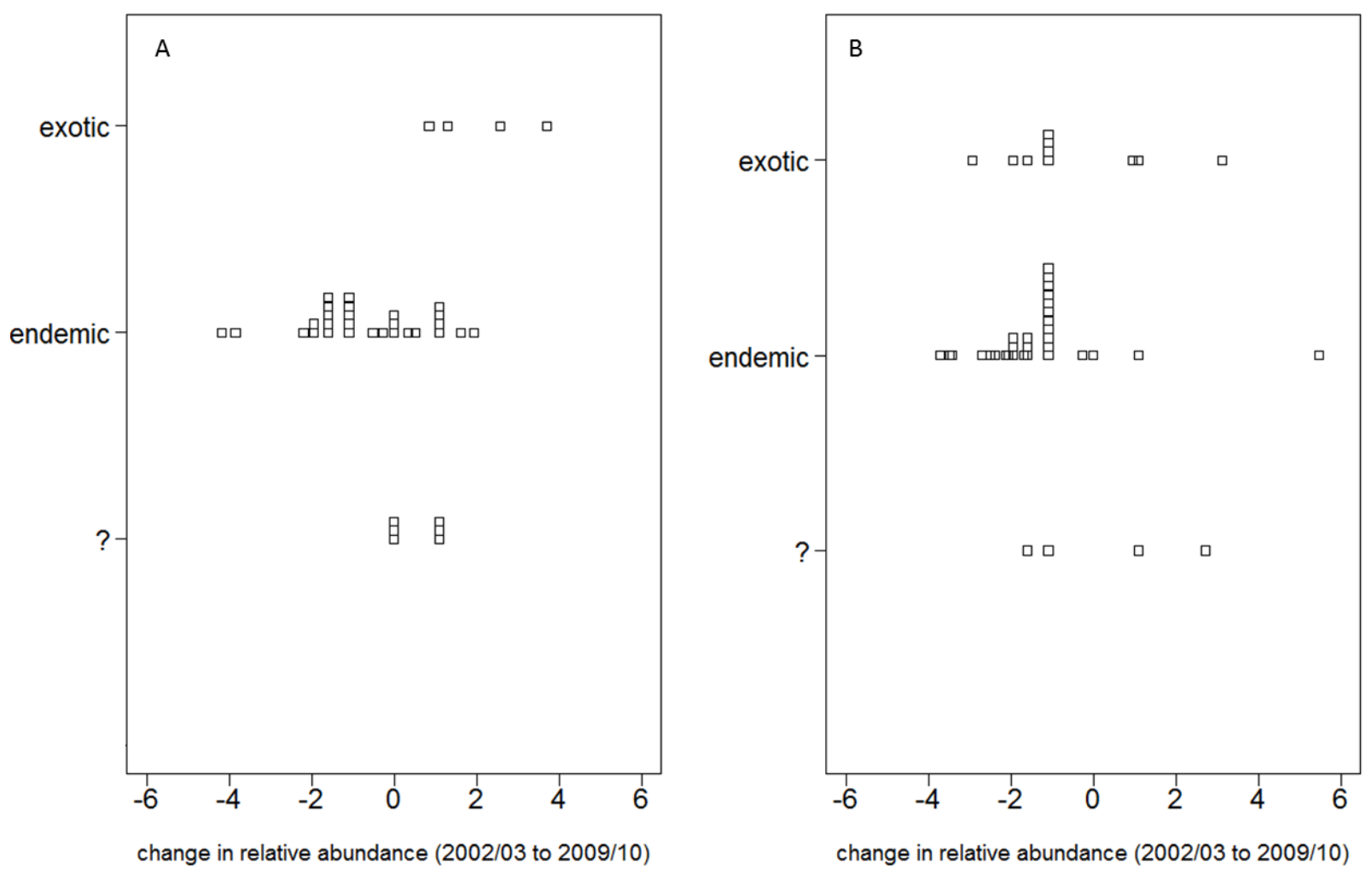

Fig. 4.11. Changes in relative abundances of endemic and exotic beetle species between 2002/2003 and 2009/2010 at A) Piha and B) Baylys Beach. The change in relative abundance of each beetle species was calculated as $\left(\mathrm{x}_{2}+0.5\right) /\left(\mathrm{x}_{1}+0.5\right)$, where $\mathrm{x}_{1}$ is the number of individuals of a species collected in 2002/03 and $\mathrm{x}_{2}$ is the number of individuals of "the same species collected in 2009/10. ( $n=42$ stations with three pitfall traps in each, $1 \mathrm{~m}$ apart). ?=species unspecified either as endemic or exotic.

\section{Beetle community composition}

At both study sites, the composition of beetle communities differed between Argentine ants invaded and uninvaded areas, and changed over time. Dissimilarity in beetle community composition between Argentine ant invaded and uninvaded areas was 57\% at Baylys Beach and $70 \%$ at Piha. Number of species found in both invaded and uninvaded areas at Piha was less than $30 \%$. Species composition dissimilarity tended to increase over time at both Piha and Baylys Beach (Table 4.1). For example, on average, beetle communities sampled in 2002 and 2010 were more than $89 \%$ dissimilar at Baylys Beach and across the same time period at Piha they were about 54\% dissimilar (Table 4.1). 
Table 4.1. Dissimilarity in the beetle community composition sampled over time at Baylys Beach and Piha. Bray-Curtis distance measures of dissimilarity are reported. The scale ranges from 0 to 1 . $0=100 \%$ species compostion similarity and $1=100 \%$ species compostion dissimilarity.

\begin{tabular}{rrrrr}
\hline \multicolumn{7}{c}{ Piha } \\
Year & $\mathbf{2 0 0 2}$ & $\mathbf{2 0 0 4}$ & $\mathbf{2 0 0 9}$ & $\mathbf{2 0 1 0}$ \\
\hline $\mathbf{2 0 0 2}$ & 0 & 0.42 & 0.67 & 0.54 \\
$\mathbf{2 0 0 4}$ & \multicolumn{0}{c}{0} & 0.60 & 0.48 \\
$\mathbf{2 0 0 9}$ & \multicolumn{7}{c}{0} & 0.44 \\
$\mathbf{2 0 1 0}$ & \multicolumn{7}{c}{ Baylys Beach } \\
\hline Year & $\mathbf{2 0 0 2}$ & $\mathbf{2 0 0 4}$ & $\mathbf{2 0 0 9}$ & $\mathbf{2 0 1 0}$ \\
\hline $\mathbf{2 0 0 2}$ & 0 & 0.55 & 0.87 & 0.89 \\
$\mathbf{2 0 0 4}$ & & 0 & 0.90 & 0.93 \\
$\mathbf{2 0 0 9}$ & & & 0 & 0.34 \\
$\mathbf{2 0 1 0}$ & & & & 0 \\
\hline
\end{tabular}

\subsection{Discussion}

\section{Changes in Argentine ant distribution over time}

The objective of this study was to evaluate the association between Argentine ant invasion and beetle species richness and composition using a before-after-control-impact study design. This analysis was not possible however, as the Argentine ants' distribution pattern remained virtually unchanged between 2002 and 2010 at Baylys Beach while at Piha there was an overall reduction in the area invaded confounded with a change in vegetation structure in the area of retreat. My repeat survey found these invasive ants became localized to the northern part of the Piha study area which is mostly a short herb habitat. In 2010 trees covered $45 \%$ to $100 \%$ of the area from which Argentine ants had retreated whereas in 2002 the average cover of bushes and trees was about $12 \%$. The change in the Argentine ants' distribution therefore seems to be related to a change in vegetation structure over time as their present association with the vegetation structure is similar to their earlier (2002) associations. In relatively cool-wet climates (such as New Zealand) Argentine ants prefer open patch habitats (Hartley et al. 2010) that could be due to low temperature under high tree cover (Martens, 2000; Bennie et al, 2008; Hartley et al., 2010). Argentine ants are sensitive to temperature, for example colonies die if temperatures remain below $5^{\circ} \mathrm{C}$ for extended periods of time (Brightwell, 2010). Their global distribution is limited to areas with a mean annual temperature above $10-12^{\circ} \mathrm{C}$ (Hartley et al. 2006) and the optimal temperature for their reproduction in laboratory is about $28{ }^{\circ} \mathrm{C}$ (Abril et al., 2008). 


\section{Arthropod associations with Argentine ants}

A greater abundance and diversity of arthropods were associated with the areas (and types of vegetation) invaded by Argentine ants at Piha. Other studies have also reported that some arthropods are more abundant in Argentine ant invaded areas, and the association is suggested to be due to habitat suitability rather than due to any direct positive effect of Argentine ants (Cole et al., 1992). The uninvaded area at Piha was characterized by a dense canopy of tall trees, which many arthropods likely avoid due to low understorey radiation resulting in low temperature (Martens, 2000; Bennie et al, 2008; Hartley et al., 2010), which results in lower species richness in these habitats (Tykarski, 2006). At Baylys Beach, in contrast, higher abundances of arthropod orders were found in the uninvaded area. Most of the Argentine ant invasion is on one bank of a small river. The invaded and uninvaded areas were environmentally similar in terms of vegetation type and structure, soil type, slope and aspect. Here, it is more likely that the variation in abundance of arthropod species may be associated with the Argentine invasion, although it remains possible that there are some unmeasured environmental differences between the two areas that were not obvious to me, but which affect arthropod distribution patterns.

\section{Beetle species associations with Argentine ants}

At the species level I found more beetle species in the invaded habitat at Piha. Data collected in 2009 and 2010 show an increase in abundance of exotic beetle species and a decrease in abundance of endemics. The Argentine ant invaded area seems to attract more exotic species and a number of endemic species found in that area appear to be at a low abundance in $2009 \mathrm{~N}$ 2010 compared to earlier years 2002 and 2004. In Hawaii, Argentine ant invaded areas are typically associated with higher numbers of exotic and a reduction in endemic beetle species (Cole et al., 1992). Some endemic species that were in the Argentine ant invaded area in 2002 and 2004, notably Phycosecis limbata and Sapintus aucklandensis, appear to have been extirpated (or reduced in abundance). This is accompanied by large changes in species composition between the invaded and uninvaded areas as well as between different years which is similar to the pattern reported by the study of Krushelnycky and Gillespie (2008).

The removal of keystone species can cause changes in community structure (Paine, 1971). Such disturbances result in changes with serious negative effects on some species and benefits to other species (Huston, 1994). The establishment of invasive species may leave the habitat prone to secondary invasion. An example of invasion facilitating secondary invasion is that of land snails promoted by exotic ant species on Christmas Island, i.e. the ants remove land crabs 
which are predators of the snails (Green et al., 2011). Species disturbance that could be associated with the invasion by the Argentine ants is reflected in high species turnover rate.

In this study the Argentine ants seem to have negatively affected endemic beetle species richness, and there was also high species richness of exotic beetle species associated with the uninvaded area. Because insects' abundances fluctuate annually (Barlow et al., 2002), it is possible that this fluctuation contributed to the results. However, as the observed declines in beetle species richness were statistically significant at both study sites, it is more probable the decline is associated with the Argentine ant invasion.

Low temperature reduces the activity of most insects (Dolezal et al., 2007; Abril et al., 2008), and the Argentine ant invaded habitat at Piha was open patches covered with short herbs and about only $30 \%$ trees. Thus, the temperature was likely to be lower at the uninvaded sites. Although pitfall trap sampling is commonly used and considered an effective method (Lindsey and Skinner, 2001; Santos et al., 2007), it is important to note that pitfall traps record insect activity rather than abundance per se (Cole et al., 1992), and some studies have recorded a bias toward large-bodied insects captured in pitfall traps (Spence and Niemelä, 1994). In other words, insects may be more abundant in the shrubby and tree habitats than the pitfall trap data suggests. High abundances of beetle species have been associated with high herbaceous plant richness (Forbes et al., 2005), and the richness of herbaceous plant species is generally higher in open patches and less in tree covered habitats (Uhercikova and Nemethova, 2006). Thus, temperature suitability and diet availability may support the higher exotic beetle species observed in the Argentine ant invaded area.

It is widely accepted that establishment of exotic species and their subsequent spread occur faster when the recipient habitat has low abundance and low richness of resident species (Allstadt et al., 2009). Conversely, high diversity in a community is thought to shrink niches which allows the coexistence of more species locally (Rosenzweig and Ziv, 1999) and creates greater biotic resistance (Elton 1958). Less competitive species are displaced from areas of high species competition (Wieters et al., 2009; Kath and Dunn, 2009) which could be the reason for the capture of less endemic species in the Argentine ant invaded area. At Baylys Beach in 2002 the invaded area had higher beetle species richness than the uninvaded area, but this pattern was reversed in 2010. This change may be associated with an initial early invasion stage with the Argentine ants at lower density, progressively changing beetle species richness over time. 
In New Zealand, Argentine ants are still thought to be at an early stage of expansion (Ward et al., 2010), and were only detected in 1990 in Auckland (Green, 1990). Other studies have also found that the Argentine ants can reduce arthropod species richness and severely affect endemic beetle species (Cole et al., 1992; Krushelnycky and Gillespie, 2008). Yet, Argentine ants do not always affect other non-ant arthropods (Holway, 1998). Sometimes, Argentine ants interact positively with other insects. For example, mutually interacting, Argentine ants increase abundance of gall wasps (Inouye and Agrawal, 2004) and membracid, Beaufortiana sp. (Lach, 2007) which may facilitate invasion by the Argentine ants (Nelson and Daane, 2007). In addition to predictable changes in community structure in response to invasive species much variation in abundance or distribution cannot be easily explained and may be the result of demographic or environmental stochasticity that can result in an exaggerated outcome in population dynamics (Haegeman and Loreau, 2011; Lv and Pitchford, 2007).

Community assembly is a dynamic process. Arriving organisms must cope with the environmental conditions and interact with other organisms in vertical and horizontal trophic relationships (Hunsaker et al., 2001). Species in a community may reach an approximate equilibrium, as a result of competitive interactions (Conrad, 1972; Mori et al., 2007; Zu et al., 2008) and predator-prey relationships (e.g. Perez-Matus and Shima, 2010). However, even though not all exotic species are harmful, many invasive species change the balance of endemic communities (Elton, 1958; Cadotte et al., 2006). As a result of invasive species displacing keystone species such as important predators and pollinators (Cole et al., 1992) endemic communities can be disassembled (Sanders et al., 2003; Paine, 1971).

At Piha a new ant species (Pheidole rugosula) appeared in the community in 2009/2010. Pheidole rugosula are exotic to New Zealand, however, little is known about their impact apart from their tendency to be generalist foragers (Don, 2007). Their close relative, Pheidole megacephala are invasive species with negative impacts on other ant species (Dejean et al., 2008). If P. rugosula are shown to negatively affect other arthropod species in New Zealand, this may have severe consequences as these ants have invaded habitat types where Argentine ants are not commonly found. Lower beetle species richness was found in areas uninvaded by the Argentine ants. It is possible that the presence of $P$. rugosula may have contributed in this result. Because there are so many potential interactions happening simultaneously, it is difficult to infer process from field studies alone. 


\section{Conclusion}

Habitat/vegetation structure variation mediates the effects of Argentine ant invasion. Although I am unable to definitively identify an effect of the Argentine ant invasion on beetle species richness and composition, there are associations between species richness and composition changes with the invasion, including an association between higher exotic beetle species abundances with Argentine ant invaded habitats. However, these effects may be mediated by temporal and spatial changes in habitat. At Baylys Beach as there was less vegetation variability between the invaded and uninvaded areas it appears more likely that Argentine ants reduce beetle species richness. By contrast, at Piha, because vegetation structure differed between the invaded and uninvaded areas, and perhaps because of a new invasion by another ant species ( $P$. rugosula), it was not possible to unravel the effects of individual factors (Green et al., 2011). Therefore, I suggest further studies on the effect of Argentine ants on other arthropod species, in particular the interactions between the effects of Argentine ant invasion, vegetation structure and the effects of $P$. rugosula on other arthropod species. Because natural fluctuations in the expansion and decline of invasive species are not easily predicted these studies would likely have to be long-term in nature in order to observe sufficient before-andafter contrasts that are not confounded by habitat variation. 


\subsection{References}

Abril, S., J. Oliveras, and C. Gomez, 2008. Effect of temperature on the oviposition rate of Argentine ant queens (Linepithema humile Mayr) under monogynous and polygynous experimental conditions. Journal of Insect Physiology 54: 265-272.

Allstadt, A., T. Caraco, and G. Korniss, 2009. Preemptive spatial competition under a reproduction-mortality constraint. Journal of Theoretical Biology 258: 537-549.

Barlow, N. D., J. R. Beggs, and M.C. Barron, 2002. Dynamics of common wasps in New Zealand beech forests: A model with density dependence and weather. Journal of Animal Ecology 71: 663-671.

Bennie, J., B. Huntley, A. Wiltshire, M. O. Hill, and R. Baxter, 2008. Slope, aspect and climate: spatially explicit and implicit models of topographic microclimate in chalk grassland. Ecological Modelling 216: 47-59.

Biggs, R., H. Simons, M. Bakkenes, R. J. Scholes, B. Eickhout, D. van Vuuren, and R. Alkemade, 2008. Scenarios of biodiversity loss in southern Africa in the 21st century. Global Environmental Change 18: 296-309.

Brooker, R. W., J. M. J. Travisb, E. J. Clark, and C. Dytham, 2007. Modelling species' range shifts in a changing climate: The impacts of biotic interactions, dispersal distance and the rate of climate change. Journal of Theoretical Biology 245: 59-65.

Brightwell, R. J., P. E. Labadie, and J. Silverman, 2010. Northward expansion of the invasive Linepithema humile (Hymenoptera: Formicidae) in the Eastern United States is constrained by winter soil temperatures. Physiological Ecology 39: 1659-1665.

Burns, K. C. and P. J. Lester, 2007. Competition and coexistence in model populations. In Jørgensen, S. E. and B. D. Fath (Ed.), population dynamics: encyclopedia of ecology (vol.5, pp.701-707). Elsevier, Oxford.

Cadotte, M. W., S. M. McMahon, and T. Fukami, 2006. Conceptual Ecology and Invasion Biology: Reciprocal Approaches to Nature. Springer, Dordrecht.

Carney, S. E., M. B. Byerley, and D. A. Holway, 2003. Invasive Argentine ants (Linepithema humile) do not replace native ants as seed dispersers of Dendromecon rigida (Papaveraceae) in California, USA. Oecologia 135: 576-582.

Carrasco, L. R., J. D. Mumford, A. MacLeod, T. Harwood, G. Grabenweger, A. W. Leach, J. D. Knight, and R. H. A. Baker, 2010. Unveiling human-assisted dispersal mechanisms in invasive alien insects: Integration of spatial stochastic simulation and phenology models. Ecological Modelling 221: 2068-2075.

Chinery, M. 1986. Collins guide to the insects of Britain and Western Europe. Domino Books Ltd., Jersey.

Cole, F. R., A. C. Medeiros, L. L. Loope, and W. W. Zuehlke, 1992. Effect of the Argentine ant on arthropod fauna of Hawaiian high-elevation. Ecology 73: 1313-1322.

Conrad, M., 1972. Stability of food webs and its relation to species diversity. Journal of Theoretical Biology 34: 325-335. 
Cook, D. C. and R. W. Fraser, 2008. Trade and invasive species risk mitigation: reconciling WTO compliance with maximizing the gains from trade. Food Policy 33: 176-184.

Dejean, A., C. S. Moreau, M. Kenne, and M. Leponce, 2008. The raiding success of Pheidole megacephala on other ants in both its native and introduced ranges. Comptes Rendus Biologies 331: 631-635.

Dietz, S. and W. N. Adger, 2003. Economic growth, biodiversity loss and conservation effort. Journal of Environmental Management 68: 23-35.

Dolezal, P., O. Habustova, and F. Sehnal, 2007. Effects of photoperiod and temperature on the rate of larval development, food conversion efficiency, and imaginal diapause in Leptinotarsa decemlineata. Journal of Insect Physiology 53P: 849-857.

Don, W., 2007. Ants of New Zealand. University of Otago Press in association with the Otago Museum, Dunedin.

Elton, C., 1958. The ecology of invasions; by animals and plants. Methuen and Co. Ltd. London.

Faith, D. P., P. R. Minchin, and L. Belbin, 1987. Compositional dissimilarity as a robust measure of ecological distance. Vegetatio 69: 57-68.

Floerl, O. and A. Coutts, 2009. Potential ramifications of the global economic crisis on humanmediated dispersal of marine non-indigenous species. Marine Pollution Bulletin 58: 15951598.

Forbes, G. S., J. Zee, W. Van, W. Smith, and W. G. Whitford, 2005. Desert grassland canopy arthropod species richness: temporal patterns and effects of intense, short-duration livestock grazing. Journal of Arid Environments 60: 627-646.

Gordon, D. M., 1995. The expandable network of ant exploration. Animal Behavior 50: 9951007.

Green, O. R., 1990. Entomologist sets new record at Mt Smart, or Iridomyrmex humilis established in New Zealand. Weta 13: 14-16.

Green, P. T., D. J. O’Dowd, K. L. Abbott, M. Jeffery, K. Retallick, and R. Mac Nally, 2011. Invasional meltdown: Invader-invader mutualism facilitates a secondary invasion. Ecology 92: $1758-1768$.

Grover, C.D., K. C. Dayton, S. B. Menke, and D. A. Holway, 2008. Effects of aphids on foliar foraging by Argentine ants and the resulting effects on other arthropods. Ecological Entomology 33: 101-106.

Haegeman, B. and M. Loreau, 2011. A mathematical synthesis of niche and neutral theories in community ecology. Journal of Theoretical Biology 269: 150-165.

Hartley, S., P. D. Krushelnycky, and P. J. Lester, 2010. Integrating physiology, population dynamics and climate to make multi-scale predictions for the spread of an invasive insect: the Argentine ant at Haleakala National Park, Hawaii. Ecography 33: 83-94. 
Hartley, S., R. Harris, and P. J. Lester, 2006. Quantifying uncertainty in the potential distribution of an invasive species: climate and the Argentine ant. Ecology Letters 9: 10681079 .

Holway, D. A., 2005. Edge effects of an invasive species across a natural ecological boundary. Biological Conservation 121: 561-567.

Holway, D. A., 1998. Effect of Argentine ant invasions on ground-dwelling arthropods in northern California riparian woodlands. Oecologia 116:252-258.

Holway, D. A. and T. J. Case, 2001. Effects of colony-level variation on competitive ability in the invasive Argentine ant. Animal Behaviour 61: 1181-1192.

Holway, D. A. and T.J. Case, 2000. Mechanisms of dispersed central-place foraging in polydomous colonies of the Argentine ant. Animal Behaviour 59: 433-441.

Holway, D A. and A. V. Suarez, 2006. Homogenization of ant communities in Mediterranean California: The effects of urbanization and invasion. Biological Conservation 127: 319-326.

Holway, D. A., L. Lach, A. V. Suarez, N. D. Tsutsui, and T. J. Case, 2002. The ecological causes and consequences of ant invasions. Annual Review Ecology and Systematics 33:181233.

Hunsaker, C. T., M. F.Goodchild., M. A. Field, and T. J. Case, 2001. Spatial uncertainty in ecology: implications for remote sensing and GIS applications. Springer-Verlag inc., New York.

Huston, M. A., 1994. The coexistence of species on changing landscapes. Cambridge University Press, Cambridge.

Hutchings, M. J., E. A. John, and A. J. A. Stewart, 2000. The ecological consequences of environmental heterogeneity. Blackwell Science Ltd. Cambridge University Press, Cambridge.

Ingram, K. K., 2002. Flexibility in nest density and social structure in invasive populations of the Argentine ant, Linepithema humile. Oecologia 133: 492-500.

Inouye, B. D. and A. A. Agrawal, 2004. Ant mutualists alter the composition and attack rate of the parasitoid community for the gall wasp Disholcaspis eldoradensis (cynipidae). Ecological Entomology 29: 692-696.

Jonsen, I. D., R. S. Bourchier, and J. Roland, 2007. Influence of dispersal, stochasticity, and an Allee effect on the persistence of weed biocontrol introductions. Ecological Modelling 203: 521-526.

Kac M., 1983. When is random random? Mathematical Social Science 4: 181-188.

Kaiser, B. A. and K. M. Burnett, 2010. Spatial economic analysis of early detection and rapid response strategies for an invasive species. Resource and Energy Economics 32: 566-585.

Kath, J., M. Maron, and P. K. Dunn, 2009. Interspecific competition and small bird diversity in an urbanizing landscape. Landscape and Urban Planning 92: 72-79. 
Klimaszewski, J. and J. C. Watt, 1997. Fauna of New Zealand: Coleoptera: family-group review and keys to identification. Manaaki Whenua Press, Lincoln.

Krushelnycky, P. and R. G. Gillespie, 2008. Compositional and functional stability of arthropod communities in the face of ant invasions. Ecological Applications 18: 1547-1562.

Lach, L., 2007. A mutualism with a native membracid facilitates pollinator displacement by Argentine ants. Ecology 88:1994-2004.

Lalouette, L., C. M. Williams, F. Hervant, B. J. Sinclair, and D. Renault, 2011. Metabolic rate and oxidative stress in insects exposed to low temperature thermal fluctuations. Comparative Biochemistry and Physiology 158: 229-234.

Lepš, J. and P. Šmilauer, 1999. Multivariate Analysis of Ecological Data. Faculty of Biological Sciences, University of South Bohemia, Ceské Budejovice.

Lindsey, P. A. and J. D. Skinner, 2001. Ant composition and activity patterns as determined by pitfall trapping and other methods in three habitats in the semi-arid Karoo. Journal of Arid Environments 48: 551-568.

Lodge, D. M., 1993. Biological invasions: lesson for ecology. Trends in Ecology and Evolution 8: 133-137.

Lv, Q. and J. W. Pitchford, 2007. Stochastic von Bertalanffy models, with applications to fish recruitment. Journal of Theoretical Biology 244: 640-655.

Martens, S. N., D. D. Breshears, and C. W. Meyer, 2000. Spatial distributions of understorey light along the grassland/forest continuum: effects of cover, height, and spatial pattern of tree canopies. Ecological Modelling 126: 79-93.

Menke, S. B., R. N. Fisher, W. Jetz, and D. A. Holway, 2007. Biotic and abiotic controls of Argentine ant invasion success at local and landscape scales. Ecology 88: 3164-3173.

Mori, A. S., E. Mizumachi, and A. Komiyama, 2007. Roles of disturbance and demographic non-equilibrium in species coexistence, inferred from 25-year dynamics of a latesuccessional old-growth subalpine forest. Forest Ecology and Management 241: 74-83.

Nelson, E. H. and K. M. Daane, 2007. Improving liquid bait programs for Argentine ant control: bait station density. Environmental Entomology 36: 1475-1484.

Nonacs, P. and J. L. Soriano, 1998. Patch sampling behaviour and future foraging expectations in Argentine ants, Linepithema humile. Animal Behavior 55: 519-527.

Olff, H. and M. E. Ritchie, 2002. Fragmented nature: consequences for biodiversity. Landscape and Urban Planning 58: 83-92.

Paine, R. T., 1971. A short-term experimental investigation of resource partitioning in a New Zealand rocky intertidal habitat. Ecology 52: 1096-1106. 
Pellikka, P. K. E., M. Lotjonen, M. Siljander, and L. Lens, 2009. Airborne remote sensing of spatiotemporal change (1955-2004) in indigenous and exotic forest cover in the Taita Hills, Kenya. International Journal of Applied Earth Observation and Geoinformation 11: 221232.

Perez-Matus, A. and J. S. Shima, 2010. Density and trait-mediated effects of fish predators on amphipod grazers: indirect benefits for the giant kelp, Macrocystis pyrifera. Marine Ecology Progress Series 417:151-158.

Pimentel, D., L. Lach, R. Zuniga, and D. Morrison, 2000. Environmental and economic costs of nonindigenous species in the United States. Bioscience 50: 53-65.

Pimentel, D., R. Zuniga, and D. Morrison, 2006. Update on the environmental and economic costs associated with alien-invasive species in the United States. Ecological Economics 52: 273-288.

Ricketts, T. and M. Imhoff, 2003. Biodiversity, urban areas, and Agriculture: locating priority ecoregions for conservation. Conservation Ecology 8:1-15.

Roder, J., C. Bassler, R. Brandl, L. Dvorak, A. Floren, M. M. Gosner, A. Gruppe, A. JarzabekMuller, O. Vojtech, C. Wagner, and J. Muller, 2010. Arthropod species richness in the Norway Spruce (Picea abies (L.) Karst.) canopy along an elevation gradient. Forest Ecology and Management 259: 1513-1521.

Rosenzweig, M. L. and Y. Ziv, 1999. The echo pattern of species diversity: pattern and processes. Ecography 22: 614-628.

Sabu, T. K. and R. T. Shiju, 2009. Efficacy of pitfall trapping, Winkler and Berlese extraction methods for measuring ground-dwelling arthropods in moist deciduous forests in the Western Ghats. Journal of Insect Science 98: 1-17.

Sanders, N. J., N. J. Gotelli, N. E. Heller, and D. M. Gordon, 2003. Community disassembly by an invasive species. Proceedings of National Academy of Sciences 100: 2474-2477.

Santos, S. A. P., J. E. Cabanas, and J. A. Pereira, 2007. Abundance and diversity of soil arthropods in olive grove ecosystem (Portugal): effect of pitfall trap type. European Journal of Soil Biology 43: 77-83.

Simberloff, D., 2000. Global climate change and introduced species in United States forests. The Science of the Total Environment 262: 253-261.

Spence, J. R. and J. K. Niemelä, 1994. Sampling carabid assemlages with pitfall traps: the madness and the method. The Canadian Entomologist 126: 881-894.

Tykarski, P., 2006. Beetles associated with scolytids (Coleoptera, Scolytidae) and the elevational gradient: diversity and dynamics of the community in the Tatra National Park, Poland. Forest Ecology and Management 225: 146-159.

Uhercíkovà, E. and D. N_Methovà, 2006. The dynamics of Bodícka brána forest vegetation. Biologia, Bratislava 61: 421-431. 
Vitousek, P. M., H. A. Mooney, J. Lubchenco, J .M. Melillo, 1997. Human domination of earth's ecosystems. Science 277: 494-499.

Hutchings, M. J., E. A. John, and A. J. A. Stewart, 2000. The ecological consequences of environmental heterogeneity. Blackwell Science Ltd. Cambridge University Press, Cambridge.

Ward, D. F, C. Green, R. J. Harris, S. Hartley P. J. Lester, M. Stanley, D. M. Suckling, R. J. Toft, 2010. Twenty years of Argentine ants in New Zealand: past research and future priorities for applied management. New Zealand Entomologist 33: 68-78.

Wieters, E. A., E. Salles, S. M. Januario, and S. A. Navarrete, 2009. Refuge utilization and preferences between competing intertidal crab species. Journal of Experimental Marine Biology and Ecology 374: 37-44.

Wilcove, D. S., D. Rothstein, J. Dubow, A. Phillips, and E. Losos, 1998. Quantifying threats to imperiled species in the United States. Bioscience 48: 607-615.

Wilson, J. R. U., E. E. Dormontt, P. J. Prentis, A. J. Lowe, and D. M. Richardson, 2008. Something in the way you move: dispersal pathways affect invasion success. Trends in Ecology and Evolution 24: 136-144.

Wotton, D. M., C. O’Brien, M. D. Stuart, and D. J. Fergus, 2004. Eradication success down under: heat treatment of a sunken trawler to kill the invasive seaweed Undaria pinnatifida. Marine Pollution Bulletin 49: 844-849.

Yemshanov, D. , D. W. McKenney, P. de Groot, D. Haugen, J. Pedlar, D. Sidders, and B. Joss, 2011. A harvest failure approach to assess the threat from an invasive species. Journal of Environmental Management 92: 205-213.

Zu, J., W. Wang, Y, Takeuchi, B. Zu, and K. Wang, 2008. On evolution under symmetric and asymmetric competitions. Journal of Theoretical Biology 254: 239-251. 


\subsection{Appendix.}

4.6.1 Beetle species at Piha in invaded and uninvaded habitats $(2009+2010, \mathrm{n}=49$ pitfall traps in invade areas and 77 pitfall taps in uninvaded areas). ?=not yet determined as either exotic or endemic.

\begin{tabular}{|c|c|c|c|}
\hline Species at Piha & in invaded & $\begin{array}{c}\text { in } \\
\text { uninvaded }\end{array}$ & status \\
\hline Actizeta albata & 3 & 0 & endemic \\
\hline Anthicus kreusleri & 7 & 25 & exotic \\
\hline Asowpus sp. & 0 & 1 & $?$ \\
\hline Cecyropa sp. & 38 & 6 & endemic \\
\hline Diomus notescens & 20 & 0 & exotic \\
\hline Hetronychus arator & 1 & 0 & $?$ \\
\hline Hypharpax australis & 1 & 4 & exotic \\
\hline Loberus nitens & 6 & 4 & endemic \\
\hline Mandalotus sp & 18 & 14 & endemic \\
\hline Microcryptorhychus sp. & 1 & 0 & $?$ \\
\hline Mimopeus elongatus & 4 & 0 & endemic \\
\hline $\begin{array}{l}\text { Neocicindela } \\
\text { tuberculatus }\end{array}$ & 1 & 0 & endemic \\
\hline Ochocternus gealardicus & 2 & 3 & $?$ \\
\hline Odontria nesobia & 1 & 0 & endemic \\
\hline Pristorus antarcticus & 0 & 1 & endemic? \\
\hline Psilocnaeia sp. & 1 & 0 & endemic \\
\hline Pyronotasp. & 1 & 0 & endemic \\
\hline Rhyzobius sp. & 2 & 0 & endemic \\
\hline $\begin{array}{l}\text { Stephanorhynchus } \\
\text { crassus }\end{array}$ & 0 & 1 & $?$ \\
\hline $\begin{array}{l}\text { Thyreocephalus } \\
\text { orthodoxus }\end{array}$ & 1 & 2 & exotic \\
\hline Undecimpunctata & 1 & 0 & endemic \\
\hline Xylotoles griseus & 0 & 2 & endemic \\
\hline Zeadolopus sp. & 0 & 1 & endemic \\
\hline
\end{tabular}


4.6.2 Total number of beetle species at Piha. The number of pitfall traps was 63 in each year.

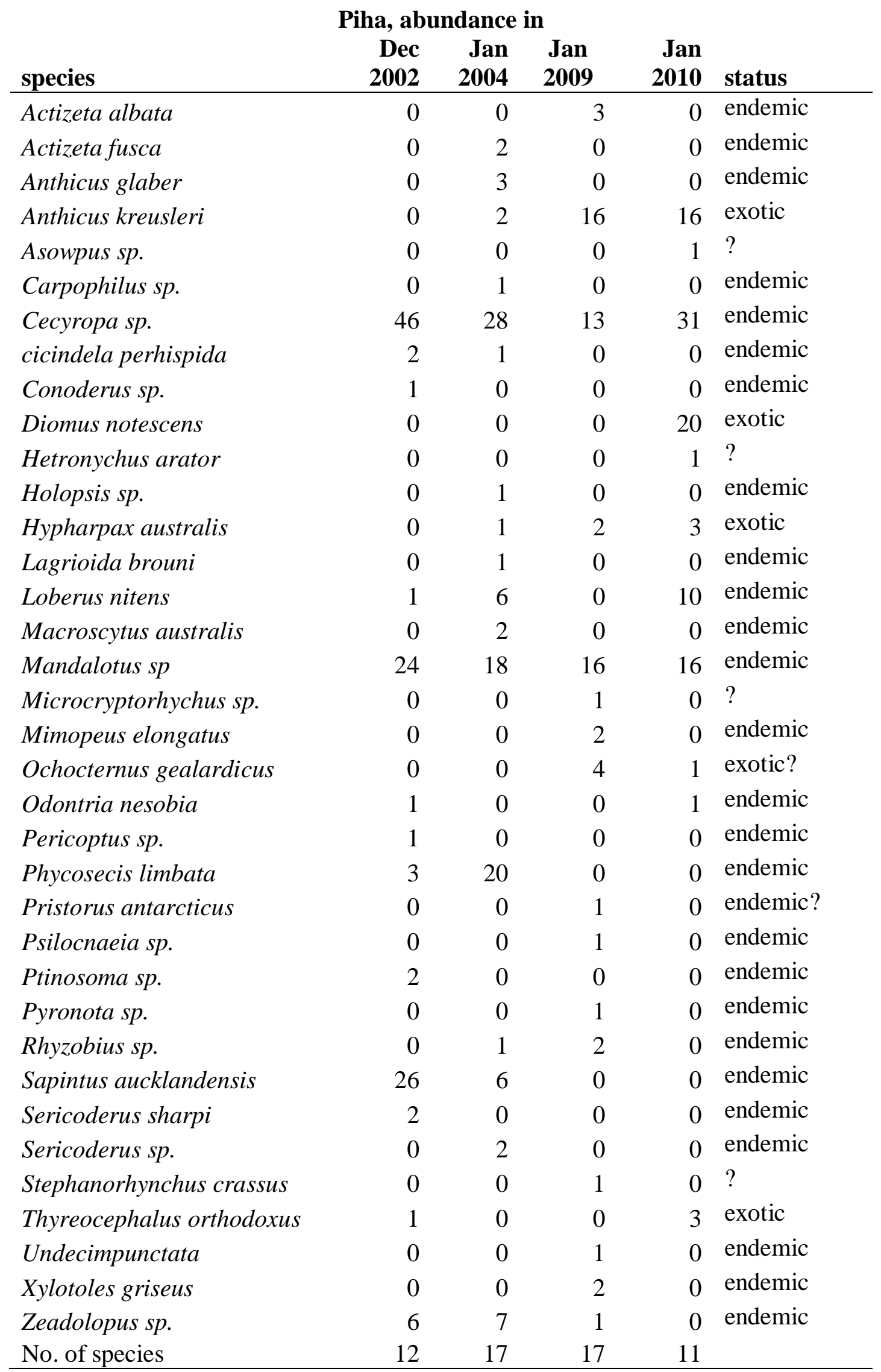


4.6.3 Total number of beetle species at Baylys Beach. The number of pitfall traps in each year was 63 .

Baylys Beach, Abundance in

\begin{tabular}{|c|c|c|c|c|c|}
\hline species & 2002 & 2004 & 2009 & 2010 & Status \\
\hline Actizeta albata & 0 & 1 & 1 & 0 & endemic \\
\hline Actizeta fusca & 0 & 7 & 0 & 0 & endemic \\
\hline Cecyropa sp. & 33 & 34 & 3 & 5 & endemic \\
\hline Cicindela perhispida & 0 & 40 & 7 & 0 & endemic \\
\hline Ciconissus sp. & 0 & 3 & 0 & 0 & endemic \\
\hline Colon hirtale & 17 & 3 & 0 & 0 & endemic \\
\hline Dysnocryptus sp. & 0 & 1 & 0 & 0 & endemic \\
\hline Holoparamecus sp. & 1 & 2 & 0 & 0 & endemic \\
\hline Holopsis sp. & 1 & 2 & 0 & 0 & endemic \\
\hline Lagrioida brouni & 0 & 1 & 0 & 0 & endemic \\
\hline Lagynodes gastroleius & 0 & 1 & 0 & 0 & endemic \\
\hline Loberus nitens & 4 & 8 & 0 & 1 & endemic \\
\hline Mandalotus sp & 6 & 12 & 1 & 0 & endemic \\
\hline Micrambina sp. & 0 & 2 & 0 & 0 & endemic \\
\hline Microtribus huttoni & 4 & 1 & 0 & 0 & endemic \\
\hline Mimopeus elongatus & 2 & 0 & 0 & 0 & endemic \\
\hline Cicindela tuberculata & 0 & 0 & 64 & 45 & endemic \\
\hline Novitas sp. & 0 & 1 & 0 & 0 & endemic \\
\hline Odontria nesobia & 0 & 0 & 1 & 0 & endemic \\
\hline Phloeophagosoma sp. & 0 & 1 & 0 & 0 & endemic \\
\hline Phycosecis limbata & 11 & 1 & 8 & 1 & endemic \\
\hline Ptinosoma sp. & 0 & 1 & 0 & 0 & endemic \\
\hline Rhyzobius rarus & 0 & 1 & 0 & 0 & endemic \\
\hline Sapintus aucklandensis & 11 & 5 & 0 & 0 & endemic \\
\hline Scelodolichus sp. & 1 & 0 & 0 & 0 & endemic \\
\hline Triphyllus sp. & 0 & 1 & 0 & 0 & endemic \\
\hline Triplosarus novaezealandiae & 1 & 0 & 0 & 0 & endemic \\
\hline Xylotoles sp. & 0 & 1 & 0 & 0 & endemic \\
\hline Zeadolopus sp. & 12 & 3 & 0 & 0 & endemic \\
\hline Macroscytus australis & 2 & 0 & 0 & 0 & native \\
\hline Anotylus sp. & 1 & 1 & 0 & 0 & exotic \\
\hline Anthicus kreusleri & 0 & 0 & 9 & 2 & exotic \\
\hline Cercyon sp. & 1 & 0 & 0 & 0 & exotic \\
\hline Clivina sp. & 0 & 1 & 0 & 0 & exotic \\
\hline Conoderus sp. & 0 & 1 & 0 & 0 & exotic \\
\hline Diomus notescens & 0 & 4 & 0 & 1 & exotic \\
\hline Diomus terminatus & 0 & 0 & 0 & 1 & exotic \\
\hline Sericoderus sp. & 0 & 9 & 0 & 0 & exotic \\
\hline Sitona lepidus & 0 & 3 & 0 & 0 & exotic \\
\hline Thyreocephalus orthodoxus & 2 & 0 & 2 & 4 & exotic \\
\hline Epuraea sp. & 0 & 2 & 0 & 0 & $?$ \\
\hline Melanophthalma sp. & 0 & 1 & 0 & 0 & $?$ \\
\hline Ochocternus gealardicus & 0 & 0 & 5 & 1 & $?$ \\
\hline Phlyctinus callosus & 0 & 0 & 1 & 0 & $?$ \\
\hline No. of species & 17 & 32 & 11 & 9 & \\
\hline
\end{tabular}


4.6.4 Most abundant exotic and endemic beetle species movement exchange at Piha.

\begin{tabular}{lccccc} 
species & $\mathbf{2 0 0 2}$ & $\mathbf{2 0 0 4}$ & $\mathbf{2 0 0 9}$ & $\mathbf{2 0 1 0}$ & status \\
\hline Anthicus kreusleri & 0 & 2 & 16 & 16 & exotic \\
Diomus notescens & 0 & 0 & 0 & 20 & exotic \\
Hypharpax australis & 0 & 1 & 2 & 3 & exotic \\
Ochocternus gealardicus & 0 & 0 & 4 & 1 & exotic? \\
Thyreocephalus orthodoxus & 1 & 0 & 0 & 3 & exotic \\
Zeadolopus sp. & 6 & 7 & 0 & 1 & Endemic \\
Phycosecis limbata & 3 & 20 & 0 & 0 & Endemic \\
Sapintus aucklandensis & 26 & 6 & 0 & 0 & Endemic \\
\hline
\end{tabular}




\section{Chapter 5}

\section{Role of interspecific competition and temperature in resisting invasion}

\subsection{Introduction}

Invasive species have been recognized as one of the leading causes of biodiversity deterioration throughout the world. Invasive species inflict serious ecological and economic damage (Truscott et al., 2008; Pimentel et al. 2000). The impact of invasion by exotic species is second only to the effect of habitat destruction on the loss of biodiversity (Vitousek et al., 1997; Wotton et al., 2004). About 42 percent of the endangered species at risk are mainly because of invasive species (Pimentel et al., 2006) often due to their competitive superiority over resident species (Wilcove et al., 1998) which is a unique attribute of invader species (Thomsen et al., 2011). Dispersal of invasive species to extra-range habitats occurs mainly by human-assisted transport (Wilson et al., 2009). It commonly happens accidentally (Lodge, 1993; Cole et al., 1992) or it can happen also by deliberate introduction of species as part of biological control measures (Jonsen et al, 2007) and cultivation (Pellikka, 2009). Insects have been recognized as some of the leading causes of ecological and economic damages (Hong et al, 2012; Sanders et al., 2003). However, just as there are a number of factors facilitating invasions, there are also biotic and abiotic factors that may prevent or delay invasion.

\section{Biotic interactions}

Competition between species can be broadly divided into two types: interference competition (e.g. direct behavioural interactions to protect space and/or resources) and exploitative competition (e.g. pre-emptive use of resources) (Burns and Lester, 2007). The success of many invasive species is mostly related to either their efficient exploitative competition (Ingram, 2002) or aggressive interference with other competitors (Grover et al., 2008). High propagule pressure during competition is one of the mechanisms underlying the success of many invasive species success (Walters and Mackay, 2005). How well an invasive species has established is measured in terms of species biomass (Finnoff and Tschirhart, 2005). However, biotic resistance by resident species plays an important role in resisting establishment of invasive species (Holway and Suarez 2006; Cole et al., 1992; Walters and Mackay, 2005). Because of the biotic interactions between invasive and endemic species, areas of high species richness are less vulnerable to invasion (Elton, 1958; Case, 1990; Stachowicz et al., 1999; Tilman, 1999). In contrast to this effect, some biotic interactions between invasive and native/resident species may facilitate invasion. For example, invasion by exotic ants may be facilitated by homopteran insects (Lester et al., 2003) and gall wasps (Inouye and Agrawal, 2004) with which they show 
positive symbiotic relationships. Nevertheless, other abiotic factors such as temperature may contribute in the process of establishment of invasive species.

\section{Temperature effect}

Ecologists have investigated effect of temperature on the distribution patterns of invasive species. It is possible to predict future global distribution of invasive species based on climate envelope (Hartley and Lester, 2003; Hartley et al., 2006). Climate change has been implicated in new invasion frontiers (Bardsley and Edwards-Jones, 2007; Patrick et al., 2012). Nowadays, due to climate change, invasive species have made their way even to Antarctica - a region previously unavailable to invasive species because of its low temperature (Hughes and Convey, 2012; Sinclair and Stevens, 2006). Spread of invasive species may be constrained or facilitated by temperature. Temperature affects their reproduction (e.g. see Abril et al., 008) and growth rate (Riis et al, 2012), and thereby regulates their distribution locally as well as globally (Hartley et al., 2006; Ficetola et al., 2007). Survival and feeding activities of invasive species are regulated by temperature (Sugiura, 2009). To control invasive species, different biotic and abiotic factors have been tested.

Biotic resistance against invasive species or pests could be a promising biological application. A safe and effective practice of suppressing invasive species is selecting agents for biological control so as to minimize or avoid inadvertent consequences (Raghu and Dhileepan, 2005). Biological control serves mainly to protect biodiversity, ecosystem services and products of natural systems (Driesche et al., 2010). Application of two or more biotic control agents against a single invasive or pest species frequently gives better results than a single agent as they can have an additive effect (Turner, 2010). Effects of multiple factors in some cases build beyond simple sum of two or more factors. Although studies of the interactive effects of multiple factors are less common (Didham, 2007), it is well-known that multiple factors have synergistic, interactive effects on biological response variables (e.g. Shivji, 1985). Chemical control of invasive species can be effective (Liang and Tang, 2010). Insect pests have been effectively controlled by the applications of chemicals (Jansen, 2000; Zettler and Arthur, 2000) however there is concern about its impact on human health and non-target species (Matthias et al., 2008; Mayo and Werf, 1996). In spite of all these considerable efforts there is still lack of tests of the combined effects of multiple natural factors (biotic and abiotic) on invasive species (Gurevitch and Padilla, 2004). There is also lack of information on the effects of temperature on the competitive and defensive behaviour of invasive species when interacting with recipient taxa. Jumbam et al. (2008) suggest a thorough investigation on 
behavioural changes and their implications. To address this, I have selected one invasive (Linepithema humile) and two native ant species (Monomorium antarcticum and Prolasius advenus) in the face of varying temperature levels.

\section{Linepithema humile}

The Argentine ants (Linepithema humile) are widespread invasive species (Walters and Mackay, 2005). Originating from South America (Wild, 2004), Mediterranean-style habitat with 300-1200 mm rainfall per year is most suitable for this species (Holway et al., 2002). Argentine ant colonies spread and contract both seasonally and annually (Heller et al., 2006). My previous research (chapter 2) also shows that Argentine ants in New Zealand spread slightly in some study sites and contracted in other areas. Their natural rate of spread by budding is between $100 \mathrm{~m}$ and 150m per year (Suarez et al., 2001; Ingram and Gordon, 2003; Krushelnycky et al., 2004). Argentine ant colonies relocate nests and retreat from patches of low food presence (Nonacs \& Soriano, 1998).

Argentine ants are highly efficient competitors partly due to their occupation of multiple nests and nest budding ability (Ingram, 2002), rapid recruitment of workers to food, redistribution of workers among nests, and flexible relocation of brood (Holway and Case, 2000). They are found to hinder seed dispersal by other ant species and expose seeds to predators (Carney et al., 2003), as well as deterring pollination by other insects, ultimately negatively affecting plant's reproductive success (Lach, 2007). Argentine ants not only reduce species richness but also disturb species assemblages in the site of invasion (Sanders et al., 2003).

\section{Monomorium antarcticum and Prolasius advenus}

These two species are native to New Zealand and are distributed throughout New Zealand (Don, 2007). Both species nest mainly in soil under stones, but also occur in and under rotting logs. Habitats exploited by M. antarcticum include native forests and grasslands, pastures and household gardens. P. advenus inhabit native forests. They are found occasionally nesting in the open but still close to the forest edge. Both species have poloygynous (multi-queened) colonies and both are generalists foraging and scavenging for small arthropods (Don, 2007). 


\section{Objective}

In this study, I conducted a laboratory experiment to examine the relative roles of temperature and biotic resistance from native ant species (M. antarcticum and P. advenus) on Argentine competitiveness such as foraging and aggression towards other species. The rationale for selecting these two native ant species is that they are found sympatrically in Wellington (more specifically in Kelburn in close proximity to the botanical gardens) where they have come into contact with Argentine ants. To investigate specific mechanisms affecting biotic interactions I measured speed of walking of all three species, foraging abundance and aggressive behaviour as a function of temperature. I also studied the response of the species L. humile to changes of its own colony sizes and that of the competitor.

\subsection{Methods}

\subsubsection{Establishing Laboratory Colonies.}

I contained ant nests in cylindrical plastic containers of $15 \mathrm{~cm}$ diameter and $12 \mathrm{~cm}$ height. They were half filled with soil. The soil humidity was maintained by adding drops of water throughout the experimental period. Vials of about $20 \mathrm{ml}$ size were half filled with water and plugged with cotton wool, were put in the plastic nests for the ants. Empty containers of the same types as the plastic nests were connected via plastic tubes of diameter $10 \mathrm{~mm}$ to the ant nests to be used as foraging arenas. The ants were fed every two days; rotating between mealworms, fruits or cooked eggs. The foraging containers of two different species were connected by a third empty container via a tube but remained plugged with cotton to be open only when a test of the interaction between two species was in progress (Fig. $5.1 \mathrm{a}$ and b). The nesting and foraging chambers were covered with fine mesh to contain the ants, while the inner side of the empty chamber was painted with "Fluon ${ }^{\mathrm{TM}}$ " to stop ants from escaping when it was left open. Control colonies that never interacted with other species were housed in nesting chambers connected to foraging arenas (Fig. 5.2). 
(a)

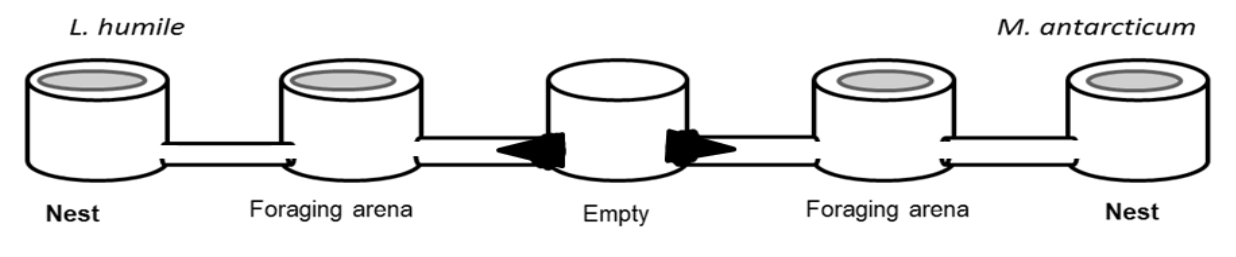

(b)

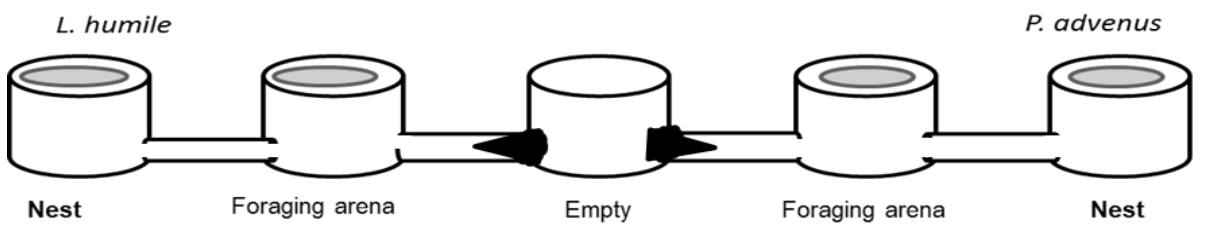

Fig. 5.1. Experimental set-up with middle chamber labelled "empty" for species interaction tests. Access to the central chamber was controlled by temporary removal of cotton wool bungs.

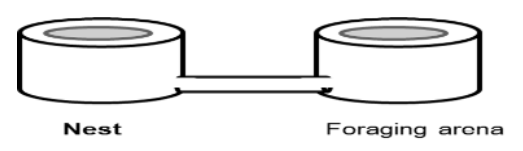

Fig. 5.2. Nest connected to a foraging arena for testing foraging abundance and walking speed change with temperature in the absence of other ant species competitors.

\subsubsection{Sampling and experiment}

I collected ten colonies of $L$. humile and six colonies each of $M$. antarcticum and $P$. advenus (Table 5.1 and 5.2). Eight colonies of L. humile and four colonies of each of the other two species were used to test species interactions (Table 5.1). Two colony sizes of each species, large and small were used to test the effect of temperature change in the absence of any other interacting species (Table 5.2). I collected the whole ant colonies within each nest in the field to avoid any effect of partial removal of ants from a whole colony. I collected the ants when the weather was cold and a bit rainy. This helps to ensure almost all the foraging ants are in their nests. However, I aimed at collecting colonies of different sizes. Colonies of each species were paired up against a colony of a heterospecific. I paired a relatively large colony of one species against a relatively small colony of another species, and vice versa. I also paired two large colonies of different species against each other and two small colonies against each other (Table 1). It was difficult to collect more colonies of equal or similar sizes from the field. Moreover, I was unable to control simultaneous interactions of more than four pairs. Repeated interactions test of one pair at one temperature level was also found impractical. At the end of each interaction the colonies get disturbed and it took about four days to come to their normal foraging behaviour. With many replicates or repeated experiments, testing interactions of four or less pairs at a time would have been time consuming considering the time frame. Therefore, I was unable to present replicates of each pair. 
The experiment was conducted in temperature controlled rooms $\left(+/-0.5^{\circ} \mathrm{C}\right)$. Three explanatory factors were considered; temperature, identity of the heterospecific - $M$. antarcticum and $P$. advenus, and the relative size of the two colonies. Five temperature levels were employed from $12^{\circ} \mathrm{C}$ to $20^{\circ} \mathrm{C}$, in two degree increments. The two native ant species, M. antarcticum and $P$. advenus were collected from Wellington (Kaitoke) and the Argentine ants from Hastings. I chose these places for collection based on the abundant presence of each ant species, though they are all found in Hastings. Before the start of any experiment, ant colonies were allowed to acclimatize for a week at each temperature level. Pairs of interacting colonies were kept unchanged throughout all the different temperature levels during tests of interaction changes with temperature i.e. each specific pairing of colonies was maintained throughout all temperature levels, moving from $20^{\circ} \mathrm{C}$ to $16^{\circ} \mathrm{C}$ to $12^{\circ} \mathrm{C}$, back to $14^{\circ} \mathrm{C}$ and concluding at $18^{\circ} \mathrm{C}$. Colony size was estimated as high or low at the start of experiment and measured more precisely at the end of the experiment. Estimation was taken visually from their nest and foraging abundance before the start of experiment. At the end of the experiment, each colony was put in a white plastic box to be photographed. To move the colonies into the plastic boxes the nests were connected to a white box with plastic tubes of diameter $10 \mathrm{~mm}$. The bases of the plastic boxes were covered with aluminium foil so that the ants could move underneath. Then slowly drops of water were put into the nests. To avoid the water all the ants move out into the plastic boxes.

Table 5.1. Description of the ant colonies used in species-interaction pairings. Numbers are rounded to the nearest ten. No interaction between high colony size of $L$. humile and low $P$. advenus was tested. The first row, interaction between $L$. humile and $P$. advenus was estimated to be high $L$. humile against low $P$. advenus; however the actual count proved it high against high. In the last row although higher than the matching colony size of L. humile, P. advenus is defined as 'low' as it was difficult to sustain an interacting colony below this size.

\begin{tabular}{cccllc}
\multicolumn{2}{c}{$\begin{array}{l}\text { R. humile against } \\
\text { M. antarcticum }\end{array}$} & $\begin{array}{l}\text { (L.hum/ } \\
\text { M.ant) }\end{array}$ & L. humile against P. advenus & $\begin{array}{c}\text { Ratio } \\
\text { L.hum/ } \\
\text { P.adv }\end{array}$ \\
\hline High (800) & Low (550) & 1.5 & High (800) & High (830) & 1 \\
Low (320) & High (510) & 0.6 & Low (620) & High (2820) & 0.2 \\
High (1010) & High (1170) & 0.9 & Low (1300) & High (1830) & 0.7 \\
Low (550) & Low (600) & 0.9 & Low (230) & Low (670) & 0.3 \\
\hline
\end{tabular}

Table 5.2. Colony sizes of non-interacting groups.

\begin{tabular}{cccc} 
Colony & L. humile & M. antarcticum & P. advenus \\
\hline High & 650 & 710 & 2310 \\
Low & 380 & 510 & 930 \\
\hline
\end{tabular}




\subsubsection{Non-interacting colonies Daily foraging patterns in response to temperature change}

Two non-interacting colonies of different sizes, from each species were maintained (control colonies). To identify diel patterns in foraging activity I initially counted the foragers in the foraging chamber every hour between $9 \mathrm{am}$ and $5 \mathrm{pm}$ over a four day period. I identified the period between $10 \mathrm{am}$ and $1 \mathrm{pm}$ as the time of peak activity for all species. Number of foragers at each temperature level of each species was recorded at their peak foraging activity (10am to $1 \mathrm{pm})$ every hour for four days.

\section{Speed of walking change with temperature}

The walking speed of ants was measured from the control colonies by recording the distance travelled over a 2 second interval as they entered the foraging arena. Data were recorded only if the ants walked continuously for 2 seconds without stopping. If ants moved erratically or made brief stops before 2 seconds, I excluded the data. Distance travelled was measured in millimetres by placing a ruler under the transparent floor of the foraging container. In each temperature level, measurement of ant speeds repeated 20 times randomly without aiming at any specific ant. Their speeds were measured at five different temperature levels, from $12^{\circ} \mathrm{C}$ to $20^{\circ} \mathrm{C}$, in two degree increments.

\subsubsection{Species Interactions}

Four measures of behavioural interactions were assessed: abundance, fighting, invasion and biting. As access to the central interaction chamber was opened, the number of ants of each species present in the central arena was recorded after 5 minutes at the beginning and every 9 minutes thereafter until one of the species was displaced by the other (this usually took about 90 minutes). At the same time I counted the number of "fights" occurring in 1 minute interval after 5 minutes of interaction, and then for 1 minute at every nine-minute interval. Fights were defined as aggressive interactions where two (or more) ants were locked in prolonged direct contact, mandibles holding on to the legs or antennae of the other individual. I also counted the number of ants that had crossed into the foraging chamber of the opposite species every nine minutes which I called "invasion". This behaviour was tested at all five temperature levels stated above and with varying colony sizes.

I also counted the number of bites per minute separately from number of fights. Argentine ants behaved differently at the different stages of interaction with the other species. At the beginning, when they first encountered another ant species they attacked and maintained a grip on the legs of the other species ("fighting"). However, when they were about to displace the 
other species from the interaction chamber they bit and released repeatedly so as to urge them out of the chamber (="biting"). I counted the number of bites per minute for about 20 minutes at $20^{\circ} \mathrm{C}, 16^{\circ} \mathrm{C}$ and $12^{\circ} \mathrm{C}$ to evaluate whether the rate of biting changed with temperature. Number of bites was recorded as the sum of bites and releases of all ants every minute which I recorded for 20 minutes long. The behaviour of biting and releasing was manifested towards the end of the interaction when the Argentine ants start to defeat the other species.

\subsubsection{Data Analysis}

I employed different methods of analysis depending on the data type available. I used one-way ANOVA to test change in numbers of foragers and change in walking speed as a function of temperature. Temperature was taken as categorical variable with five levels $12^{\circ} \mathrm{C}, 14^{\circ} \mathrm{C}, 16^{\circ} \mathrm{C}$, $18^{\circ} \mathrm{C}$ and $20^{\circ} \mathrm{C}$ respectively. I preferred ANOVA over regression as my objective was to evaluate the effect of changing temperature, without pre-supposing a linear trend. Where global significance was detected a Tukey HSD post-hoc test was used to compare between specific temperature levels. Nonetheless, in most cases the effect of temperature was a monotonic increase or decrease, and therefore to test the effect of multiple-factors (temperature, colony size and identity of species) I fitted a Generalized Linear Model (GLM), treating temperature as a continuous variable and assuming a Poisson distribution error structure (Crawley, 2007). Additionally, I used classification trees to evaluate the level of importance of each explanatory variable. Regression trees identify key break points in variables as opposed to linear trends. Analyses were performed using R version 2.11.1. I also used Statistica version 7.1 for graph building and SPSS statistics 19 to display interactive effect of temperature and colony size.

Data transformation: Analysis of variance and GLMs are considered robust to deviations from their statistical assumptions (Zar, 1974). Nonetheless, data that showed significant deviations from a normal or Poisson distribution according to a Shapiro-Wilk test, were transformed to better fit the assumptions of the ANOVA or GLM, using a logarithmic or square-root transformation (Zar, 1974), (Table 5.3). Data that remained non-normal or heterogenic after transformation were analysed using nonparametric methods (Wilcoxon ranksum test). Although I transformed data using different methods for different species, the comparison of interest was within a species, across different temperature levels. That is, there was no intention of comparing foraging abundances or differences in walking speed between two different, non-interacting species. In displaying the results graphically, I used line graphs with error bars generated from the raw data. 
Table 5.3. Methods of data transformation. Data not meeting the statistical assumptions (normality and homogeneity) were transformed using appropriate methods.

\begin{tabular}{|c|c|c|c|}
\hline Data type & species & method of transformation & comment \\
\hline $\begin{array}{l}\text { Foraging abundance of } \\
\text { non-interacting colonies }\end{array}$ & $\begin{array}{l}\text { L. humile } \\
\text { M. antarcticum } \\
\text { P. advenus }\end{array}$ & $\begin{array}{l}\text { square root transformed } \\
\text { double log transformed } \\
\text { no transformation can correct it }\end{array}$ & \multirow{3}{*}{$\begin{array}{l}\text { data unable to } \\
\text { be corrected by } \\
\text { transformation } \\
\text { were analysed } \\
\text { using non- } \\
\text { parametric } \\
\text { methods }\end{array}$} \\
\hline $\begin{array}{l}\text { Walking speed during } \\
\text { foraging }\end{array}$ & $\begin{array}{l}\text { L. humile } \\
\text { M. antarcticum } \\
\text { P. advenus }\end{array}$ & $\begin{array}{l}\text { square root transformed } \\
\text { square root transformed } \\
\text { no transformation can correct it }\end{array}$ & \\
\hline Rate of biting & L. humile & no transformation can correct it & \\
\hline
\end{tabular}

\subsection{Results}

\subsubsection{Foraging abundance (non-interacting colonies)}

Foraging abundances of all three species, L. humile, M. antarcticum and P. advenus were tested at different temperature levels in the absence of other species' interference. Forager abundance of $L$. humile dropped significantly when transferred from $20^{\circ} \mathrm{C}$ to $18^{\circ} \mathrm{C}$ (TukeyHSD, $\mathrm{p}<0.001$ ). Decline in temperature from $18^{\circ} \mathrm{C}$ to $16^{\circ} \mathrm{C}$ did not show any significant difference. At temperatures below $16^{\circ} \mathrm{C}$ they significantly decreased their foraging abundance (TukeyHSD, $\mathrm{p}<0.001)$. However, the higher colony size did not significantly respond to the drop in temperature from $14^{\circ} \mathrm{C}$ to $12^{\circ} \mathrm{C}$ (Fig. $5.3 \mathrm{~A}$ ). Monomorium antarcticum forager abundance was greatest at abundance $20^{\circ} \mathrm{C}$ and number of foragers dropped significantly (Tukey HSD, $\mathrm{p}<0.05)$ when the temperature was lowered to $18^{\circ} \mathrm{C}$. There was no significant difference in number of foragers of the higher colony size between the temperatures $18^{\circ} \mathrm{C}$ and $16^{\circ} \mathrm{C}, 16^{\circ} \mathrm{C}$ and $14^{\circ} \mathrm{C}$, and $14^{\circ} \mathrm{C}$ and $12^{\circ} \mathrm{C}$. But, lowering temperature to $12^{\circ} \mathrm{C}$ showed a significant reduction compared to the number of foragers at $16^{\circ} \mathrm{C}, 18^{\circ} \mathrm{C}$, and $20^{\circ} \mathrm{C}$ (Tukey HSD, $\mathrm{p}<0.05$, Fig. $5.3 \mathrm{~B}$ ). Unlike these two species, foraging abundances of the higher colony size of $P$. advenus were found to decrease towards $20^{\circ} \mathrm{C}$ compared to foraging at $16^{\circ} \mathrm{C}$ and $18^{\circ} \mathrm{C}$, although not significantly different (Tukey HSD, p=0.28, Fig. $5.3 \mathrm{C}$ ). Their foraging abundance at $14^{\circ} \mathrm{C}$ was smallest and significantly different from all the levels of temperature, $20^{\circ} \mathrm{C}, 18^{\circ} \mathrm{C}$ and $16^{\circ} \mathrm{C}$ (Tukey HSD, $\mathrm{p}<0.05$ ). Similarly their foraging abundance was the smallest at $12^{\circ} \mathrm{C}$ and was significantly different from all levels of temperature tested (Tukey HSD, $p<0.001$ ) as in Fig. 5.3 C. The responses of all the lower colony sizes of all three species also varied with temperature. Their patterns of responses were similar to the higher colony size of their respective species. 

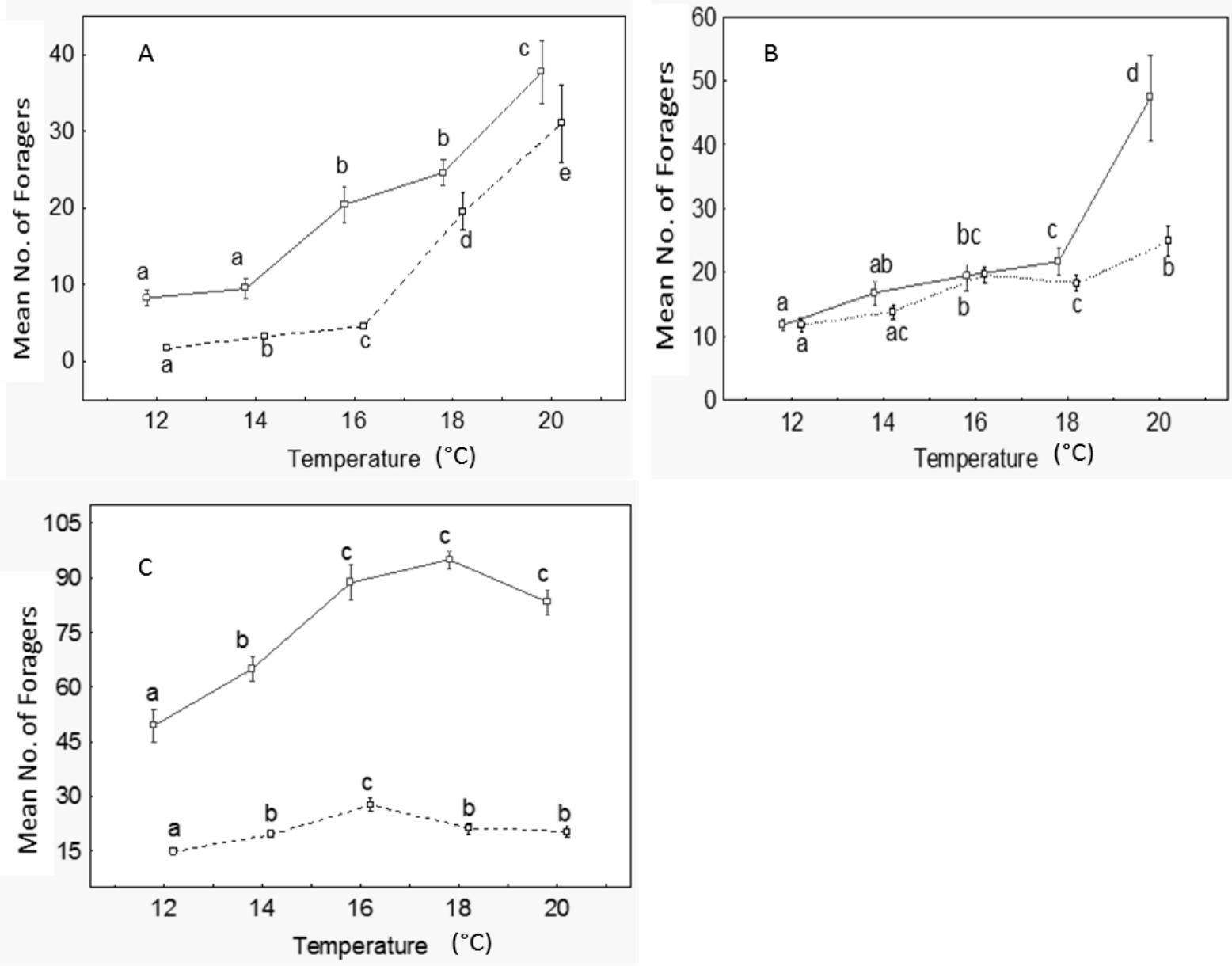

Fig. 5.3. Graphs show mean number of foragers in the foraging chamber \pm SE. Bars sharing the same letter do not have significant difference. Comparison is within a colony. Graphs with smooth curves represent the higher colony sizes' foraging abundances and the broken for lower colony sizes of A) L. humile, B) M. antarcticum and C) P. advenus. $\mathrm{n}=15$ counts of numbers of foragers every hour between 10am and $1 \mathrm{pm}$.

\subsubsection{Speed of walking}

Raising the temperature from $12^{\circ} \mathrm{C}$ to $20^{\circ} \mathrm{C}$ significantly increased the walking speed of all three ant species. This change was most pronounced for the invasive ant (L. humile), which increased their average walking speed over three-fold from approximately $6 \mathrm{~mm} / \mathrm{s}$ at $12^{\circ} \mathrm{C}$ to $20 \mathrm{~mm} / \mathrm{s}$ at $20^{\circ} \mathrm{C}$ (Tukey HSD, $<<0.001$, Fig.5.4). The speed of M. antarcticum more than doubled from $5 \mathrm{~mm} / \mathrm{s}$ at $12^{\circ} \mathrm{C}$ and $14^{\circ} \mathrm{C}$ to $11 \mathrm{~mm} / \mathrm{s}$ at $20^{\circ} \mathrm{C}$ (Tukey HSD, $\mathrm{p}<0.001$ ). In the case of $P$. advenus, there was a significant change in walking speed when the temperature was raised from $12^{\circ} \mathrm{C}$ to $14^{\circ} \mathrm{C}$, (Wilcoxon rank-sum statistic: $\mathrm{W}=0, \mathrm{p}<0.001$, Fig. 5.4), but at temperatures $14^{\circ} \mathrm{C}$ and above walking speed remained more or less constant at about 10 $12 \mathrm{~mm} / \mathrm{s}$. 


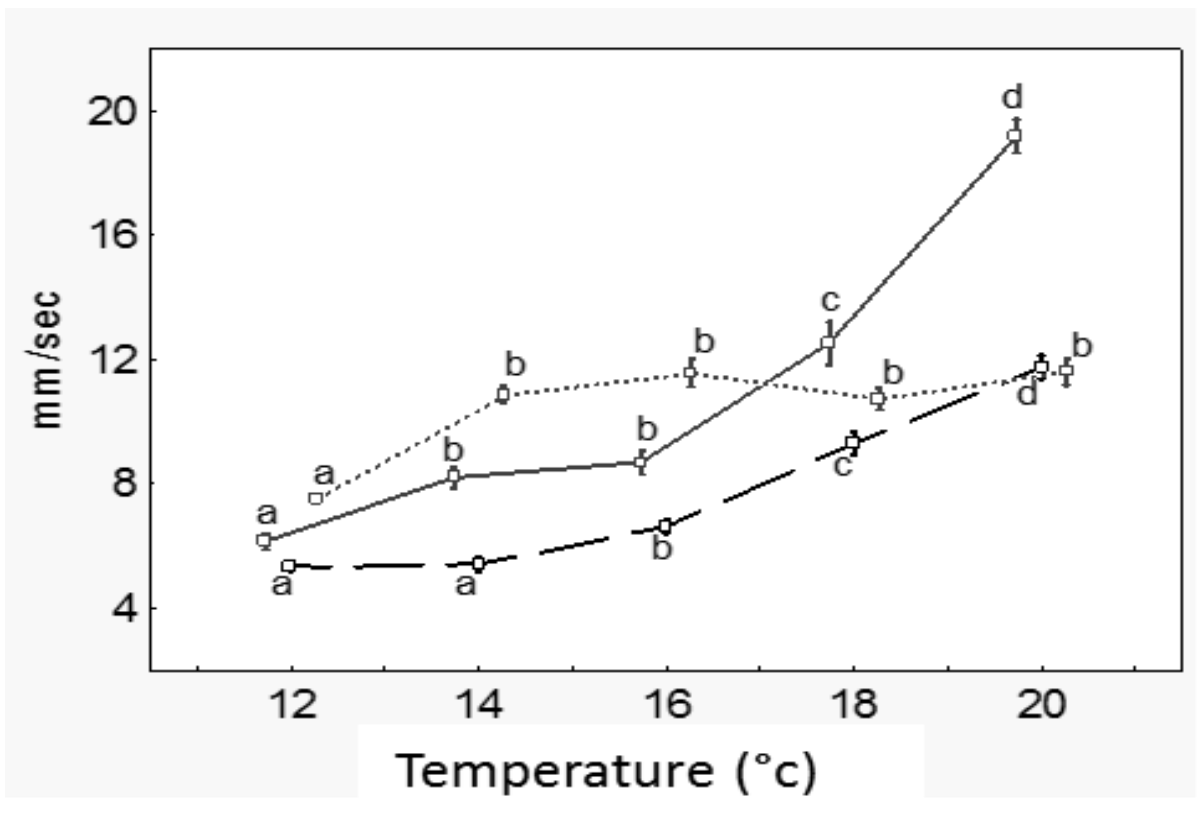

Fig. 5.4. Walking speed changes of ants with temperature (mean \pm SE). $n=20$ (speed of 20 individuals measured). Solid curve $=L$. humile, dashed curve is $M$. antarcticum and dotted curve is $P$. advenus. Comparison is within a species. Bars sharing the same letter are not significantly different $(\mathrm{P}>0.05)$.

\subsubsection{Species' interactions}

\subsubsection{Interactions between $L$. humile and $M$. antarcticum: foraging, fighting, attack rate} and invading

During the initial period of interaction between L. humile and M. antarcticum, both species tend to increase their foraging activity. However, at a later stage one species typically dominates and displaces the other species (e.g. Fig. 5.5). Fighting aggressively, the larger colony of $L$. humile displaced the smaller colony of $M$. antarcticum from the central interaction arena at temperature levels $20^{\circ} \mathrm{C}, 18^{\circ} \mathrm{C}$ and $16^{\circ} \mathrm{C}$. After displacing them L. humile started to cross into the foraging arena of $M$. antarcticum. At $14^{\circ} \mathrm{C}$ the two species co-occurred for a long period in the central chamber with fewer fighting interactions. At the lowest temperature $\left(12^{\circ} \mathrm{C}\right)$ the effect was reversed, i.e. L. humile were displaced by M. antarcticum (Fig. 5.6A). When $L$. humile ants were set to interact with an equal or greater colony size of $M$. antarcticum, they were displaced by M. antarcticum at all temperature levels (Fig. 5.6B and C). There was low interaction when both species were kept at low colony sizes and L. humile were able to displace the other species at $20^{\circ} \mathrm{C}$ (Fig. 5.6D). Aggression of L. humile measured in terms of biting rate changed significantly with temperature (Wilcoxon rank-sum test: $\mathrm{W}=0$ $\mathrm{p}<0.01$, Fig. 5.8). There was no aggression at $12^{\circ} \mathrm{C}$ while it was rare and mild at $14^{\circ} \mathrm{C}$ and did not have an effect on the foraging of the other species (Fig. 5.7 \& Fig. 5.8). There was a significant effect of temperature (GLM: $\beta=0.78, z=3.89, \mathrm{p}<0.01)$ and colony size (GLM: 
$\beta=9.51, z=2.36, p<0.05)$ on the foraging abundance and fighting success of L. humile. There was also a significant interactive effect of temperature and colony size on the foraging activity of L. humile (GLM: $\beta=9.5068, z=2.362 \mathrm{p}<0.05$, Fig. 5.9). Temperature had an important influence on the performance of $L$. humile. In a regression tree analysis, temperature and colony size of $L$. humile were the most important factors affecting foraging density of $L$. humile. Relative to the temperature and colony size of L. humile, colony size of M. antarcticum was significant but of less importance according to regression trees analysis (see Fig. 5.10 and Table 5.4 for further detail).

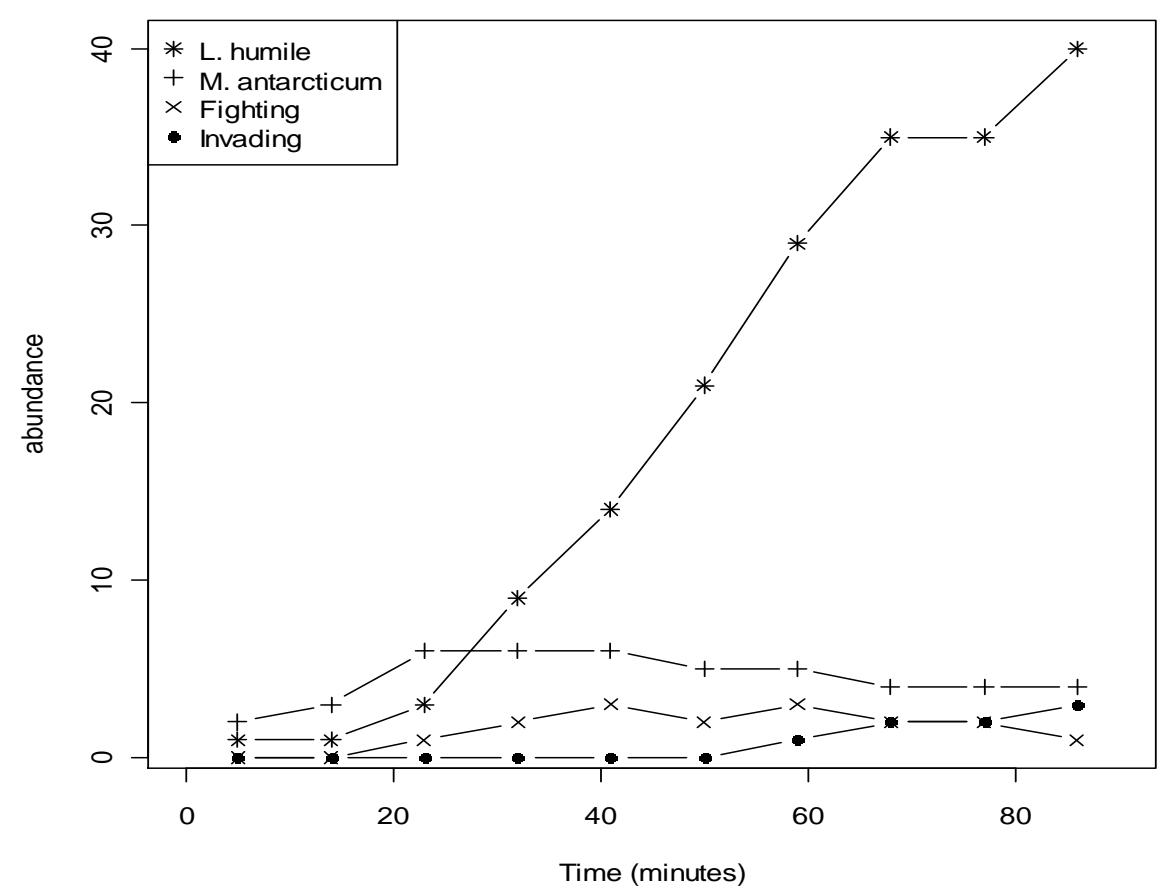

Fig. 5.5. Sample of interaction progress. Abundance and number of fights were measured in the central chamber. Invading refers to the number of L. humile crossing into the foraging arena of $M$. antarcticum. Interaction observed at $18^{\circ} \mathrm{C}$ when the colony size of L. humile was 800 and that of $M$. antarcticum was 550. 

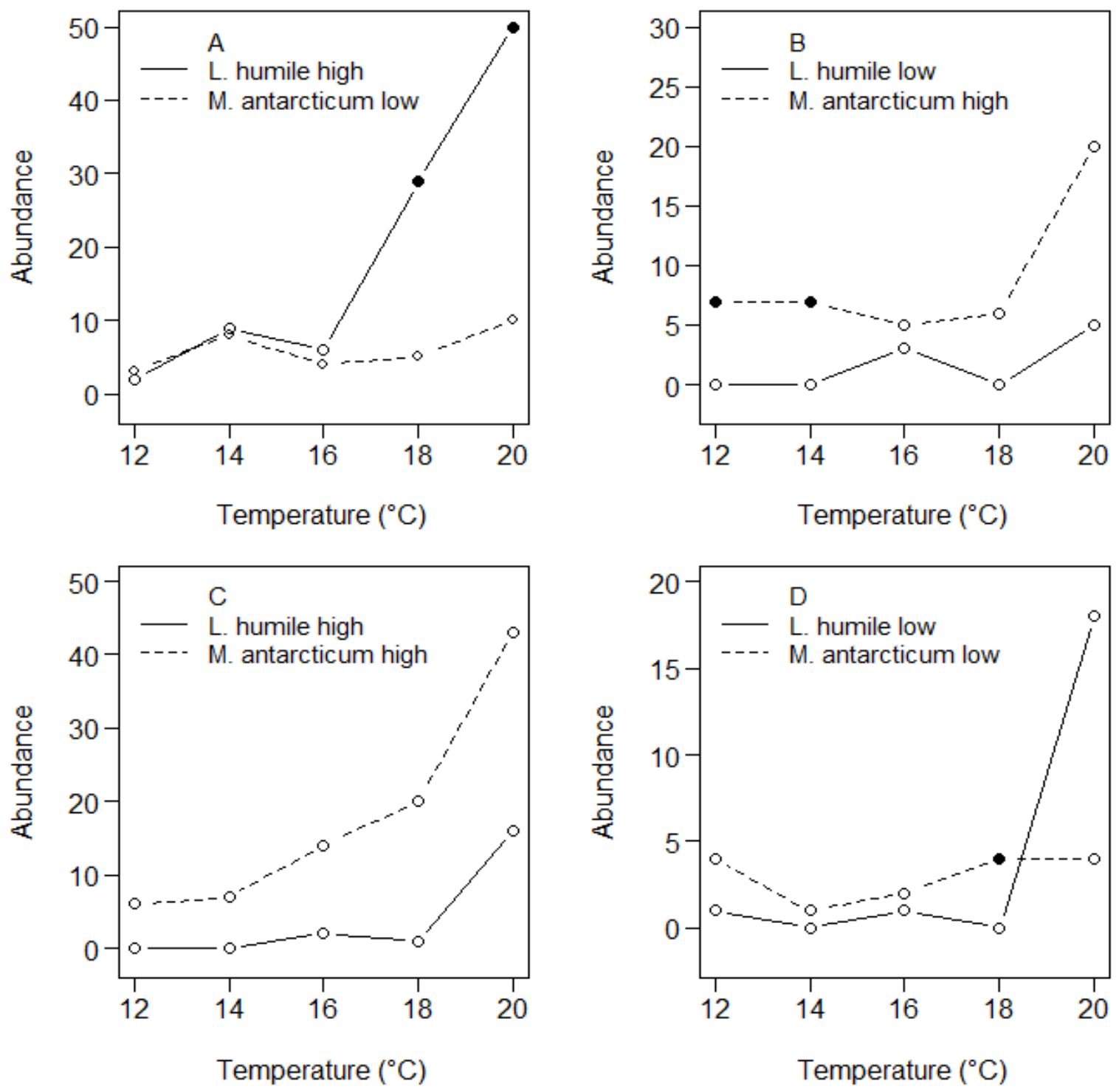

Fig. 5.6. Interaction between $L$. humile and M. antracticum at different colony sizes and temperature levels. Black points refer to crossing into foraging arena of the other species termed as 'invading'. Abundance of each species was recorded (no replication and thus no SE) just before the subordinate species starts to be disrupted in its nest. At this stage interaction test stops as both species were needed for subsequent test at another temperature level.

Table 5.4. Dominant species in the interaction chamber at different temperatures and with pairings of different size colonies. $*=L$. humile numerically dominant by $5: 1$, $\#=M$. antarcticum numerically dominant by $5: 1$.

\begin{tabular}{lccccc} 
& \multicolumn{5}{c}{ Temperature $\left({ }^{\circ} \mathrm{C}\right)$} \\
\cline { 2 - 6 } & 12 & 14 & 16 & 18 & 20 \\
Relative colony sizes of & & & & & \\
L.humile andM.antarcticum & M.ant & L.hum & L.hum & L.hum * $^{*}$ & L.hum \\
L.hum high vs M.ant low & M.ant\# & M.ant\# & M.ant\# & M.ant\# & M.ant\# \\
L.hum high vs M.ant high & M.ant\# & M.ant\# & M.ant\# & M.ant\# & L.hum* \\
L.hum low vs M.ant low & M.ant\# & M.ant\# & M.ant & M.ant\# & M.ant\# \\
L.hum low vs M.ant high & & & & & \\
\hline
\end{tabular}




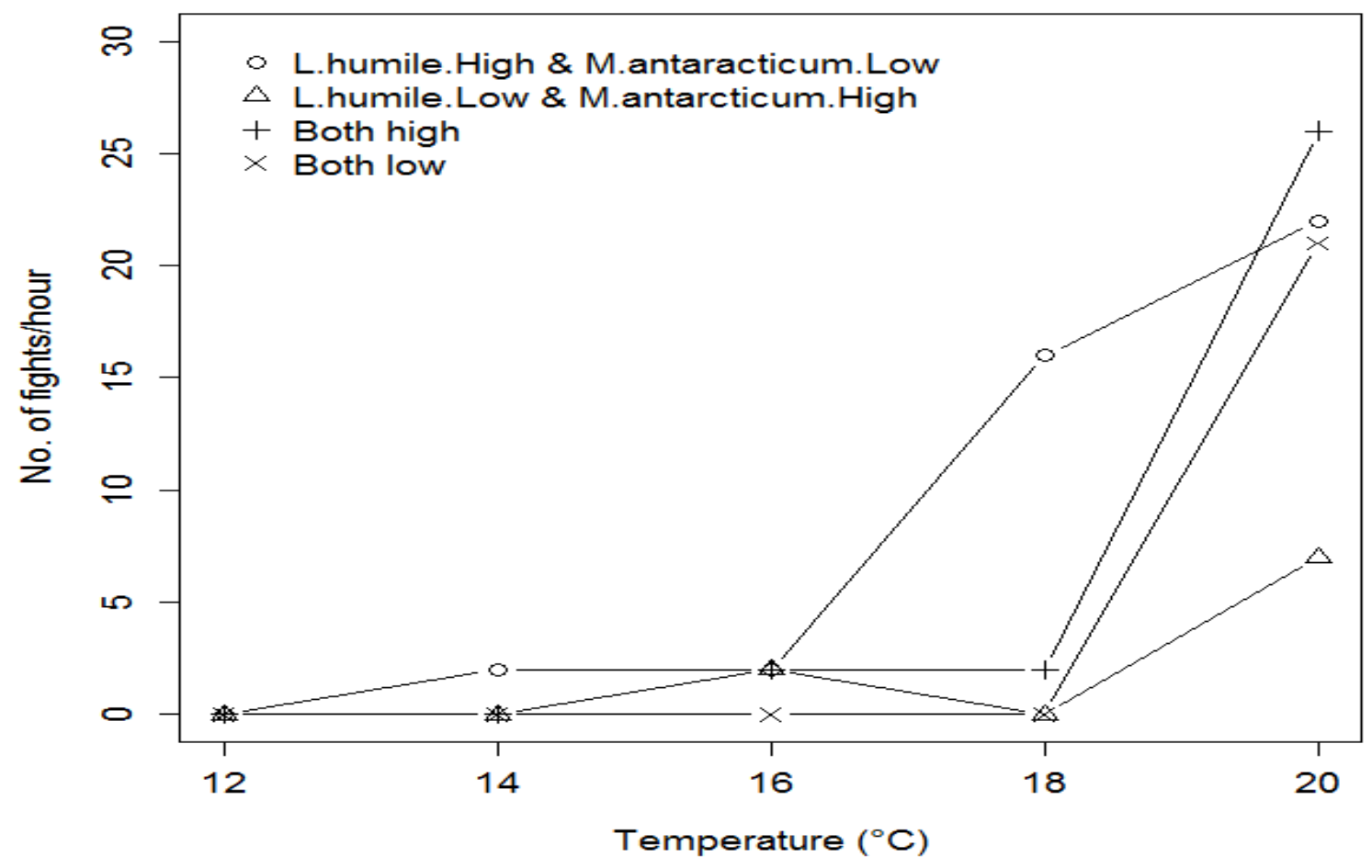

Fig. 5.7. Intensity of fighting change with temperature: Fighting was recorded for an hour from the start of interaction although interaction continued for extra half an hour in some tests. Interaction after an hour is mostly biting and not fighting. As one species loses the fight the other starts to bite and chase.

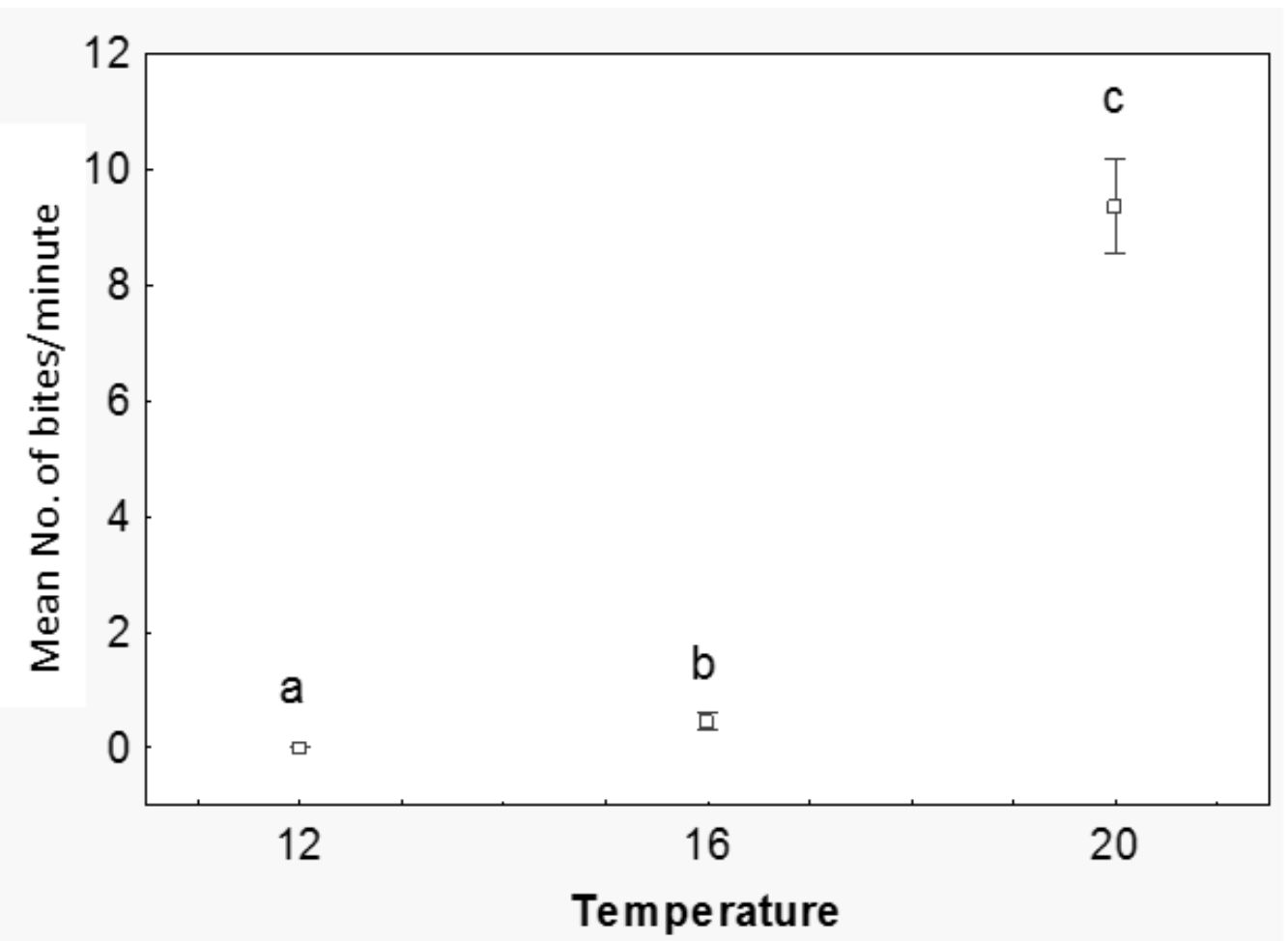

Fig. 5.8. Biting (attack) rate of $L$. humile at different temperature levels (mean $\pm \mathrm{SE}$ ). The interaction was between high $L$. humile and low M. antarcticum. Each observation was for 1 minute, $\mathrm{n}=20$ per temperature. 


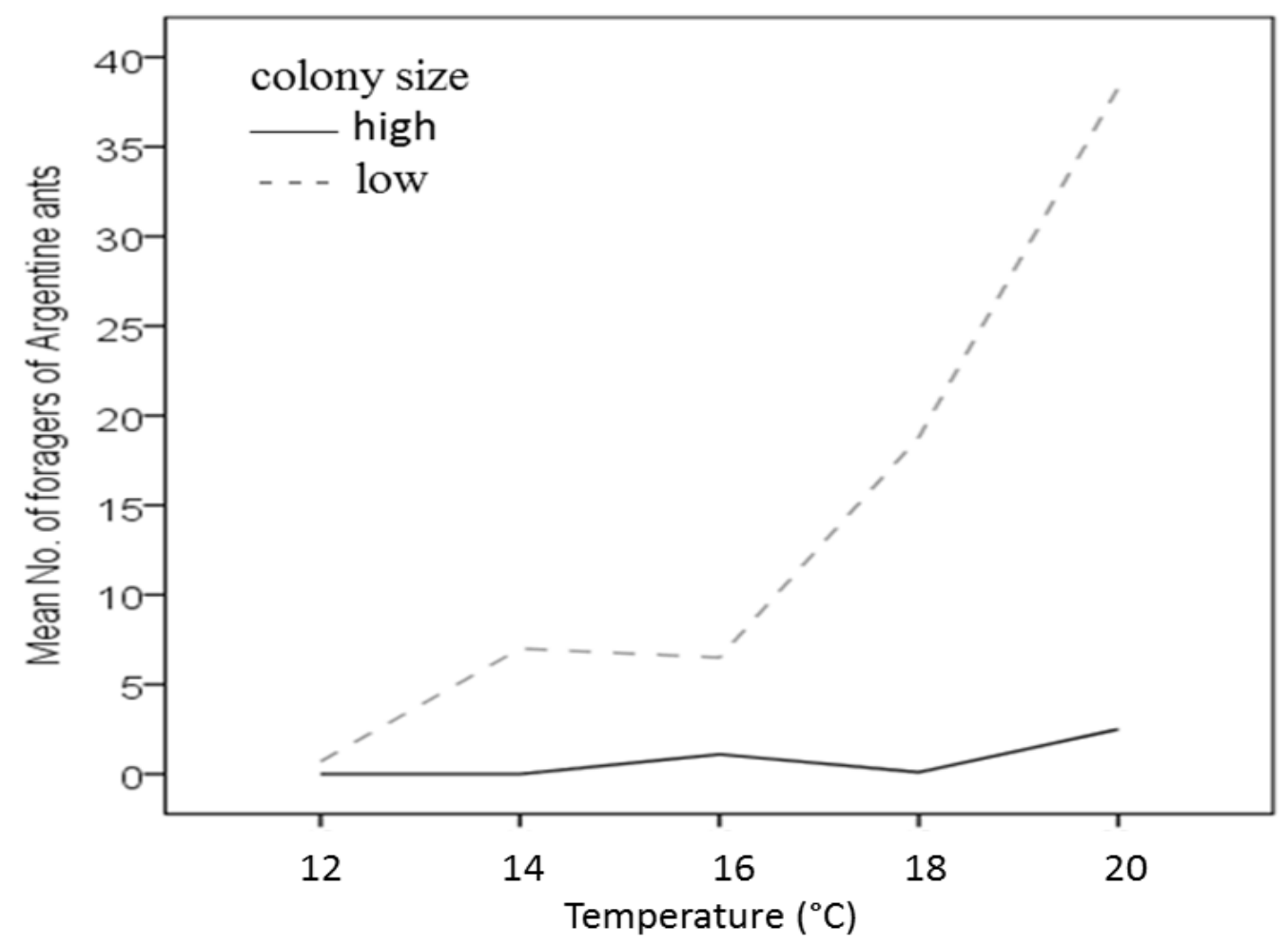

Fig. 5.9. Interactive effect of temperature and colony size of $M$. antarcticum on the mean foraging abundance of $L$. humile $(\mathrm{n}=10)$. $\mathrm{Y}$-axis is foraging abundance of L. humile. When lines are parallel there is no interactive effect. Significance of interactive effect is detailed under the subtitle "5.3.3 Species' Interactions."

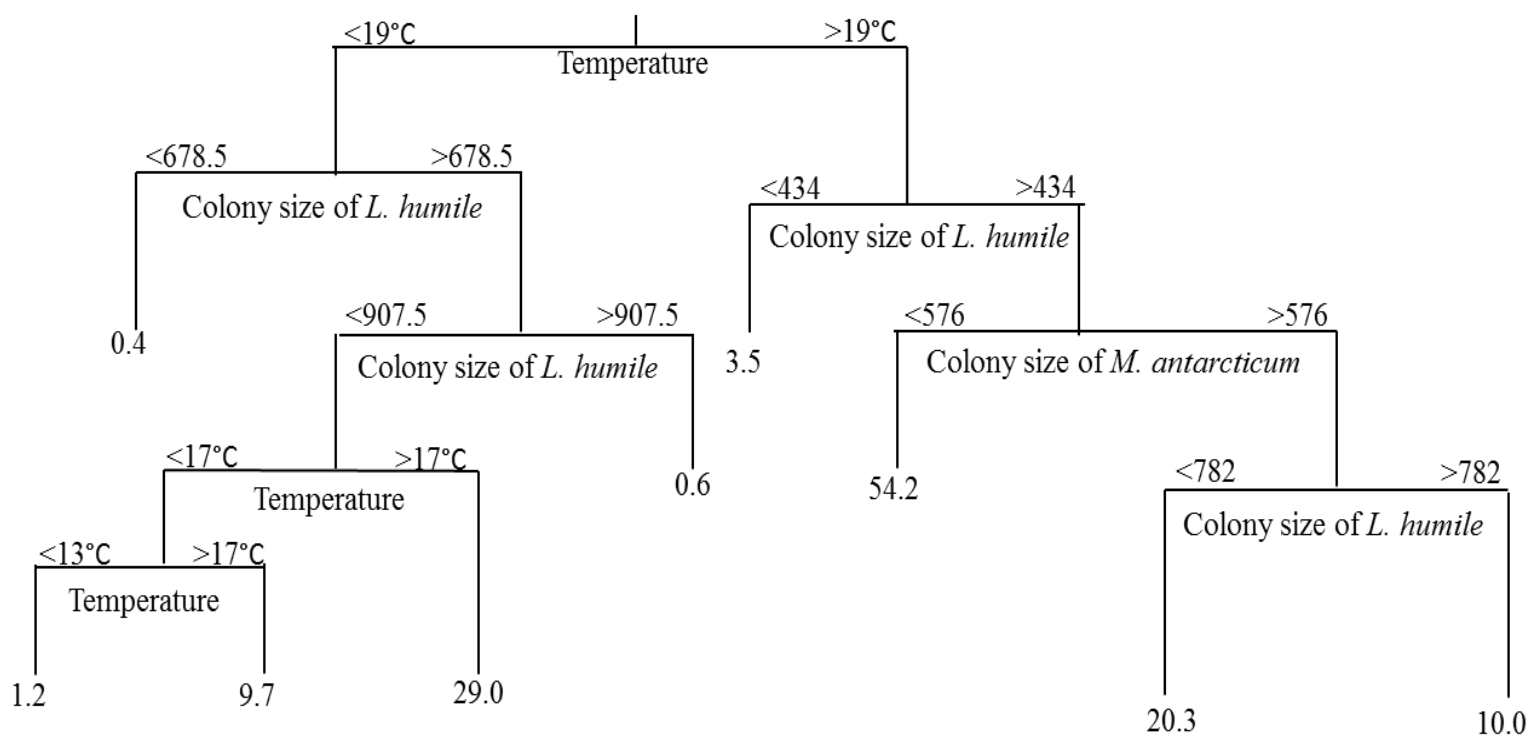

Fig. 5.10. Regression tree analysis of the foraging performance of L. humile in the face of multiple factors: temperature, its own colony size, and colony size of $M$. antarcticum. The most important factor is placed on the top of the diagram and the next after that. The model divides each explanatory factor at the threshold that best separates the responses variable into homogeneous sub-groups: relatively higher numbers of L. humile to the right and relatively fewer to the left. Unbranched limb means no significant explanatory variable and the value at the tips is the mean expected number of foraging $L$. humile. 


\subsubsection{Interaction between $L$. humile and $P$. advenus: Foraging, Fighting and Invading}

Foraging abundances of both species increased in the central chamber during the initial interaction, but as the interaction continued forager abundance of one of the species typically declined and is eventually displaced by the other species. The large colony size of L. humile displaced the similarly large-sized colony of $P$. advenus at temperature levels $20^{\circ} \mathrm{C}$ and $18^{\circ} \mathrm{C}$, while at $16-12^{\circ} \mathrm{C}$ P. advenus displaced L. humile (Fig. 5.11A). Another pair of colonies, $L$. humile (1300 individuals) against $P$. advenus (1830 individuals) showed similar result. Linepithema humile displaced P. advenus at temperature levels $20^{\circ} \mathrm{C}$ and $18^{\circ} \mathrm{C}$, but after changing temperature levels to $16^{\circ} \mathrm{C}, 14^{\circ} \mathrm{C}$ and $12^{\circ} \mathrm{C}$ L. humile species were displaced by $P$. advenus species (Fig. 5.11C). When a large colony of $P$. advenus (2820 individuals) was paired with a small L. humile colony (620), P. advenus species dominated the interaction chamber at all temperature levels tested $\left(20^{\circ} \mathrm{C}, 18^{\circ} \mathrm{C}, 16^{\circ} \mathrm{C}, 14^{\circ} \mathrm{C}\right.$ and $\left.12^{\circ} \mathrm{C}\right)$ as shown in Fig. 5.11B. In the interaction between the two small colonies (low versus low) L. humile displaced P. advenus at temperature levels $20^{\circ} \mathrm{C}$ and $18^{\circ} \mathrm{C}$. However, lowering temperature to $16^{\circ} \mathrm{C}, 14^{\circ} \mathrm{C}$ and $12^{\circ} \mathrm{C}$ confined both species to their foraging arena. They did not come to the middle chamber where the interaction was tested (Fig. 5.11D). Their aggressive behaviour changed with temperature significantly (GLM: $\beta=3.75, z=4.83, p<0.05$, Fig. 5.12). Their foraging abundances were found to be affected significantly by all the three factors: temperature (GLM: $\beta=0.45, z=9.43$, $\mathrm{p}<0.001$ ), colony size of $P$. advenus (GLM: $\beta=-0.4, \mathrm{z}=-2.20, \mathrm{p}<0.05)$ and colony size of $L$. humile (GLM: $\beta=-2.17, \mathrm{z}=-7.42, \mathrm{p}<0.001$ ). I did not find any significant interactive effect of temperature and colony size on the foraging behaviour of L. humile. Temperature had the most important influence in the performance of $L$. humile and colony size of L. humile was the second most influential factor in contributing to the foraging abundance of $L$. humile according to regression trees analysis (see Fig. 5.13 and Table 5.5 for further detail). 

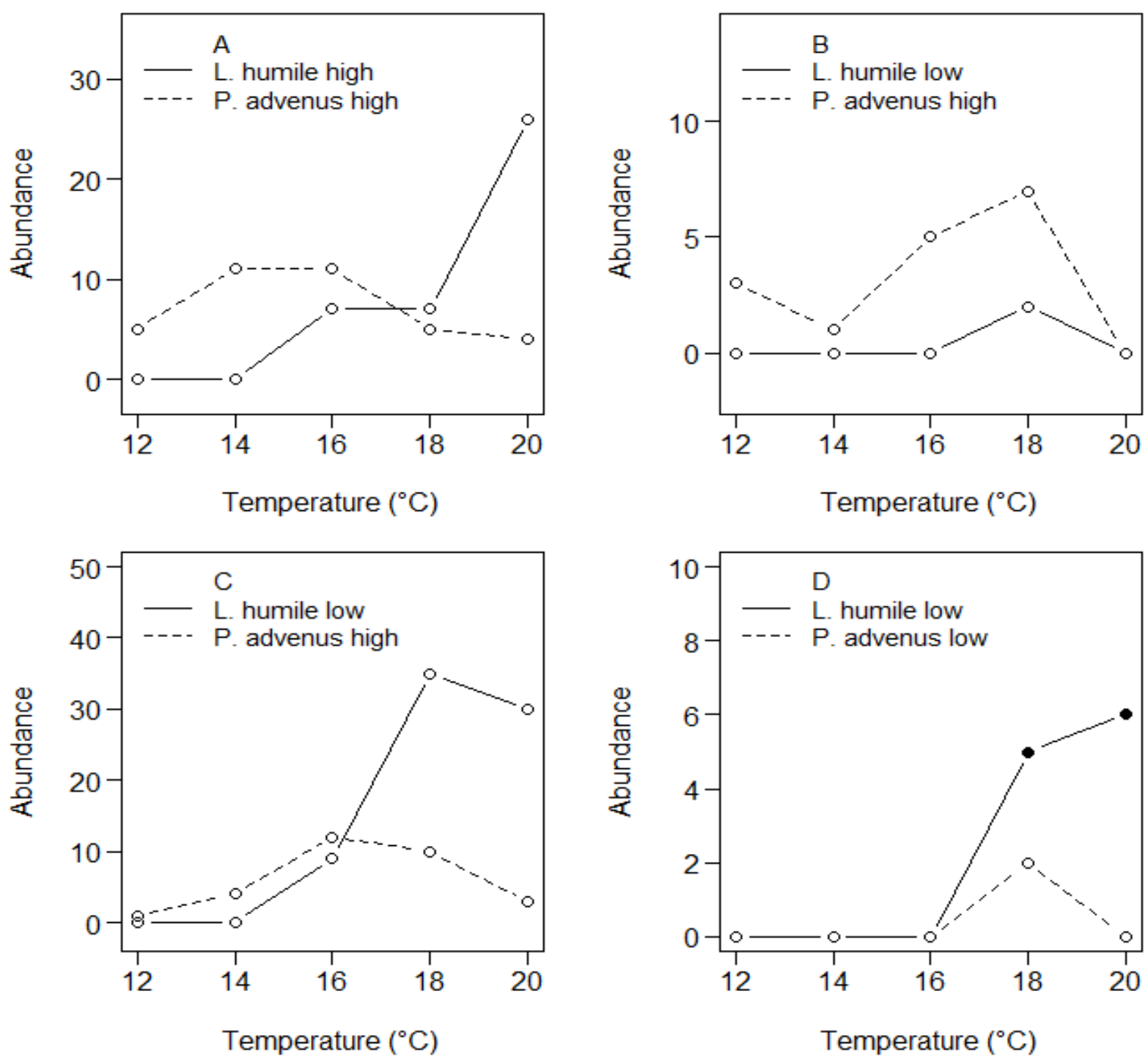

Fig. 5.11. Interaction between $L$. humile and $P$. advenus at different colony sizes and temperature levels. Black points refer to crossing into foraging arena of the other species termed as 'invading'. Abundance of each species was recorded (no replication and thus no SE) just before the subordinate species starts to be disrupted in its nest. At this stage interaction test stops as both species were needed for subsequent tests at another temperature level.

Table 5.5. Dominant species in the interaction chamber at different temperatures and with pairings of different size colonies. $*=$ L. humile numerically dominant by $5: 1, \#=$ P.advenus numerically dominant by 5:1. 0:0=both absent in foraging chamber. Colony sizes in row two L.huminle low (620) vs $P$. advenus high (2820) and row three $L$. humile low (1300) vs $P$. advenus high (1830).

\begin{tabular}{lccccc} 
& \multicolumn{5}{c}{ Temperature $\left({ }^{\circ} \mathrm{C}\right)$} \\
\cline { 2 - 6 } Relative colony sizes of & 12 & 14 & 16 & 18 & 20 \\
L. humile and P. advenus & & & & & \\
\hline L.hum high vs P.adv high & P.adv\# & P.adv\# & P.adv & L.hum & L.hum* \\
L.hum low vs P.adv high & P.adv\# & P.adv\# & P.adv & P.adv & P.adv \\
L.hum low vs P.adv high & $P . a d v$ & P.adv\# & P.adv & L.hum* & L.hum* \\
L.hum low vs P.adv low & $0: 0$ & $0: 0$ & $0: 0$ & L.hum & L.hum \\
\hline
\end{tabular}




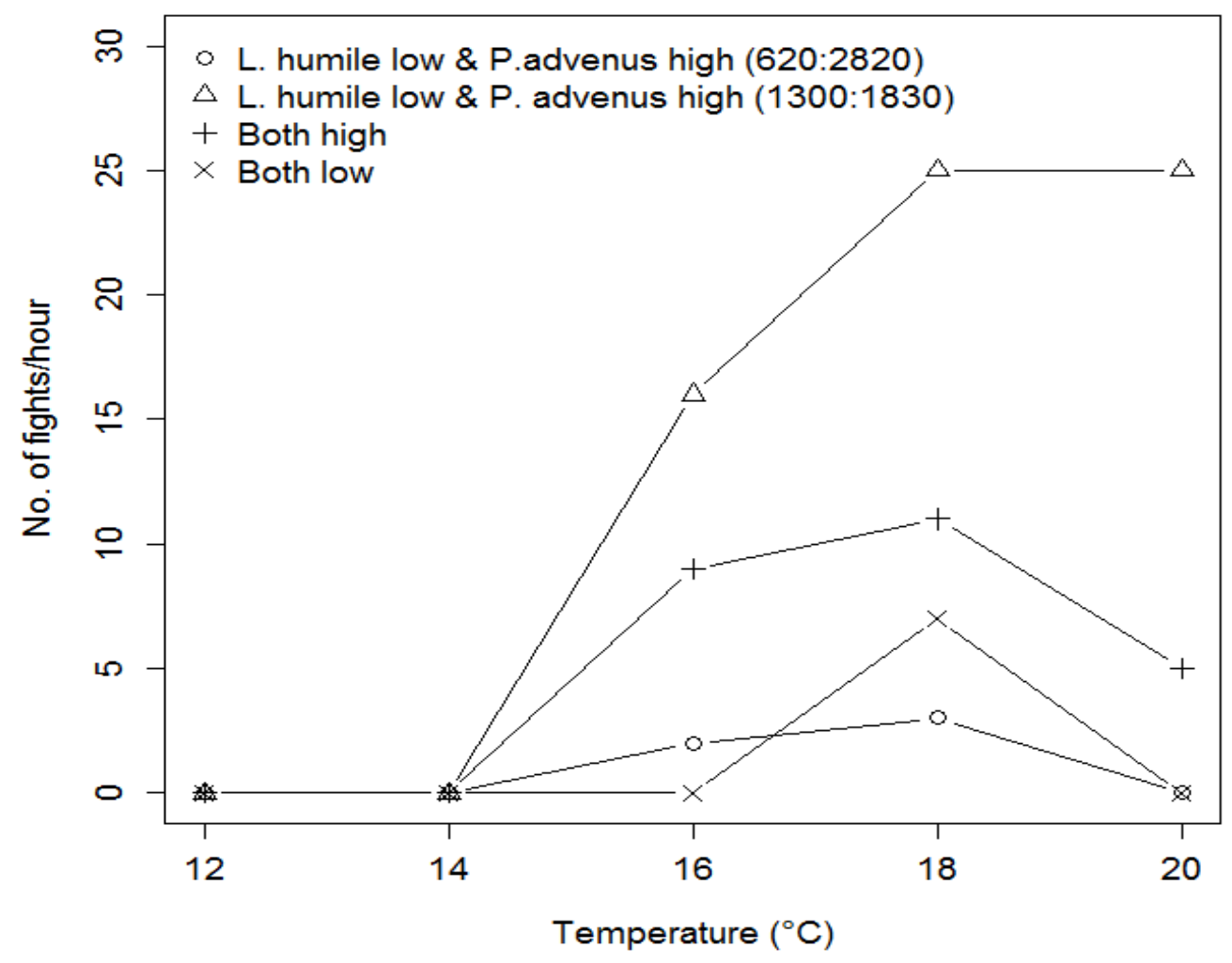

Fig. 5.12. Intensity of fighting change with temperature. Fighting recorded for an hour from the start of interaction although interaction continued for extra half an hour in some tests. Interaction after an hour is mostly biting and not fighting. As one species loses the fight the other starts to bite and chase.

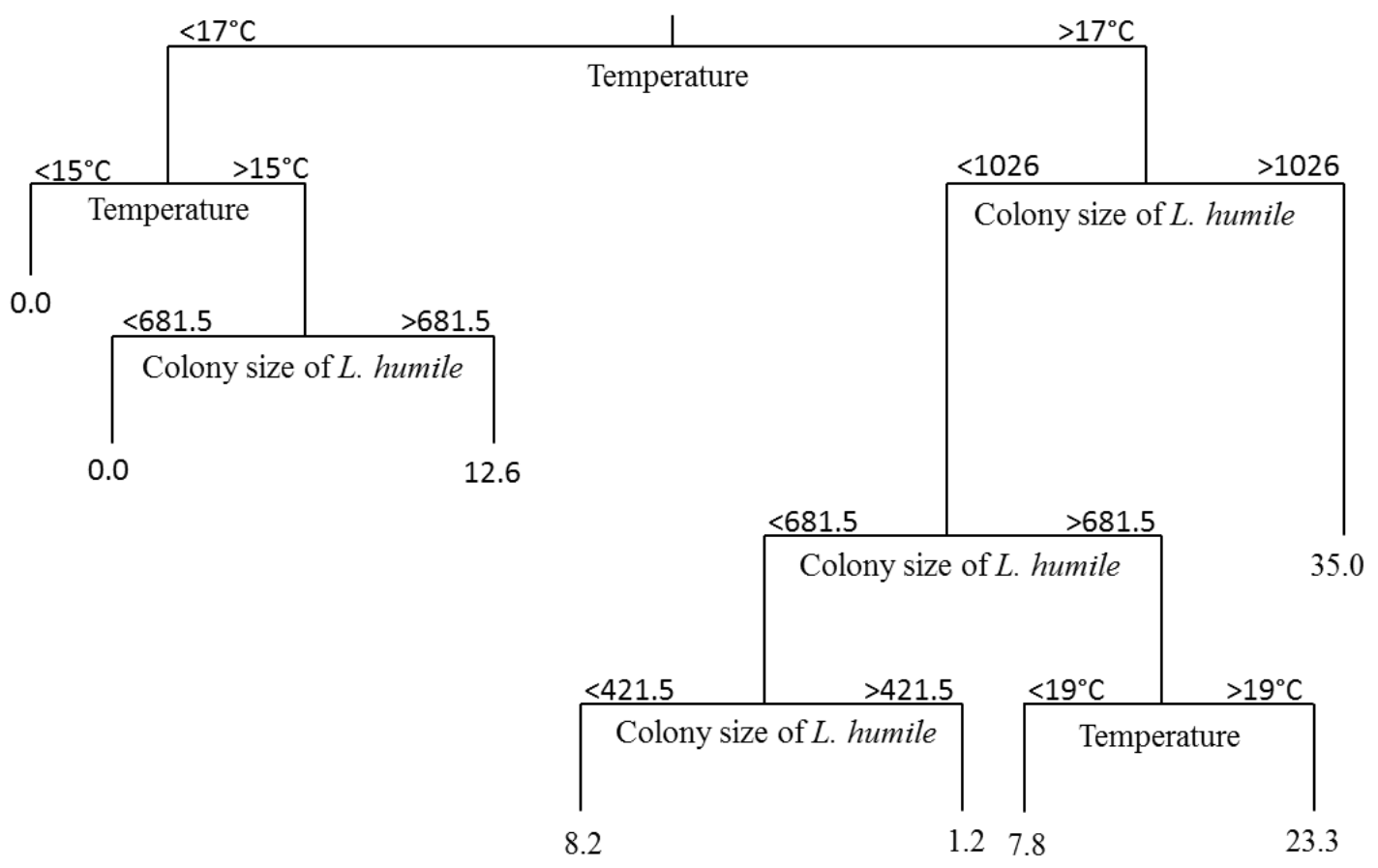

Fig. 5.13. Foraging performance of $L$. humile in the face of multiple factors: its own colony size, temperature, and colony size of $P$. advenus. The most important factor is placed on the top of the diagram and the next after that. The model divides each explanatory factor at the threshold between the upper and lower levels, right side upper and the left side lower level. Unbranched limb means no significant explanatory variable and the value given is the mean foraging density of L. humile. 


\subsection{Discussion}

This study provides experimental results of the effect of temperature on L. humile foraging behaviour, walking speed and aggression towards other resident species. This study also tested how L. humile's ability of controlling resources in the foraging arena changes with changes in their own colony size as well as the colony size of the other competing ant species. More importantly, this experiment tested how the interactive effect of the two factors, temperature and biotic resistance affected the ability of $L$. humile to control new space.

Foraging activity and walking speed of Argentine ants were found to decline with decrease in temperature. These ants are more active at higher temperature levels, especially for reproduction where oviposition activity peaks at about $28{ }^{\circ} \mathrm{C}$ (Abril et al., 2008), but warmer habitats should be accompanied by high moisture in order to remain favourable (Holway et al., 2002). Different colony sizes responded differently to temperature variation in laboratory experiments. My field study (chapter 3) of distribution pattern of L. humile also suggests the importance of temperature variation within microhabitat, supporting the results of this laboratory experiment. I found foraging activities and walking speed of the two other species (M. antarcticum and P. advenus) also decreased with temperature. However, temperature seems to affect the speed of $L$. humile more severely than that of the other two species. Over the range $20-12^{\circ} \mathrm{C}$ Argentine ants speed decreased more than twice that of $M$. antarcticum and more than three times of that of $P$. advenus. This could be due to the origin of L. humile is warmer Mediterranean-style climate, South America (Wild, 2004). They are adapted to high temperature areas such as Mediterranean climate (Jumbam et al., 2008; Abril et al., 2008; Holway et al., 2000; Hartley et al., 2006). On the other hand M. antarcticum and P. advenus are forest species native to New Zealand (Don, 2007). It is not surprising to see their speed to be less limited by decrease in temperature as they are adapted to a cooler climate. Regardless of whether a species is exotic or native, climate plays a key role in controlling species abundance and distribution pattern (Hairston et al., 1960) and as my results indicate this can be manifested in terms of physiological processes such as walking speed, foraging abundance as well as aggressiveness towards other species.

High biotic resistance and low propagule size also impedes invasive species. As a component of resistance to invasion, I measured biotic resistance in the laboratory. Colony size of $M$. antarcticum had a significant effect on foraging activity of $L$. humile. Similarly, I found that $L$. humile responding differently to different colony sizes of $P$. advenus. Foraging performance of L. humile not only depended on colony size of the competitor species but also on how low or 
high the numbers of both species were. That is foraging response of L. humile when both species were kept low was different from both species at high colony size. When colony sizes of both species were low $(L$. humile $=550$ and $M$. antarcticum $=610)$ L. humile displaced $M$. antarcticum at $20^{\circ} \mathrm{C}$. On the other hand, at the same temperature level, when colony sizes of both species were high $($ L. humile $=1010$, M. antarcticum $=1170)$ L. humile were displaced by M. antarcticum. According to my visual observation, all workers of L. humile aggressively fought while only 3 to 4 out of 30 foragers (workers) of M. antarcticum aggressively fought. With decreasing colony size, number of foragers decreases. This could have a strikingly negative impact on competitive performance of $M$. antarcticum as the number of aggressive fighters would be too low.

In interaction with another native species, $L$. humile displaced $P$. advenus when temperature was raised to 18 and $20^{\circ} \mathrm{C}$ even if $L$. humile were competing against higher colony size of $P$. advenus (unless they were extremely higher). In testing competition between L. humile and Iridomyrmex rufoniger, Walters and Mackay (2005) showed that colony size of L. humile should be 5 to 10 times that of the other competing ants to outcompete them. However, competition success of $L$. humile not only depends on colony size but also on other factors such as temperature. The additive effect of multiple factors has a remarkable effect in controlling invasive species (Turner, 2010). Moreover, in some cases multiple factors may have synergistic effect. For example decreased temperature and increased predator species density significantly alter prey species abundance (Fulton, 1983). Although I found that less favourable temperature and biotic resistance significantly affect the foraging activities of Argentine ants independently, the most striking result was the interactive effect of both temperature and biotic resistance against the invasion of $L$. humile. According to my results, the impact of low temperature not only decreases number of foragers of L. humile, but also importantly impairs the mechanisms (walking speed, aggressiveness and biting rate) necessary when competing with other species. A study of other insect species (Trichogramma brassicae) also shows that walking speed depends on temperature (Suverkropp et al., 2001). This paper is the first of its kind studying the interactive effect of temperature and biotic resistance and elucidating mechanisms regulating the outcome of the effect of the Argentine ants.

The experimental set up of my study did not provide a chance for the ants to ignore fighting while at the same time explore a new site if they want. That is, the ants had either to fight or retreat as there was no other space to explore. Sometimes the effect of colony size may be conditional upon environmental conditions. For example in the findings of Sagata and Lester 
(2008) colony size played an important role in survival of laboratory colonies, while in the field colony size had no effect. In the field, they may be less obliged to recruit more fighters as there may be more space to explore without being engaged in a fight. Therefore, there is a possibility that our results show less severe interactions between the two ant species had it been observed in the field.

Experimental studies show that $L$. humile colonies die when kept at temperatures of $5^{\circ} \mathrm{C}$ and below (Brightwell, 2010). Based on the critical thermal limit, other researchers also suggest that workers of $L$. humile can forage down to $0^{\circ} \mathrm{C}$ (e.g. Jumbam et al., 2008). However, in this study, I found L.humile workers' walking speed to slow to about $5 \mathrm{~mm} / \mathrm{sec}$, and that they displayed no aggressive behaviour towards other ant species at $12^{\circ} \mathrm{C}$. These reductions in speed and aggression made them subordinate to other native species. At intermediate temperature levels (e.g. $\left.16^{\circ} \mathrm{C}\right)$ I observed that once they open their mandible to bite the other species they were noticeably slow to close it which could be due to high cost of activity. Even if they may survive at temperatures as low as $0^{\circ} \mathrm{C}$, (Jumbam et al., 2008) and forage well at $7-14^{\circ} \mathrm{C}$ (Hartley et al., 2006), their success of colony establishment and competitive interactions may not be attained at lower temperatures. However, in the absence of biotic resistance, in places with wide ranges of winter and summer temperatures, survival at the lower critical temperature (Brightwell, 2010; Jumbam et al., 2008) may enable them to thrive in summer (Hartley and Lester, 2003). The future global distribution of Argentine ants has been predicted to include a wide range of countries (Hartley et al., 2006). However, previous studies to predict invasive species distribution based upon climate pattern have often met with little success (Williamson, 1999). This may be explained by a failure to consider species interactions such as competition and facilitation (Case et al., 2005; Davis et al., 1998). Therefore, based on the outcome of my study it is essential to take into account the nature (in terms of identity and colony size) of native species inhabiting each predicted invasion front as different species respond to the same invasive species differently. One of the few studies to incorporate the effects of likely biotic resistance with climate envelope modelling is that of Roura-Pascual et al. (2011).

Ecologists should realize that invasive and recipient species cannot be studied separately (Lodge, 1993). My study reveals that M. antarcticum are more resistant than P. advenus to invasion by $L$. humile. Nevertheless, supported by less favourable temperature, P. advenus may play a key role in keeping off invasive species. In New Zealand, L. humile and P. advenus typically occupy different habitats as $P$. advenus mainly occur in forested habitats, this could be interpreted as a result of different habitat preferences, but could equally be reinforced by the 
different competitive advantages of each species in each habitat, mediated by differences in temperature. In chapter 3 I found L. humile to occur more in open patches and they were less abundant in other microhabitats such as tall grasses and trees. This may be related to the competitive advantage of $M$. antarcticum in these alternative, slightly cooler habitats. Nests of L. humile spread and contract both seasonally and annually (Heller et al., 2006). This could be also a good example of the advantage of surviving extreme winter conditions or could be interpreted as effect of biotic resistance fluctuating with seasonal temperature. That is during the cold season native species may be displacing them whereas in warmer season L. humile may reverse the course.

\section{Conclusion}

I tested interactions between two species once at every temperature level. There is a possibility that the result of some tests would be reversed if the test was repeated many times at each temperature level. However, I believe that the overall result would remain the same. The result is robust as the behaviour of $L$. humile was consistent across all temperature levels tested. This study indicates that a combination of biotic and abiotic factors act to limit the advance of an invasive species and provides a basis for further studies on effects of microclimate variation induced by vegetation structure as well as types of other species distribution patterns in invasion frontiers. 


\subsection{References}

Abril, S., J. Oliveras, and C. Gomez, 2008. Effect of temperature on the oviposition rate of Argentine ant queens (Linepithema humile Mayr) under monogynous and polygynous experimental conditions. Journal of Insect Physiology 54: 265-272.

Bardsley, D. K. and G. Edwards-Jones, 2007. Invasive species policy and climate change: social perceptions of environmental change in the Mediterranean. Environmental Science and policy 10: 230-242.

Brightwell, R. J., P. E. Labadie, and J. Silverman, 2010. Northward expansion of the invasive Linepithema humile (Hymenoptera: Formicidae) in the Eastern United States is constrained by winter soil temperatures. Physiological Ecology 39: 1659-1665

Burns, K. C. and P. J. Lester, 2007. Competition and coexistence in model populations. In Jørgensen, S. E. and B. D. Fath (Ed.), Population Dynamics: Encyclopedia of Ecology (vol.5, pp.701-707). Elsevier, Oxford.

Carney, S. E., M. B. Byerley, and D. A. Holway, 2003. Invasive Argentine ants (Linepithema humile) do not replace native ants as seed dispersers of Dendromecon rigida (Papaveraceae) in California, United States of America. Oecologia 135: 576-582.

Case, T. J., R. D. Holt, M. A. McPeek, and T. H. Keitt, 2005. The community context of species-borders: ecological and evolutionary perspectives. Oikos 108: 28-46.

Case, T. J., 1990. Invasion resistance arises in strongly interacting species-rich model competition communities. Proceedings of the National Academy of the Sciences of the United States of America 87:9610-9614.

Cole, F.R., A. C. Medeiros, L. L. Loope, and W. W. Zuehlke, 1992. Effect of the Argentine ant on arthropod fauna of Hawaiian high-elevation shrubland. Ecology 73: 1313-1322.

Crawley, M. J., 2007. The R book. John Wiley and Sons, Ltd. London.

Davis, A. J., L. S. Jenkinson, J. H. Lawton, B. Shorrocks, and S. Wood, 1998. Making mistakes when predicting shifts in species range in response to global warming. Nature 391: 783-786.

Didham, R. K., J. M. Tylianakis, N. J. Gemmell, T. A. Rand, and R. M. Ewers, 2007. Interactive effects of habitat modification and species invasion on native species decline. Trends in Ecology and Evolution 22: 489-496.

Don, W., 2007. Ants of New Zealand. University of Otago Press in association with the Otago Museum, Dunedin.

Elton, C., 1958. The ecology of invasions; by animals and plants. Methuen and Co. Ltd., London.

Ficetola, G. F., W. Thuiller, and C. Miaud, 2007. Prediction and validation of the potential global distribution of a problematic alien invasive species - the American bullfrog. Diversity and Distributions 13: 476-485. 
Finnoff, D. and J. Tschirhart, 2005. Identifying, preventing and controlling invasive plant species using their physiological traits. Ecological Economics 52: 397-416.

Fulton, R. S., 1983. Interactive effect of temperature and predation on an estuarine zooplankton community. Journal of Experimental Marine Biology and Ecology 72: 67-81.

Grover, C. D., K. C. Dayton, S. B. Menke, and D. A. Holway, 2008. Effects of aphids on foliar foraging by Argentine ants and the resulting effects on other arthropods. Ecological Entomology 33: 101-106.

Gurevitch, J. and D. K. Padilla, 2004. Response to Ricciardi. Assessing species invasions as a cause of extinction. Trends in Ecology and Evolution 19: 620-620.

Hairston, N.G., F. E. Smith, and S. L. Slobodkin, 1960. Community structure, population control, and competition. American Naturalist 94: 421-425.

Hartley, S. and P. Lester, 2003. Temperature-dependent development of the Argentine ant, Linepithema humile Mayr) (Hymenoptera: Formicidae): a degree-day model with implications for range limits in New Zealand. New Zealand Entomologist 26: 91-100.

Hartley, S., R. Harris, and P. J. Lester, 2006. Quantifying uncertainty in the potential distribution of an invasive species: climate and the Argentine ant. Ecology Letters 9: 10681079 .

Heller. N. E., N. J. Sanders, and D. M. Gordon, 2006. Linking temporal and spatial scales in the study of an Argentine ant invasion. Biological Invasions 8: 501-507.

Holway, D. A., 2005. Edge effects of an invasive species across a natural ecological boundary. Biological Conservation 121: 561-67.

Holway, D. A., A. V. Suarez, and T. J. Case, 2002. Role of abiotic Factors in governing susceptibility to invasion: a test with argentine ants. Ecology 83: 1610-1619.

Holway, D. A. and A. V. Suarez, 2006. Homogenization of ant communities in Mediterranean California: the effects of urbanization and invasion. Biological Conservation 127: 319-326.

Holway, D. A. and T. J. Case, 2000. Mechanisms of dispersed central-place foraging in polydomous colonies of the Argentine ant. Animal Behaviour 59: 433-441.

Hong, K., J. Lee, G. Lee, and S. Lee, 2012. The status quo of invasive alien insect species and plant quarantine in Korea. Journal of Asia-Pacific Entomology 15: 521-532.

Hughes, K. A. and P. Convey, 2012. Determining the native/non-native status of newly discovered terrestrial and freshwater species in Antarctica e current knowledge, methodology and management action. Journal of Environmental Management 93: 52-66. 
Ingram, K. K., 2002. Flexibility in nest density and social structure in invasive populations of the Argentine ant, Linepithema humile. Oecologia 133:492-500.

Ingram, K. K. and D. M. Gordon, 2003. Genetic analysis of dispersal dynamics in an invading population of Argentine ants. Ecology 84: 2832-2842.

Inouye, B. D. and A. A. Agrawal, 2004. Ant mutualists alter the composition and attack rate of the parasitoid community for the gall wasp Isholcaspis eldoradensis (Cynipidae). Ecological Entomology 29: 692-696.

Jansen, S., 2000. Chemical - warfare techniques for insect control: insect 'pest' in Germany before and after World War I. Endeavour 24: 28-33.

Jonsen, I. D., R. S. Bourchier, and J. Roland, 2007. Influence of dispersal, stochasticity, and an Allee effect on the persistence of weed biocontrol introductions. Ecological Modelling 203: 521-526.

Jumbam, K. R., S. Jackson, J. S. Terblanche, M. A. McGeoch, and S. L. Chown, 2008. Acclimation effects on critical and lethal thermal limits of workers of the Argentine ant, Linepithema humile. Journal of Insect Physiology 54: 1008-1014.

Krushelnycky, P. D., L. L. Loope, and S. M. Joe, 2004. Limiting spread of a unicolonial invasive insect and characterization of seasonal patterns of range expansion. Biological Invasions 6: 47-57.

Lach, L., 2007. A mutualism with a native membracid facilitates pollinator displacement by Argentine ants. Ecology 88:1994-2004.

Lester, P. J., 2005. Determinants for the successful establishment of exotic ants in New Zealand. Diversity and Distribution 11: 279-288.

Lester, P. J., C. W. Baring, C. G. Longson, and S. Hartley, 2003. Argentine and other ants (Hymenoptera: Formicidae) in New Zealand horticultural ecosystems: distribution, hemipteran hosts, and review. New Zealand Entomologist 26: 79-89.

Liang, J. and S. Tang, 2010. Optimal dosage and economic threshold of multiple pesticide applications for pest control. Mathematical and Computer Modelling 51: 487-503.

Lodge, D. M., 1993. Biological invasions: lessons for ecology. Trends in Ecology and Evolution 8:133-137.

Lopes, C., T. Spataro, L. Lapchin, and R. Arditi, 2009. Optimal release strategies for the biological control of aphids in melon greenhouses. Biological Control 48: 12-21.

Matthias, L., R. B. Schäfer, and C. A. Schriever, 2008. The footprint of pesticide stress in communities-species traits reveal community effects of toxicants. Science of the Total Environment 406: 484-490.

Nonacs, P. and J. L. Soriano, 1998. Patch sampling behaviour and future foraging expectations in Argentine ants, Linepithema humile. Animal Behavior 55: 519-527. 
Patrick, D. A., N. Boudreau, Z. Bozic, G. S. Carpenter, D. M. Langdon, S. R. LeMay, S. M. Martin, R. M. Mourse, S. L. Prince, and K. M. Quinn, 2012. Effects of climate change on late-season growth and survival of native and non-native species of watermilfoil (Myriophyllum spp.): implications for invasive potential and ecosystem change. Aquatic Botany 103:83-88.

Pellikka, P. K. E., M. Lotjonen, M. Siljander, and L. Lens, 2009. Airborne remote sensing of spatiotemporal change (1955-2004) in indigenous and exotic forest cover in the Taita Hills, Kenya. International Journal of Applied Earth Observation and Geoinformation 11: 221232. Pimentel, D., R. Zuniga, and D. Morrison, 2005. Update on the environmental and economic costs associated with alien-invasive species in the United States. Ecological Economics 52: 273-288.

Raghu, S. and K. Dhileepan, 2005. The value of simulating herbivory in selecting effective weed biological control agents. Biological Control 34: 265-273.

Riis, T., B. Olesen, J. S. Clayton, C. Lambertini, H. Brix, and B. K. Sorrell, 2012. Growth and morphology in relation to temperature and light availability during the establishment of three invasive aquatic plant species. Aquatic Botany 102: 56-64.

Roura-Pascuala, N., C. Hui, T. Ikeda, G. Leday, D. M. Richardson, S. Carpintero, X. Espadaler, C. Gómez, B. Guénard, S. Hartley, P. Krushelnycky, P. J. Lester, M. A. McGeoch, S. B. Menke, J. S. Pedersen, J. P. W. Pitt, J. Reyes, N. J. Sanders, A. V. Suarez, Y. Touyama, D. Ward, P. S. Ward, and S. P. Worner, 2011. Relative roles of climatic suitability and anthropogenic influence in determining the pattern of spread in a global invader. Proceedings of the National Academy of Sciences 108: 220-225.

Sagata, K. and P. J. Lester, 2008. Behavioural plasticity associated with propagule size, resources, and the invasion success of the Argentine ant Linepithema humile. Journal of Applied Ecology 46: 19-27.

Sanders, N. J., N. J. Gotelli, N. E. Heller, and D. M. Gordon, 2003. Community disassembly by an invasive species. Proceedings of National Academy of Sciences of the United States of America 100: 2474-2477.

Shivji, M. S., 1985. Interactive effects of light and nitrogen on growth and chemical composition of juvenile Macrocystzs pyrzfera (L.) C. Ag. (Phaeophyta) sporophytes. Journal of Experimental Marine Biology and Ecology 89: 81-96.

Sinclair, B. J. and M. I. Stevens, 2006. Terrestrial microarthropods of Victoria Land and Queen Maud Mountains, Antarctica: implications of climate change. Soil Biology and Biochemistry 38: $3158-3170$.

Stachowicz, J. J., R. B. Whitlatch, and R. W. Osman,1999. Species Diversity and Invasion Resistance in a Marine Ecosystem. Science 286: 1577-1579.

Suarez, A. V., D. A. Holway, and T. J. Case, 2001. Patterns of spread in biological invasions dominated by long-distance jump dispersal: Insights from Argentine ants. Proceedings of Natural Academy of Sciences of the United States of America 98: 1095-1100. 
Sugiura, S., 2009. Seasonal fluctuation of invasive flatworm predation pressure on land snails: implications for the range expansion and impacts of invasive species. Biological Conservation 142: 3013-3019.

Suverkropp, B. P., F. Bigler, and J. C. van Lenteren, 2001. Temperature influences walking speed and walking activity of Trichogramma brassicae (Hymenoptera, Trichogrammatidae). Journal of Applied Entomology 125: 303-307.

Thomsen, M. S., J. D. Olden, T. Wernberg, J. N.Griffin, and B. R. Silliman, 2011. A broad framework to organize and compare ecological invasion impacts. Environmental Research 111: 899-908.

Tilman, D., 1999. The ecological consequences of changes in biodiversity: a search for general principles. Ecology 80: 1455-1474.

Truscott, A., S. C. Palmer, C. Soulsby, S. Westaway, and P. E. Hulme, 2008. Consequences of invasion by the alien plant Mimulus guttatus on the species composition and soil properties of riparian plant communities in Scotland. Perspectives in Plant Ecology, Evolution and Systematics 10: 231-240.

Turner, P. J., L. Morin, D. G. Williams, and D. J. Kriticos, 2010. Interactions between a leafhopper and rust fungus on the invasive plant Asparagus asparagoides in Australia: a case of two agents being better than one for biological control. Biological Control 54: 322330 .

Van Driesche, R.G., R. I. Carruthers, T. Center, M. S. Hoddle, J. Hough-Goldstein, L. Morin, L. Smith, D. L. Wagner, B. Blossey, V. Brancatini, R. Casagrande, C. E. Causton, J. A. Coetzee, J. Cuda, J. Ding, S. V. Fowler, J. H. Frank, R. Fuester, J. Goolsby, M. Grodowitz, T. A. Heard, M. P. Hill, J. H. Hoffmann, J. Huber, M. Julien, M. T .K. Kairo, M. Kenis, P. Mason, J. Medal, R. Messing, R. Miller, A. Moore, P. Neuenschwander, R. Newman, H. Norambuena, W. A. Palmer, R. Pemberton, A. Perez Panduro, P. D. Pratt, M. Rayamajhi, S. Salom, D. Sands, S. Schooler, M. Schwarzländer, A. Sheppard, R. Shaw, P. W. Tipping, and R. D. van Klinken, 2010. Classical biological control for the protection of natural ecosystems. Biological Control 54: S2-S33.

Vitousek, P. M., H. A. Mooney, J. Lubchenco, and J. M. Melillo, 1997. Human domination of Earth's ecosystems. Science 277: 494-499.

Walters, A. C. and D. A. Mackay, 2005. Importance of large colony size for successful invasion by Argentine ants (Hymenoptera: Formicidae): Evidence for biotic resistance by native ants. Austral Ecology 30: 395-406.

Van der Werf, H. M. G., 1996. Assessing the impact of pesticides on the environment. Agriculture, Ecosystem and Environment 60: 81-96.

Wilcove, D. S, D. Rothstein, J. Dubow, A. Phillips, and E. Losos 1998. Quantifying threats to imperilled species in the United States. BioScience 48: 607-615.

Wild, A. L., 2004. Taxonomy and distribution of the Argentine ant, Linepithema humile (Hymenoptera: Formicidae). Annals of the Entomological Society of America 97: 12041215. 
Williamson, M., 1999. Invasions. Ecography 22: 5-12.

Wilson, J. R. U., E. E. Dormontt, P. J. Prentis, A. J. Lowe, and D. M. Richardson, 2009. Something in the way you move: dispersal pathways affect invasion success. Trends in Ecology and Evolution 24: 136-144.

Wotton, D. M., C. O’Brien, M. D. Stuart, and D. J. Fergus, 2004. Eradication success down under: heat treatment of a sunken trawler to kill the invasive seaweed Undaria pinnatifida. Marine Pollution Bulletin 49: 844-849.

Zar, J. H., 1974. Ecological statistical methods. Englewood Cliffs, Prentice-Hall, New Jersey.

Zettler, J. L. and F. H. Arthur, 2000. Chemical control of stored product insects with fumigants and residual treatments. Crop Protection 19: 577-582. 


\subsection{Appendix}

5.6.1. Interaction between $L$. humile and $M$. antarcticum at different temperature $\left({ }^{\circ} \mathrm{C}\right)$ levels. $\mathrm{Lh}=L$. humile and $\mathrm{Ma}=M$. antarcticum.

\begin{tabular}{|c|c|c|c|c|c|c|}
\hline Colony & time & Temperature & L. humile & M. antarcticum & Fighting & Crossing \\
\hline Lh high Ma low & 5 & 20 & 3 & 4 & 0 & 0 \\
\hline Lh high Ma low & 14 & 20 & 10 & 4 & 3 & 0 \\
\hline Lh high Ma low & 23 & 20 & 15 & 7 & 3 & 0 \\
\hline Lh high Ma low & 32 & 20 & 30 & 6 & 4 & 0 \\
\hline Lh high Ma low & 41 & 20 & 37 & 8 & 2 & 0 \\
\hline Lh high Ma low & 50 & 20 & 40 & 10 & 3 & 0 \\
\hline Lh high Ma low & 59 & 20 & 50 & 10 & 3 & 2 \\
\hline Lh high Ma low & 68 & 20 & 65 & 7 & 1 & 4 \\
\hline Lh high Ma low & 77 & 20 & 65 & 4 & 2 & 6 \\
\hline Lh high Ma low & 86 & 20 & 68 & 3 & 1 & 9 \\
\hline Lh high Ma low & 5 & 18 & 1 & 2 & 0 & 0 \\
\hline Lh high Ma low & 14 & 18 & 1 & 3 & 0 & 0 \\
\hline Lh high Ma low & 23 & 18 & 3 & 6 & 1 & 0 \\
\hline Lh high Ma low & 32 & 18 & 9 & 6 & 2 & 0 \\
\hline Lh high Ma low & 41 & 18 & 14 & 6 & 3 & 0 \\
\hline Lh high Ma low & 50 & 18 & 21 & 5 & 2 & 0 \\
\hline Lh high Ma low & 59 & 18 & 29 & 5 & 3 & 1 \\
\hline Lh high Ma low & 68 & 18 & 35 & 4 & 2 & 2 \\
\hline Lh high Ma low & 77 & 18 & 35 & 4 & 2 & 2 \\
\hline Lh high Ma low & 86 & 18 & 40 & 4 & 1 & 3 \\
\hline Lh high Ma low & 5 & 16 & 2 & 1 & 0 & 0 \\
\hline Lh high Ma low & 14 & 16 & 2 & 2 & 0 & 0 \\
\hline Lh high Ma low & 23 & 16 & 2 & 2 & 0 & 0 \\
\hline Lh high Ma low & 32 & 16 & 4 & 4 & 0 & 0 \\
\hline Lh high Ma low & 41 & 16 & 4 & 3 & 0 & 0 \\
\hline Lh high Ma low & 50 & 16 & 4 & 3 & 0 & 0 \\
\hline Lh high Ma low & 59 & 16 & 6 & 4 & 0 & 0 \\
\hline Lh high Ma low & 68 & 16 & 9 & 3 & 0 & 0 \\
\hline Lh high Ma low & 77 & 16 & 12 & 4 & 1 & 0 \\
\hline Lh high Ma low & 86 & 16 & 20 & 3 & 1 & 0 \\
\hline Lh high Ma low & 5 & 14 & 0 & 0 & 0 & 0 \\
\hline Lh high Ma low & 14 & 14 & 1 & 2 & 0 & 0 \\
\hline Lh high Ma low & 23 & 14 & 2 & 2 & 0 & 0 \\
\hline Lh high Ma low & 32 & 14 & 6 & 3 & 0 & 0 \\
\hline Lh high Ma low & 41 & 14 & 4 & 5 & 0 & 0 \\
\hline Lh high Ma low & 50 & 14 & 4 & 6 & 0 & 0 \\
\hline Lh high Ma low & 59 & 14 & 9 & 8 & 0 & 0 \\
\hline Lh high Ma low & 68 & 14 & 14 & 10 & 1 & 0 \\
\hline Lh high Ma low & 77 & 14 & 13 & 11 & 0 & 0 \\
\hline Lh high Ma low & 86 & 14 & 17 & 11 & 1 & 0 \\
\hline Lh high Ma low & 5 & 12 & 0 & 0 & 0 & 0 \\
\hline Lh high Ma low & 14 & 12 & 0 & 1 & 0 & 0 \\
\hline
\end{tabular}




\begin{tabular}{|c|c|c|c|c|c|}
\hline Lh high Ma low & 23 & 12 & 0 & 1 & 0 \\
\hline Lh high Ma low & 32 & 12 & 0 & 1 & 0 \\
\hline Lh high Ma low & 41 & 12 & 2 & 3 & 0 \\
\hline Lh high Ma low & 50 & 12 & 2 & 3 & 0 \\
\hline Lh high Ma low & 59 & 12 & 2 & 3 & 0 \\
\hline Lh high Ma low & 68 & 12 & 1 & 2 & 0 \\
\hline Lh high Ma low & 77 & 12 & 0 & 2 & 0 \\
\hline Lh high Ma low & 86 & 12 & 0 & 2 & 0 \\
\hline Lh low Ma high & 5 & 20 & 2 & 8 & 1 \\
\hline Lh low Ma high & 14 & 20 & 0 & 10 & 0 \\
\hline Lh low Ma high & 23 & 20 & 0 & 13 & 0 \\
\hline Lh low Ma high & 32 & 20 & 2 & 18 & 2 \\
\hline Lh low Ma high & 41 & 20 & 6 & 20 & 2 \\
\hline Lh low Ma high & 50 & 20 & 4 & 25 & 1 \\
\hline Lh low Ma high & 59 & 20 & 5 & 20 & 1 \\
\hline Lh low Ma high & 68 & 20 & 4 & 20 & 0 \\
\hline Lh low Ma high & 77 & 20 & 1 & 25 & 0 \\
\hline Lh low Ma high & 86 & 20 & 1 & 21 & 0 \\
\hline Lh low Ma high & 5 & 18 & 0 & 1 & 0 \\
\hline Lh low Ma high & 14 & 18 & 0 & 1 & 0 \\
\hline Lh low Ma high & 23 & 18 & 0 & 4 & 0 \\
\hline Lh low Ma high & 32 & 18 & 0 & 8 & 0 \\
\hline Lh low Ma high & 41 & 18 & 0 & 8 & 0 \\
\hline Lh low Ma high & 50 & 18 & 0 & 8 & 0 \\
\hline Lh low Ma high & 59 & 18 & 0 & 6 & 0 \\
\hline Lh low Ma high & 68 & 18 & 1 & 10 & 0 \\
\hline Lh low Ma high & 77 & 18 & 0 & 7 & 0 \\
\hline Lh low Ma high & 86 & 18 & 0 & 8 & 0 \\
\hline Lh low Ma high & 5 & 16 & 0 & 3 & 0 \\
\hline Lh low Ma high & 14 & 16 & 0 & 1 & 0 \\
\hline Lh low Ma high & 23 & 16 & 0 & 2 & 0 \\
\hline Lh low Ma high & 32 & 16 & 0 & 4 & 0 \\
\hline Lh low Ma high & 41 & 16 & 2 & 4 & 0 \\
\hline Lh low Ma high & 50 & 16 & 2 & 2 & 1 \\
\hline Lh low Ma high & 59 & 16 & 3 & 5 & 0 \\
\hline Lh low Ma high & 68 & 16 & 2 & 4 & 1 \\
\hline Lh low Ma high & 77 & 16 & 1 & 3 & 0 \\
\hline Lh low Ma high & 86 & 16 & 1 & 3 & 0 \\
\hline Lh low Ma high & 5 & 14 & 0 & 0 & 0 \\
\hline Lh low Ma high & 14 & 14 & 0 & 2 & 0 \\
\hline Lh low Ma high & 23 & 14 & 0 & 2 & 0 \\
\hline Lh low Ma high & 32 & 14 & 0 & 5 & 0 \\
\hline Lh low Ma high & 41 & 14 & 0 & 4 & 0 \\
\hline Lh low Ma high & 50 & 14 & 0 & 7 & 0 \\
\hline Lh low Ma high & 59 & 14 & 0 & 7 & 0 \\
\hline Lh low Ma high & 68 & 14 & 0 & 9 & 0 \\
\hline Lh low Ma high & 77 & 14 & 0 & 5 & 0 \\
\hline Lh low Ma high & 86 & 14 & 0 & 6 & 0 \\
\hline
\end{tabular}




\begin{tabular}{|c|c|c|c|c|c|}
\hline Lh low Ma high & 5 & 12 & 0 & 2 & 0 \\
\hline Lh low Ma high & 14 & 12 & 0 & 5 & 0 \\
\hline Lh low Ma high & 23 & 12 & 0 & 5 & 0 \\
\hline Lh low Ma high & 32 & 12 & 0 & 4 & 0 \\
\hline Lh low Ma high & 41 & 12 & 0 & 6 & 0 \\
\hline Lh low Ma high & 50 & 12 & 0 & 7 & 0 \\
\hline Lh low Ma high & 59 & 12 & 0 & 7 & 0 \\
\hline Lh low Ma high & 68 & 12 & 0 & 10 & 0 \\
\hline Lh low Ma high & 77 & 12 & 0 & 10 & 0 \\
\hline Lh low Ma high & 86 & 12 & 0 & 10 & 0 \\
\hline both high & 5 & 20 & 3 & 35 & 0 \\
\hline both high & 14 & 20 & 5 & 36 & 0 \\
\hline both high & 23 & 20 & 9 & 35 & 0 \\
\hline both high & 32 & 20 & 12 & 45 & 3 \\
\hline both high & 41 & 20 & 11 & 40 & 5 \\
\hline both high & 50 & 20 & 10 & 45 & 5 \\
\hline both high & 59 & 20 & 16 & 43 & 8 \\
\hline both high & 68 & 20 & 11 & 46 & 2 \\
\hline both high & 77 & 20 & 8 & 48 & 1 \\
\hline both high & 86 & 20 & 4 & 45 & 2 \\
\hline both high & 5 & 18 & 0 & 4 & 0 \\
\hline both high & 14 & 18 & 0 & 7 & 0 \\
\hline both high & 23 & 18 & 1 & 11 & 1 \\
\hline both high & 32 & 18 & 0 & 19 & 0 \\
\hline both high & 41 & 18 & 2 & 18 & 1 \\
\hline both high & 50 & 18 & 1 & 20 & 0 \\
\hline both high & 59 & 18 & 1 & 20 & 0 \\
\hline both high & 68 & 18 & 0 & 16 & 0 \\
\hline both high & 77 & 18 & 0 & 19 & 0 \\
\hline both high & 86 & 18 & 0 & 15 & 0 \\
\hline both high & 5 & 16 & 1 & 4 & 0 \\
\hline both high & 14 & 16 & 0 & 4 & 0 \\
\hline both high & 23 & 16 & 2 & 8 & 0 \\
\hline both high & 32 & 16 & 1 & 8 & 0 \\
\hline both high & 41 & 16 & 1 & 6 & 0 \\
\hline both high & 50 & 16 & 2 & 12 & 0 \\
\hline both high & 59 & 16 & 2 & 14 & 0 \\
\hline both high & 68 & 16 & 2 & 12 & 1 \\
\hline both high & 77 & 16 & 1 & 10 & 0 \\
\hline both high & 86 & 16 & 1 & 14 & 1 \\
\hline both high & 5 & 14 & 0 & 0 & 0 \\
\hline both high & 14 & 14 & 0 & 0 & 0 \\
\hline both high & 23 & 14 & 0 & 3 & 0 \\
\hline both high & 32 & 14 & 0 & 2 & 0 \\
\hline both high & 41 & 14 & 0 & 4 & 0 \\
\hline both high & 50 & 14 & 0 & 4 & 0 \\
\hline both high & 59 & 14 & 0 & 7 & 0 \\
\hline both high & 68 & 14 & 0 & 13 & 0 \\
\hline
\end{tabular}




\begin{tabular}{|c|c|c|c|c|c|}
\hline both high & 77 & 14 & 1 & 9 & 0 \\
\hline both high & 86 & 14 & 1 & 13 & 0 \\
\hline both high & 5 & 12 & 0 & 2 & 0 \\
\hline both high & 14 & 12 & 0 & 2 & 0 \\
\hline both high & 23 & 12 & 0 & 4 & 0 \\
\hline both high & 32 & 12 & 0 & 4 & 0 \\
\hline both high & 41 & 12 & 0 & 4 & 0 \\
\hline both high & 50 & 12 & 0 & 7 & 0 \\
\hline both high & 59 & 12 & 0 & 6 & 0 \\
\hline both high & 68 & 12 & 0 & 11 & 0 \\
\hline both high & 77 & 12 & 0 & 17 & 0 \\
\hline both high & 86 & 12 & 0 & 17 & 0 \\
\hline both low & 5 & 20 & 1 & 2 & 0 \\
\hline both low & 14 & 20 & 3 & 2 & 0 \\
\hline both low & 23 & 20 & 5 & 4 & 2 \\
\hline both low & 32 & 20 & 8 & 4 & 4 \\
\hline both low & 41 & 20 & 9 & 6 & 5 \\
\hline both low & 50 & 20 & 12 & 5 & 2 \\
\hline both low & 59 & 20 & 18 & 4 & 3 \\
\hline both low & 68 & 20 & 23 & 2 & 3 \\
\hline both low & 77 & 20 & 30 & 1 & 1 \\
\hline both low & 86 & 20 & 30 & 2 & 1 \\
\hline both low & 5 & 18 & 0 & 0 & 0 \\
\hline both low & 14 & 18 & 0 & 0 & 0 \\
\hline both low & 23 & 18 & 0 & 1 & 0 \\
\hline both low & 32 & 18 & 0 & 3 & 0 \\
\hline both low & 41 & 18 & 0 & 4 & 0 \\
\hline both low & 50 & 18 & 0 & 4 & 0 \\
\hline both low & 59 & 18 & 0 & 4 & 0 \\
\hline both low & 68 & 18 & 0 & 3 & 0 \\
\hline both low & 77 & 18 & 0 & 6 & 0 \\
\hline both low & 86 & 18 & 0 & 7 & 0 \\
\hline both low & 5 & 16 & 0 & 3 & 0 \\
\hline both low & 14 & 16 & 0 & 2 & 0 \\
\hline both low & 23 & 16 & 0 & 4 & 0 \\
\hline both low & 32 & 16 & 0 & 3 & 0 \\
\hline both low & 41 & 16 & 0 & 3 & 0 \\
\hline both low & 50 & 16 & 0 & 4 & 0 \\
\hline both low & 59 & 16 & 1 & 2 & 0 \\
\hline both low & 68 & 16 & 0 & 2 & 0 \\
\hline both low & 77 & 16 & 1 & 3 & 0 \\
\hline both low & 86 & 16 & 1 & 5 & 0 \\
\hline both low & 5 & 14 & 0 & 0 & 0 \\
\hline both low & 14 & 14 & 0 & 0 & 0 \\
\hline both low & 23 & 14 & 0 & 0 & 0 \\
\hline both low & 32 & 14 & 0 & 0 & 0 \\
\hline both low & 41 & 14 & 0 & 0 & 0 \\
\hline both low & 50 & 14 & 0 & 0 & 0 \\
\hline
\end{tabular}




\begin{tabular}{lcccccc} 
both low & 59 & 14 & 0 & 1 & 0 & 0 \\
both low & 68 & 14 & 0 & 0 & 0 & 0 \\
both low & 77 & 14 & 1 & 3 & 0 & 0 \\
both low & 86 & 14 & 1 & 3 & 0 & 0 \\
both low & 5 & 12 & 0 & 1 & 0 & 0 \\
both low & 14 & 12 & 0 & 1 & 0 & 0 \\
both low & 23 & 12 & 0 & 2 & 0 & 0 \\
both low & 32 & 12 & 0 & 1 & 0 & 0 \\
both low & 41 & 12 & 0 & 3 & 0 & 0 \\
both low & 50 & 12 & 0 & 4 & 0 & 0 \\
both low & 59 & 12 & 1 & 4 & 0 & 0 \\
both low & 68 & 12 & 1 & 5 & 0 & 0 \\
both low & 77 & 12 & 1 & 7 & 0 & 0 \\
both low & 86 & 12 & 1 & 7 & 0 & 0 \\
\hline
\end{tabular}

5.6.2. Interaction between $L$. humile and $P$. advenus at different temperature $\left({ }^{\circ} \mathrm{C}\right)$ levels.

\begin{tabular}{|c|c|c|c|c|c|c|}
\hline Colony size & time & temperature & L.humile & P. advenus & Fighting & Crossing \\
\hline both high & 5 & 12 & 0 & 0 & 0 & 0 \\
\hline both high & 14 & 12 & 0 & 0 & 0 & 0 \\
\hline both high & 23 & 12 & 0 & 0 & 0 & 0 \\
\hline both high & 32 & 12 & 0 & 1 & 0 & 0 \\
\hline both high & 41 & 12 & 0 & 0 & 0 & 0 \\
\hline both high & 50 & 12 & 0 & 2 & 0 & 0 \\
\hline both high & 59 & 12 & 0 & 5 & 0 & 0 \\
\hline both high & 68 & 12 & 0 & 5 & 0 & 0 \\
\hline both high & 77 & 12 & 0 & 4 & 0 & 0 \\
\hline both high & 86 & 12 & 0 & 7 & 0 & 0 \\
\hline both high & 5 & 14 & 0 & 2 & 0 & 0 \\
\hline both high & 14 & 14 & 0 & 2 & 0 & 0 \\
\hline both high & 23 & 14 & 0 & 4 & 0 & 0 \\
\hline both high & 32 & 14 & 0 & 3 & 0 & 0 \\
\hline both high & 41 & 14 & 0 & 6 & 0 & 0 \\
\hline both high & 50 & 14 & 0 & 6 & 0 & 0 \\
\hline both high & 59 & 14 & 0 & 11 & 0 & 0 \\
\hline both high & 68 & 14 & 0 & 13 & 0 & 0 \\
\hline both high & 77 & 14 & 0 & 10 & 0 & 0 \\
\hline both high & 86 & 14 & 0 & 17 & 0 & 0 \\
\hline both high & 5 & 16 & 0 & 3 & 0 & 0 \\
\hline both high & 14 & 16 & 0 & 4 & 0 & 0 \\
\hline both high & 23 & 16 & 1 & 7 & 0 & 0 \\
\hline both high & 32 & 16 & 0 & 11 & 0 & 0 \\
\hline both high & 41 & 16 & 2 & 15 & 0 & 0 \\
\hline both high & 50 & 16 & 4 & 13 & 1 & 0 \\
\hline both high & 59 & 16 & 7 & 11 & 0 & 0 \\
\hline both high & 68 & 16 & 12 & 11 & 2 & 0 \\
\hline both high & 77 & 16 & 19 & 12 & 4 & 0 \\
\hline
\end{tabular}




\begin{tabular}{|c|c|c|c|c|c|}
\hline both high & 86 & 16 & 24 & 9 & 2 \\
\hline both high & 5 & 18 & 0 & 1 & 0 \\
\hline both high & 14 & 18 & 1 & 1 & 0 \\
\hline both high & 23 & 18 & 1 & 3 & 0 \\
\hline both high & 32 & 18 & 1 & 4 & 0 \\
\hline both high & 41 & 18 & 0 & 4 & 0 \\
\hline both high & 50 & 18 & 2 & 7 & 0 \\
\hline both high & 59 & 18 & 7 & 5 & 3 \\
\hline both high & 68 & 18 & 9 & 5 & 2 \\
\hline both high & 77 & 18 & 13 & 4 & 3 \\
\hline both high & 86 & 18 & 16 & 4 & 3 \\
\hline both high & 5 & 20 & 2 & 1 & 0 \\
\hline both high & 14 & 20 & 5 & 1 & 0 \\
\hline both high & 23 & 20 & 5 & 1 & 0 \\
\hline both high & 32 & 20 & 11 & 2 & 0 \\
\hline both high & 41 & 20 & 14 & 1 & 0 \\
\hline both high & 50 & 20 & 18 & 4 & 1 \\
\hline both high & 59 & 20 & 26 & 4 & 1 \\
\hline both high & 68 & 20 & 24 & 2 & 0 \\
\hline both high & 77 & 20 & 26 & 4 & 2 \\
\hline both high & 86 & 20 & 32 & 3 & 1 \\
\hline L.humile low & 5 & 12 & 0 & 0 & 0 \\
\hline L.humile low & 14 & 12 & 0 & 1 & 0 \\
\hline L.humile low & 23 & 12 & 0 & 1 & 0 \\
\hline L.humile low & 32 & 12 & 0 & 3 & 0 \\
\hline L.humile low & 41 & 12 & 0 & 2 & 0 \\
\hline L.humile low & 50 & 12 & 0 & 3 & 0 \\
\hline L.humile low & 59 & 12 & 0 & 3 & 0 \\
\hline L.humile low & 68 & 12 & 0 & 5 & 0 \\
\hline L.humile low & 77 & 12 & 0 & 8 & 0 \\
\hline L.humile low & 86 & 12 & 0 & 8 & 0 \\
\hline L.humile low & 5 & 14 & 0 & 0 & 0 \\
\hline L.humile low & 14 & 14 & 0 & 0 & 0 \\
\hline L.humile low & 23 & 14 & 0 & 0 & 0 \\
\hline L.humile low & 32 & 14 & 0 & 0 & 0 \\
\hline L.humile low & 41 & 14 & 0 & 0 & 0 \\
\hline L.humile low & 50 & 14 & 0 & 0 & 0 \\
\hline L.humile low & 59 & 14 & 0 & 1 & 0 \\
\hline L.humile low & 68 & 14 & 0 & 3 & 0 \\
\hline L.humile low & 77 & 14 & 0 & 3 & 0 \\
\hline L.humile low & 86 & 14 & 0 & 6 & 0 \\
\hline L.humile low & 5 & 16 & 1 & 4 & 0 \\
\hline L.humile low & 14 & 16 & 1 & 8 & 1 \\
\hline L.humile low & 23 & 16 & 0 & 9 & 0 \\
\hline L.humile low & 32 & 16 & 0 & 9 & 1 \\
\hline L.humile low & 41 & 16 & 0 & 5 & 0 \\
\hline L.humile low & 50 & 16 & 0 & 3 & 0 \\
\hline L.humile low & 59 & 16 & 0 & 5 & 0 \\
\hline
\end{tabular}




\begin{tabular}{|c|c|c|c|c|c|}
\hline L.humile low & 68 & 16 & 0 & 7 & 0 \\
\hline L.humile low & 77 & 16 & 0 & 7 & 0 \\
\hline L.humile low & 86 & 16 & 0 & 5 & 0 \\
\hline L.humile low & 5 & 18 & 0 & 1 & 0 \\
\hline L.humile low & 14 & 18 & 0 & 4 & 0 \\
\hline L.humile low & 23 & 18 & 1 & 4 & 0 \\
\hline L.humile low & 32 & 18 & 3 & 4 & 1 \\
\hline L.humile low & 41 & 18 & 3 & 3 & 2 \\
\hline L.humile low & 50 & 18 & 2 & 4 & 0 \\
\hline L.humile low & 59 & 18 & 2 & 7 & 0 \\
\hline L.humile low & 68 & 18 & 2 & 7 & 0 \\
\hline L.humile low & 77 & 18 & 3 & 10 & 0 \\
\hline L.humile low & 86 & 18 & 0 & 9 & 0 \\
\hline L.humile low & 5 & 20 & 0 & 0 & 0 \\
\hline L.humile low & 14 & 20 & 0 & 0 & 0 \\
\hline L.humile low & 23 & 20 & 0 & 0 & 0 \\
\hline L.humile low & 32 & 20 & 0 & 0 & 0 \\
\hline L.humile low & 41 & 20 & 0 & 1 & 0 \\
\hline L.humile low & 50 & 20 & 0 & 0 & 0 \\
\hline L.humile low & 59 & 20 & 0 & 0 & 0 \\
\hline L.humile low & 68 & 20 & 0 & 2 & 0 \\
\hline L.humile low & 77 & 20 & 1 & 4 & 0 \\
\hline L.humile low & 86 & 20 & 1 & 4 & 0 \\
\hline L.humile low & 5 & 12 & 0 & 0 & 0 \\
\hline L.humile low & 14 & 12 & 0 & 0 & 0 \\
\hline L.humile low & 23 & 12 & 0 & 0 & 0 \\
\hline L.humile low & 32 & 12 & 0 & 0 & 0 \\
\hline L.humile low & 41 & 12 & 0 & 0 & 0 \\
\hline L.humile low & 50 & 12 & 0 & 0 & 0 \\
\hline L.humile low & 59 & 12 & 0 & 1 & 0 \\
\hline L.humile low & 68 & 12 & 0 & 1 & 0 \\
\hline L.humile low & 77 & 12 & 0 & 1 & 0 \\
\hline L.humile low & 86 & 12 & 0 & 1 & 0 \\
\hline L.humile low & 5 & 14 & 0 & 0 & 0 \\
\hline L.humile low & 14 & 14 & 0 & 0 & 0 \\
\hline L.humile low & 23 & 14 & 0 & 0 & 0 \\
\hline L.humile low & 32 & 14 & 0 & 3 & 0 \\
\hline L.humile low & 41 & 14 & 0 & 3 & 0 \\
\hline L.humile low & 50 & 14 & 0 & 1 & 0 \\
\hline L.humile low & 59 & 14 & 0 & 4 & 0 \\
\hline L.humile low & 68 & 14 & 0 & 5 & 0 \\
\hline L.humile low & 77 & 14 & 0 & 8 & 0 \\
\hline L.humile low & 86 & 14 & 0 & 11 & 0 \\
\hline L.humile low & 5 & 16 & 1 & 3 & 0 \\
\hline L.humile low & 14 & 16 & 2 & 6 & 2 \\
\hline L.humile low & 23 & 16 & 1 & 11 & 0 \\
\hline L.humile low & 32 & 16 & 3 & 10 & 0 \\
\hline L.humile low & 41 & 16 & 3 & 10 & 0 \\
\hline
\end{tabular}




\begin{tabular}{|c|c|c|c|c|c|}
\hline L.humile low & 50 & 16 & 4 & 12 & 2 \\
\hline L.humile low & 59 & 16 & 9 & 12 & 3 \\
\hline L.humile low & 68 & 16 & 14 & 10 & 2 \\
\hline L.humile low & 77 & 16 & 26 & 11 & 4 \\
\hline L.humile low & 86 & 16 & 27 & 7 & 3 \\
\hline L.humile low & 5 & 18 & 7 & 1 & 0 \\
\hline L.humile low & 14 & 18 & 11 & 3 & 2 \\
\hline L.humile low & 23 & 18 & 16 & 5 & 3 \\
\hline L.humile low & 32 & 18 & 20 & 7 & 4 \\
\hline L.humile low & 41 & 18 & 31 & 12 & 4 \\
\hline L.humile low & 50 & 18 & 39 & 13 & 3 \\
\hline L.humile low & 59 & 18 & 35 & 10 & 4 \\
\hline L.humile low & 68 & 18 & 35 & 7 & 3 \\
\hline L.humile low & 77 & 18 & 30 & 4 & 2 \\
\hline L.humile low & 86 & 18 & 45 & 3 & 0 \\
\hline L.humile low & 5 & 20 & 4 & 3 & 0 \\
\hline L.humile low & 14 & 20 & 7 & 3 & 2 \\
\hline L.humile low & 23 & 20 & 11 & 5 & 2 \\
\hline L.humile low & 32 & 20 & 18 & 7 & 4 \\
\hline L.humile low & 41 & 20 & 25 & 8 & 3 \\
\hline L.humile low & 50 & 20 & 31 & 5 & 4 \\
\hline L.humile low & 59 & 20 & 30 & 3 & 5 \\
\hline L.humile low & 68 & 20 & 36 & 3 & 3 \\
\hline L.humile low & 77 & 20 & 38 & 2 & 1 \\
\hline L.humile low & 86 & 20 & 45 & 2 & 1 \\
\hline both low & 5 & 12 & 0 & 0 & 0 \\
\hline both low & 14 & 12 & 0 & 0 & 0 \\
\hline both low & 23 & 12 & 0 & 0 & 0 \\
\hline both low & 32 & 12 & 0 & 0 & 0 \\
\hline both low & 41 & 12 & 0 & 0 & 0 \\
\hline both low & 50 & 12 & 0 & 0 & 0 \\
\hline both low & 59 & 12 & 0 & 0 & 0 \\
\hline both low & 68 & 12 & 0 & 1 & 0 \\
\hline both low & 77 & 12 & 0 & 1 & 0 \\
\hline both low & 86 & 12 & 0 & 1 & 0 \\
\hline both low & 5 & 14 & 0 & 0 & 0 \\
\hline both low & 14 & 14 & 0 & 0 & 0 \\
\hline both low & 23 & 14 & 0 & 0 & 0 \\
\hline both low & 32 & 14 & 0 & 0 & 0 \\
\hline both low & 41 & 14 & 0 & 0 & 0 \\
\hline both low & 50 & 14 & 0 & 0 & 0 \\
\hline both low & 59 & 14 & 0 & 0 & 0 \\
\hline both low & 68 & 14 & 0 & 0 & 0 \\
\hline both low & 77 & 14 & 0 & 0 & 0 \\
\hline both low & 86 & 14 & 0 & 0 & 0 \\
\hline both low & 5 & 16 & 0 & 0 & 0 \\
\hline both low & 14 & 16 & 0 & 0 & 0 \\
\hline both low & 23 & 16 & 0 & 0 & 0 \\
\hline
\end{tabular}




\begin{tabular}{lcccccc} 
both low & 32 & 16 & 0 & 0 & 0 & 0 \\
both low & 41 & 16 & 0 & 0 & 0 & 0 \\
both low & 50 & 16 & 0 & 0 & 0 & 0 \\
both low & 59 & 16 & 0 & 0 & 0 & 0 \\
both low & 68 & 16 & 0 & 0 & 0 & 0 \\
both low & 77 & 16 & 0 & 0 & 0 & 0 \\
both low & 86 & 16 & 0 & 0 & 0 & 0 \\
both low & 5 & 18 & 0 & 0 & 0 & 0 \\
both low & 14 & 18 & 0 & 0 & 0 & 0 \\
both low & 23 & 18 & 1 & 0 & 0 & 0 \\
both low & 32 & 18 & 2 & 1 & 0 & 0 \\
both low & 41 & 18 & 5 & 1 & 0 & 0 \\
both low & 50 & 18 & 6 & 0 & 0 & 0 \\
both low & 59 & 18 & 5 & 2 & 0 & 1 \\
both low & 68 & 18 & 10 & 3 & 2 & 3 \\
both low & 77 & 18 & 13 & 3 & 3 & 5 \\
both low & 86 & 18 & 15 & 3 & 2 & 9 \\
both low & 5 & 20 & 0 & 0 & 0 & 0 \\
both low & 14 & 20 & 0 & 0 & 0 & 0 \\
both low & 23 & 20 & 1 & 0 & 0 & 0 \\
both low & 32 & 20 & 4 & 0 & 0 & 0 \\
both low & 41 & 20 & 3 & 0 & 0 & 0 \\
both low & 50 & 20 & 4 & 0 & 0 & 0 \\
both low & 59 & 20 & 6 & 0 & 0 & 2 \\
both low & 68 & 20 & 10 & 0 & 0 & 2 \\
both low & 77 & 20 & 20 & 0 & 0 & 0 \\
both low & 86 & 12 & 0 & 0 & 0 \\
\hline
\end{tabular}

5.6.3. Rate of biting of Argentine ants at different temperature levels. Rate of biting was measured in terms of number of bites per minute.

\begin{tabular}{ccc} 
At $12^{\circ} \mathrm{C}$ & At $16^{\circ} \mathrm{C}$ & At $20^{\circ} \mathrm{C}$ \\
\hline 0 & 1 & 5 \\
0 & 0 & 3 \\
0 & 2 & 7 \\
0 & 0 & 10 \\
0 & 1 & 9 \\
0 & 0 & 7 \\
0 & 1 & 12 \\
0 & 0 & 10 \\
0 & 0 & 15 \\
0 & 1 & 13 \\
0 & 0 & 12 \\
0 & 0 & 15 \\
0 & 0 & 10 \\
0 & 1 & 6 \\
0 & 0 & 9 \\
0 & 0 & 16 \\
0 & 0 & 5
\end{tabular}




\begin{tabular}{ccc}
0 & 2 & 7 \\
0 & 0 & 10 \\
0 & 0 & 6 \\
\hline
\end{tabular}

5.6.4. Walking speed of ants at different temperature $\left({ }^{\circ} \mathrm{C}\right)$ levels.

\begin{tabular}{|c|c|c|c|c|c|c|c|}
\hline $\begin{array}{l}\text { Tempe } \\
\text { rature }\end{array}$ & $\begin{array}{l}\text { L. } \\
\text { humile }\end{array}$ & $\begin{array}{l}M . \\
\text { antarcticum }\end{array}$ & $\begin{array}{l}P . \\
\text { advenus }\end{array}$ & $\begin{array}{l}\text { Tempe } \\
\text { rature }\end{array}$ & $\begin{array}{l}\text { L. } \\
\text { humile }\end{array}$ & $\begin{array}{l}M . \\
\text { antarcticum }\end{array}$ & $\begin{array}{l}P . \\
\text { advenus }\end{array}$ \\
\hline 12 & 4 & 6.5 & 7.5 & 16 & 10 & 5 & 9 \\
\hline 12 & 8 & 5 & 7 & 16 & 7.5 & 5 & 10 \\
\hline 12 & 5 & 5 & 8 & 16 & 6 & 7 & 11.5 \\
\hline 12 & 6 & 4 & 7.5 & 16 & 10 & 9 & 12.5 \\
\hline 12 & 7.5 & 5 & 7.5 & 16 & 11.5 & 6.5 & 12.5 \\
\hline 12 & 5 & 5 & 7.5 & 16 & 8 & 6 & 11.5 \\
\hline 12 & 5 & 6 & 7 & 16 & 9 & 7 & 10 \\
\hline 12 & 6 & 6 & 8 & 16 & 6 & 7.5 & 14 \\
\hline 12 & 6.5 & 5 & 7 & 16 & 12.5 & 7 & 12.5 \\
\hline 12 & 6.5 & 5 & 7.5 & 16 & 10 & 5 & 15 \\
\hline 12 & 8 & 6.5 & 7 & 18 & 12.5 & 5 & 13 \\
\hline 12 & 6 & 4 & 8 & 18 & 17.5 & 10 & 12.5 \\
\hline 12 & 5 & 5 & 8 & 18 & 15 & 9 & 9 \\
\hline 12 & 8 & 6.5 & 7.5 & 18 & 14 & 10 & 13 \\
\hline 12 & 8 & 5 & 7 & 18 & 19 & 12.5 & 9 \\
\hline 12 & 6 & 5 & 8 & 18 & 10 & 11 & 9 \\
\hline 12 & 6.5 & 6 & 8 & 18 & 15 & 10 & 10 \\
\hline 12 & 5 & 5 & 7 & 18 & 10 & 9 & 10 \\
\hline 12 & 6 & 6.5 & 8 & 18 & 12.5 & 10 & 13 \\
\hline 12 & 5 & 5 & 7 & 18 & 17.5 & 10 & 9 \\
\hline 14 & 7.5 & 5 & 10 & 18 & 10 & 9 & 10 \\
\hline 14 & 8 & 7.5 & 12.5 & 18 & 9 & 10 & 10 \\
\hline 14 & 10 & 5 & 12.5 & 18 & 9 & 10 & 13 \\
\hline 14 & 10 & 5 & 10 & 18 & 10 & 5 & 10 \\
\hline 14 & 12.5 & 4 & 12.5 & 18 & 10 & 9 & 12.5 \\
\hline 14 & 7.5 & 4 & 10 & 18 & 12.5 & 10 & 10 \\
\hline 14 & 7.5 & 5 & 10 & 18 & 9 & 9 & 9 \\
\hline 14 & 7.5 & 5 & 10 & 18 & 9 & 10 & 10 \\
\hline 14 & 7.5 & 5 & 12 & 18 & 14 & 10 & 12.5 \\
\hline 14 & 7.5 & 6 & 10 & 18 & 15 & 7.5 & 10 \\
\hline 14 & 7 & 7.5 & 10 & 20 & 22.5 & 14 & 11.5 \\
\hline 14 & 7.5 & 4 & 12 & 20 & 21 & 12.5 & 9 \\
\hline 14 & 9 & 6 & 12.5 & 20 & 22.5 & 10 & 12.5 \\
\hline 14 & 9 & 7.5 & 10 & 20 & 15 & 9 & 15 \\
\hline 14 & 7 & 5 & 12.5 & 20 & 16.5 & 12.5 & 12.5 \\
\hline 14 & 7 & 6 & 10 & 20 & 17.5 & 12.5 & 10 \\
\hline 14 & 9 & 5 & 12 & 20 & 19 & 12.5 & 10 \\
\hline 14 & 10 & 4 & 9 & 20 & 20 & 12.5 & 14 \\
\hline 14 & 8 & 6 & 10 & 20 & 17.5 & 9 & 13 \\
\hline 14 & 5 & 6 & 10 & 20 & 17.5 & 12.5 & 12.5 \\
\hline 16 & 10 & 7.5 & 12.5 & 20 & 20 & 10 & 9 \\
\hline 16 & 9 & 6.5 & 10 & 20 & 22.5 & 12.5 & 9 \\
\hline
\end{tabular}




\begin{tabular}{cccccccc}
16 & 9 & 7 & 14 & 20 & 15 & 9 & 9 \\
16 & 10 & 5 & 14 & 20 & 17.5 & 10 & 10 \\
16 & 7.5 & 6.5 & 10 & 20 & 20 & 10 & 12.5 \\
16 & 7.5 & 6.5 & 15 & 20 & 17.5 & 12.5 & 15 \\
16 & 7.5 & 6 & 9 & 20 & 22.5 & 14 & 12.5 \\
16 & 9 & 8 & 8.5 & 20 & 22.5 & 15 & 12.5 \\
16 & 6.5 & 7.5 & 10 & 20 & 20 & 12.5 & 10 \\
16 & 7.5 & 7 & 10 & 20 & 17.5 & 12.5 & 12.5 \\
\hline
\end{tabular}

5.6.5. Foraging abundance change of non-interacting ant species with temperature.

\begin{tabular}{|c|c|c|c|c|c|c|}
\hline 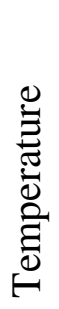 & 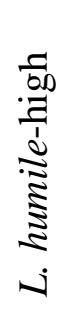 & 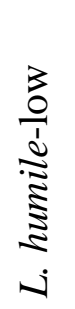 & 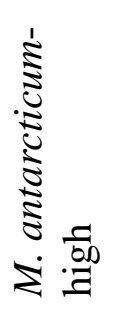 & 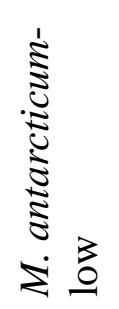 & 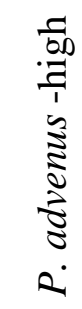 & 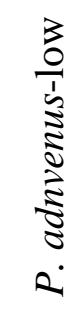 \\
\hline 20 & 26 & 17 & 23 & 28 & 80 & 20 \\
\hline 20 & 60 & 66 & 80 & 30 & 70 & 16 \\
\hline 20 & 60 & 60 & 75 & 35 & 75 & 18 \\
\hline 20 & 40 & 45 & 65 & 30 & 90 & 20 \\
\hline 20 & 45 & 30 & 40 & 20 & 65 & 18 \\
\hline 20 & 35 & 20 & 30 & 11 & 75 & 15 \\
\hline 20 & 21 & 17 & 20 & 10 & 60 & 16 \\
\hline 20 & 18 & 7 & 21 & 15 & 100 & 14 \\
\hline 20 & 16 & 4 & 14 & 38 & 95 & 26 \\
\hline 20 & 15 & 5 & 11 & 36 & 105 & 33 \\
\hline 20 & 40 & 30 & 75 & 25 & 70 & 30 \\
\hline 20 & 55 & 45 & 80 & 30 & 100 & 19 \\
\hline 20 & 35 & 35 & 65 & 20 & 90 & 22 \\
\hline 20 & 60 & 50 & 70 & 20 & 85 & 18 \\
\hline 20 & 40 & 35 & 40 & 25 & 90 & 18 \\
\hline 18 & 15 & 15 & 22 & 15 & 100 & 15 \\
\hline 18 & 17 & 25 & 20 & 25 & 110 & 20 \\
\hline 18 & 20 & 26 & 18 & 19 & 90 & 18 \\
\hline 18 & 35 & 20 & 21 & 20 & 100 & 16 \\
\hline 18 & 20 & 30 & 30 & 13 & 80 & 14 \\
\hline 18 & 19 & 31 & 35 & 20 & 95 & 18 \\
\hline 18 & 24 & 18 & 30 & 22 & 90 & 20 \\
\hline 18 & 21 & 7 & 20 & 19 & 80 & 25 \\
\hline 18 & 34 & 3 & 9 & 15 & 110 & 30 \\
\hline 18 & 31 & 3 & 7 & 20 & 100 & 25 \\
\hline 18 & 25 & 25 & 18 & 25 & 95 & 35 \\
\hline 18 & 20 & 18 & 30 & 9 & 80 & 20 \\
\hline 18 & 31 & 30 & 25 & 14 & 100 & 17 \\
\hline 18 & 33 & 25 & 23 & 20 & 105 & 19 \\
\hline 18 & 25 & 18 & 17 & 19 & 90 & 23 \\
\hline \multicolumn{6}{|c|}{127} & \\
\hline
\end{tabular}




\begin{tabular}{|c|c|c|c|c|c|c|}
\hline 16 & 9 & 4 & 9 & 10 & 120 & 25 \\
\hline 16 & 15 & 3 & 15 & 11 & 110 & 14 \\
\hline 16 & 20 & 6 & 22 & 24 & 125 & 30 \\
\hline 16 & 30 & 7 & 30 & 20 & 85 & 18 \\
\hline 16 & 30 & 3 & 30 & 21 & 90 & 25 \\
\hline 16 & 30 & 4 & 31 & 18 & 100 & 26 \\
\hline 16 & 14 & 7 & 20 & 18 & 110 & 19 \\
\hline 16 & 7 & 5 & 8 & 20 & 80 & 35 \\
\hline 16 & 10 & 5 & 7 & 23 & 65 & 35 \\
\hline 16 & 12 & 4 & 4 & 17 & 80 & 20 \\
\hline 16 & 25 & 3 & 20 & 20 & 80 & 37 \\
\hline 16 & 20 & 4 & 25 & 25 & 75 & 35 \\
\hline 16 & 30 & 7 & 20 & 19 & 65 & 31 \\
\hline 16 & 30 & 5 & 30 & 26 & 70 & 34 \\
\hline 16 & 25 & 3 & 21 & 21 & 75 & 30 \\
\hline 14 & 2 & 1 & 8 & 4 & 60 & 24 \\
\hline 14 & 6 & 4 & 8 & 12 & 80 & 20 \\
\hline 14 & 18 & 3 & 12 & 16 & 70 & 25 \\
\hline 14 & 16 & 6 & 15 & 7 & 100 & 19 \\
\hline 14 & 14 & 3 & 16 & 10 & 60 & 17 \\
\hline 14 & 9 & 3 & 19 & 17 & 70 & 20 \\
\hline 14 & 10 & 4 & 20 & 11 & 65 & 20 \\
\hline 14 & 7 & 6 & 31 & 15 & 60 & 16 \\
\hline 14 & 2 & 1 & 28 & 13 & 40 & 21 \\
\hline 14 & 3 & 3 & 11 & 19 & 70 & 18 \\
\hline 14 & 10 & 3 & 7 & 16 & 60 & 20 \\
\hline 14 & 13 & 3 & 16 & 20 & 45 & 18 \\
\hline 14 & 16 & 2 & 20 & 12 & 60 & 18 \\
\hline 14 & 10 & 4 & 22 & 16 & 75 & 15 \\
\hline 14 & 7 & 5 & 19 & 19 & 60 & 20 \\
\hline 12 & 5 & 1 & 8 & 10 & 80 & 10 \\
\hline 12 & 7 & 2 & 10 & 8 & 90 & 11 \\
\hline 12 & 6 & 1 & 14 & 12 & 60 & 19 \\
\hline 12 & 15 & 5 & 16 & 18 & 51 & 20 \\
\hline 12 & 15 & 1 & 12 & 18 & 55 & 19 \\
\hline 12 & 8 & 1 & 12 & 11 & 40 & 20 \\
\hline 12 & 6 & 2 & 18 & 18 & 32 & 13 \\
\hline 12 & 8 & 3 & 8 & 10 & 25 & 15 \\
\hline 12 & 4 & 1 & 8 & 7 & 50 & 13 \\
\hline 12 & 3 & 2 & 11 & 5 & 55 & 13 \\
\hline 12 & 8 & 1 & 12 & 7 & 40 & 14 \\
\hline 12 & 14 & 3 & 10 & 12 & 55 & 16 \\
\hline 12 & 12 & 2 & 16 & 13 & 37 & 13 \\
\hline 12 & 7 & 1 & 11 & 18 & 30 & 14 \\
\hline 12 & 7 & 1 & 10 & 9 & 40 & 10 \\
\hline
\end{tabular}




\section{Chapter 6}

\section{Summary and General Discussion}

\section{Effects of invasive species on invertebrate communities}

The main focus of my study was to investigate how invasive species affect the community they invade, and to examine some of the biotic and abiotic factors that might provide resistance to invasion. I investigated the spatio-temporal distribution of Linepithema humile (Argentine ants) in relation to habitat and associated distributions of other arthropod species.

It is widely acknowledged that the strongest interaction of Argentine ants with arthropods is usually with other ant species, which they typically displace from the areas they invade (Holway and Suarez, 2006; Cooling et al., 2012). I observed that areas that had been invaded by Argentine ants also had a low species richness of other ants (Chapter 3) and a low species richness of endemic arthropods (Chapter 4). Studies in Hawaii also reported lower arthropod diversity in the presence of Argentine ants (Cole et al., 1992; Krushelnysky and Gillespie 2008).However, without data on the areas prior to invasion it is difficult to know if preexisiting low diversity allowed an invasion, or if the invasion caused a reduction in diversity. Hawaii has no native ant species, and the ant fauna of New Zealand is very depauperate, which suggests that the native beetles of these two regions may have few natural adaptations to resist predation and competition from ants.

My study also showed that area invaded by the Argentine ants had more exotic beetle species than the uninvaded areas - an effect that has also been observed in other countries (Cole et al., 1992). Invasions can destabilise communities, hence facilitating future invasions and leading to high species turnover (Shea and Chesson, 2002); a process known as "invasional meltdown" (Green et al., 2011). Analysis of species composition at coastal sites (Chapter 4) showed that there was a continuous change in species composition that could be due to primary and secondary invasions. Apart from some endemic species persisting in the invaded habitat, a number of them appear to be extirpated and more are on the verge of extirpation.

In Hawaii, invasion by Argentine ants seemed to facilitate secondary invasion by other beetle species (Cole et al., 1992). I believe the displacement of endemic beetles species at Piha is likely due to the invasion by the Argentine ants and not by the exotic beetle species. However, the exotic beetle species may have some effect on the endemic ones, and there is little research on the exotic beetles and endemic beetle species recorded at my study sites. 


\section{Confounding effects}

At Piha, the invaded habitat was different from the uninvaded in terms of vegetation type and structure. The uninvaded area typically had $100 \%$ cover of tall herbs under $45 \%$ to $100 \%$ tree cover while the invaded area had a ground cover of c. $80 \%$ short herbs and about $30 \%$ tree cover. Exotic ant species (Pheidole rugosula) new to this area were found in the uninvaded habitat as well as some areas from which Argentine ants had retreated. Because of this additional invasion, and a temporal shift in vegetation structure in some areas, it is difficult to conclude whether differences in the beetle community between areas invaded and uninvaded by the Argentine ants are due to differences in vegetation structure or a result of the presence of the P. rugosula. Pheidole rugosula is an exotic species to New Zealand, however, little is known about their impact apart from that they are generalist foragers (Don, 2007). Their close relative, Pheidole megacephala is an invasive species with negative impact on other ant species (Dejean et al., 2008).

\section{Habitat associations}

The distribution patterns of ant species in response to different microhabitat structures were studied in chapter 3. Microhabitats were categorized as concrete, bare earth/sand, short grass/herbs, long grass/herbs and trees. Study sites include; Wellington (Kelburn), Hastings, Piha and Dargaville. Argentine ants were most frequently found in concrete habitat types in the urban sites and in short herbs in the rural site(s). Interestingly, one of the endemic species to New Zealand, M. antarcticum was found to be associated with the same microhabitat type as the Argentine ants, mainly in the southern part of the North Island (Wellington), but at sites further north that experience a warmer climate $M$. antarcticum was more commonly found in more shaded habitat such as tall grass. Although there were a number of other species found in the same habitat as Argentine ants, their abundance was greater in areas where the Argentine ants were not common.

\section{Distributions predicted from temperature and climate}

A number of studies have predicted the potential global distribution of the Argentine ants using bioclimatic models (Hartley et al. 2006; Roura-Pascual et al. 2004, Roura-Pascual et al. 2011). These predictions are based on fairly coarse-scale associations between existing distribution and climate. An earlier study by Hartley and Lester (2003) predicted the potential distribution of Argentine ants in New Zealand based specifically upon temperature requirements for development from ant egg to an adult stage. The inferred threshold of 445 
degree days above $15.9 \mathrm{C}$ was found to correspond well with the rate-of-spread and limits of distribution in Haleakala National Park, Hawaii (Hartley et al., 2010).

Based on the degree-day model (Hartley and Lester 2003), I calculated the number of generations the Argentine ants can be expected to develop in each microhabitat type. My results (Chapter 3) predicted that the Argentine ants in northern New Zealand were unable to develop a single generation (from egg to adult) in one year under long grass and trees which is also the habitat where they were least frequently found. Hence, the distribution pattern of the ants across microhabitat types may be partly due to different developmental rates (optimal temperature for reproduction of the Argentine ants is about $28^{\circ} \mathrm{C}$ (Abril et al., 2008)), but equally other important physiological processes also correlate with differences in surface temperature, such as speed of walking and foraging behaviour (Suverkropp et al., 2001). These temperature-dependent processes were the subject of a later investigation with laboratory colonies (Chapter 5).

\section{Habitat associations affecting competitive interactions}

I find two important points to underscore. First, if other ant species inhabit the same habitat type as Argentine ants this will likely expose them to competition and/or aggressive interaction. Second, higher abundance of other ant species in the other microhabitats (especially at lower temperatures) may prevent the Argentine ants from spreading. Argentine ants are rarely found in New Zealand's forest habitats (Don, 2007). In tests of interactions with forest species such as $P$. advenus and $M$. antarcticum, Argentine ants were subordinate under low temperatures (e.g. $<16^{\circ} \mathrm{C}$ ), but dominant at higher temperatures (Chapter 5). Thus one may conclude that it is the combination of low temperatures and biotic resistance that keep Argentine ants out of forest habitats.

Other studies have also found that ant distribution patterns are strongly associated with vegetation structures (Rios-Casanova et al., 2006) that could be mainly due to temperature variation (Holec et al., 2006) as regulation of body temperature of ectotherms depends on environmental temperature (Dillon et al., 2012). However, other factors may also be important in influencing distribution patterns across habitat types. For example, variation in food availability (Perez-Ramos et al., 2008) and differences in predator distribution (Boukal et al., 2007) can also result in variation in species density, richness and distribution patterns variation among different microhabitat types (Guido and Gianelle, 2001; Miller et al., 2012). The study of ant species distribution patterns in relation to microhabitat types stresses the importance of identifying ant species that are likely to encounter each other in a shared microhabitat. 


\section{Spread fluctuations and decline in Argentine ant populations}

In chapter 2 I examined the changing distribution of the Argentine ants at five sites in New Zealand in an attempt to measure local rates of spread. Argentine ants spread between $100 \mathrm{~m}$ (Ingram and Gordon, 2003; Krushelnycky et al., 2004) and 150m per year (Suarez et al., 2001).

Despite the fact that a number of common microhabitats (such as around concrete and short grass) appear to provide a suitable thermal environment for the development of Argentine ants I found that populations of Argentine ants showed an overall decline in three urban study sites, Dargaville, Hastings and Wellington. At the coastal sites there seemed to be a slight increase at Baylys Beach and at Piha a decline. This suggests that temperature and climatic considerations alone are not always sufficient to predict whether an introduced population will increase or decline. It is important to remember that most insect abundances fluctuate annually (Barlow et al., 2002), nonetheless an independent study that revisited many sites across New Zealand concluded that at approximately one-third of the sites Argentine ant populations had undergone a dramatic decline or "collapse" over the past 10-20 years (Cooling et al., 2012). The causes of the decline can only be a matter of speculation. Models of population growth and regulation that include time lags often demonstrate that species may overshoot their local carrying capacity and then decline - undergoing oscillations which in extreme cases can result in a population crash and local extirpation (May, 1974). Some untested mechanisms that may have been responsible for the declines include a build-up of specialist predators against invasive species (e.g. Derivera et al, 2005), control by a pathogenic microorganism (e.g. Hajek et al, 2005) or exhaustion of suitable food resources (e.g. Nonacs and Soriano, 1998).

\section{Interaction of temperature and colony size}

The majority of species moved outside of their native ranges fail to establish (e.g. the ten's rule of Williamson and Fitter, 1996) According to my laboratory results, small colony size (e.g. Allee effects) and unfavourable temperatures are believed to be important predictors in resisting invasion. Endemic species may be expected to have an advantage over exotic species as they could be better adapted to certain climate regions which may be out of the tolerance range of the invasive species. The interactive effect of colony size and low temperature appears to be more of an advantage to the endemic ant species during fighting. Field study also reveals the combined effect of climate and biotic resistance from neighbouring species on increasing mortality of ant species (Sanders and Gordon, 2004). Some of the mechanisms impairing the success of invaders due to low temperature are reduced developmental times, slowed walking speed, and decreased foraging abundance and aggression as my results show. Accompanied by 
low temperature $\left(16^{\circ} \mathrm{C}\right), M$. antarcticum successfully displaced the Argentine ants from the foraging arena in laboratory experiment (Chapter 5).

\section{Management implications}

The community disturbance generated by the invasion of one species can be exacerbated by subsequent invasions in a process called "invasional meltdown" (Montgomery et al., 2012) which sets further challenges to control measures. Eradication of invasive species (Donlan et al., 2007) and habitat restoration allows species to reclaim their niche through time (Prach and Pysek, 2001). In the case of invasion, the community is set to continuous instability (Krushelnycky and Gillespie, 2008). That is, although some of the endemic species may attempt to come back during the invasion period, as long as the Argentine ants are there the endemic species may not be able to reclaim their habitat by displacing the secondary invaders, such as the exotic beetle species.

In this study I have investigated the role of temperature and biotic resistance in halting establishment of the invasive species, the Argentine ants. However, these effects may change with human intervention. Some of the causes of loss of biodiversity are disturbances such as habitat fragmentation (Gibb and Hochuli, 2002; Ricketts and Imhoff, 2003) which facilitates invasion (Carpintero et al., 2003). Habitat fragmentation accompanied by climatic changes further challenges the efforts of conservation of biodiversity (Opdam and Wascher, 2004). Exponential human population growth is resulting in serious habitat degradation that threatens biodiversity (Estes et al., 2012; Holdren and Ehrlich, 1974; Meyer and Turner, 1992). Climate change driven by global warming (Akerlof et al., 2012; Corfee-Morlot and Hohne, 2003) has been associated with invasion success (Crossman, 2011; Kleinbauer, 2010). Therefore, the two factors (temperature and biotic resistance) implicated here in halting spread of an invasive species seem to present a grim prospect for the future as temperature is rising due to climate change and biodiversity is further deteriorating due to habitat degradation. Nevertheless, under present climatic conditions, in hand with the economic benefits they provide, habitat management, such as tree planting or natural regeneration, may have contributed to controlling or minimizing the spread of invasive species through unfavourable (cooler) habitat. This suggests that restoration of natural habitats may be an effective way of combating the spread of other invasive species in the face of future global climate change. 


\subsection{References}

Abril, S., J. Oliveras, and C. Gomez, 2008. Effect of temperature on the oviposition rate of Argentine ant queens (Linepithema humile Mayr) under monogynous and polygynous experimental conditions. Journal of Insect Physiology 54: 265-272.

Akerlof, K., E. W. Maibach, D. Fitzgerald, A. Y. Cedeno, and A. Neuman, 2012. Do people "personally experience" global warming, and if so how, and does it matter? Global Environmental Change [Online Early] Doi: 10.1016/j.gloenvcha.2012.07.006.

Barlow, N. D., J. R. Beggs, and M. C. Barron, 2002. Dynamics of common wasps in New Zealand beech forests: A model with density dependence and weather. Journal of Animal Ecology 71: 663-671.

Boukal, D. S., M. W. Sabelis, and L. Berec, 2007. How predator functional responses and Allee effects in prey affect the paradox of enrichment and population collapses. Theoretical Population Biology 72: 136-147.

Carpintero, S., J. Reyes-Lopez, and L. A. Reyna, 2003. Impact of human dwellings on the distribution of the exotic Argentine ant: a case study in the Donana National Park, Spain. Biological Conservation 115: 279-289.

Cole, F. R., A. C. Medeiros, L. L. Loope, and W. W. Zuehlke, 1992. Effect of the Argentine ant on arthropod fauna of Hawaiian high-elevation. Ecology 73: 1313-1322.

Cooling, M., S. Hartley, D. A. Sim, and P. J. Lester, 2012. The widespread collapse of an invasive species: Argentine ants (Linepithema humile). Biology Letters Biology Letters 8: 430-433.

Corfee-Morlot, J. and N. Hohne, 2003. Climate change: long-term targets and short-term commitments. Global Environmental Change 13: 277-293.

Crossman, N. D., B. A. Bryan, and D. A. Cooke, 2011. An invasive plant and climate change threat index for weed risk management: integrating habitat distribution pattern and dispersal process. Ecological Indicators 11: 183-198.

Dejean, A., C. S. Moreau, M. Kenne, and M. Leponce, 2008. The raiding success of Pheidole megacephala on other ants in both its native and introduced ranges. Comptes Rendus Biologies 331: 631-635.

Derivera, C. E., G. M. Ruiz, A. H. Hines, and P. Jivoff, 2005. Biotic resistance to invasion: native predator limits abundance of an introduced crab. Ecology 86: 3364-3376.

Dillon, M. E., R. Liu, G. Wang, and R. B. Huey, 2012. Disentangling thermal preference and the thermal dependence of movement in ectotherms. Journal of Thermal Biology 37: 631639.

Don, W., 2007. Ants of New Zealand. University of Otago Press in association with the Otago Museum, Dunedin. 
Donlan, C. J., K. Campbell, W. Cabrera, C. Lavoie, V. Carrion, F. Cruz, 2007. Recovery of the Galapagos rail (Laterallus spilonotus) following the removal of invasive mammals. Biological Conservation 138: 520-524.

Estes, A. B., T. Kuemmerle , H. Kushnir, V. C. Radeloff, and H. H. Shugart, 2012. Land-cover change and human population trends in the greater Serengeti ecosystem from 1984-2003. Biological Conservation 147: 255-263.

Gibb, H. and D. F. Hochuli, 2002. Habitat fragmentation in an urban environment: large and small fragments support different arthropod assemblages. Biological Conservation 106: 91100.

Green, P. T., D. J. O’Dowd, K. L. Abbott, M. Jeffery, K. Retallick, and R. M. Nally, 2011. Invasional meltdown: invader-invader mutualism facilitates a secondary invasion. Ecology 92: $1758-1768$.

Guido, M. and D. Gianelle, 2001. Distribution patterns of four orthoptera species in relation to microhabitat heterogeneity in an ecotonal area. Acta Oecologica 22: 175-185.

Hajek, A. E., M. L. McManus, and I. D. Junior, 2007. A review of introductions of pathogens and nematodes for classical biological control of insects and mites. Biological Control 41: $1-13$.

Hartley, S. and P. J. Lester, 2003. Temperature-dependent development of the Argentine ant, Linepithema humile (Mayr) (Hymenoptera: Formicidae): a degree-day model with implications for range limits in New Zealand. New Zealand Entomologist 26:91-100.

Hartley, S., R. Harris, and P. J. Lester, 2006. Quantifying uncertainty in the potential distribution of an invasive species: climate and the Argentine ant. Ecology Letters 9: 10681079 .

Holdren, J. P. and P. R. Ehrlich, 1974. Human population and the global environment: population growth, rising per capita material consumption and disruptive technologies have made civilization a global ecological force. American Scientist 62: 282-292.

Holec, M., J. Frouz, and R. Pokorný, 2006. The influence of different vegetation patches on the spatial distribution of nests and the epigeic activity of ants (Lasius niger) on a spoil dump after brown coal mining (Czech Republic). European Journal of Soil Biology 42: 158-165.

Holway, D. A. and A. V. Suarez, 2006. Homogenization of ant communities in Mediterranean California: the effects of urbanization and invasion. Biological Conservation 127: 319-326.

Kleinbauer, I., S. Dullinger, J. Peterseil, and F. Ess1, 2010. Climate change might drive the invasive tree Robinia pseudacacia into nature reserves and endangered habitats. Biological Conservation 143: 382-390.

Krushelnycky, P. and R. G. Gillespie, 2008. Compositional and Functional Stability of Arthropod Communities in the Face of Ant invasions. Ecological Applications 18: 15471562.

Landcare Research, 2012. New Zealand response to pest invasions. http://www.isinz.com/nz.asp. 
May, R. M., 1974. Biological population with nonoverlapping generations: stable points, stable cycles, and chaos. Science, New Series 186: 645-647.

Meyer, W. B. and B. L. Turner II, 1992. Human population growth and global land-use/cover change. Annual Review of Ecology and Systematics 23: 39-61.

Miller, S. L., J. S. Shima, and N. E. Phillips, 2012. Effects of microhabitat availability on estimates of density of a reef fish: implications for assessments of marine protected areas. Hydrobiologia 685: 173-190.

Montgomery, W. I., M. G. Lundy, and N. Reid, 2012. Invasional meltdown: evidence for unexpected consequences and cumulative impacts of multispecies invasions. Biological Invasions 14: 1111-1125.

Nonacs, P. and J. L. Soriano, 1998. Patch sampling behavior and future foraging expectations in Argentine ants, Linepithema humile. Animal Behavior 55: 519-527.

Opdam, P. and D. Wascher, 2004. Climate change meets habitat fragmentation: linking landscape and biogeographical scale levels in research and conservation. Biological Conservation 117: 285-297.

Perez-Ramos, I. M., M. A. Zavala, T. Maranon, M. D. Diaz-Villa, and F. Valladares, 2008. dynamics of understorey herbaceous plant diversity following shrub clearing of cork oak forests: a five-year study. Forest Ecology and Management 255: 3242-3253.

Prach, K. and P. Pysek, 2001. Using spontaneous succession for restoration of human-disturbed habitats: experience from Central Europe. Ecological Engineering 17: 55-62.

Ricketts, and T. M. Imhoff, 2003. Biodiversity, urban areas, and Agriculture: locating priority ecoregions for Conservation. Conservation Ecology 8:1-15.

Ríos-Casanova, L., A. Valiente-Banuea, and V. Rico-Gray, 2006. Ant diversity and its relationship with vegetation and soil factors in an alluvial fan of the Tehuacán Valley, Mexico. Acta Oecologica 29: 316-323.

Rosenzweig, M. L. and Y. Ziv, 1999. The echo pattern of species diversity: pattern and process. Ecography 22:614-628.

Roura-Pascual, N., A. Suarez, C. Gomez, P. Pons, Y. Touyama, A. L. Wild, and A. T. Peterson, 2004. Geographic potential of Argentine ants (Linepithema humile Mayr) in the face of global climate change. Proceedings of the Royal Society of London Series B-Biological Sciences 271: 2527-2534.

Roura-Pascual, N., C. Hui, T. Ikeda, G. Leday, D. M. Richardson, S. Carpintero, X. Espadaler, C. Gómez, B. Guénard, S. Hartley, P. Krushelnycky, P. J. Lester, M. A. McGeoch, S. B. Menke, J. S. Pedersen, J. P. W. Pitt, J. Reyes, N. J. Sanders, A. V. Suarez, Y. Touyama, D. Ward, P. S. Ward, and S. P. Worner, 2011. Relative roles of climatic suitability and anthropogenic influence in determining the pattern of spread in a global invader. Proceedings of the National Academy of Sciences 108: 220-225. 
Sagata, K. and P. J. Lester, 2008. Behavioural plasticity associated with propagule size, resources, and the invasion success of the Argentine ant Linepithema humile. Journal of Applied Ecology 46: 19-27.

Sanders, N. J. and D. M. Gordon, 2004. The interactive effects of climate, life history, and interspecific neighbours on mortality in a population of seed harvester ants. Ecological Entomology 29: 632-637.

Shea, K. and P. Chesson, 2002. Community ecology theory as a framework for biological invasions. Trends in Ecology and Evolution 17:170-176.

Suverkropp, B. P., F. Bigler, and J. C. van Lenteren, 2001. Temperature influences walking speed and walking activity of Trichogramma brassicae (Hymenoptera, Trichogrammatidae). Journal of Applied Entomology 125: 303-307.

Verberk, W. C. E. P., G .A. van Duinen, A. M. T. Brock, R. S. E. W. Leuven, H. Siepel, P. F. M. Verdonschot, G. van der Velde, and H. Esselink, 2006. Importance of landscape heterogeneity for the conservation of aquatic microinvertebrate diversity in bog landscapes. Journal for Nature Conservation 14: 78-90.

Williamson, M. H. and A. Fitter, 1996. The Characters of successful Invaders. Biological Conservation 78: 163-170. 


\subsection{Appendix}

7.1. Coordinate points (New Zealand Map Grid) in each study site from which samples were collected. Prefixes: PI=Piha, BB=Baylys Beach.

\begin{tabular}{cccccc} 
Sample ID & eastings & northings & sample ID & easting & northing \\
\hline PI1 & 2640553 & 6472746 & BB1 & 2577080 & 6583705 \\
PI2 & 2640579 & 6472697 & BB2 & 2577117 & 6583653 \\
PI3 & 2640610 & 6472649 & BB3 & 2577143 & 6583607 \\
PI4 & 2640622 & 6472597 & BB4 & 2577176 & 6583575 \\
PI5 & 2640657 & 6472536 & BB5 & 2577203 & 6583542 \\
PI6 & 2640688 & 6472493 & BB6 & 2577213 & 6583526 \\
PI7 & 2640698 & 6472427 & BB7 & 2577253 & 6583471 \\
PI8 & 2640712 & 6472375 & BB8 & 2577298 & 6583420 \\
PI9 & 2640740 & 6472325 & BB9 & 2577358 & 6583338 \\
PI10 & 2640759 & 6472268 & BB10 & 2577386 & 6583286 \\
PI11 & 2640799 & 6472216 & BB11 & 2577471 & 6583229 \\
PI12 & 2640839 & 6472153 & BB12 & 2577530 & 6583129 \\
PI13 & 2640851 & 6472116 & BB13 & 2577553 & 6583062 \\
PI14 & 2640889 & 6472072 & BB14 & 2577600 & 6583010 \\
PI15 & 2640926 & 6472029 & BB15 & 2577636 & 6582961 \\
PI16 & 2640888 & 6471981 & BB16 & 2577664 & 6582929 \\
PI17 & 2640892 & 6471930 & BB17 & 2577684 & 6582868 \\
PI18 & 2640939 & 6471887 & BB18 & 2577759 & 6582801 \\
PI19 & 2640954 & 6471861 & BB19 & 2577795 & 6582785 \\
PI20 & 2641011 & 6471817 & BB20 & 2577850 & 6582687 \\
PI21 & 2640543 & 6472804 & BB21 & 2577865 & 6582645 \\
\hline
\end{tabular}

7.2. Coordinate points (New Zealand Map Grid) in each study site from which samples were collected. Prefixes: K=Wellington (Kelburn), H=Hastings, DG=Dargaville.

$\begin{array}{lllllllll}\text { Sample } & \text { eastings } & \text { northings } & \text { Sample } & \text { eastings } & \text { northings } & \begin{array}{l}\text { Sample } \\ \text { ID }\end{array} & \text { eastings } & \text { northings } \\ \text { K001 } & 2657928 & 5989601 & \text { K018 } & 2657799 & 5989610 & \text { K035 } & 2657739 & 5989668 \\ \text { K002 } & 2657926 & 5989636 & \text { K019 } & 2657804 & 5989573 & \text { K036 } & 2657750 & 5989670 \\ \text { K003 } & 2657952 & 5989658 & \text { K020 } & 2657777 & 5989562 & \text { K037 } & 2657783 & 5989661 \\ \text { K004 } & 2657946 & 5989675 & \text { K021 } & 2657775 & 5989510 & \text { K038 } & 2657788 & 5989678 \\ \text { K005 } & 2657977 & 5989708 & \text { K022 } & 2657749 & 5989483 & \text { K039 } & 2657806 & 5989656 \\ \text { K006 } & 2657958 & 5989713 & \text { K023 } & 2657752 & 5989452 & \text { K040 } & 2657831 & 5989660 \\ \text { K007 } & 2658000 & 5989740 & \text { K024 } & 2657728 & 5989433 & \text { K041 } & 2657756 & 5989712 \\ \text { K008 } & 2658047 & 5989788 & \text { K025 } & 2657686 & 5989430 & \text { K042 } & 2657740 & 5989726 \\ \text { K009 } & 2657998 & 5989775 & \text { K026 } & 2657643 & 5989466 & \text { K043 } & 2657771 & 5989768 \\ \text { K010 } & 2657902 & 5989736 & \text { K027 } & 2657658 & 5989473 & \text { K044 } & 2657750 & 5989760 \\ \text { K011 } & 2657874 & 5989732 & \text { K028 } & 2657652 & 5989498 & \text { K045 } & 2657762 & 5989786 \\ \text { K012 } & 2657878 & 5989771 & \text { K029 } & 2657673 & 5989506 & \text { K046 } & 2657780 & 5989794 \\ \text { K013 } & 2657889 & 5989800 & \text { K030 } & 2657668 & 5989536 & \text { K047 } & 2657773 & 5989811 \\ \text { K014 } & 2657933 & 5989726 & \text { K031 } & 2657698 & 5989570 & \text { K048 } & 2657774 & 5989813 \\ \text { K015 } & 2657870 & 5989717 & \text { K032 } & 2657686 & 5989587 & \text { K049 } & 2657729 & 5989705 \\ \text { K016 } & 2657851 & 5989690 & \text { K033 } & 2657715 & 5989611 & \text { K050 } & 2657720 & 5989693 \\ \text { K017 } & 2657827 & 5989654 & \text { K034 } & 2657703 & 5989630 & \text { K051 } & 2657697 & 5989699 \\ & & & & 138 & & & & \end{array}$




\begin{tabular}{|c|c|c|c|c|c|c|c|c|}
\hline K052 & 2657678 & 5989709 & K100 & 2657728 & 5989673 & H058A & 2840318 & 6168886 \\
\hline K053 & 2657662 & 5989707 & H001 & 2840021 & 6168710 & H059 & 2840357 & 6168208 \\
\hline K054 & 2657651 & 5989709 & H002 & 2840072 & 6168401 & H059A & 2840345 & 6168187 \\
\hline K055 & 2657632 & 5989705 & H003 & 2840032 & 6167325 & H062 & 2840362 & 6167719 \\
\hline K056 & 2657615 & 5989696 & H004 & 2840099 & 6167316 & H063 & 2840258 & 6167449 \\
\hline K057 & 2657596 & 5989683 & H005 & 2839972 & 6167015 & H064 & 2840342 & 6168817 \\
\hline K058 & 2657560 & 5989664 & H006 & 284121 & 6168940 & H065 & 2840365 & 6168458 \\
\hline K059 & 2657549 & 5989663 & H007 & 2840149 & 6167678 & H066 & 2840378 & 6167985 \\
\hline K060 & 2657613 & 5989704 & H008 & 2840074 & 6168413 & H067 & 2840409 & 6168131 \\
\hline K061 & 2657656 & 5989718 & H009 & 2840063 & 6168631 & H068 & 2840420 & 6167472 \\
\hline K062 & 2657689 & 5989714 & H010 & 2840047 & 6168659 & H069 & 2840449 & 6167135 \\
\hline K063 & 2657899 & 5989575 & H011 & 2840173 & 6167712 & H070 & 2840386 & 6167562 \\
\hline K064 & 2657892 & 5989525 & H012 & 2840127 & 6168084 & H071 & 2840411 & 6167660 \\
\hline K065 & 2657863 & 5989496 & H014 & 2840109 & 6167763 & H072 & 2840376 & 6168787 \\
\hline K066 & 2657861 & 5989449 & H017 & 2840106 & 6168736 & H073 & 2840469 & 6168851 \\
\hline K067 & 2657830 & 5989397 & H018 & 2840132 & 6168514 & H074 & 2840510 & 6168555 \\
\hline K068 & 2657771 & 5989382 & H019 & 2840053 & 6167434 & H077 & 2840412 & 6168323 \\
\hline K069 & 2657754 & 5989361 & H021 & 2840084 & 6167320 & H077A & 2840421 & 6168314 \\
\hline K070 & 2657713 & 5989364 & H022 & 2840153 & 6167159 & H078 & 2840488 & 6167996 \\
\hline K071 & 2657677 & 5989344 & H023 & 2840111 & 6167988 & H079 & 2840467 & 6167057 \\
\hline K072 & 2657643 & 5989355 & H026 & 2840123 & 6168764 & H080 & 2840469 & 6168191 \\
\hline K073 & 2657616 & 5989332 & H027 & 2840169 & 6168292 & H081 & 2840433 & 6168674 \\
\hline K074 & 2657576 & 5989385 & H028 & 2840145 & 6166933 & H081A & 2840451 & 6168689 \\
\hline K075 & 2657552 & 5989414 & H031 & 2840173 & 6168578 & H082 & 2840570 & 6167271 \\
\hline K076 & 2657518 & 5989446 & H033 & 2840262 & 6168641 & H083 & 2840560 & 6167878 \\
\hline K077 & 2657520 & 5989480 & H034 & 2840217 & 6169007 & H084 & 2840573 & 6167683 \\
\hline K078 & 2657508 & 5989516 & H035 & 2840166 & 6167380 & H085 & 2840585 & 6167846 \\
\hline K079 & 2657523 & 5989531 & H036 & 2840220 & 6168397 & H086 & 2840555 & 6168110 \\
\hline K080 & 2657520 & 5989548 & H037 & 2840195 & 6168136 & H088 & 2840541 & 6167219 \\
\hline K081 & 2657552 & 5989547 & H038 & 2840234 & 6169009 & H089 & 2840607 & 6167416 \\
\hline K082 & 2657556 & 5989573 & H039 & 2840226 & 6168001 & H091 & 2840518 & 6168545 \\
\hline K083 & 2657579 & 5989566 & H040 & 2840266 & 6167594 & H094 & 2840605 & 6168288 \\
\hline K084 & 2657593 & 5989577 & H041 & 2840314 & 6168677 & H095 & 2840940 & 6168600 \\
\hline K085 & 2657492 & 5989562 & H042 & 2840323 & 6167114 & H097 & 2840674 & 6167952 \\
\hline K086 & 2657459 & 5989587 & H043 & 2840297 & 6168922 & H098 & 2840703 & 6167797 \\
\hline K087 & 2657465 & 5989613 & H044 & 2840277 & 6168086 & H099 & 2840678 & 6168226 \\
\hline K088 & 2657476 & 5989667 & H046 & 2840165 & 6167383 & H100 & 2840733 & 6167586 \\
\hline K089 & 2657494 & 5989708 & H047 & 2840286 & 6168908 & H101 & 2840743 & 6167257 \\
\hline K090 & 2657490 & 5989735 & H048 & 2840317 & 6168590 & H102 & 2840681 & 6168326 \\
\hline K091 & 2657498 & 5989777 & H050 & 2840307 & 6168899 & H103 & 2840720 & 6167114 \\
\hline K092 & 2657520 & 5989728 & H051 & 2840323 & 6168252 & H104 & 2840679 & 6168227 \\
\hline K093 & 2657543 & 5989754 & H052 & 2840297 & 6168403 & H105 & 2840757 & 6168282 \\
\hline K094 & 2657580 & 5989757 & H053 & 2840347 & 6167770 & H106 & 2840768 & 6167468 \\
\hline K095 & 2657595 & 5989780 & H054 & 2840361 & 6167943 & H107 & 2840786 & 6167211 \\
\hline K096 & 2657611 & 5989809 & H055 & 2840346 & 6167571 & H109 & 2840797 & 6168913 \\
\hline K097 & 2657629 & 5989845 & H056 & 2840319 & 6168128 & H110 & 2840997 & 6168596 \\
\hline K098 & 2657645 & 5989851 & H057 & 2840359 & 6167050 & H112 & 2840857 & 6168024 \\
\hline K099 & 2657727 & 5989638 & H058 & 2840305 & 6168878 & H113 & 2840844 & 6167697 \\
\hline
\end{tabular}




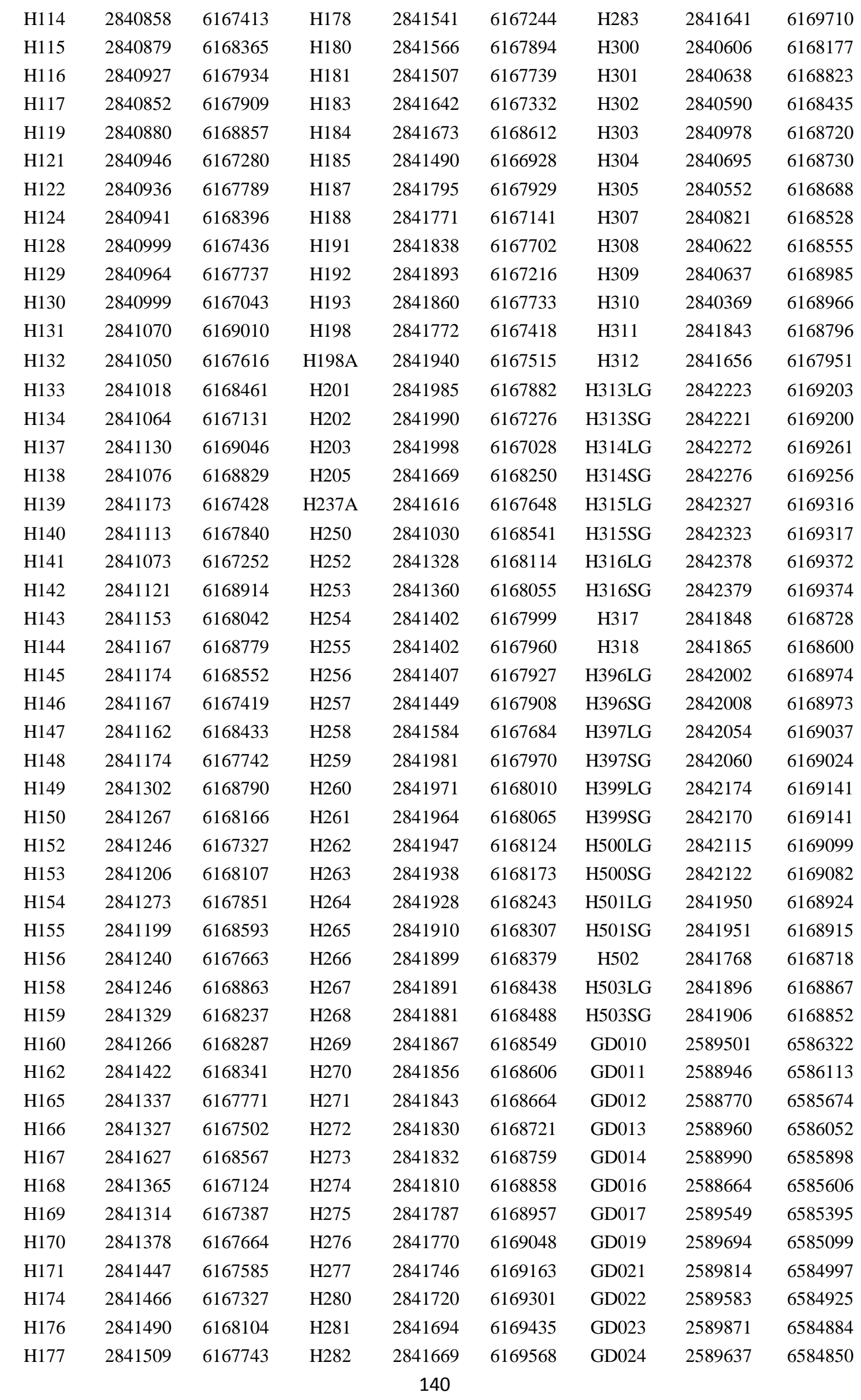




\begin{tabular}{|c|c|c|c|c|c|c|c|c|}
\hline GD025 & 2589681 & 6584764 & GD098 & 2589445 & 6584340 & GD167 & 2589258 & 6585 \\
\hline D026 & 588813 & 6584824 & GD099 & 2587861 & 6584380 & GD168 & 2588800 & \\
\hline GD027 & 589168 & 6584794 & GD100 & 2588078 & 6584321 & GD169 & 2588406 & 6585080 \\
\hline GD028 & 2588268 & 6584747 & GD101 & 2589564 & 6584761 & GD170 & 588114 & 585061 \\
\hline GD029 & 2589461 & 6584659 & GD102 & 89846 & 6584899 & GD171 & 88686 & 85098 \\
\hline GD031 & 2588945 & 6584614 & GD104 & 2589682 & 6584550 & GD172 & 2588350 & 6585058 \\
\hline GD032 & 2589499 & 6584550 & GD108 & 2589731 & 6584639 & GD173 & 2588288 & 6585010 \\
\hline GD033 & 2588737 & 6584514 & GD118 & 2590035 & 6584 & GD174 & 2588195 & 584994 \\
\hline GD034 & 2589451 & 6584379 & GD121 & 2588276 & 6585214 & GD175 & 2589225 & 6585033 \\
\hline GD035 & 2588222 & 6584216 & GD124 & 2588598 & 6584938 & GD176 & 2588191 & 6584930 \\
\hline GD036 & 2589521 & 6585234 & GD125 & 2588601 & 6585312 & GD177 & 2588436 & 6584934 \\
\hline GD037 & 2589583 & 6585177 & GD126 & 2589125 & 6585094 & GD178 & 2588552 & 6584942 \\
\hline GD038 & 258 & 6585001 & GD128 & 258 & 658 & GD179 & 2589364 & 935 \\
\hline GD039 & 2589435 & 6584977 & GD129 & 2588835 & 6585042 & GD18 & 2589672 & 6585221 \\
\hline GD040 & 2589453 & 6584839 & GD130 & 2589092 & 6584920 & GD180 & 2589512 & 84865 \\
\hline GD041 & 2589388 & 6584888 & GD131 & 179 & 03 & GD181 & 2588625 & 4866 \\
\hline GD042 & 2589989 & 6584938 & GD133 & 2589418 & 6585260 & GD182 & 2588695 & 6584793 \\
\hline GD043 & 2587900 & 6584357 & GD135 & 2589123 & 6586162 & GD183 & 2588738 & 6584772 \\
\hline GD044 & 2587962 & 6584346 & GD136 & 2589194 & 6586169 & GD184 & 2588095 & 6584737 \\
\hline GD045 & 2588122 & 6584306 & GD137 & 2589593 & 6586009 & GD185 & 2588466 & 6584647 \\
\hline GD046 & 2588192 & 6584306 & GD139 & 2589996 & 6585140 & GD186 & 2588075 & 6584666 \\
\hline GD062 & 2589681 & 6584697 & GD140 & 2588681 & 6584997 & GD187 & 2588657 & 6584642 \\
\hline GD07( & 258 & & GD141 & & & 188 & 88538 & \\
\hline GD071 & 2589792 & 6585053 & GD142 & 2590066 & 6584881 & GD189 & 2588339 & 6584664 \\
\hline GD072 & 2589792 & 6584985 & GD143 & 2588249 & 6584968 & GD190 & 2588532 & 6584557 \\
\hline GD073 & 2589130 & 6584946 & GD144 & 2589004 & 6584878 & GD191 & 2588717 & 6584544 \\
\hline GD074 & 2589705 & 6584949 & GD145 & 2589585 & 6584906 & GD192 & 2588563 & 6584506 \\
\hline GD076 & 2588856 & 6584875 & GD146 & 2589590 & 6585861 & GD193 & 38609 & 6584449 \\
\hline GD077 & 2588784 & 6584811 & GD148 & 2588682 & 6585061 & GD194 & 2589307 & 6585306 \\
\hline GD078 & 2588987 & 658 & GD15 & 63 & 6585085 & GD195 & 413 & 584318 \\
\hline D079 & 2588754 & 6584792 & GD150 & 2588919 & 6586 & GD197 & 2588271 & 6584298 \\
\hline GD080 & 2588680 & 6584787 & GD151 & 2588277 & 6584699 & GD200 & 2588225 & 6585167 \\
\hline D081 & 7 & 658 & GD152 & 35 & 658 & GD201 & $258^{\prime}$ & 6585172 \\
\hline GD083 & 2589454 & 6584760 & GD153 & 2588880 & 6586401 & GD202 & 2588020 & 6585140 \\
\hline GD084 & 2588062 & 6584615 & GD154 & 2588864 & 6586466 & GD203 & 2589679 & 6584809 \\
\hline GD085 & 2589616 & 6584670 & GD155 & 2588883 & 6586353 & GD204 & 2588831 & 6584430 \\
\hline GD086 & 2589178 & 6584617 & GD156 & 2588977 & 6585963 & GD205 & 2588636 & 6584368 \\
\hline GD087 & 2589873 & 6584626 & GD157 & 2588419 & 6584727 & GD206 & 2588172 & 6585113 \\
\hline GD089 & 2589416 & 6584568 & GD158 & 2588691 & 6585659 & GD207 & 2589264 & 6585065 \\
\hline GD090 & 2589804 & 6584545 & GD159 & 2589456 & 6585366 & GD211 & 2589034 & 6586196 \\
\hline GD091 & 2589644 & 6584528 & GD160 & 2588511 & 6585338 & GD212 & 2589654 & 6586041 \\
\hline GD092 & 2589573 & 6584501 & GD161 & 2589266 & 6585303 & GD213 & 2589526 & 6585998 \\
\hline GD093 & 2589044 & 6584492 & GD162 & 2589188 & 6585386 & GD214 & 2588980 & 6585983 \\
\hline GD094 & 2588046 & 6584528 & GD163 & 2588564 & 6585315 & GD215 & 2588986 & 6585928 \\
\hline GD095 & 2589344 & 6584499 & GD164 & 2589750 & 6585111 & GD216 & 2588999 & 6585857 \\
\hline GD096 & 2589191 & 6584383 & GD165 & 2589234 & 6585278 & GD217 & 2588453 & 6585583 \\
\hline 097 & 2589009 & 84452 & GD166 & 2589160 & 6585015 & GD218 & 2588470 & 658 \\
\hline
\end{tabular}




$\begin{array}{ccc}\text { GD219 } & 2588948 & 6585469 \\ \text { GD220 } & 2589011 & 6585378 \\ \text { GD221 } & 2588753 & 6585110 \\ \text { GD222 } & 2588473 & 6585027 \\ \text { GD224 } & 2588875 & 6585025 \\ \text { GD225 } & 2588875 & 6585025 \\ \text { GD226 } & 2589927 & 6584741 \\ \text { GD227 } & 2588209 & 6584665 \\ \text { GD228 } & 2590025 & 6585069 \\ \text { GD229 } & 2589402 & 658529 \\ \text { GD236 } & 2588283 & 6584274 \\ \text { GD238 } & 2588678 & 6584160 \\ \text { GD240 } & 2588811 & 6584651 \\ \text { GD242 } & 2588784 & 6585324 \\ \text { GD248 } & 2588616 & 6585456 \\ \text { GD250 } & 2589194 & 6585006 \\ \text { GD252 } & 2588912 & 6584356 \\ \text { GD254 } & 2589320 & 6585038 \\ \text { GD256 } & 2589405 & 6586302 \\ \text { GD258 } & 2589008 & 6585823 \\ \text { GD260 } & 2588340 & 6584271 \\ \text { GD262 } & 2588660 & 6585381 \\ \text { GD264 } & 2588173 & 6585023 \\ \text { GD266 } & 2588225 & 6584812 \\ \text { GD268 } & 2588337 & 6584727 \\ \text { GD270 } & 2589680 & 6585055 \\ \text { GD272 } & 2588447 & 6584255 \\ \text { GD30 } & 2588673 & 6584636 \\ \text { GD300 } & 2588939 & 6585615 \\ \text { GD301 } & 2588928 & 6585566 \\ \text { GD302 } & 2588941 & 6585666 \\ \text { GD303 } & 2588918 & 6585726 \\ \text { GD304 } & 2588937 & 6585813 \\ \text { GD305 } & 2588885 & 6585821 \\ \text { GD306 } & 2588919 & 6585860 \\ & & \end{array}$

